\title{
Advance care planning in life-limiting illnesses
}

Citation for published version (APA):

Houben, C. (2018). Advance care planning in life-limiting illnesses. [Doctoral Thesis, Maastricht University]. Datawyse / Universitaire Pers Maastricht. https://doi.org/10.26481/dis.20180309ch

Document status and date:

Published: 01/01/2018

DOI:

10.26481/dis.20180309ch

Document Version:

Publisher's PDF, also known as Version of record

\section{Please check the document version of this publication:}

- A submitted manuscript is the version of the article upon submission and before peer-review. There can be important differences between the submitted version and the official published version of record.

People interested in the research are advised to contact the author for the final version of the publication, or visit the DOI to the publisher's website.

- The final author version and the galley proof are versions of the publication after peer review.

- The final published version features the final layout of the paper including the volume, issue and page numbers.

Link to publication

\footnotetext{
General rights rights.

- You may freely distribute the URL identifying the publication in the public portal. please follow below link for the End User Agreement:

www.umlib.nl/taverne-license

Take down policy

If you believe that this document breaches copyright please contact us at:

repository@maastrichtuniversity.nl

providing details and we will investigate your claim.
}

Copyright and moral rights for the publications made accessible in the public portal are retained by the authors and/or other copyright owners and it is a condition of accessing publications that users recognise and abide by the legal requirements associated with these

- Users may download and print one copy of any publication from the public portal for the purpose of private study or research.

- You may not further distribute the material or use it for any profit-making activity or commercial gain

If the publication is distributed under the terms of Article $25 \mathrm{fa}$ of the Dutch Copyright Act, indicated by the "Taverne" license above, 
沵

\section{ADVANCE CARE PLANNING IN LIFE-LIMITING ILLNESSES}
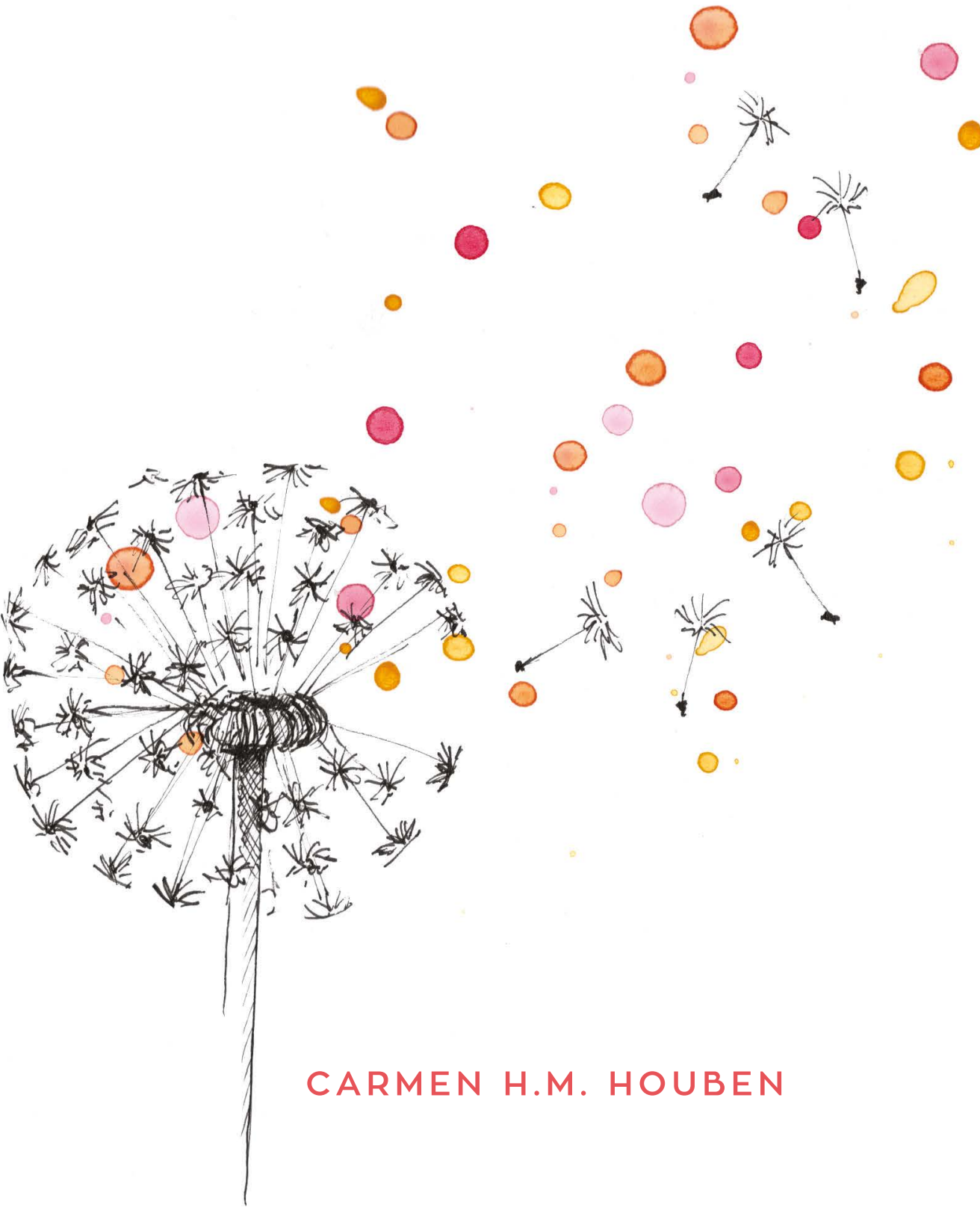

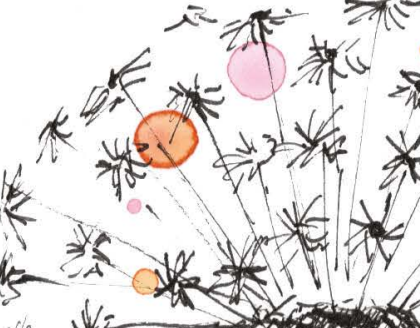

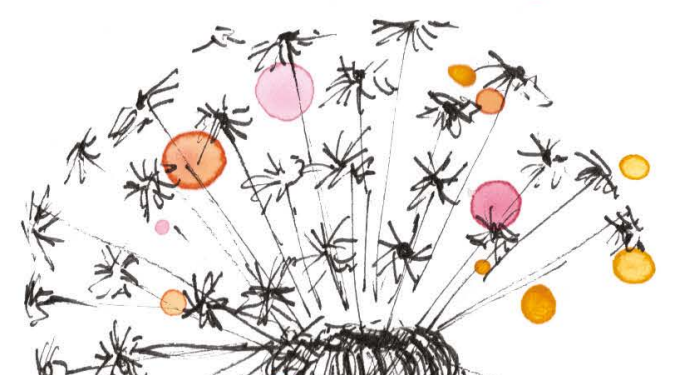


Copyright (C) Carmen H.M. Houben, Maastricht 2018

ISBN: $\quad 9789461598004$

Layout: Datawyse | Universitaire Pers Maastricht

Cover: $\quad$ Milou Curvers | Mevrouw Knot, Grafisch Ontwerp Studio

Production: Datawyse | Universitaire Pers Maastricht

This thesis was financially supported by Ciro, Horn, the Netherlands and Lung Foundation Netherlands, Amersfoort, the Netherlands (Grant 3.4.12.022)

Printing and distribution of this thesis was kindly financially supported by Ciro, Horn, the Netherlands; Lung Foundation Netherlands, Amersfoort, the Netherlands; Chiesi Pharmaceuticals B.V., Rijswijk, the Netherlands and Teva Netherlands B.V., Haarlem, the Netherlands. 


\title{
Advance care planning in life-limiting illnesses
}

\author{
PROEFSCHRIFT
}

ter verkrijging van de graad van doctor

aan de Universiteit Maastricht,

op gezag van de Rector Magnificus, Prof. dr. Rianne M. Letschert, volgens het besluit van het College van Decanen,

in het openbaar te verdedigen op

vrijdag 9 maart 2018 om 16.00 uur

door

Carmen Huberta Maria Houben

geboren op 22 augustus 1988 te Weert 


\section{Promotors}

Prof. dr. E.F.M. Wouters

Prof. dr. M.A. Spruit

\section{Copromotor}

Dr. D.J.A. Janssen

\section{Beoordelingscommissie}

Prof. dr. F.W.J.M. Smeenk (voorzitter)

Prof. dr. M.H.J. van den Beuken

Prof. dr. C.M.P.M. Hertogh, VU Medisch Centrum Amsterdam

Prof. dr. J.W.M. Muris

Dr. J.A.C. Rietjens, Erasmus Medisch Centrum Rotterdam 


\section{Table of contents}

Chapter 1 General introduction 7

Chapter 2 Efficacy of advance care planning: A systematic review and metaanalysis

Chapter 3 Patient-clinician communication about end-of-life care in patients with advanced chronic organ failure during one year

Chapter 4 Instability of willingness to accept life-sustaining treatments of patients with advanced chronic organ failure during one year

Chapter 5 "Am I dying Doctor?": How end-of-life care is portrayed in television medical dramas

Chapter 6 A randomized controlled trial on the efficacy of advance care planning on the quality of end-of-life care and communication in patients with COPD: The research protocol

Chapter 7 A cluster-randomized trial of a nurse-led advance care planning session in patients with COPD and their loved ones

Chapter 8 General discussion

Summary

Samenvatting

Valorization

Dankwoord

Curriculum vitae

List of publications 



\section{General introduction}
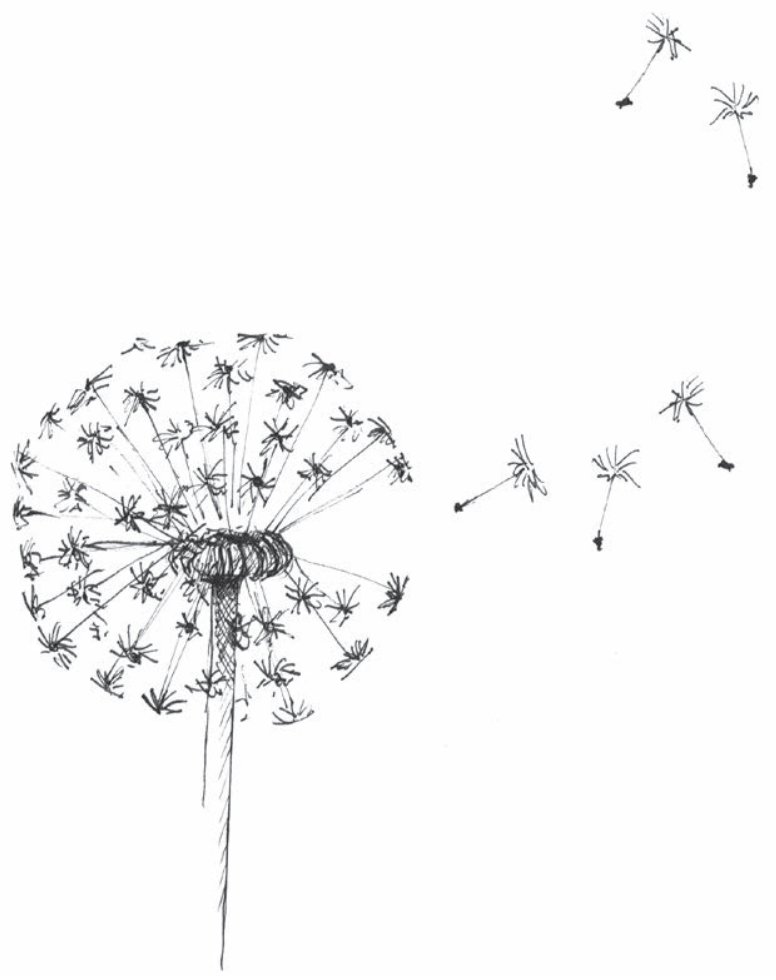



\section{CHRONIC OBSTRUCTIVE PULMONARY DISEASE (COPD)}

COPD is defined as 'a common, preventable and treatable disease that is characterized by persistent respiratory symptoms and airflow limitation that is due to airway and/or alveolar abnormalities usually caused by significant exposure to noxious particles or gases.' ${ }^{1}$ The most common symptoms of COPD are dyspnea, fatigue and muscle weakness. ${ }^{2}$ Traditionally, the severity of COPD was graded according to the degree of airflow limitation. However, it has become clear that the degree of airflow limitation is a poor predictor of morbidity and mortality in individuals with COPD. Moreover, patients with COPD often suffer from comorbidities, such as hyperglycemia, hypertension, and atherosclerosis ${ }^{3}$, which cannot be predicted by the degree of airflow limitation, but substantially contribute to the disease severity. ${ }^{1}$ Therefore the current Global Initiative for Chronic Obstructive Lung Disease (GOLD) guideline describes a combined assessment of COPD, in which disease severity is based on the degree of airflow limitation, the impact on patient's health status, and the risk of future events (such as exacerbations and hospital admissions). ${ }^{1}$ The prevalence of COPD varies across countries due to differences in survey methods, diagnostic criteria, and analytical approaches. ${ }^{1,4,5}$ The global prevalence of COPD has been estimated around $4.77 \%{ }^{6}$ A study in Maastricht, the Netherlands, showed that the prevalence of GOLD-defined COPD in the general population aged 40 years and older is $24 \%{ }^{7}$ The prevalence of COPD is expected to increase in the next years ${ }^{8}$, due to continued exposure to risk factors for COPD and the ageing population. ${ }^{1}$ Furthermore, COPD is an important cause of mortality worldwide. ${ }^{9}$ In 2015 , $3,188,300$ people died of COPD, corresponding to $5.7 \%$ of total deaths globally. ${ }^{10}$ COPD is expected to be the fourth leading cause of death worldwide by $2030 .^{11}$

COPD is a chronic disease, which cannot be cured. Therefore, management of COPD is focused on reduction of risk factors, like smoking cessation; pharmacological treatment, like inhaled bronchodilators; and non-pharmacological treatment, such as pulmonary rehabilitation, oxygen therapy, endoscopic lung volume reduction, and surgical treatment. Surgical treatments like lung volume reduction surgery and lung transplant can be beneficial for carefully selected patients with advanced COPD. In addition, clinical guidelines recommend the use of non-invasive ventilation in patients with acute respiratory failure or severe chronic hypercapnia. ${ }^{1}$ As a result, the use of non-invasive ventilation in patients with COPD has increased. ${ }^{12,13}$ Finally, palliative care is recommended for patients with advanced COPD to prevent and relieve suffering, by controlling symptoms and enhancing quality of life. ${ }^{1}$ 


\section{DISEASE TRAJECTORY OF PATIENTS WITH COPD}

The theoretical disease trajectory of COPD is typically characterized by a progressive decline punctuated by potentially serious, but unpredictable episodes of acute exacerbations (Figure 1). ${ }^{14}$ These exacerbations are associated with an increased risk of dying. ${ }^{15}$ Indeed, in a UK sample of patients with an acute exacerbation of COPD (AECOPD) requiring hospitalization, the in-hospital mortality rate was $10.4 \% .{ }^{16}$ A large long-term prospective study even shows that the long-term risk of death is high following hospital admission for an AECOPD, with $45 \%$ of patients dying within 48 months. ${ }^{17}$ However, previous research has shown that only a minority of patients with chronic organ failure confirm to the theoretical disease trajectory. ${ }^{18}$ Indeed, for individual patients with COPD it remains extremely difficult to accurately predict life expectancy. ${ }^{19,20}$ In addition, patients, loved ones and healthcare professionals often have different views about the illness trajectory of COPD. ${ }^{21}$ Patients and loved ones often struggle to identify when the illness has started and describe COPD more as a way of life than an illness. ${ }^{21,22}$ Although patients were aware of the severity of their symptoms, death is not considered as an imminent threat and as a result end-of-life care wishes are often not discussed with healthcare professionals and loved ones. ${ }^{22}$ Indeed, previous research has shown that although the majority of patients with COPD do have life-sustaining treatment preferences, only $5.9 \%$ of the patients had discussed these preferences with their chest physician. ${ }^{23}$

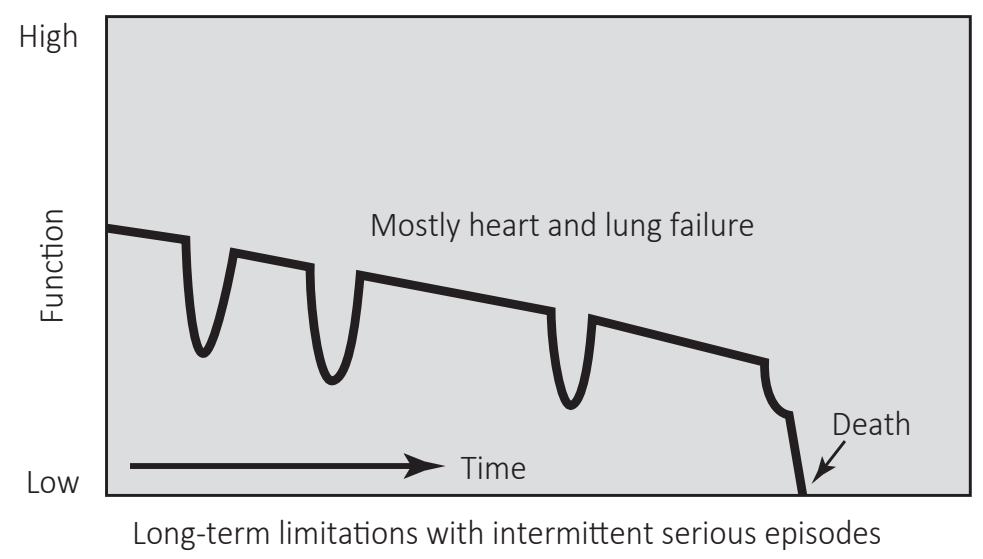

Figure 1. Theoretical disease trajectory of COPD. Reprinted with permission from JOURNAL OF PALLIATIVE MEDICINE, 2006, by Lorenz et al, published by Mary Ann Liebert, Inc., New Rochelle, NY. 


\section{PALLIATIVE CARE}

Palliative care is defined by the World Health Organization (WHO) as 'an approach that improves the quality of life of patients and their families facing the problem associated with life-threatening illness, through the prevention and relief of suffering by means of early identification and impeccable assessment and treatment of pain and other problems, physical, psychosocial and spiritual. Palliative care: provides relief from pain and other distressing symptoms; affirms life and regards dying as a normal process; intends neither to hasten or postpone death; integrates the psychological and spiritual aspects of patient care; offers a support system to help patients live as actively as possible until death; offers a support system to help the family cope during the patients illness and in their own bereavement; uses a team approach to address the needs of patients and their families, including bereavement counselling, if indicated; will enhance quality of life, and may also positively influence the course of illness; is applicable early in the course of illness, in conjunction with other therapies that are intended to prolong life, such as chemotherapy or radiation therapy, and includes those investigations needed to better understand and manage distressing clinical complications'. ${ }^{24}$

The Official American Thoracic Society Clinical Policy Statement: Palliative Care for Patients with Respiratory Diseases and Critical Illnesses describes an individualized integrated model of palliative care in which patients receive palliative care concurrently with curative/restorative care at the onset of symptoms in an individualized manner. The intensity of palliative care increases and decreases to reflect the needs and preferences of patients and his/her loved ones. (Figure 2 ). ${ }^{25}$

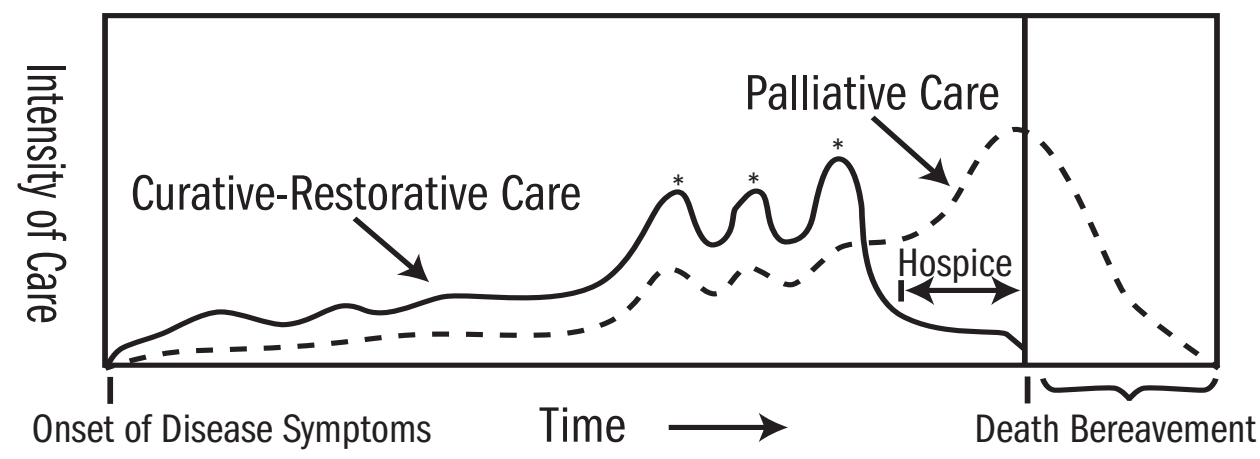

Figure 2. Individualized integrated model of palliative care. Reprinted with permission of the American Thoracic Society. Copyright (C) 2017 American Thoracic Society. Lanken PN, Terry PB, Delisser HM, et al. 2008. An official American Thoracic Society clinical policy statement: palliative care for patients with respiratory diseases and critical illnesses. Am J Respir Crit Care Med 177:912-27. The American Journal of Respiratory and Critical Care Medicine is an official journal of the American Thoracic Society. 
Although palliative care has been shown to improve symptom burden, quality of life and patient satisfaction in different patient populations ${ }^{26-28}$, many patients with COPD have unmet palliative care needs. ${ }^{29}$ The Study to Understand Prognoses and Preferences for Outcomes and Risks of Treatments (SUPPORT) has for example shown that an equal proportion, and the majority, of hospitalized patients with COPD or lung cancer prefer comfort care rather than care focused on lifeextension. ${ }^{30}$ However, in clinical practice patients with COPD were, in comparison with patients with cancer, more likely to receive life-sustaining treatments, such as invasive mechanical ventilation (MV) and cardiopulmonary resuscitation (CPR), before dying. In addition, patients with COPD were less likely to have an advance directive at the time of death and were less likely to have documented discussions about preferences for end-of-life care, in comparison with patients with cancer. ${ }^{31}$ Indeed, healthcare for patients with COPD is often initiated in response to acute exacerbations instead of being initiated in advance based on a previously developed care plan. ${ }^{32,33}$ Timely communication between healthcare professionals, patients and loved ones about preferences for end-of-life care seem to be crucial in order to improve the concordance between delivered end-of-life care and preferred end-oflife care in patients with COPD. ${ }^{34}$

\section{ADVANCE CARE PLANNING (ACP)}

Traditionally, ACP was defined as the process by which patients could indicate their end-of-life care treatment preferences and was therefore often seen as synonymous with the completion of advance directives. ${ }^{35}$ Early research of advance directives proved to be disappointing. In fact, advance directives did not influence the quality of end-of-life care in patients with life-limiting illnesses ${ }^{36}$ and it has been suggested that advance directives, without the process of end-of-life care communication, are unlikely to improve patients' outcomes. ${ }^{37}$ Therefore, nowadays ACP is seen as 'the whole process of discussion of end-of-life care, clarification of related values and goals, and embodiment of preferences through written documents and medical orders. This process can start at any time and be revisited periodically, but it becomes more focused as health status changes. Ideally, these conversations occur with a person's healthcare agent and primary clinician, along with other members of the clinical team; are recorded and updated as needed; and allow for flexible decision making in the context of the patient's current medical situation'. ${ }^{38}$ The last two decades, multiple studies were published about interventions to improve ACP. Initially, these studies were mainly focused on patients with cancer and show for example that patient-physician end-of-life care communication is associated with 
improved quality of life at the end-of-life and decreased intensive care resource use at the end-of-life. ${ }^{39}$ Due to the aging population and increased prevalence of chronic diseases, more recent studies focused on interventions to improve ACP in other patient populations, such as elderly patients admitted to the hospital or patients with chronic renal failure or COPD. ${ }^{40-43}$ A prospective randomized controlled trial showed for example that ACP improves end-of-life care in elderly patients admitted to the hospital and reduces psychosocial distress in bereaved family members. ${ }^{42}$ In addition, previous research has shown that early patient-clinician communication can improve quality of end-of-life care communication in patients with COPD. ${ }^{43}$ Despite these benefits, the unpredictable disease trajectory and the high mortality rate of COPD, ACP in these patients is uncommon. At the same time, patients with COPD usually want to talk about end-of-life care and are able to discuss their preferences regarding life-sustaining treatments. ${ }^{23,44}$ Indeed, previous research showed that $71 \%$ of patients with advanced COPD reported to prefer CPR and/or MV. Only a minority of the patients was not able to indicate preferences regarding CPR (2\%) or MV (4\%). ${ }^{23}$

\section{BARRIERS TO ACP IN COPD}

Insight into barriers to end-of-life care communication is necessary to develop interventions to improve ACP for patients with COPD. ${ }^{34}$ Previous research has shown that physicians, patients and loved ones report several barriers to communication about end-of-life care.

\section{Barriers endorsed by physicians}

The most frequently physician-reported barrier for ACP is lack of time. Indeed, a previous study aimed at identifying physician-reported barriers for end-of-life care communication in patients with COPD has shown that $64 \%$ of the physicians reported that there is too little time during their appointments to discuss everything they should. ${ }^{34}$ Although patients often prefer physicians to discuss their preferences for end-of-life care, they also accept other healthcare professionals as facilitators for ACP. Indeed, there is growing recognition for an interdisciplinary approach of ACP. ${ }^{45}$ Therefore the barrier of lack of time can possibly be overcome by facilitating ACP by other healthcare professionals, such as for example trained nurses. They have specific skills that may facilitate end-of-life care communication. In fact, nurses can provide prognostic information and support patients' hopes by understanding individual aspects of hope, focusing on patient's quality of life and 
building trust with patients. ${ }^{45}$ Previous research showed that nurse-led ACP led to a higher concordance between preferred and delivered end-of-life care in elderly hospitalized patients. ${ }^{42}$ Another important physician-endorsed barrier is the unpredictable disease trajectory of COPD, which makes it difficult for physicians to choose the appropriate timing for ACP. In fact, physicians often postpone discussions about end-of-life care until patients are too ill to participate in the decision making process. ${ }^{46}$ However, there are some clinical events which can be used by physicians as moments to initiate ACP-discussions, for example hospitalizations or the start of oxygen therapy. ${ }^{47}$ Finally, physicians often avoid ACP-discussions because they worry that talking about end-of-life care takes away patient's hope or causes psychosocial distress. ${ }^{34,48}$ Indeed, being engaged in ACP is suggested to be stressful for patients, because it confronts people with their own deterioration. ${ }^{48}$

\section{Barriers endorsed by patients}

Despite the fact that patients with COPD do have preferences about end-of-life care and are able to discuss these preferences ${ }^{23}$, they will often wait for their physician to initiate these discussions. ${ }^{49}$ This could be related to the fact that patients with COPD are frequently unaware of the life-limiting character of their illness. ${ }^{46}$ Indeed, only $31 \%$ of the patients with advanced COPD, estimated their life-expectancy to be less than one year in the month before they died. ${ }^{50}$ If patients were aware of the fact that they could die from COPD, they often gained this information from the media and it can be questioned if this information is valid. ${ }^{51}$ Indeed, elderly patients often obtain information about for example life-sustaining treatments from television. $^{52}$ However, a previous study showed that in movies dealing with lifethreatening illness and death the level of reality is limited. ${ }^{53}$ In addition, patients often reported that they were not ready to talk about end-of-life care yet and prefer to concentrate on staying alive instead of talking about death. ${ }^{34,44}$ The fact that even patients with severe COPD see themselves as living with, and not dying of, COPD may strengthen this barrier. ${ }^{54}$ However, this barrier can possibly be overcome by start a conversation in an accessible manner, for example by talking about what is important in patient's life in order to maintain a certain degree of quality of life. This may also provide patients uncomfortable with ACP-discussions the opportunity to think about their future health and make plans for the future. ${ }^{44,55-57}$ The previously discussed clinical events as moments to initiate ACP-discussions, may also serve as stimuli for patients to start thinking about their preferences for end-of-life care. ${ }^{47,54}$ Nevertheless, it is important for clinicians to assess patient's readiness for participation in ACP-discussions to adapt these discussions to the patient's needs. ${ }^{58}$ 
In the current literature, studies are mainly focused on physician- and patientendorsed barriers of ACP. However, given the important role of loved ones in the process of palliative care it is also important to explore their barriers to participate in ACP-discussions. ${ }^{35}$ A qualitative study identified the following major categories to describe barriers for ACP endorsed by loved ones: loved ones' attributes; access to physicians and information about ACP; and the interaction between physicians, patients, and loved ones. ${ }^{58}$ Another cross-sectional study ${ }^{59}$ shows that the most important barriers for talking about end-of-life care reported by loved ones are related to uncertainty about expected care and focus on staying alive instead of dying. In this study limited agreement was found between barriers reported by patients with advanced chronic organ failure and their loved ones. ${ }^{59}$ Therefore, it is recommended to take these different perceptions into account when discussing preferences for end-of-life care.

\section{FACILITATORS TO ACP IN COPD}

Previous studies also describe several facilitators to communication about end-oflife care.

First, the quality of the interpersonal relationship between healthcare professionals and patients is identified as a facilitator for ACP. ${ }^{34,58,59}$ Indeed, a good relationship based on mutual trust and respect is an important component in the process of ACP. ${ }^{60,61}$ Second, physician's experience in ACP and the treatment of COPD in general, will help patients, loved ones and healthcare professionals to start an ACPdiscussion. ${ }^{34,59}$ Third, physicians indicate that it is more easy to start an ACPdiscussion when patients had been very sick in the past. ${ }^{34}$ In fact, some physicians use for example hospital admissions as a time to initiate a discussion about future treatment preferences. ${ }^{47}$ Finally, patients identify that personal experience with endof-life care or death influenced their willingness to have an ACP-discussion. ${ }^{34,58,59}$

\section{AIMS OF THE THESIS}

The general introduction described the importance of ACP as a prerequisite to deliver high-quality end-of-life care. In addition, it also described the lack of ACP in patients with COPD and barriers for ACP were discussed. In order to improve ACP 
for patients with advanced COPD and their loved ones, a cluster-randomized controlled trial was designed. In addition, longitudinal data with regard to quality of communication and willingness to accept life-sustaining treatments, based on a previous longitudinal observational study, were analyzed.

The specific aims of this PhD thesis were:

- To systematically review the efficacy of ACP interventions in different adult patient populations.

- To examine the quality of end-of-life care communication during one year follow-up of patients with advanced chronic organ failure.

- To examine stability of willingness to accept life-sustaining treatments during one-year follow-up in patients with advanced chronic organ failure.

- To explore communication about end-of-life care between healthcare professionals and patients or loved ones in popular medical dramas on television.

- To assess whether and to what extent a structured nurse-led ACP-session can improve quality of end-of-life care communication between physicians and patients with COPD.

\section{OUTLINE OF THE THESIS}

Following this general introduction, Chapter 2 describes the results of a systematic review and meta-analysis, at the start of the current project, which addresses the efficacy of ACP in different adult patient populations. Chapter 3 describes the quality of end-of-life care communication during one year follow-up in patients with advanced chronic organ failure. Chapter 4 describes the stability of willingness to accept-life sustaining treatments during one-year follow-up in patients with advanced chronic organ failure. Chapter 3 and 4 are both based on a previous longitudinal observational study on palliative care needs of patients with chronic organ failure and gave direction to the randomized controlled trial we performed for this thesis. Chapter 5 explores how healthcare professionals, patients and loved ones communicate about end-of-life care in popular medical dramas on television. Chapter 6 describes the research protocol of the cluster-randomized controlled trial we performed for this thesis in detail. Chapter 7 presents the results of this randomized controlled trial. More specifically, this chapter describes the efficacy of a structured, 1.5-hours, nurse-led ACP-session on quality of end-of-life care communication between physicians and patients with COPD. Chapter 8 is the general discussion and discusses all chapters in a broader context, including the clinical implications of this thesis and future directions for research. 


\section{REFERENCES}

1. Global Initiative for Chronic Obstructive Lung Disease (GOLD). Global strategy for the diagnosis, management, and prevention of chronic obstructive pulmonary disease (COPD). 2017. Available from: http://goldcopd.org Accessed 30-03-2017.

2. Janssen DJ, Spruit MA, Uszko-Lencer NH, Schols JM, Wouters EF. Symptoms, comorbidities, and health care in advanced chronic obstructive pulmonary disease or chronic heart failure. J Palliat Med 2011;14:735-43.

3. Vanfleteren LE, Spruit MA, Groenen M, et al. Clusters of comorbidities based on validated objective measurements and systemic inflammation in patients with chronic obstructive pulmonary disease. Am J Respir Crit Care Med 2013;187:728-35.

4. Gibson G, Loddenkemper, R., Sibille, Y., Lundbäck, B. The European Lung White Book. Sheffield: European Respiratory Society; 2013.

5. Lopez-Campos JL, Tan W, Soriano JB. Global burden of COPD. Respirology 2016;21:14-23.

6. Vos T, Flaxman AD, Naghavi M, et al. Years lived with disability (YLDs) for 1160 sequelae of 289 diseases and injuries 1990-2010: a systematic analysis for the Global Burden of Disease Study 2010. Lancet 2012;380:2163-96.

7. Vanfleteren LE, Franssen FM, Wesseling G, Wouters EF. The prevalence of chronic obstructive pulmonary disease in Maastricht, the Netherlands. Respir Med 2012;106:871-4.

8. Adeloye D, Chua S, Lee C, et al. Global and regional estimates of COPD prevalence: Systematic review and meta-analysis. J Glob Health 2015;5:020415.

9. Lopez AD, Shibuya K, Rao C, et al. Chronic obstructive pulmonary disease: current burden and future projections. Eur Respir J 2006;27:397-412.

10. GBD 2015 Mortality and Causes of Death Collaborators. Global, regional, and national life expectancy, all-cause mortality, and cause-specific mortality for 249 causes of death, 1980-2015: a systematic analysis for the Global Burden of Disease Study 2015. Lancet. 2016;388(10053):1459-544.

11. Mathers CD, Loncar D. Projections of global mortality and burden of disease from 2002 to 2030. PLoS Med 2006;3:e442.

12. Toft-Petersen AP, Torp-Pedersen C, Weinreich UM, Rasmussen BS. Trends in assisted ventilation and outcome for obstructive pulmonary disease exacerbations. A nationwide study. PLoS One 2017; 12:e0171713.

13. Funk GC, Bauer P, Burghuber OC, et al. Prevalence and prognosis of COPD in critically ill patients between 1998 and 2008. Eur Respir J 2013;41:792-9.

14. Lorenz KA, Shugarman LR, Lynn J. Health care policy issues in end-of-life care. J Palliat Med 2006;9:73148.

15. Murray SA, Kendall M, Boyd K, Sheikh A. Illness trajectories and palliative care. BMJ 2005;330:1007-11.

16. Steer J, Gibson J, Bourke SC. The DECAF Score: predicting hospital mortality in exacerbations of chronic obstructive pulmonary disease. Thorax 2012;67:970-6.

17. Piquet J, Chavaillon JM, David P, et al. High-risk patients following hospitalisation for an acute exacerbation of COPD. Eur Respir J 2013;42:946-55.

18. Gott M, Barnes S, Parker C, et al. Dying trajectories in heart failure. Palliat Med 2007;21:95-9.

19. Christakis NA, Escarce JJ. Survival of Medicare patients after enrollment in hospice programs. N Engl J Med 1996;335:172-8.

20. Coventry PA, Grande GE, Richards DA, Todd CJ. Prediction of appropriate timing of palliative care for older adults with non-malignant life-threatening disease: a systematic review. Age Ageing 2005;34:21827.

21. Kendall M, Carduff E, Lloyd A, et al. Different Experiences and Goals in Different Advanced Diseases: Comparing Serial Interviews With Patients With Cancer, Organ Failure, or Frailty and Their Family and Professional Carers. J Pain Symptom Manage 2015;50:216-24.

22. Pinnock $\mathrm{H}$, Kendall $\mathrm{M}$, Murray $\mathrm{SA}$, et al. Living and dying with severe chronic obstructive pulmonary disease: multi-perspective longitudinal qualitative study. BMJ Support Palliat Care 2011;1:174-83. 
23. Janssen DJ, Spruit MA, Schols JM, Wouters EF. A call for high-quality advance care planning in outpatients with severe COPD or chronic heart failure. Chest 2011;139:1081-8.

24. World Health Organisation. WHO definition of palliative care. Available from http://www.who.int/cancer/ palliative/definition/en/ Accessed 30-03-2017.

25. Lanken PN, Terry PB, Delisser HM, et al. An official American Thoracic Society clinical policy statement: palliative care for patients with respiratory diseases and critical illnesses. Am J Respir Crit Care Med 2008;177:912-27.

26. Wong FK, Ng AY, Lee $\mathrm{PH}$, et al. Effects of a transitional palliative care model on patients with end-stage heart failure: a randomised controlled trial. Heart 2016;102:1100-8.

27. Temel JS, Greer JA, El-Jawahri A, et al. Effects of Early Integrated Palliative Care in Patients With Lung and GI Cancer: A Randomized Clinical Trial. J Clin Oncol 2017;35:834-41.

28. Kavalieratos D, Corbelli J, Zhang D, et al. Association Between Palliative Care and Patient and Caregiver Outcomes: A Systematic Review and Meta-analysis. JAMA 2016;316:2104-14.

29. Schroedl CJ, Yount SE, Szmuilowicz E, Hutchison PJ, Rosenberg SR, Kalhan R. A qualitative study of unmet healthcare needs in chronic obstructive pulmonary disease. A potential role for specialist palliative care? Ann Am Thorac Soc 2014;11:1433-8.

30. Claessens MT, Lynn J, Zhong Z, et al. Dying with lung cancer or chronic obstructive pulmonary disease: insights from SUPPORT. Study to Understand Prognoses and Preferences for Outcomes and Risks of Treatments. J Am Geriatr Soc 2000;48:S146-53.

31. Brown CE, Engelberg RA, Nielsen EL, Curtis JR. Palliative Care for Patients Dying in the Intensive Care Unit with Chronic Lung Disease Compared with Metastatic Cancer. Ann Am Thorac Soc 2016;13:684-9.

32. Curtis JR. Palliative and end-of-life care for patients with severe COPD. Eur Respir J 2008;32:796-803.

33. Au DH, Udris EM, Finn SD, McDonell MB, Curtis JR. Differences in health care utilization at the end of life among patients with chronic obstructive pulmonary disease and patients with lung cancer. Arch Intern Med 2006;166:326-31.

34. Knauft E, Nielsen EL, Engelberg RA, Patrick DL, Curtis JR. Barriers and facilitators to end-of-life care communication for patients with COPD. Chest 2005;127:2188-96.

35. Fried TR, O'Leary JR. Using the experiences of bereaved caregivers to inform patient- and caregivercentered advance care planning. J Gen Intern Med 2008;23:1602-7.

36. Schneiderman LJ, Kronick R, Kaplan RM, Anderson JP, Langer RD. Effects of offering advance directives on medical treatments and costs. Ann Intern Med 1992;117:599-606.

37. Janssen DJ, Engelberg RA, Wouters EF, Curtis JR. Advance care planning for patients with COPD: past, present and future. Patient Educ Couns 2012;86:19-24.

38. Insitute of Medicine. Dying in America: Improving quality and honoring individual preferences near the end of life. Washington DC: The National Academies Press, 2015.

39. Wright AA, Zhang B, Ray A, et al. Associations between end-of-life discussions, patient mental health, medical care near death, and caregiver bereavement adjustment. JAMA 2008;300:1665-73.

40. Song MK, Ward SE, Fine JP, et al. Advance care planning and end-of-life decision making in dialysis: a randomized controlled trial targeting patients and their surrogates. Am J Kidney Dis 2015;66:813-22.

41. Sinclair C, Auret KA, Evans SF, et al. Advance care planning uptake among patients with severe lung disease: a randomised patient preference trial of a nurse-led, facilitated advance care planning intervention. BMJ Open 2017; 7:e013415.

42. Detering KM, Hancock AD, Reade MC, Silvester $W$. The impact of advance care planning on end of life care in elderly patients: randomised controlled trial. BMJ 2010;340:c1345.

43. Au DH, Udris EM, Engelberg RA, et al. A randomized trial to improve communication about end-of-life care among patients with COPD. Chest 2012;141:726-35.

44. Janssen DJ, Curtis JR, Au DH, et al. Patient-clinician communication about end-of-life care for Dutch and US patients with COPD. Eur Respir J 2011;38:268-76.

45. Reinke LF, Shannon SE, Engelberg RA, Young JP, Curtis JR. Supporting hope and prognostic information: nurses' perspectives on their role when patients have life-limiting prognoses. J Pain Symptom Manage 2010;39:982-92. 
46. Gott M, Gardiner C, Small N, et al. Barriers to advance care planning in chronic obstructive pulmonary disease. Palliat Med 2009;23:642-8.

47. Reinke LF, Engelberg RA, Shannon SE, et al. Transitions regarding palliative and end-of-life care in severe chronic obstructive pulmonary disease or advanced cancer: themes identified by patients, families, and clinicians. J Palliat Med 2008;11:601-9.

48. Voogt $E$, van der Heide A, Rietjens JA, et al. Attitudes of patients with incurable cancer toward medical treatment in the last phase of life. J Clin Oncol 2005;23:2012-9.

49. Heffner JE, Fahy B, Hilling L, Barbieri C. Attitudes regarding advance directives among patients in pulmonary rehabilitation. Am J Respir Crit Care Med 1996;154:1735-40.

50. Fried TR, Bradley EH, O'Leary J. Changes in prognostic awareness among seriously ill older persons and their caregivers. J Palliat Med 2006;9:61-9.

51. Gardiner C, Gott M, Small N, et al. Living with advanced chronic obstructive pulmonary disease: patients concerns regarding death and dying. Palliat Med 2009;23:691-7.

52. Schonwetter RS, Teasdale TA, Taffet G, Robinson BE, Luchi RJ. Educating the elderly: cardiopulmonary resuscitation decisions before and after intervention. J Am Geriatr Soc 1991;39:372-7.

53. Drukarczyk L, Klein C, Ostgathe C, Stiel S. Life threatening illness in popular movies-a first descriptive analysis. Springerplus 2014;3:411.

54. Landers A, Wiseman R, Pitama S, Beckert L. Patient perceptions of severe COPD and transitions towards death: a qualitative study identifying milestones and developing key opportunities. NPJ Prim Care Respir Med 2015;25:15043.

55. Steinhauser KE, Alexander SC, Byock IR, George LK, Olsen MK, Tulsky JA. Do preparation and life completion discussions improve functioning and quality of life in seriously ill patients? Pilot randomized control trial. J Palliat Med 2008;11:1234-40.

56. Goldstein NE, Back AL, Morrison RS. Titrating guidance: a model to guide physicians in assisting patients and family members who are facing complex decisions. Arch Intern Med 2008;168:1733-9.

57. Ford D, Zapka J, Gebregziabher M, Yang C, Sterba K. Factors associated with illness perception among critically ill patients and surrogates. Chest 2010;138:59-67.

58. Simon J, Porterfield P, Bouchal SR, Heyland D. 'Not yet' and 'Just ask': barriers and facilitators to advance care planning--a qualitative descriptive study of the perspectives of seriously ill, older patients and their families. BMJ Support Palliat Care 2015;5:54-62.

59. Van den Heuvel LA, Spruit MA, Schols JM, Hoving C, Wouters EF, Janssen DJ. Barriers and facilitators to end-of-life communication in advanced chronic organ failure. Int J Palliat Nurs 2016;22:222-9.

60. Mistry B, Bainbridge D, Bryant D, Tan Toyofuku S, Seow H. What matters most for end-of-life care? Perspectives from community-based palliative care providers and administrators. BMJ Open 2015;5:e007492.

61. Heyland DK, Dodek P, Rocker G, et al. What matters most in end-of-life care: perceptions of seriously ill patients and their family members. CMAJ 2006;174:627-33. 



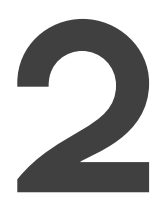

\section{Efficacy of advance care planning: A systematic review and meta-analysis}
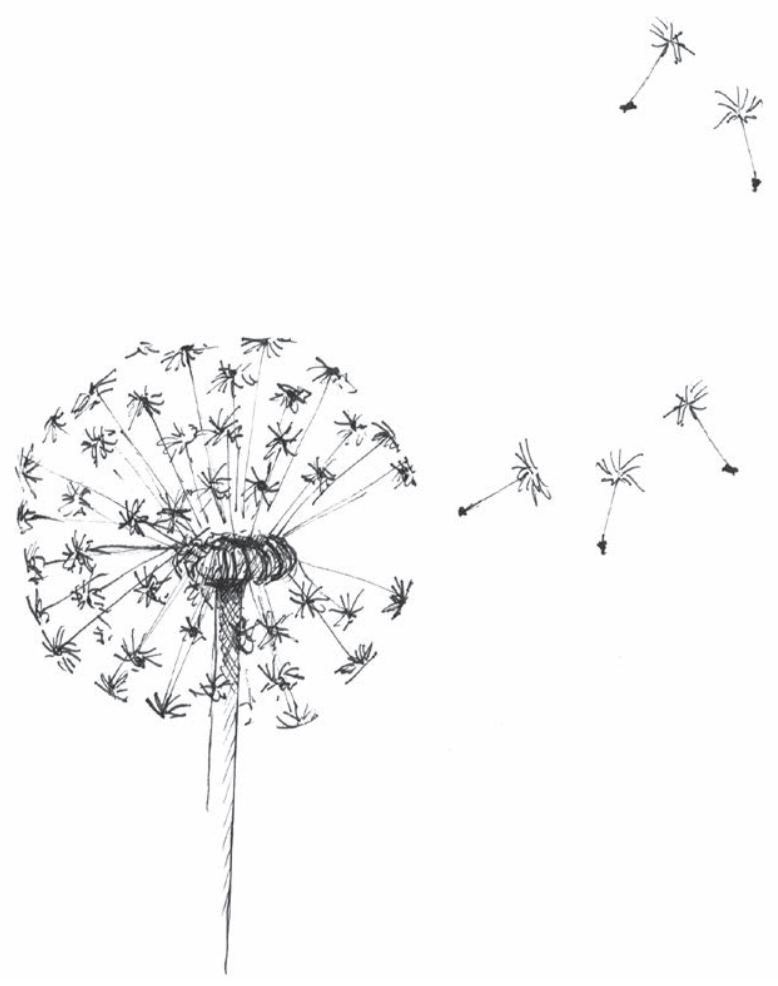

Carmen H.M. Houben, Martijn A. Spruit, Miriam T.J. Groenen, Emiel F.M. Wouters, and Daisy J.A. Janssen.

JAMDA, 2014. 15(7):477-489.

Reproduced with permission from JAMDA. 


\section{ABSTRACT}

Objective: To systematically review the efficacy of advance care planning (ACP) interventions in different adult patient populations.

Design: Systematic review and meta-analyses.

Data Sources: Medline/PubMed, Cochrane Central Register of Controlled Trials (1966 to September 2013), and reference lists.

Study Selection: Randomized controlled trials that describe original data on the efficacy of ACP interventions in adult populations and were written in English.

Data Extraction and Synthesis: Fifty-five studies were identified. Study details were recorded using a predefined data abstraction form. Methodological quality was assessed using the PEDro scale by two independent reviewers. Meta-analytic techniques were conducted using a random effects model. Analyses were stratified for type of intervention: 'advance directives' and 'communication'.

Main Outcomes and Measures: Primary outcome measures were completion of advance directives and occurrence of end-of-life discussions. Secondary outcomes were concordance between preferences for care and delivered care, knowledge of $A C P$, end-of-life care preferences, quality of communication, satisfaction with healthcare, decisional conflict, use of healthcare services, and symptoms.

Results: Interventions focusing on advance directives as well as interventions that also included communication about end-of-life care increased the completion of advance directives and the occurrence of end-of-life care discussions between patients and healthcare professionals. In addition, interventions that also included communication about ACP, improved concordance between preferences for care and delivered care and may improve other outcomes, such as quality of communication.

Conclusions: ACP interventions increase the completion of advance directives, occurrence of discussions about ACP, concordance between preferences for care and delivered care, and are likely to improve other outcomes for patients and their loved ones in different adult populations. Future studies are necessary to reveal the effective elements of ACP and should focus on the best way to implement structured ACP in standard care. 


\section{INTRODUCTION}

Advance care planning ( $A C P)$ is the process whereby patients, in consultation with healthcare professionals, family members, and other loved ones, make individual decisions about their future healthcare, to prepare for future medical treatment decisions. ${ }^{1}$ In the previous decades, ACP was often seen as synonymous with the completion of advance directives. More recently, ACP is seen as an ongoing process and includes discussions about goals of care, resuscitation and life support, palliative care options, surrogate decision making, and advance directives. ${ }^{2}$

Patients usually want to talk about end-of-life care, and are able to discuss their preferences regarding life-sustaining treatments. Discussions about ACP, however, do not occur as frequently as they should. ${ }^{3}$ Physicians and patients report different barriers to communication about end-of-life care. Physicians' barriers include lack of time and communication skills, discomfort with emotions from the patient, and concerns about the potential to erode hope. Patients are not aware of the relevance of ACP and have the assumption that the physician will initiate ACP discussions when they are needed. ${ }^{2}$ Because of the lack of ACP, decisions about lifesustaining treatments are often crisis-oriented, may not be in concordance with patient's preferences for end-of-life care, and may cause distress in loved ones. ${ }^{4}$

The last two decades, multiple studies were published about interventions to improve ACP. Initially, these studies were limited to oncology patients, but because of the aging population and increased prevalence of chronic diseases, current research also focusses on interventions to improve ACP in other patient populations with life-limiting diseases. ${ }^{5}$ Interventions investigated in early ACP studies, which were mostly limited to the completion of advance directives ${ }^{6,7}$ did not improve endof-life care. A recent study suggests that discussions about ACP can be effective in changing outcomes for patients and their loved ones. ${ }^{8}$

The purpose of the present systematic review is to study the efficacy of ACP interventions in different adult patient populations. The primary outcome measures are completion of advance directives and occurrence of end-of-life discussions. Secondary outcomes are concordance between preferences for care and delivered care, knowledge of ACP, end-of-life care preferences, quality of communication, satisfaction with healthcare, decisional conflict, use of healthcare services, and symptoms . A priori, we hypothesized that ACP interventions increase completion of advance directives as well as occurrence of end-of-life discussions. In addition, we hypothesized that ACP interventions can improve other outcomes, such as quality 
of communication about end-of-life care, and concordance between preferences for end-of-life care and delivered care.

\section{METHODS}

\section{Data sources and searches}

A computerized literature search was performed in the databases Medline/PubMed and Cochrane Central Register of Controlled Trials from 1966 through September 2013. The following key words were used: ACP; advance directives; end-of-life communication; life-sustaining treatment preferences; end-of-life decision making; and living will. The key words were combined using 'or'. In addition, reference lists of selected articles were searched by hand to identify relevant articles that may have been missed by the initial search strategy.

\section{Study selection}

Articles had to meet the following criteria to be selected for the review: 1) describe original data; 2) randomized controlled trial; and 3) written in English. Articles about patients younger than 21 years were excluded. In addition, studies about psychiatric advance directives were excluded because these directives were focused on treatment decisions involving mental health instead of physical health. ${ }^{9}$ Titles and abstracts were independently screened against inclusion criteria by two reviewers (C.H. and M.S.). Disagreements were solved by consensus.

\section{Data extraction and quality assessment}

A predesigned data abstraction form was used to obtain data on study design and relevant results. For each study, first author, journal, year of publication, aim, study design, setting, eligibility criteria, sample size, patient characteristics (sex, age, disease), intervention (description, frequency, delivered by), control group, measurements, outcome parameters, instruments, response rate, relevant findings, conclusion, and limitations were recorded.

The methodological quality was assessed using the Physiotherapy Evidence-Based Database (PEDro) Scale. ${ }^{10}$ The PEDro scale is based largely on the Delphi List and expert consensus. It consists of eleven items: one item to score the external validity and ten items to score the internal validity and statistics. Items scored a 'yes' if the criterion was clearly satisfied. The 'yes' from criteria 2-11 were summed to calcu- 
late the PEDro score. ${ }^{10}$ Previously, trials with a PEDro score of $\geq 6$ points were classified as "high-quality trials", while trials with a PEDro score $\leq 5$ points were classified as "low-quality trials". ${ }^{11}$ The methodological quality of the included trials was scored independently by two reviewers (C.H. and D.J.). Agreement between the two reviewers was 0.89 ( $95 \%$ confidence interval $(\mathrm{Cl}), 0.86$ to $0.93 ; \mathrm{p}<0.0001$ ) based on the actual PEDro score of each study. Disagreements were solved by consensus. If no consensus could be achieved, a third reviewer (M.S.) was consulted. This was the case for only three PEDro-items (0.5\%).

Data synthesis and analysis

Interventions were classified into two categories: 1) advance directives: interventions that were limited to the completion of advance directives (durable power of attorney for healthcare, living wills, and signing limitations of care "code status" forms); and 2) communication: interventions in which one of the components was focused on communication about $A C P$, in addition to advance directives. $A X^{2}$ test was used to explore the relationship between the kind of intervention and years of publication (1992-1998 versus 1999-2005, 1999-2005 vs. 2006-2012, and 19921998 versus 2006-2012). IBM SPSS statistics 21.0 was used for this analysis. Metaanalytic techniques were conducted using a random effects model in RevMan 5. Completion of advance directives, occurrence of discussions about end-of-life care preferences between patient and healthcare professional, and concordance between preferences for end-of-life care and delivered end-of-life care were analyzed as dichotomous outcomes. Pooled odds ratios (OR) with $95 \% \mathrm{Cls}$ were calculated using a random effects model. If a study included more than one intervention group, both intervention groups were included in the analysis. Subgroup of interest was type of intervention (advance directives vs communication). The use of metaanalytic techniques for data-analysis was not possible for other outcome measures such as concordance between preferences for care and delivered care, knowledge of ACP, end-of-life care preferences, quality of communication, satisfaction with health care, decisional conflict, use of healthcare services, and symptoms, because of variability in definition and measurement. The statistical significance level was set at $\mathrm{p} \leq .05$ for all analysis.

\section{RESULTS}

In total, 26,628 articles were found in the electronic searches. Fifty-six studies were identified (Table 1). These studies included patients with different diseases and 
were published between 1992 and 2012 (Figure 1). Fifteen studies (26.8\%) recruited participants from an inpatient setting; 37 studies (66.1\%) from an outpatient setting; and four studies (7.1\%) from both settings.

\section{Quality assessment}

Median PEDro score was 5 points (range 2-8 points; Table 2). Thirty-one trials $(55.4 \%)$ scored $<6$ points on the PEDro scale and were classified as "low-quality trials". The most prevalent methodological shortcomings were failure to blind patients $(n=55,98.2 \%)$, therapists $(n=55,98.2 \%)$, and/or outcome assessors $(n=44$, $78.6 \%)$; no treatments as allocated or intention to treat ( $n=35,62.5 \%)$; and no concealed allocation ( $n=33,58.9 \%$ ) (Table 2 ).

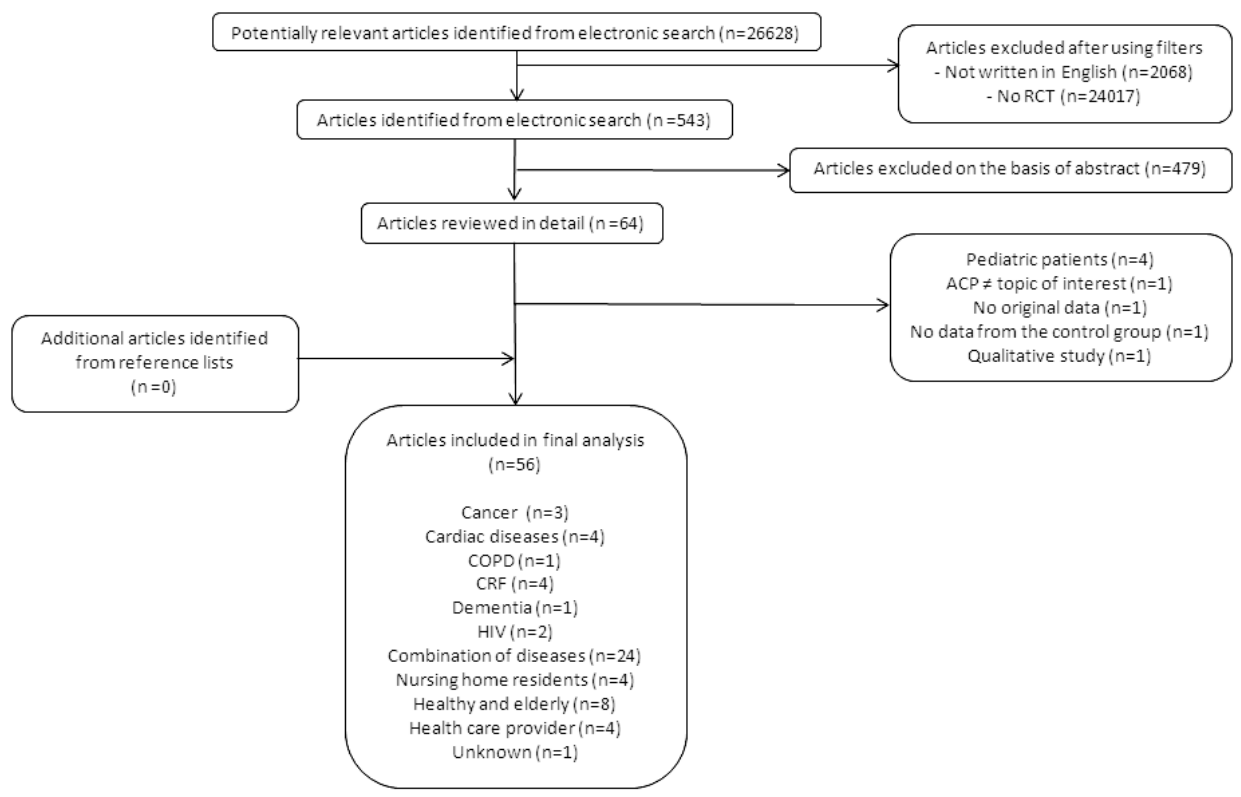

Figure 1. Screening and selection process of trials.

Abbreviations: $A C P=A d v a n c e$ Care Planning; $C O P D=C h r o n i c$ Obstructive Pulmonary Disease; $C R F=C h r o n i c$ Renal Failure; RCT=Randomized Controlled Trial. 
Efficacy of advance care planning

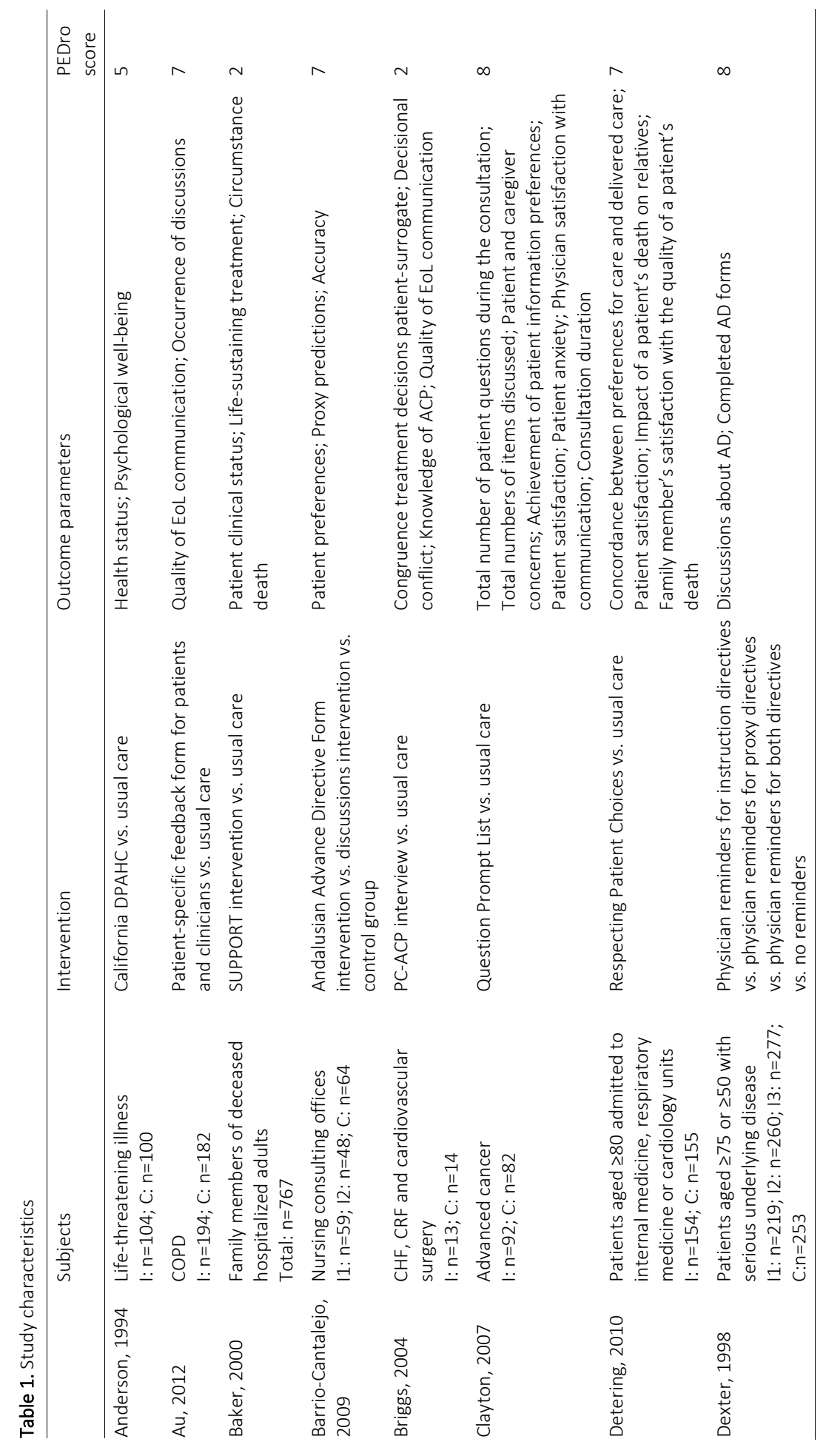




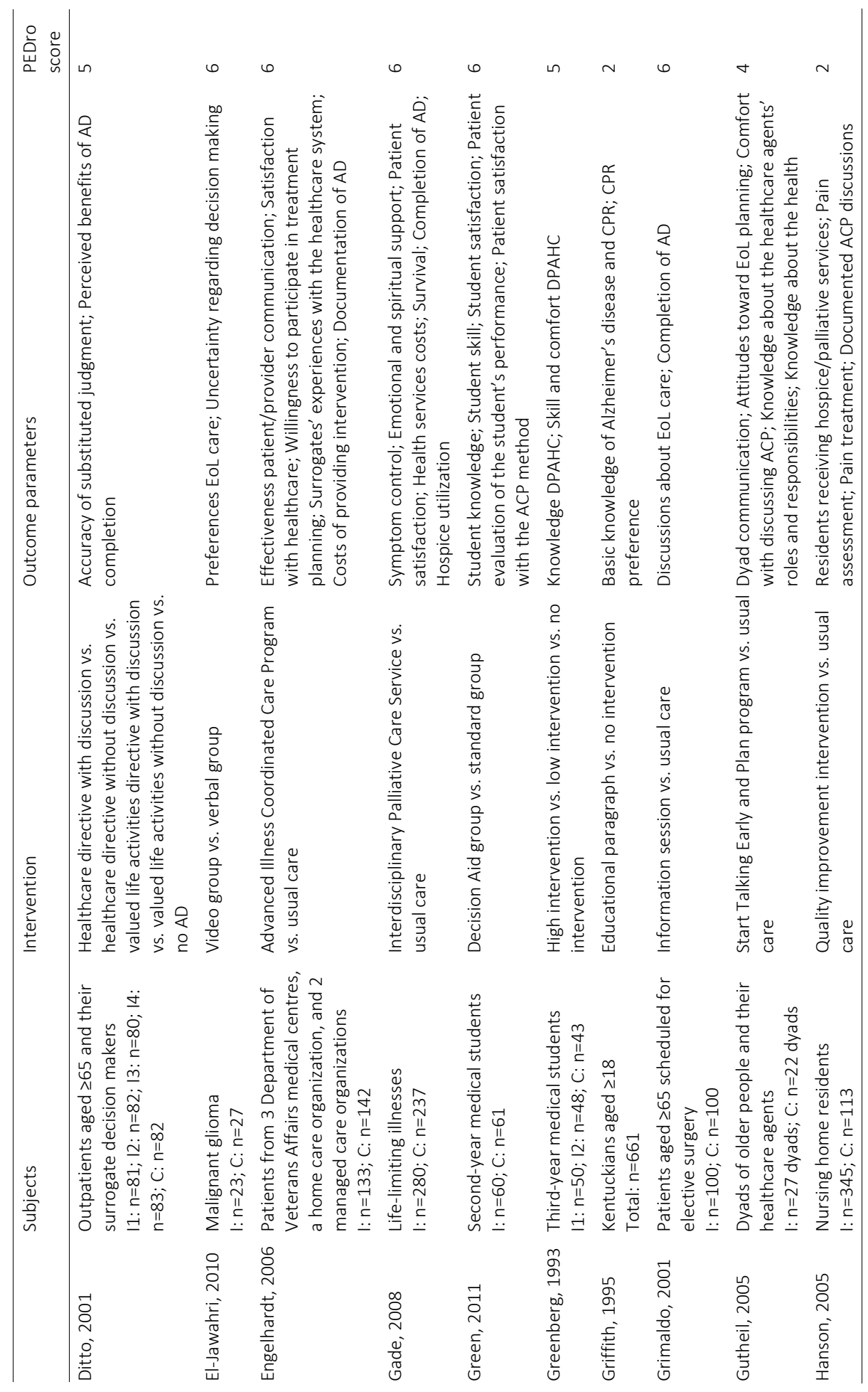


Efficacy of advance care planning

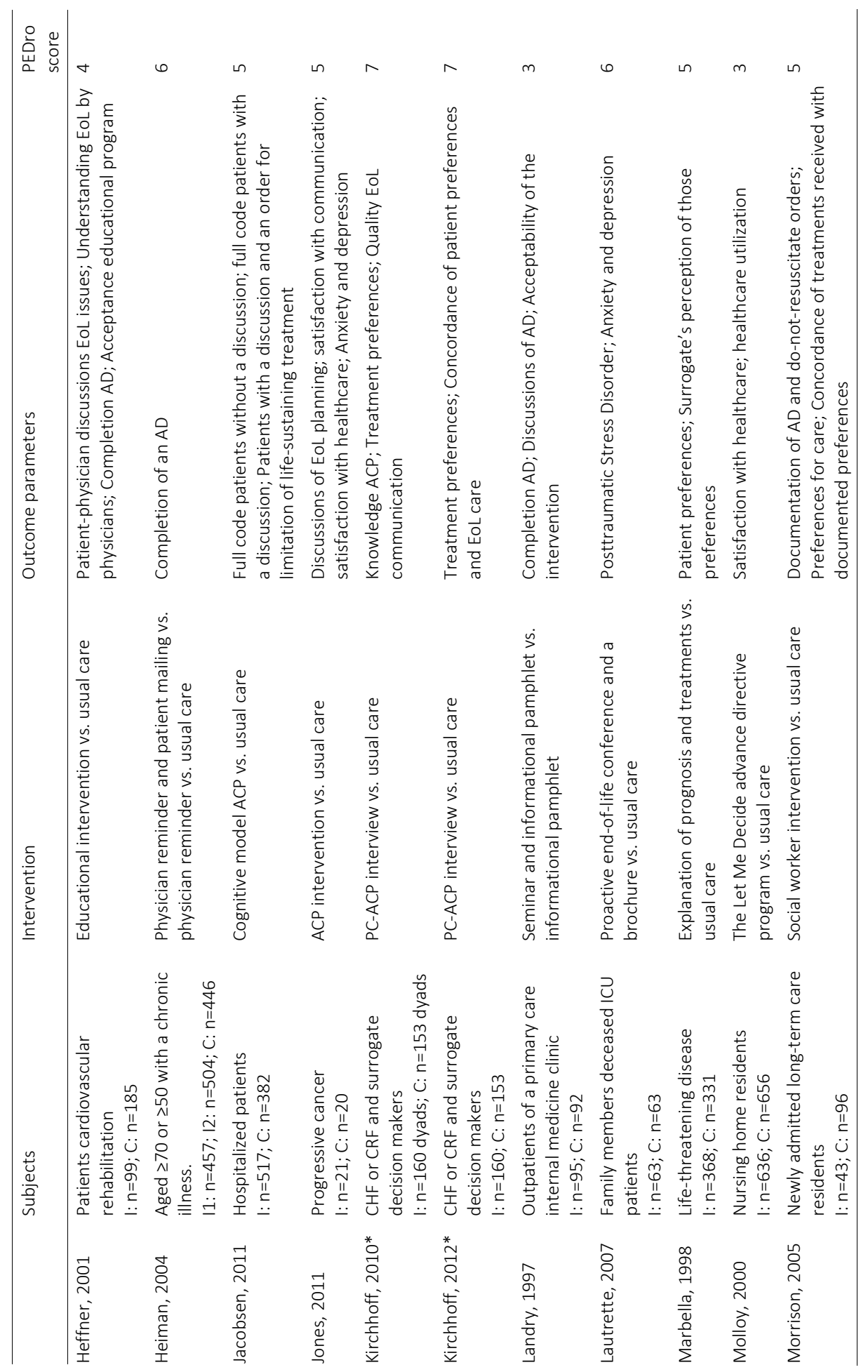




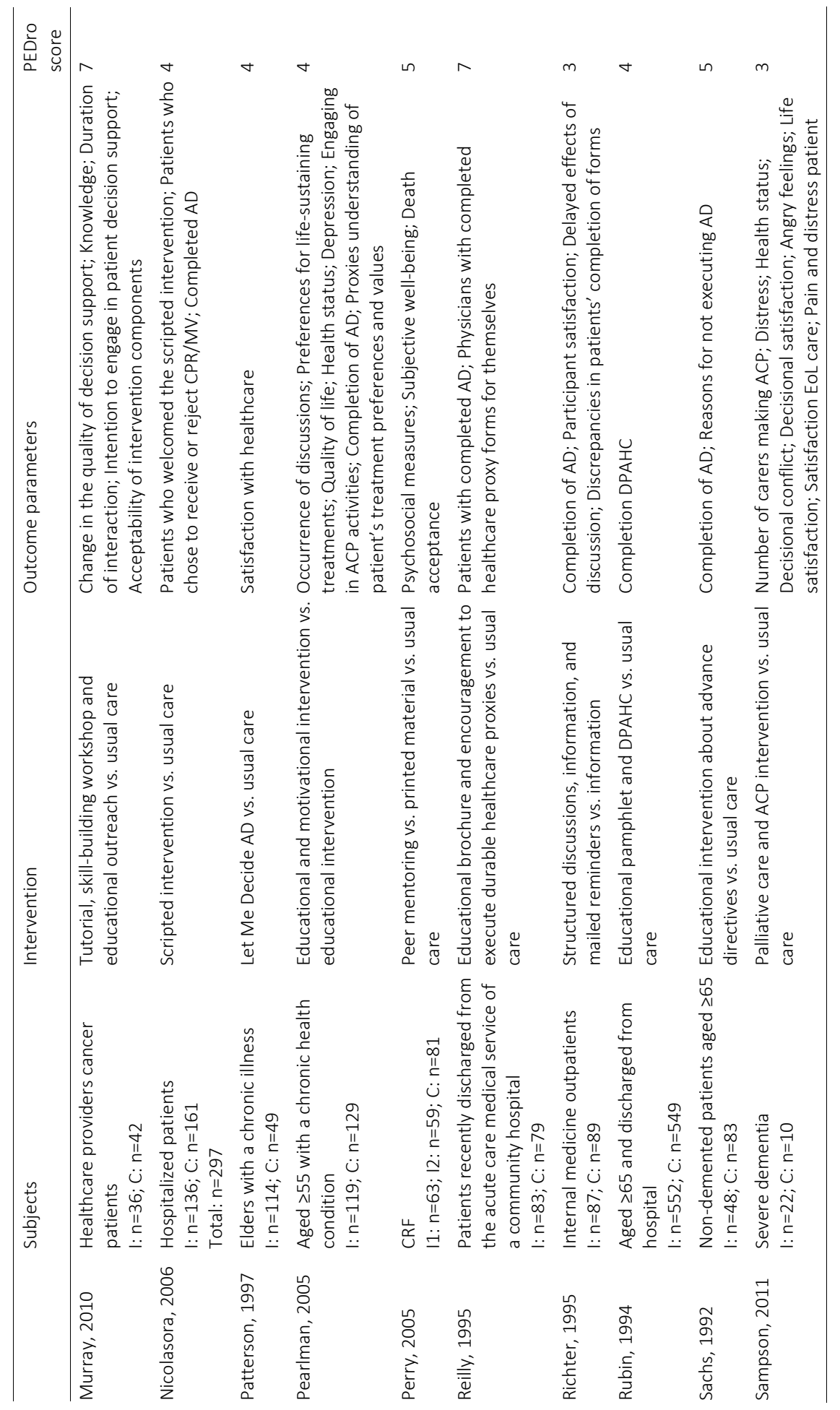


Efficacy of advance care planning

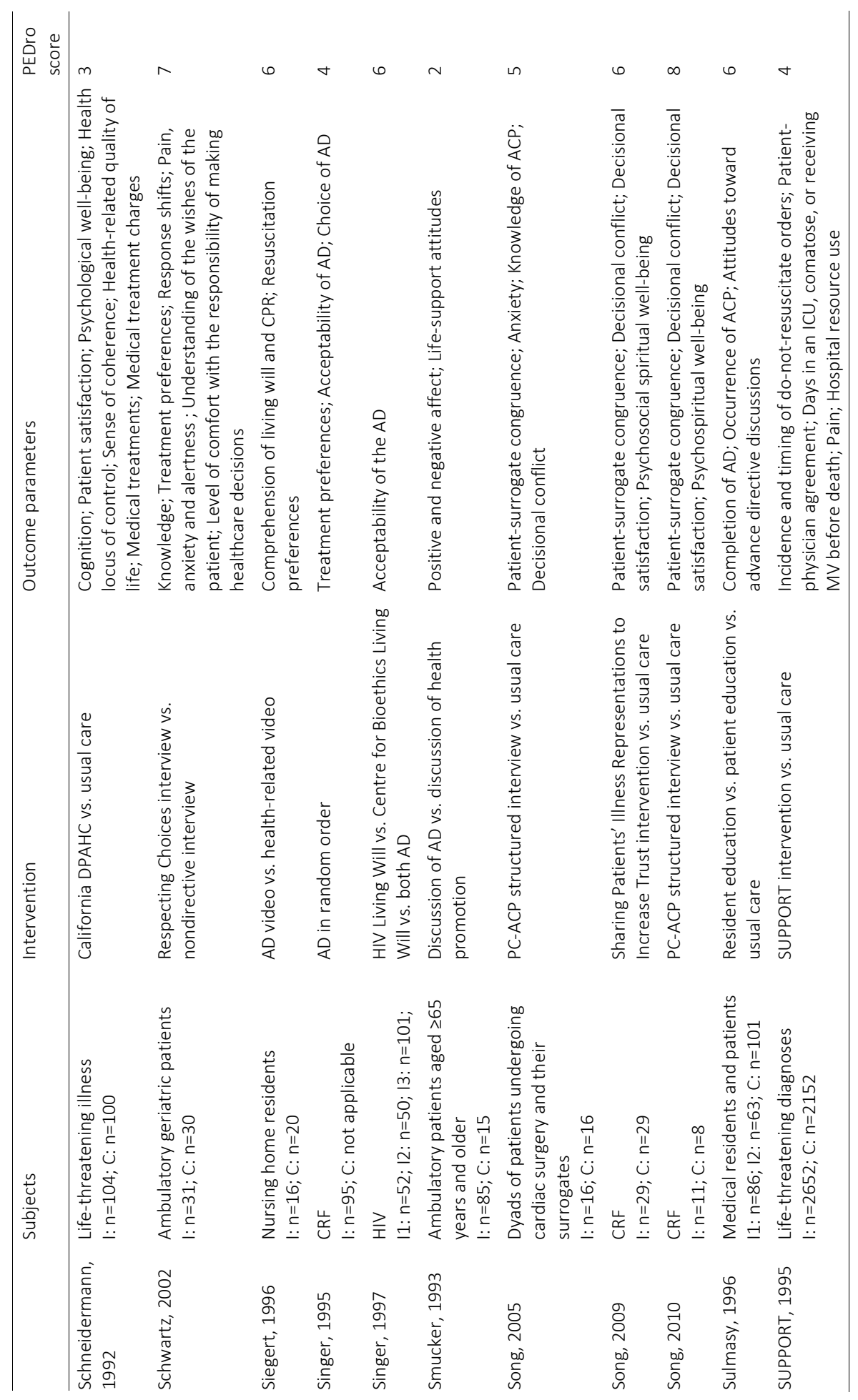




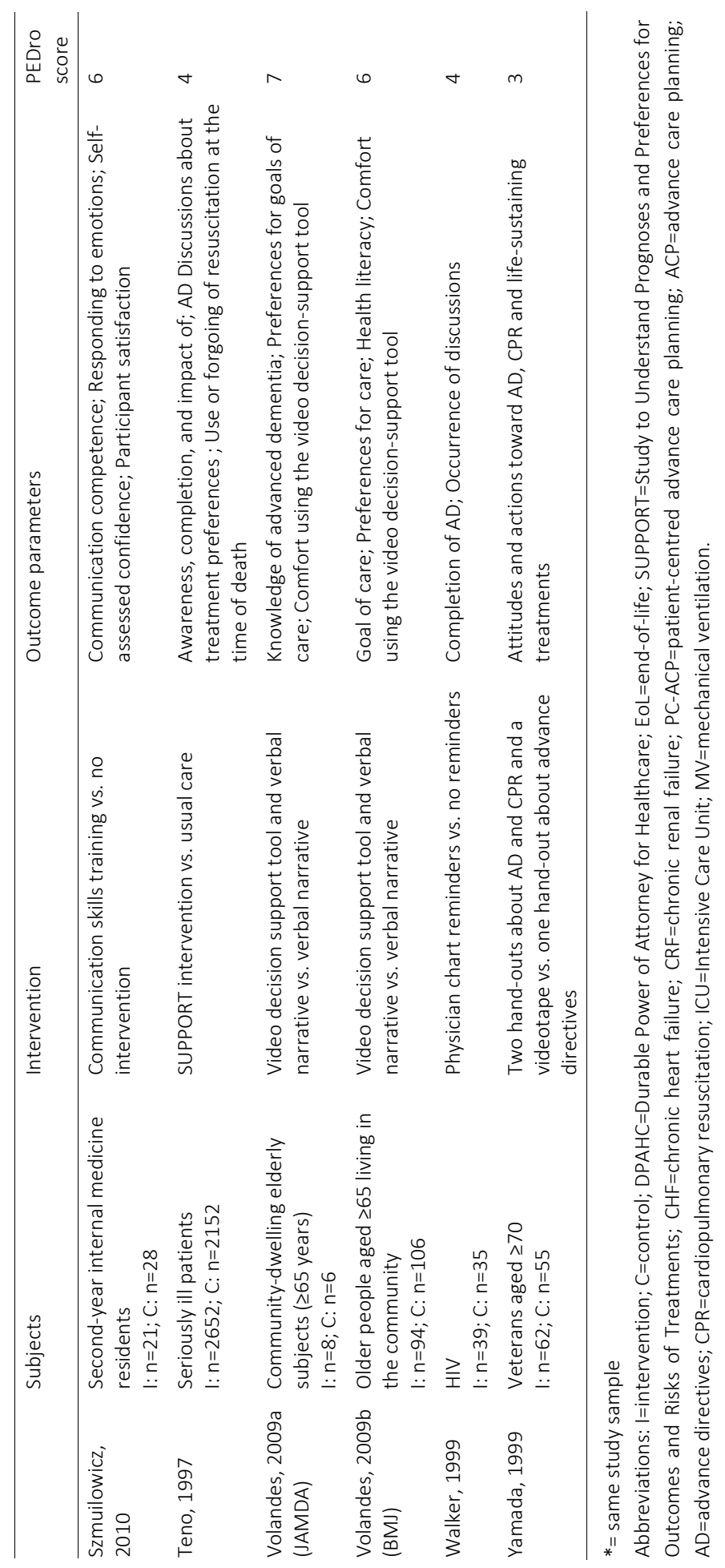




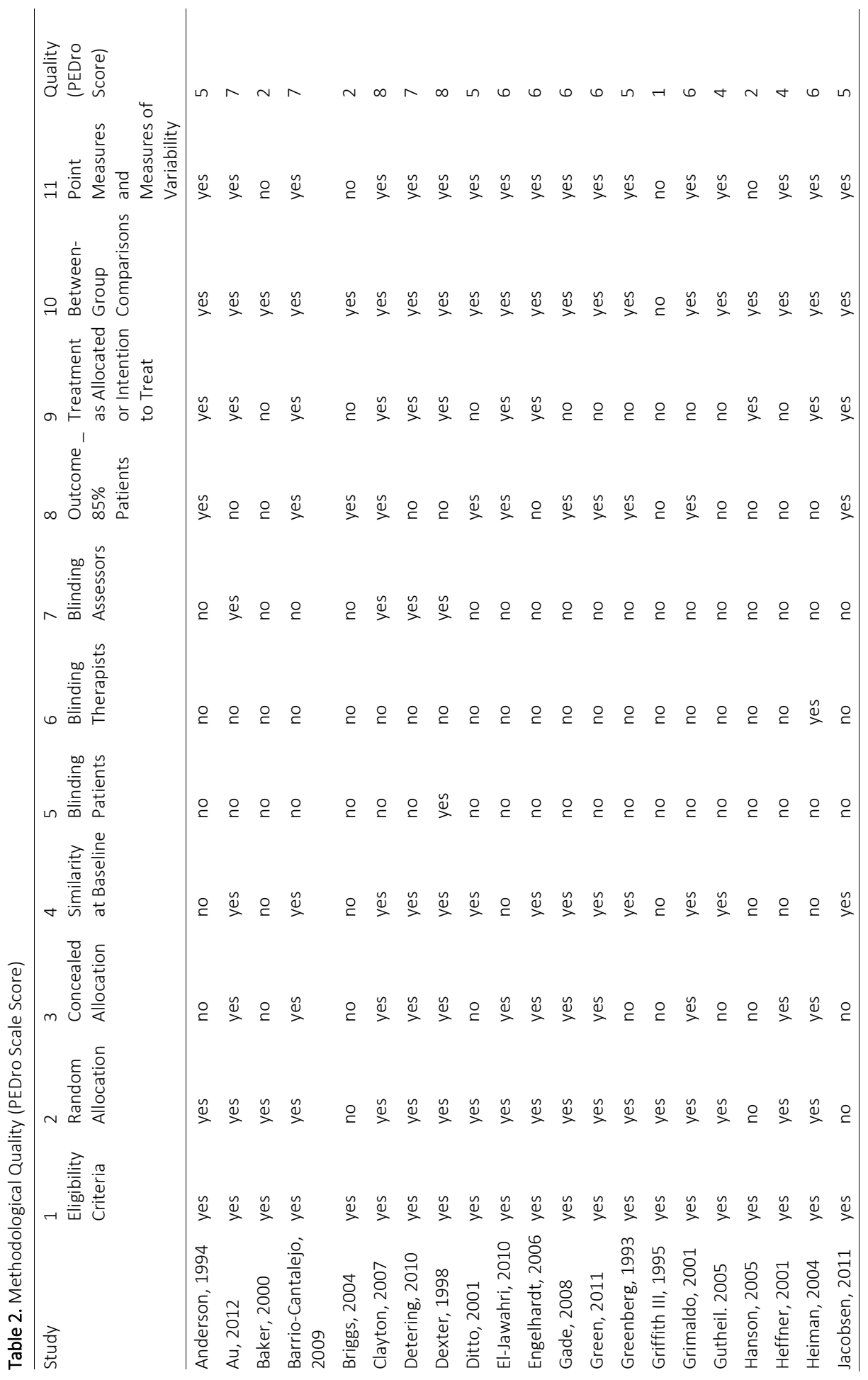


Chapter 2

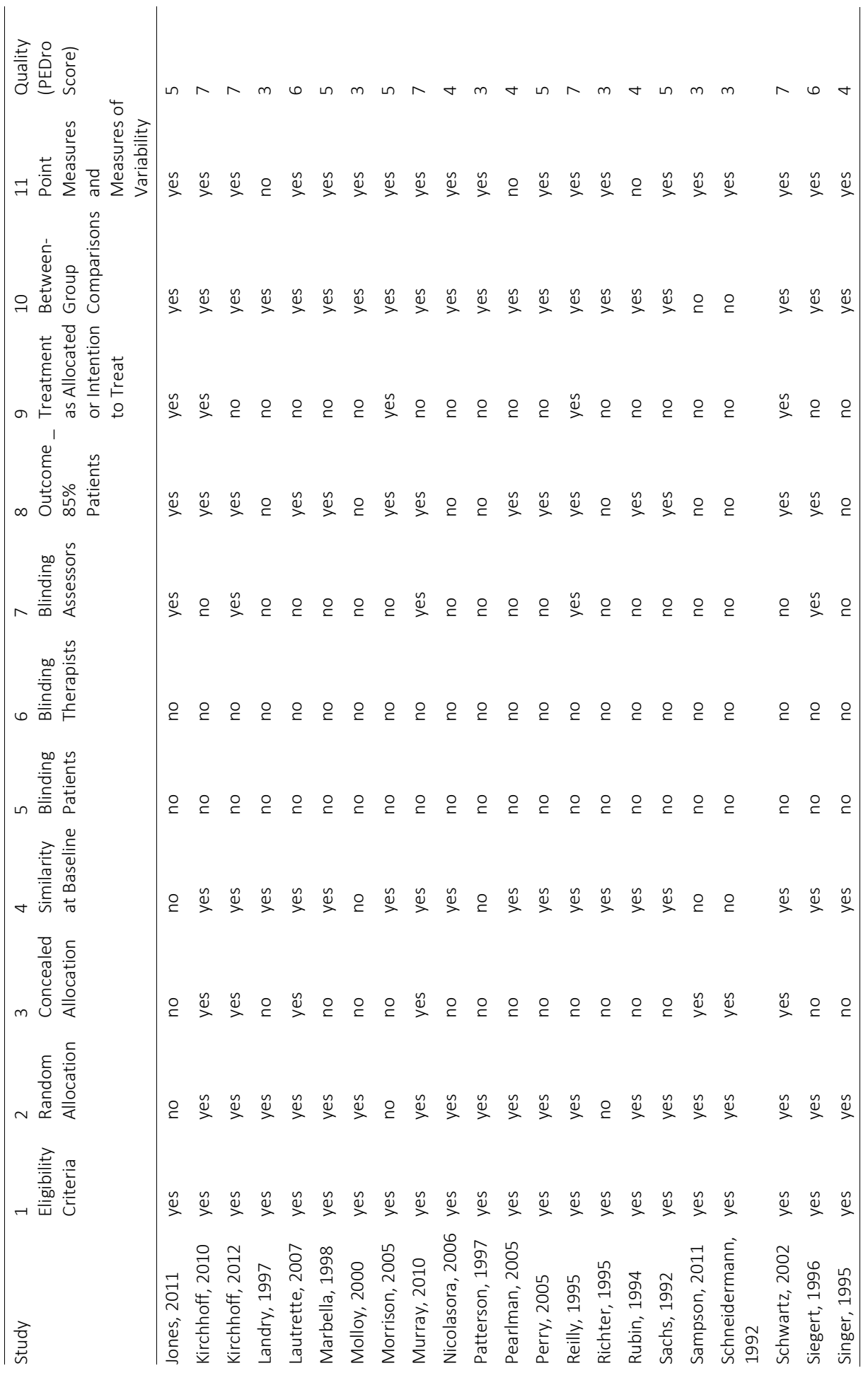




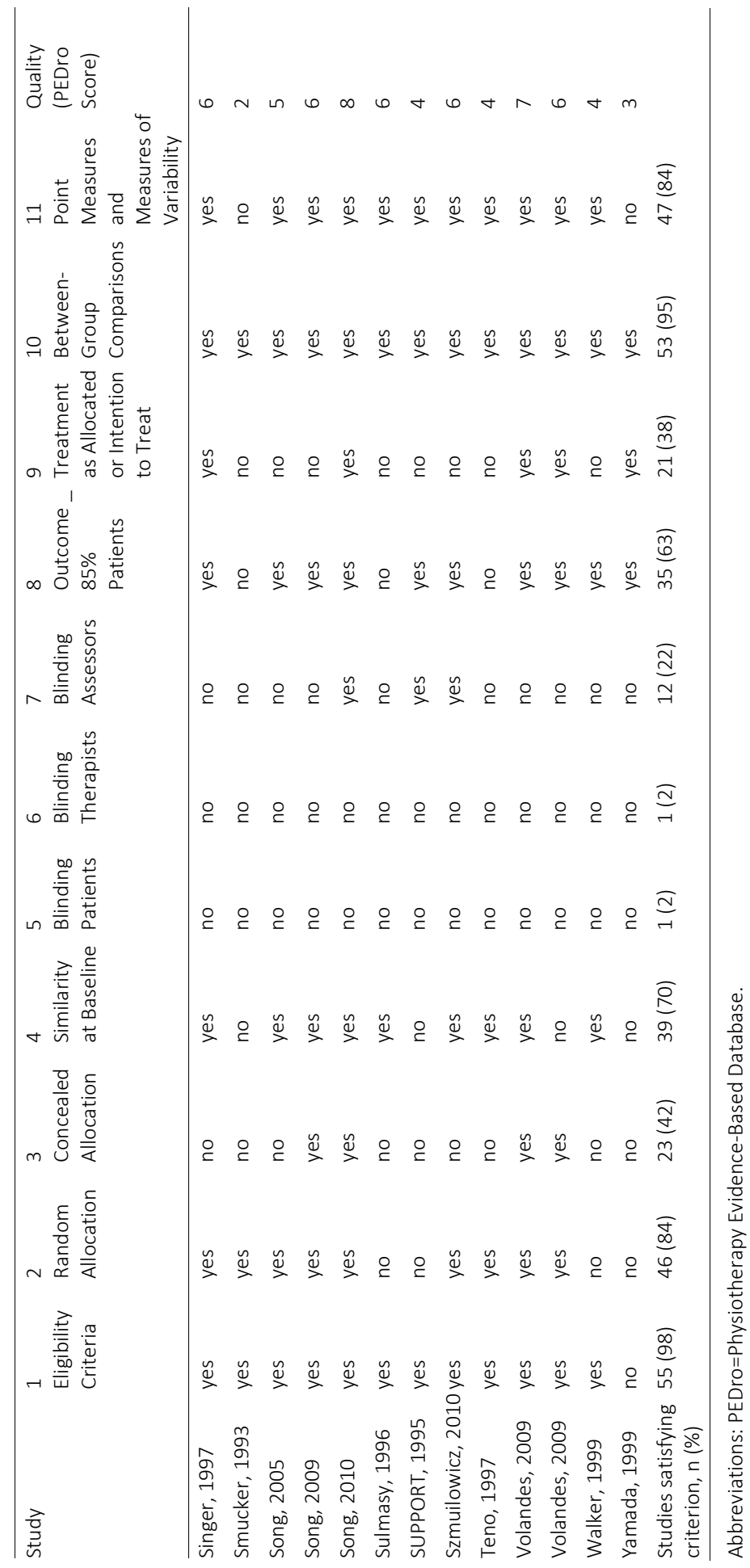


In 26 trials, the intervention was classified as focusing on advance directives ${ }^{7,12-36}$, and in 30 trials as also including communication in addition to advance directives. ${ }^{8,37-65}$ A significant association was found between the type of intervention and the period in which the study was conducted $(p<.001)$. In the periods 1999-2005 and 2006-2012, there were significantly more publications in the category communication in comparison with the publications in 1992-1998, $p=.012$ and $\mathrm{p}<0.005$, respectively (Figure 2).

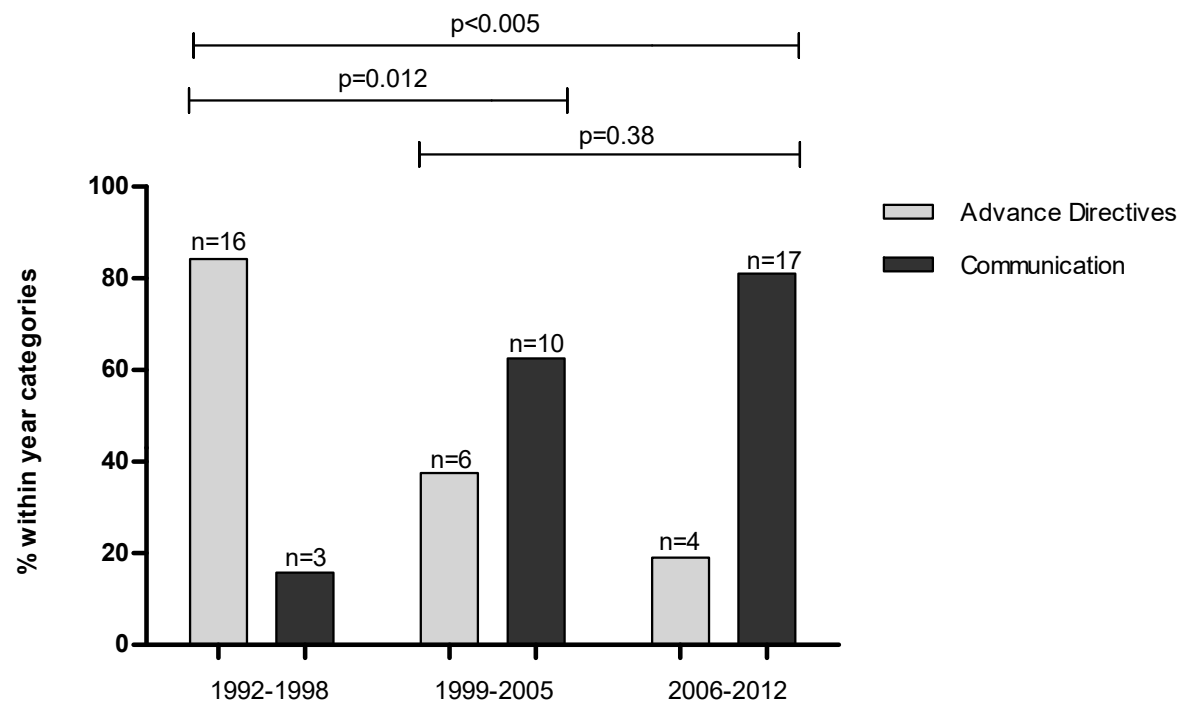

Figure 2. Proportion of studies within year categories about interventions limited to the completion of advance directives or interventions also including communication

\section{Completion of advance directives}

Completion of advance directives was reported as an outcome in 18 trials (advance directives: $n=9^{14,19,20,23,25-27,32,36}$; communication: $n=9^{37,43,45,48,55,57-59,65}$ ). Three trials were excluded from meta-analysis because absolute changes in completion of advance directives were not available $37,55,65$, and one was excluded because only the intervention group was offered the opportunity to complete an advance directive. ${ }^{59}$ Of the remaining 13 trials, four trials included two or more intervention groups in addition to the control group. ${ }^{14,19,23,32}$ In meta-analysis, each of these intervention groups was compared with the control group, resulting in five extra comparisons. Results showed an increased likelihood for the completion of advance directives 
compared to usual care (OR 3.26; 95\% Cl 2.00-5.32; $\mathrm{p<.00001).} \mathrm{The} \mathrm{increased} \mathrm{likeli-}$ hood for completion of advance directives was comparable in the trials focusing on advance directives (OR 3.31; $95 \% \mathrm{Cl}$ 1.69-6.50) and those also including communication (OR 2.76; 95\% Cl 1.41-5.37) ( $p=.71$ ) (Figure 3a).

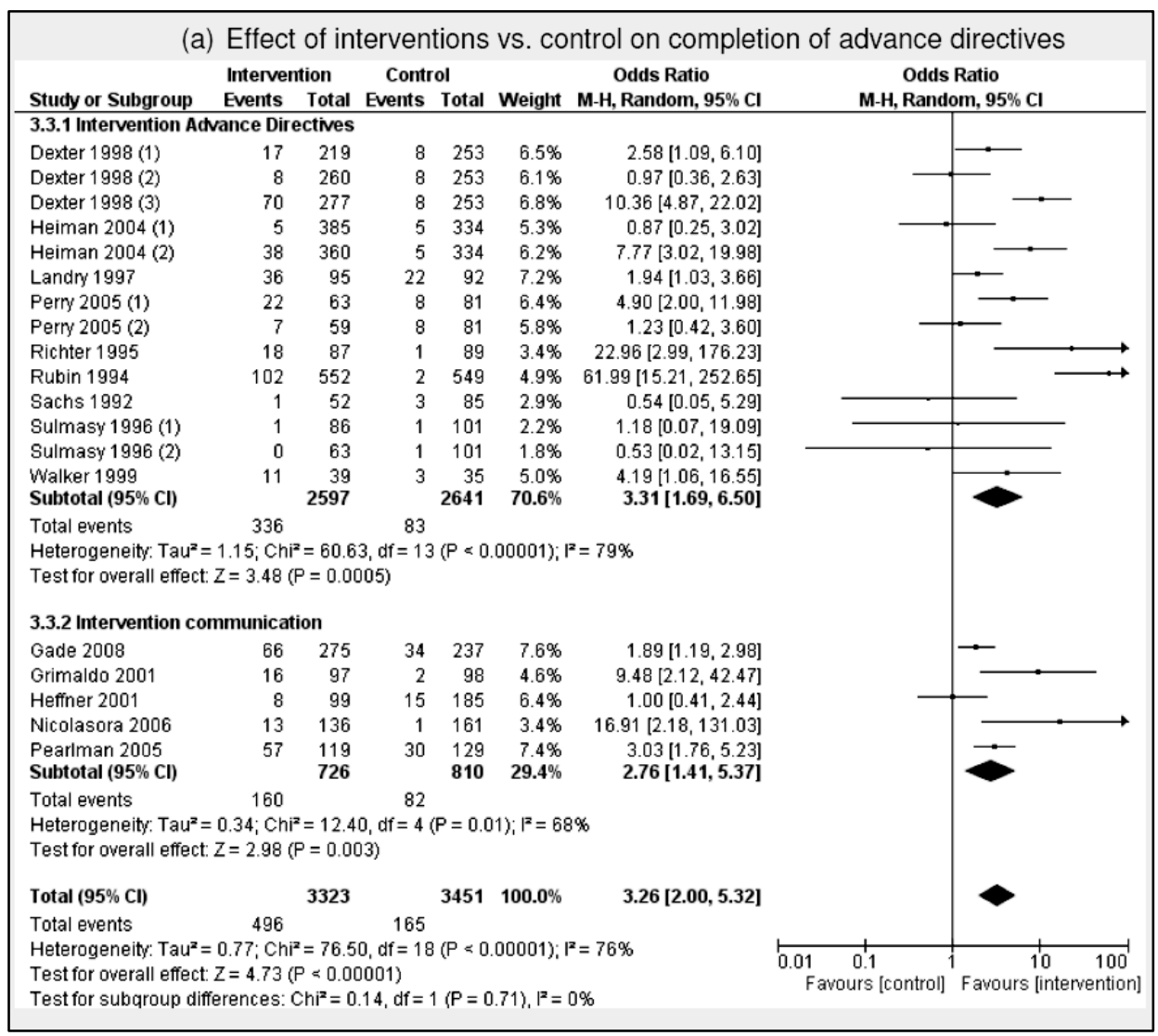

Figure 3a. Effect of interventions on completion of advance directives. (1) Instruction directive reminder vs control; (2) Proxy directive reminder vs control; (3) Instruction directive and proxy directive reminders vs control; (4) Physician reminder vs control; (5) Physician reminder and patient mailing vs control; (6) Peer intervention vs control; (7) Printed materials vs control; (8) Resident education group vs control; (9) Patient education group vs control.

Abbreviations: $\mathrm{Cl}=$ Confidence Interval; $\mathrm{M}-\mathrm{H}-$ Mantel-Haenszel.

Occurrence of end-of-life care discussions

Eleven trials reported as an outcome the occurrence of discussions about end-oflife care preferences between patients and healthcare professionals (advance directives: $n=3^{14,20,36}$; communication: $n=8^{38,41,47-50,58,65}$ ). Five trials were excluded from meta-analysis because no between-group comparisons were reported, ${ }^{65}$ data for 
control group or baseline were not available, ${ }^{36,47,58}$ or the occurrence of discussions was measured as a continuous instead of a dichotomous variable. ${ }^{50}$ In one trial, three intervention groups and one control group were used. ${ }^{14}$ In meta-analyses, all intervention groups were compared with the same control group, resulting in two extra comparisons. Meta-analyses showed an increased likelihood for the occurrence of discussions about end-of-life preferences between patients and healthcare professionals following an intervention compared with control groups (OR 2.82; $95 \% \mathrm{Cl} 2.09$ to 3.79; $\mathrm{p}<.00001)$. The increased likelihood for the occurrence of discussions was comparable in the subgroups advance directives (OR $3.41 ; 95 \% \mathrm{Cl}$ 1.94-5.98) and communication (OR 2.48; 95\% Cl 1.78-3.44) ( $p=.34)$ (Figure 3b).

\begin{tabular}{|c|c|c|c|c|c|c|c|c|}
\hline \multirow[t]{2}{*}{ (b) Eff } & \multicolumn{8}{|c|}{$\begin{array}{c}\text { (b) Effect of interventions vs. control on occurrence of discussions about end-of-life } \\
\text { preferences }\end{array}$} \\
\hline & \multicolumn{2}{|c|}{ Intervention } & \multicolumn{2}{|c|}{ Control } & Weight & $\begin{array}{l}\text { Odds Ratio } \\
\text { M- } \mathrm{H}, \text { Random, } 95 \% \mathrm{Cl}\end{array}$ & \multicolumn{2}{|c|}{$\begin{array}{l}\text { Odds Ratio } \\
\text { M- } \mathrm{H}, \text { Random, } 95 \% \mathrm{Cl}\end{array}$} \\
\hline \multicolumn{9}{|c|}{ 2.2.1 Intervention Advance Directives } \\
\hline Dexter 1998 (1) & 33 & 219 & 11 & 253 & $9.4 \%$ & $3.90[1.92,7.93]$ & & 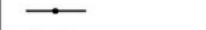 \\
\hline Dexter 1998 (2) & 26 & 260 & 11 & 253 & $9.1 \%$ & $2.44[1.18,5.06]$ & & \\
\hline Dexter 1998 (3) & 67 & 277 & 11 & 253 & $10.0 \%$ & $7.02[3.61,13.63]$ & & \\
\hline Landry 1997 & 69 & 95 & 52 & 92 & $10.8 \%$ & $2.04[1.11,3.76]$ & & \\
\hline Subtotal $(95 \% \mathrm{Cl})$ & & 851 & & 851 & $39.4 \%$ & $3.41[1.94,5.98]$ & & \\
\hline Total events & 195 & & 85 & & & & & \\
\hline \multicolumn{9}{|c|}{$\begin{array}{l}\text { Heterogeneity: Tau }=0.21 ; \mathrm{Chi}^{2}=8.29, \mathrm{df}=3(\mathrm{P}=0.04) ; \mathrm{l}^{2}=64 \% \\
\text { Test for overall effect: } Z=4.28(P<0.0001)\end{array}$} \\
\hline \multicolumn{9}{|c|}{ 2.2.2 Intervention communication } \\
\hline Au 2012 & 117 & 194 & 56 & 182 & $14.2 \%$ & $3.42[2.23,5.24]$ & & $\rightarrow$ \\
\hline Clayton 2007 & 27 & 90 & 8 & 80 & $7.5 \%$ & $3.86[1.63,9.10]$ & & \\
\hline Heffiner 2001 & 18 & 99 & 24 & 185 & $10.0 \%$ & $1.49[0.77,2.90]$ & & - \\
\hline Jacobsen 2011 & 175 & 517 & 81 & 382 & $16.5 \%$ & $1.90[1.40,2.58]$ & & $\rightarrow$ \\
\hline $\begin{array}{l}\text { Pearlman } 2005 \\
\text { Subtotal }(95 \% \mathrm{CI})\end{array}$ & 76 & $\begin{array}{r}119 \\
1019\end{array}$ & 49 & $\begin{array}{l}129 \\
958\end{array}$ & $\begin{array}{l}12.5 \% \\
\mathbf{6 0 . 6} \%\end{array}$ & $\begin{array}{l}2.89[1.72,4.83] \\
2.48[1.78,3.44]\end{array}$ & & $\because-$ \\
\hline Total events & 413 & & 218 & & & & & \\
\hline \multicolumn{9}{|c|}{$\begin{array}{l}\text { Heterogeneity: } \text { Tau }^{2}=0.07 ; \mathrm{Chi}^{2}=8.49, \mathrm{df}=4(\mathrm{P}=0.08) ; \mathrm{I}^{2}=53 \% \\
\text { Test for overall effect: } Z=5.39(P<0.00001)\end{array}$} \\
\hline Total $(95 \% \mathrm{Cl})$ & & 1870 & & 1809 & $100.0 \%$ & $2.82[2.09,3.79]$ & & $>$ \\
\hline Total events & 608 & & 303 & & & & & \\
\hline $\begin{array}{l}\text { Heterogeneity: Tauz } \\
\text { Test for overall effect } \\
\text { Test for subaroun di }\end{array}$ & $\begin{array}{l}0.12 ; \mathrm{Chi}^{2} \\
\mathrm{Z}=6.82 \\
\text { ferences: }\end{array}$ & $\begin{array}{l}2=19.8 \\
P<0.00 \\
C h i^{2}=0\end{array}$ & $\begin{array}{l}\text { 82, } \mathrm{df}=8(\mathrm{c} \\
0001) \\
0.92 . \mathrm{df}=1\end{array}$ & $\begin{array}{l}(P=0.0 \\
1(P=0\end{array}$ & $\begin{array}{l}01) ; I^{2}=60 \\
0.34) \cdot I^{2}=0\end{array}$ & & $\begin{array}{l} \\
0.01 \\
\text { Favours [control] }\end{array}$ & \begin{tabular}{|c|c|c|}
10 & 100 \\
Favours [intervention]
\end{tabular} \\
\hline
\end{tabular}

Figure 3b. Effect of interventions on occurrence of discussions about end-of-life preferences. (1) Instruction directive reminder vs control; (2) Proxy directive reminder vs control; (3) Instruction directive and proxy directive reminders vs control.

Abbreviations: $\mathrm{Cl}=$ Confidence Interval; $\mathrm{M}-\mathrm{H}-$ Mantel-Haenszel.

\section{Other outcomes}

Concordance between preferences for care and delivered care

Concordance between patient's preferences for end-of-life care and the end-of-life care received was reported as an outcome in three trials. ${ }^{8,52,55}$ All these trials in- 
cluded communication in their intervention. Patients in the intervention groups had an increased likelihood of receiving end-of-life care in concordance with their preferences compared with control groups (OR 4.66; 95\% Cl 1.20-18.08; $p=.03$; Figure $3 c)$.

(c) Effect of interventions vs. control on concordance between patient's preferences for endof-life care and the end-of-life care received

\begin{tabular}{|c|c|c|c|c|c|c|c|c|}
\hline Study or Subgroup & \multicolumn{2}{|c|}{ Intervention } & \multicolumn{2}{|c|}{ Control } & Weight & $\begin{array}{l}\text { Odds Ratio } \\
\text { M-H, Random, } 95 \% \mathrm{Cl}\end{array}$ & \multicolumn{2}{|c|}{$\begin{array}{l}\text { Odds Ratio } \\
\text { M-H, Random, } 95 \% \mathrm{Cl}\end{array}$} \\
\hline Detering 2010 & 25 & 20 & 8 & 27 & $31.6 \%$ & $14.84[3.80,56.71]$ & & \\
\hline Kirchnoff 2012 & 46 & 62 & 30 & 48 & $39.2 \%$ & $1.73[0.76,3.90]$ & & \\
\hline Morrison 2005 & 47 & 49 & 79 & 96 & $29.2 \%$ & $5.06[1.12,22.87]$ & & \\
\hline Total $(95 \% \mathrm{Cl})$ & & 140 & & 171 & $100.0 \%$ & $4.66[1.20,18.08]$ & & \\
\hline Total events & 118 & & 117 & & & & & \\
\hline \multicolumn{7}{|c|}{$\begin{array}{l}\text { Heterogeneity: } \operatorname{Tau}^{2}=1.05 ; \mathrm{Chi}^{2}=7.60, \mathrm{df}=2(P=0.02) ; \mathrm{I}^{2}=74 \% \\
\text { Test for overall effect: } Z=2.23(P=0.03)\end{array}$} & $\begin{array}{ll}0.01 & 0.1 \\
\text { Favours [control] } & 1\end{array}$ & $\begin{array}{c}10 \\
\text { Favours [intervention] }\end{array}$ \\
\hline
\end{tabular}

Figure 3c. Effect of interventions on concordance between patient's preferences for end-of-life care and the end-of-life care received.

Abbreviations: $\mathrm{Cl}=$ Confidence Interval; $\mathrm{M}-\mathrm{H}-$ Mantel-Haenszel.

Knowledge of $A C P$

Nine trials explored whether interventions can be used to improve knowledge of ACP. Five trials reported significant results in favor of the intervention. ${ }^{46,51,56,60}$ Four trials found no effect of interventions on knowledge of ACP. ${ }^{18,28,40,62}$

End-of-life care preferences

End-of-life care preferences were reported as an outcome in nine trials. In six trials, patients were more likely to prefer comfort care and to avoid life-sustaining treatments following the intervention compared with the control groups. ${ }^{16,18,33,34,51,60}$ The other trials found no effect of interventions on end-of-life care preferences. ${ }^{28,52,58}$

\section{Quality of communication}

Only two trials explored how interventions can improve the quality of communication between patients and healthcare professional. ${ }^{38,56}$ Both trials reported significant results in favor of the intervention.

\section{Satisfaction with healthcare}

Satisfaction with healthcare was reported as an outcome in seven trials. Two trials reported that patients in the intervention group were more satisfied with 


\section{Chapter 2}

healthcare. ${ }^{42,43}$ The other trials found no effect of interventions on satisfaction with healthcare. ${ }^{7,21,22,39,50}$ Three trials asked the family of deceased patients about their satisfaction with the end-of-life care of their loved one. ${ }^{8,39,42}$ These trials reported that family members in the intervention groups were more likely than those of the control groups to be satisfied with end-of-life care. In addition, family members of patients in intervention groups had significantly more discussions about end-of-life care compared with family members of patients in control groups in all three studies. $^{31,45,50}$

\section{Decisional conflict}

Decisional conflict, defined as patient's level of difficulty in making choices ${ }^{61}$ was measured with the 13 -item or 16-item Decisional Conflict Scale in six trials. ${ }^{16,40,59,61-}$ ${ }^{63}$ In one trial, ${ }^{59}$ the questionnaire was administered by loved ones and, therefore, not comparable with the other trials, in which the patients completed the Decisional Conflict Scale. In three trials patients were asked to complete a decisional conflict scale after the intervention. ${ }^{16,40,62}$ These trials reported that patients in the intervention group were more certain of their end of life decision-making than patients in the control group. However, the other two trials, in which patients completed the Decisional Conflict Scale before and after the intervention, found no change over time in decisional conflict. ${ }^{61,63}$

\section{Use of healthcare services}

Five trials explored how interventions influenced the use of healthcare services. $^{7,21,37,43,47}$ In three trials, interventions increased hospice utilization and decreased hospitalizations and healthcare costs. ${ }^{21,43,47}$ Two trials showed no effect of ACP on use of hospital resources. ${ }^{7,37}$

\section{Symptoms}

Symptoms of anxiety and depression, psychological well-being, health status or pain were reported as an outcome in 15 trials. ${ }^{7,12,22,28,31,37,41,43,50,58-63}$ Unfortunately, meta-analysis was not possible, due to variability in definition and measurement of the symptoms. None of these trials found a significant change in these outcomes following intervention. 


\section{DISCUSSION}

\section{Key findings}

This review systematically evaluated the efficacy of ACP interventions in different adult populations. Interventions focusing on advance directives as well as interventions that also included communication about ACP increased the completion of advance directives and the occurrence of end-of-life care discussions between patients and healthcare professionals. Moreover, interventions that also included communication about ACP in addition to advance directives, also improved concordance between patient's preferences for end-of-life care and received end-oflife care. Finally, interventions are likely to improve quality of communication while the impact on knowledge of ACP, end-of-life care preferences, satisfaction with healthcare, decisional conflict, and use of healthcare services remains unknown. Interventions are likely to have no effect on daily symptoms, like symptoms of anxiety and depression, psychological well-being, health status, and pain.

\section{Impact of ACP on advance directives and ACP discussions}

Meta-analysis showed that ACP can be effective in changing completion of advance directives and occurrence of end-of-life discussions.

First, patients in intervention groups completed an advance directive more often in comparison with control groups. Previous studies have indicated that patients who completed an advance directive received care that was more often in concordance with their preferences ${ }^{66}$ and were less likely to die in a hospital. ${ }^{67}$ In addition, completion of advance directives was associated with less caregiver burden in loved ones. $^{68}$

In contrast, other studies have criticized the value of advance directives. The authors concluded that healthcare professionals differ in the interpretation of advance directives $^{69}$ and often made treatment decisions discordant with the treatment preferences stated in advance directives. ${ }^{70}$ These studies were based on hypothetical cases and therefore, not comparable with treatment decisions made in daily care. However, previously documented advance directives may not always reflect the patient's current preference. Indeed, preferences for life-sustaining treatments and end-of-life care are likely to change. Therefore regular evaluation of documented advance directives is advisable. ${ }^{71,72}$ 
Second, patients in intervention groups had a discussion more often about end-oflife preferences with a healthcare professional in comparison with control groups. Timing of ACP discussions is important. Previous authors recommended a discussion of end-of-life preferences during regular outpatient clinical visits when patients are stable and not acutely ill. ${ }^{14}$ Studies included in our meta-analysis were all conducted in an outpatient setting during scheduled visits. All these studies showed positive results and, therefore, confirm the benefits of ACP interventions during scheduled visits. However, the efficacy of ACP interventions in a controlled setting may not be translated into the effectiveness of these interventions in a real world setting.

\section{Other outcomes}

Patients in intervention groups received end-of-life care that was more often in concordance with their end-of-life care preferences than patients in control groups. The study by Silveira et al. ${ }^{66}$ shows that concordance increases when advance directives were discussed. Therefore, advance directives seem to be a tool for ACP by opening the dialogue, but discussion about advance directives is necessary to improve end-of-life care for patients. Indeed, Sudore et al. ${ }^{73}$ stated that the aim of ACP should be to prepare patients and their loved ones to participate with professional caregivers in making the best possible in-the-moment decisions.

Interventions are likely to improve quality of communication, while the impact on knowledge of ACP, end-of-life care preferences, satisfaction with healthcare, decisional conflict, and use of healthcare services remains unknown. There is no clear explanation why, for example ACP interventions had a different impact on knowledge of ACP in different ways and did not use the same validated questionnaire. Interventions are likely to have no effect on symptoms, like symptoms of anxiety and depression, psychological well-being, health status and pain.

Although fear of causing patient psychosocial distress is a physician reported barrier for $A C P,{ }^{74}$ the current study finds no evidence that ACP increases symptoms of anxiety and depression. This is in line with the findings of a cohort study in patients with cancer which has demonstrated that ACP was not associated with a higher prevalence of depressive disorders. ${ }^{75} \mathrm{~A}$ trial by Curtis et al. ${ }^{76}$ has shown a relationship between quality of communication and the presence of symptoms of depression in patients with chronic obstructive pulmonary disease. They found a negative association between quality of communication and symptoms of depression. However, it is unclear whether this finding reflects an effect of symptoms of depression 
on patients' ratings of the quality of communication or whether the quality of communication may influence symptoms of depression.

Advance directives vs advance directives and communication about end-of-life care

A significant association was found between type of intervention and the period in which the study was conducted. Across time more studies have been conducted in which people were offering a discussion of advance care planning in addition to the opportunity to complete an advance directive. Nevertheless, the present study did not show a difference in completion of advance directives or occurrence of discussions about end-of-life preferences between interventions limited to the completion of advance directives and interventions also including communication about ACP. Therefore, both interventions are able to improve these outcomes. However, none of the studies limited to completion of advance directives explored the impact on patient's preferences for end-of-life care and the end-of-life care actually received. Meta-analysis of the three trials with interventions focusing on communication in addition to advance directives showed that patients in the intervention groups had an increased likelihood of receiving end-of-life care in concordance with their preferences compared with control groups.

Previous authors found that a successful ACP intervention should combine effective communication with the completion of advance directives. ${ }^{77}$ Indeed, a previous review concerning patient-professional communication about end-of-life issues in life-limiting conditions showed that a successful intervention should include combined components of training, patient discussion, education, and written documentation. Discussions concerning preferences about end-of-life care are seen as an essential component of $\mathrm{ACP}^{78}$ and are associated with greater patient satisfaction with communication with their physician ${ }^{79}$ and improved family satisfaction with end-of-life care. ${ }^{80}$ According to the guideline "Palliative Care: Symptom Management and End-of-Life Care" developed by the World Health Organization communication is an essential skill for delivering good end-of-life care. ${ }^{81}$ However, "good communication" is a broad concept without a clear definition. Although the key features of successful ACP interventions are identified, it is still unclear which specific elements of ACP are relevant to improve end-of-life care for patients and their loved ones. The present review shows that interventions including communication about ACP are able to improve concordance between patient's preferences and end-of-life care received. However, it remains unknown whether interventions only focusing on advance directives are able to improve end-of-life care. 


\section{METHODOLOGICAL CONSIDERATIONS}

Included trials had several limitations. First, $55.4 \%$ of the trials were classified as "low-quality trials". The most important reason for low PEDro-scores was the lack of blinding of patients, therapists, and assessors. This may have influenced the findings of the included trials. Indeed, if patients and therapists are not blinded there is a greater risk of response bias and intervention bias, respectively. ${ }^{82}$ Other highly prevalent limitations were a lack of intention to treat and concealed allocation. This may cause biases, like overestimation of clinical effectiveness ${ }^{83}$ and finding of more modest treatment effects. ${ }^{84}$ Second, meta-analysis was not possible for outcomes such as quality of communication, knowledge of ACP, end-of-life care preferences, satisfaction with healthcare, decisional conflict, use of healthcare services, and symptoms, because of variability in definition and measurement. In addition, a number of included trials used instruments that were not formally validated. This may limit the validity of the results and comparisons with other trials were not possible. Third, several trials included a relatively small sample size and often trials were conducted in only one setting, making generalizability difficult. A separate analysis of the different settings, for example nursing home studies, was not possible due to the use of different outcomes. Fourth, there was variability in timing of intervention, age, and primary diagnosis of patients in the included trials. However, despite these differences the majority of the trials showed positive results. The results of the Study to Understand Prognoses and Preferences for Outcomes and Risks of Treatments ${ }^{37}$ were disappointing, although it was the single biggest study included in this review. The methodological quality of the Study to Understand Prognoses and Preferences for Outcomes and Risks of Treatments was limited. Methodological limitations were, for example, no random allocation; allocation not concealed; lack of intention to treat analysis; and differences between the intervention and control group at baseline. In addition to these methodological considerations, it could be possible that the intervention would have been more effective if implemented earlier during the course of illness. ${ }^{37}$

The present systematic review also has several limitations. For example, several instruments are available to assess the quality of randomized controlled trials and choosing another instrument might have changed the results. The nature of the interventions makes it difficult to impossible to blind patients. The PEDro scale was used because research has shown that it is a reliable scale to measure the methodological quality of randomized controlled trials. ${ }^{85}$ Other scales such as the Jadad quality criteria do not include items to measure internal validity when blinding is not possible. ${ }^{86}$ Further, we included randomized controlled trials only because this 
study design in general has good validity and causal conclusions can be drawn. ${ }^{87}$ We were unable to include nonpublished trials, which may lead to selection bias. Despite this limitation, we were still able to include 56 trials. In addition, only full articles that were written in English were included in the review. Seven non-English randomized controlled trials were excluded. However, there is no evidence that language-restricted meta-analyses cause bias in intervention effects. ${ }^{88}$ Finally, some trials reported outcome measures without mentioning the baseline data. Unfortunately the contacted authors were not able to provide the requested data, hence, not all trials could be included in the meta-analysis.

\section{CONCLUSIONS}

In line with our hypothesis, we conclude that ACP interventions increase the completion of advance directives, the occurrence of discussions about end-of-life care preferences, and the concordance between patient's preferences and end-of-life care received in different adult populations. Moreover, ACP interventions are likely to improve other outcomes for patients and their loved ones, such as quality of communication. Further, there seems to be no detrimental effect on anxiety, depression, and psychological well-being. The effects on knowledge of ACP, end-of-life care preferences, satisfaction with healthcare, decisional conflict, and use of healthcare services remain unknown. To our knowledge, there is no randomized controlled trial in which an intervention focusing on the completion of advance directives is compared with an intervention focusing on communication about ACP. In this review, a head-to-head comparison was not done and therefore, it is unknown which ACP approach is the best. However, considering the positive effects of ACP on multiple outcomes, implementation of ACP in regular clinical care is recommended. Future studies are necessary to reveal the effective elements of ACP and should focus on the best way to implement structured ACP in standard care. Future studies should overcome known methodological shortcomings, like the lack of intention to treat, concealed allocation, and a small sample size. Second, we recommend the use of formally validated instruments to make it possible to compare outcomes of different studies. Outcomes that should be studied in future studies are the outcomes for which meta-analysis was not possible in our review because of variability in definition and measurement. These outcomes are quality of communication, knowledge of ACP, end-of-life care preferences, satisfaction with healthcare, decisional conflict, use of healthcare services, and symptoms. 


\section{REFERENCES}

1. Singer PA, Robertson G, Roy DJ. Bioethics for clinicians: 6. Advance care planning. CMAJ journal 1996;155:1689-92.

2. Patel K, Janssen DJ, Curtis JR. Advance care planning in COPD. Respirology 2012;17:72-8.

3. Janssen DJ, Spruit MA, Schols JM, Wouters EF. A call for high-quality advance care planning in outpatients with severe COPD or chronic heart failure. Chest 2011;139:1081-8.

4. Simpson C. Advance care planning in COPD: care versus "code status". Chron Respir Dis 2012;9:193-204.

5. Gore JM, Brophy CJ, Greenstone MA. How well do we care for patients with end stage chronic obstructive pulmonary disease (COPD)? A comparison of palliative care and quality of life in COPD and lung cancer. Thorax 2000;55:1000-6.

6. Danis M, Southerland LI, Garrett JM, et al. A prospective study of advance directives for life-sustaining care. N Engl J Med 1991;324:882-8.

7. Schneiderman LJ, Kronick R, Kaplan RM, Anderson JP, Langer RD. Effects of offering advance directives on medical treatments and costs. Ann Intern Med 1992;117:599-606.

8. Detering KM, Hancock $A D$, Reade MC, Silvester W. The impact of advance care planning on end of life care in elderly patients: randomised controlled trial. BMJ 2010;340:c1345.

9. Joshi KG. Psychiatric advance directives. Journal of psychiatric practice 2003;9:303-6

10. Sherrington C, Herbert RD, Maher CG, Moseley AM. PEDro. A database of randomized trials and systematic reviews in physiotherapy. Manual therapy 2000;5:223-6.

11. Foley NC, Bhogal SK, Teasell RW, Bureau Y, Speechley MR. Estimates of quality and reliability with the physiotherapy evidence-based database scale to assess the methodology of randomized controlled trials of pharmacological and nonpharmacological interventions. Physical therapy 2006;86:817-24.

12. Anderson JP, Kaplan RM, Schneiderman LJ. Effects of offering advance directives on quality adjusted life expectancy and psychological well-being among ill adults. J Clin Epidemiol 1994;47:761-72.

13. Barrio-Cantalejo IM, Molina-Ruiz A, Simon-Lorda P, et al. Advance directives and proxies' predictions about patients' treatment preferences. Nurs Ethics 2009;16:93-109.

14. Dexter PR, Wolinsky FD, Gramelspacher GP, et al. Effectiveness of computer-generated reminders for increasing discussions about advance directives and completion of advance directive forms. A randomized, controlled trial. Ann Intern Med 1998;128:102-10.

15. Ditto PH, Danks JH, Smucker WD, et al. Advance directives as acts of communication: a randomized controlled trial. Arch Intern Med 2001;161:421-30.

16. El-Jawahri A, Podgurski LM, Eichler AF, et al. Use of video to facilitate end-of-life discussions with patients with cancer: a randomized controlled trial. J Clin Oncol 2010;28:305-10.

17. Greenberg JM, Doblin BH, Shapiro DW, Linn LS, Wenger NS. Effect of an educational program on medical students' conversations with patients about advance directives: a randomized trial. J Gen Intern Med 1993;8:683-5.

18. Griffith $\mathrm{CH}, 3$ d, Wilson JF, Emmett KR, Ramsbottom-Lucier M, Rich EC. Knowledge and experience with Alzheimer's disease. Relationship to resuscitation preference. Arch Fam Med 1995;4:780-4.

19. Heiman H, Bates DW, Fairchild D, Shaykevich S, Lehmann LS. Improving completion of advance directives in the primary care setting: a randomized controlled trial. Am J Med 2004;117:318-24.

20. Landry FJ, Kroenke K, Lucas C, Reeder J. Increasing the use of advance directives in medical outpatients. J Gen Intern Med 1997;12:412-5.

21. Molloy DW, Guyatt GH, Russo R, et al. Systematic implementation of an advance directive program in nursing homes: a randomized controlled trial. JAMA 2000;283:1437-44.

22. Patterson C, Molloy DW, Guyatt GH, et al. Systematic implementation of an advance health care directive in the community. Can J Nurs Adm 1997;10:96-108.

23. Perry E, Swartz J, Brown S, Smith D, Kelly G, Swartz R. Peer mentoring: a culturally sensitive approach to end-of-life planning for long-term dialysis patients. Am J Kidney Dis 2005;46:111-9. 
24. Reilly BM, Wagner M, Ross J, Magnussen CR, Papa L, Ash J. Promoting completion of health care proxies following hospitalization. A randomized controlled trial in a community hospital. Arch Intern Med 1995;155:2202-6.

25. Richter KP, Langel S, Fawcett SB, Paine-Andrews A, Biehler L, Manning R. Promoting the use of advance directives. An empirical study. Arch Fam Med 1995;4:609-15.

26. Rubin SM, Strull WM, Fialkow MF, Weiss SJ, Lo B. Increasing the completion of the durable power of attorney for health care. A randomized, controlled trial. JAMA 1994;271:209-12.

27. Sachs GA, Stocking CB, Miles SH. Empowerment of the older patient? A randomized, controlled trial to increase discussion and use of advance directives. J Am Geriatr Soc 1992;40:269-73.

28. Siegert EA, Clipp EC, Mulhausen P, Kochersberger G. Impact of advance directive videotape on patient comprehension and treatment preferences. Arch Fam Med 1996;5:207-12.

29. Singer PA, Thiel EC, Naylor CD, et al. Life-sustaining treatment preferences of hemodialysis patients: implications for advance directives. J Am Soc Nephrol 1995;6:1410-7.

30. Singer PA, Thiel EC, Salit I, Flanagan W, Naylor CD. The HIV-specific advance directive. J Gen Intern Med 1997; 12:729-35.

31. Smucker WD, Ditto PH, Moore KA, Druley JA, Danks JH, Townsend A. Elderly outpatients respond favorably to a physician-initiated advance directive discussion. J Am Board Fam Pract 1993;6:473-82.

32. Sulmasy DP, Song KY, Marx ES, Mitchell JM. Strategies to promote the use of advance directives in a residency outpatient practice. J Gen Intern Med 1996;11:657-63.

33. Volandes AE, Mitchell SL, Gillick MR, Chang Y, Paasche-Orlow MK. Using video images to improve the accuracy of surrogate decision-making: a randomized controlled trial. J Am Med Dir Assoc 2009;10:57580.

34. Volandes $\mathrm{AE}$, Paasche-Orlow MK, Barry MJ, et al. Video decision support tool for advance care planning in dementia: randomised controlled trial. BMJ 2009;338:b2159.

35. Yamada R, Galecki AT, Goold SD, Hogikyan RV. A multimedia intervention on cardiopulmonary resuscitation and advance directives. J Gen Intern Med 1999;14:559-63.

36. Walker NM, Mandell KL, Tsevat J. Use of chart reminders for physicians to promote discussion of advance directives in patients with AIDS. AIDS Care 1999;11:9.

37. The SUPPORT Principal Investigators. A controlled trial to improve care for seriously ill hospitalized patients. The study to understand prognoses and preferences for outcomes and risks of treatments (SUPPORT). JAMA 1995;274:1591-8.

38. Au DH, Udris EM, Engelberg RA, et al. A randomized trial to improve communication about end-of-life care among patients with COPD. Chest 2012;141:726-35.

39. Baker R, Wu AW, Teno JM, et al. Family satisfaction with end-of-life care in seriously ill hospitalized adults. J Am Geriatr Soc 2000;48:S61-9.

40. Briggs LA, Kirchhoff KT, Hammes BJ, Song MK, Colvin ER. Patient-centered advance care planning in special patient populations: a pilot study. J Prof Nurs 2004;20:47-58.

41. Clayton JM, Butow PN, Tattersall MH, et al. Randomized controlled trial of a prompt list to help advanced cancer patients and their caregivers to ask questions about prognosis and end-of-life care. J Clin Oncol 2007;25:715-23.

42. Engelhardt JB, McClive-Reed KP, Toseland RW, Smith TL, Larson DG, Tobin DR. Effects of a program for coordinated care of advanced illness on patients, surrogates, and healthcare costs: a randomized trial. Am J Manag Care 2006;12:93-100.

43. Gade G, Venohr I, Conner D, et al. Impact of an inpatient palliative care team: a randomized control trial. J Palliat Med 2008;11:180-90.

44. Green MJ, Levi BH. Teaching advance care planning to medical students with a computer-based decision aid. J Cancer Educ 2011;26:82-91.

45. Grimaldo DA, Wiener-Kronish JP, Jurson T, Shaughnessy TE, Curtis JR, Liu LL. A randomized, controlled trial of advanced care planning discussions during preoperative evaluations. Anesthesiology 2001;95:4350; discussion $5 \mathrm{~A}$. 
46. Gutheil IA, Heyman JC. Communication between older people and their health care agents: results of an intervention. Health Soc Work 2005;30:107-16.

47. Hanson LC, Reynolds KS, Henderson M, Pickard CG. A quality improvement intervention to increase palliative care in nursing homes. J Palliat Med 2005;8:576-84.

48. Heffner JE, Barbieri C. Effects of advance care education in cardiovascular rehabilitation programs: a prospective randomized study. J Cardiopulm Rehabil 2001;21:387-91.

49. Jacobsen J, Robinson E, Jackson VA, Meigs JB, Billings JA. Development of a cognitive model for advance care planning discussions: results from a quality improvement initiative. J Palliat Med 2011;14:331-6.

50. Jones L, Harrington J, Barlow CA, et al. Advance care planning in advanced cancer: can it be achieved? An exploratory randomized patient preference trial of a care planning discussion. Palliat Support Care 2011;9:3-13.

51. Kirchhoff KT, Hammes BJ, Kehl KA, Briggs LA, Brown RL. Effect of a disease-specific planning intervention on surrogate understanding of patient goals for future medical treatment. J Am Geriatr Soc 2010;58:1233-40.

52. Kirchhoff KT, Hammes BJ, Kehl KA, Briggs LA, Brown RL. Effect of a disease-specific advance care planning intervention on end-of-life care. J Am Geriatr Soc 2012;60:946-50.

53. Lautrette A, Darmon M, Megarbane B, et al. A communication strategy and brochure for relatives of patients dying in the ICU. N Engl J Med 2007;356:469-78.

54. Marbella AM, Desbiens NA, Mueller-Rizner N, Layde PM. Surrogates' agreement with patients' resuscitation preferences: effect of age, relationship, and SUPPORT intervention. Study to Understand Prognoses and Preferences for Outcomes and Risks of Treatment. J Crit Care 1998;13:140-5.

55. Morrison RS, Chichin E, Carter J, Burack O, Lantz M, Meier DE. The effect of a social work intervention to enhance advance care planning documentation in the nursing home. J Am Geriatr Soc 2005;53:290-4.

56. Murray MA, Stacey D, Wilson KG, O'Connor AM. Skills training to support patients considering place of end-of-life care: a randomized control trial. J Palliat Care 2010;26:112-21.

57. Nicolasora N, Pannala R, Mountantonakis S, et al. If asked, hospitalized patients will choose whether to receive life-sustaining therapies. J Hosp Med 2006;1:161-7.

58. Pearlman RA, Starks H, Cain KC, Cole WG. Improvements in advance care planning in the Veterans Affairs System: results of a multifaceted intervention. Arch Intern Med 2005;165:667-74.

59. Sampson EL, Jones L, Thune-Boyle IC, et al. Palliative assessment and advance care planning in severe dementia: an exploratory randomized controlled trial of a complex intervention. Palliat Med 2011;25:197-209.

60. Schwartz CE, Wheeler HB, Hammes B, et al. Early intervention in planning end-of-life care with ambulatory geriatric patients: results of a pilot trial. Arch Intern Med 2002;162:1611-8.

61. Song MK, Donovan HS, Piraino BM, et al. Effects of an intervention to improve communication about end-of-life care among African Americans with chronic kidney disease. Appl Nurs Res 2010;23:65-72.

62. Song MK, Kirchhoff KT, Douglas J, Ward S, Hammes B. A randomized, controlled trial to improve advance care planning among patients undergoing cardiac surgery. Med Care 2005;43:1049-53.

63. Song MK, Ward SE, Happ MB, et al. Randomized controlled trial of SPIRIT: an effective approach to preparing African-American dialysis patients and families for end of life. Res Nurs Health 2009;32:26073.

64. Szmuilowicz E, el-Jawahri A, Chiappetta L, Kamdar M, Block S. Improving residents' end-of-life communication skills with a short retreat: a randomized controlled trial. J Palliat Med 2010;13:439-52.

65. Teno J, Lynn J, Wenger N, et al. Advance directives for seriously ill hospitalized patients: effectiveness with the patient self-determination act and the SUPPORT intervention. SUPPORT Investigators. Study to Understand Prognoses and Preferences for Outcomes and Risks of Treatment. I Am Geriatr Soc 1997;45:500-7.

66. Silveira MJ, Kim SY, Langa KM. Advance directives and outcomes of surrogate decision making before death. N Engl J Med 2010;362:1211-8.

67. Degenholtz HB, Rhee $Y$, Arnold RM. Brief communication: the relationship between having a living will and dying in place. Ann Intern Med 2004;141:113-7. 
68. Tilden VP, Tolle SW, Nelson CA, Fields J. Family decision-making to withdraw life-sustaining treatments from hospitalized patients. Nursing research 2001;50:105-15.

69. Thompson T, Barbour R, Schwartz L. Adherence to advance directives in critical care decision making: vignette study. BMJ 2003;327:1011.

70. Hardin SB, Yusufaly YA. Difficult end-of-life treatment decisions: do other factors trump advance directives? Arch Intern Med 2004;164:1531-3.

71. Janssen DJ, Spruit MA, Schols JM, et al. Predicting changes in preferences for life-sustaining treatment among patients with advanced chronic organ failure. Chest 2012;141:1251-59.

72. Janssen DJ, Spruit MA, Schols JM, Wouters EF. Dynamic preferences for site of death among patients with advanced COPD, chronic heart failure, or chronic renal failure. J Pain Symptom Manage 2013; 46(6):826-36.

73. Sudore RL, Fried TR. Redefining the "planning" in advance care planning: preparing for end-of-life decision making. Ann Intern Med 2010;153:256-61.

74. Knauft E, Nielsen EL, Engelberg RA, Patrick DL, Curtis JR. Barriers and facilitators to end-of-life care communication for patients with COPD. Chest 2005;127:2188-96.

75. Wright AA, Zhang B, Ray A, et al. Associations between end-of-life discussions, patient mental health, medical care near death, and caregiver bereavement adjustment. JAMA 2008;300:1665-73.

76. Curtis JR, Engelberg RA, Nielsen EL, Au DH, Patrick DL. Patient-physician communication about end-of-life care for patients with severe COPD. Eur Respir J 2004;24:200-5.

77. Barnes S, Gardiner C, Gott M, et al. Enhancing patient-professional communication about end-of-life issues in life-limiting conditions: a critical review of the literature. J Pain Symptom Manage 2012;44:86679.

78. Davison SN. The prevalence and management of chronic pain in end-stage renal disease. J Palliat Med 2007;10:1277-87.

79. Teno JM, Gruneir A, Schwartz Z, Nanda A, Wetle T. Association Between Advance Directives and Quality of End-of-Life Care: A National Study. Journal of the American Geriatrics Society 2007;55:189-94.

80. Heyland DK, Allan DE, Rocker G, Dodek P, Pichora D, Gafni A. Discussing prognosis with patients and their families near the end of life: impact on satisfaction with end-of-life care. Open medicine : a peerreviewed, independent, open-access journal 2009;3:e101-10.

81. World Health Organization. Palliative care: symptom management and end-of-life care. 2004. (Accessed 15/05/2013, at http://www.who.int/hiv/pub/imai/primary_palliative/en/.)

82. Schulz KF, Grimes DA. Blinding in randomised trials: hiding who got what. Lancet 2002;359:696-700.

83. Bollini P, Pampallona S, Tibaldi G, Kupelnick B, Munizza C. Effectiveness of antidepressants. Meta-analysis of dose-effect relationships in randomised clinical trials. The British journal of psychiatry : the journal of mental science 1999;174:297-303.

84. Schulz KF, Chalmers I, Hayes RJ, Altman DG. Empirical evidence of bias. Dimensions of methodological quality associated with estimates of treatment effects in controlled trials. JAMA 1995;273:408-12.

85. Maher CG, Sherrington C, Herbert RD, et al. Reliability of the PEDro scale for rating quality of randomized controlled trials. Phys Ther 2003;83:713-21

86. Bhogal SK, Teasell RW, Foley NC, Speechley MR. The PEDro scale provides a more comprehensive measure of methodological quality than the Jadas scale in stroke rehabilitation literature. J Clin Epidemiol 2005;58:668-73

87. Richter B, Berger M. Randomized controlled trials remain fundamental to clinical decision making in Type II diabetes mellitus: a comment to the debate on randomized controlled trials (For debate) [corrected]. Diabetologia 2000;43:254-8.

88. Moher D, Pham B, Klassen TP, et al. What contributions do languages other than English make on the results of meta-analyses? J Clin Epidemiol 2000;53:964-72. 



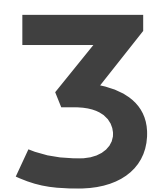

\section{Patient-clinician communication about end-of-life care in patients with advanced chronic organ failure during one year}
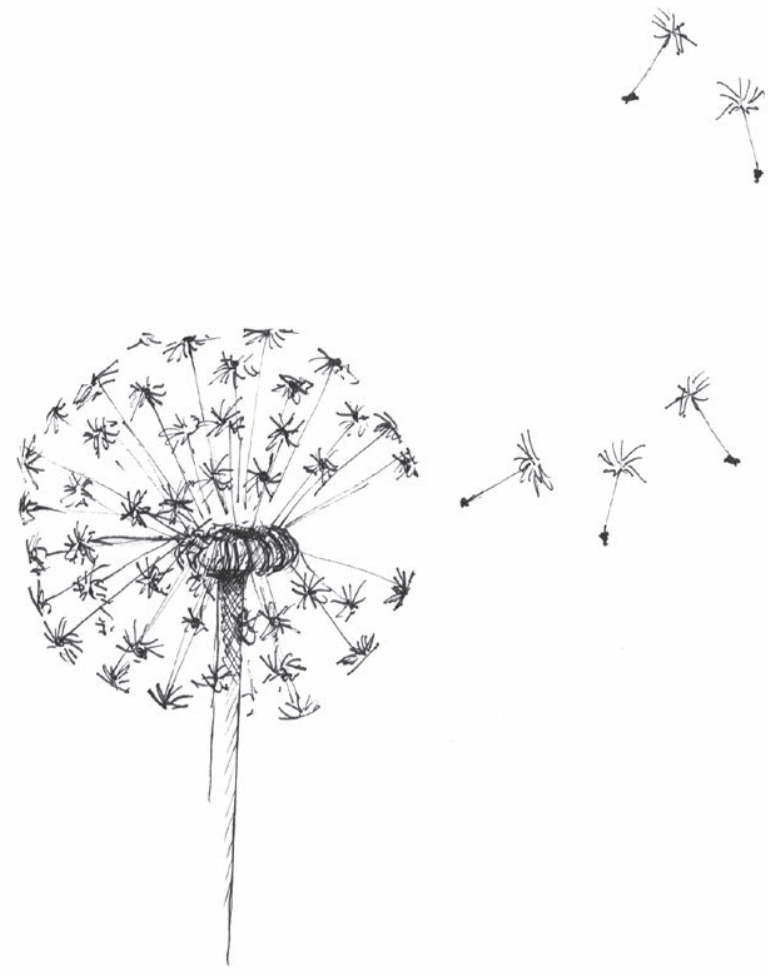

Carmen H.M. Houben, Martijn A. Spruit, Jos M.G.A. Schols, Emiel F.M. Wouters, and Daisy J.A. Janssen.

Journal of Pain and Symptom Management, 2015. 49(6):1109-1115.

Reproduced with permission from Journal of Pain and Symptom Management. 


\section{ABSTRACT}

Context: Patient-clinician communication is an important prerequisite to delivering high-quality end-of-life care. However, discussions about end-of-life care are uncommon in patients with advanced chronic organ failure.

Objectives: The aim was to examine the quality of end-of-life care communication during one year follow-up of patients with advanced chronic organ failure. In addition, we aimed to explore whether and to what extent quality of communication about end-of-life care changes toward the end-of-life and whether end-of-life care communication is related to patient-perceived quality of medical care.

Methods: Clinically stable outpatients $(n=265)$ with advanced chronic obstructive pulmonary disease, chronic heart failure, or chronic renal failure were visited at home at baseline, four, eight, and 12 months after baseline to assess quality of endof-life care communication (Quality of Communication Questionnaire). Two years after baseline, survival status was assessed, and if patients died during the study a bereavement interview was done with the closest relative.

Results: One-year follow-up was completed by $77.7 \%$ of the patients. Quality of end-of-life care communication was rated low at baseline and did not change over one year. Quality of end-of-life care communication was comparable for patients who completed two year follow-up and patients who died during the study. The correlation between quality of end-of-life care communication and satisfaction with medical treatment was weak.

Conclusion: End-of-life care communication is poor in patients with chronic organ failure and does not change toward the end of life. Future studies should develop an intervention aiming at initiating high-quality end-of-life care communication between patients with advanced chronic organ failure and their clinicians. 


\section{INTRODUCTION}

Patients with chronic obstructive pulmonary disease (COPD), chronic heart failure $(\mathrm{CHF})$, and chronic renal failure (CRF) frequently die unexpectedly. ${ }^{1-4}$ Early patientclinician end-of-life care communication (EOLCC) can improve quality of communication $^{5,6}$ and the concordance between patient's preferences and end-of-life (EOL) care received. ${ }^{7-9}$ Patients and their families identified communication as an important physician skill in EOL care. ${ }^{10}$ Patients with advanced chronic organ failure are able to discuss preferences for EOL care with their treating physician. However, these discussions are uncommon in daily practice. ${ }^{11,12}$ Most important, physicianreported barriers to EOLCC are lack of time and poor communication skills. ${ }^{13} \mathrm{~Pa}$ tients are often not aware of the fact that their disease is life limiting and will not initiate EOLCC themselves. ${ }^{13}$ Cross-sectional studies showed that death and dying were rarely or not discussed at all with patients with advanced chronic organ failure. $^{14,15}$

Currently, it is unknown whether and to what extent the quality of EOLCC will change during the course of the disease or toward the end of life. The objective of this study was to examine the quality of EOLCC during a one year follow-up in patients with advanced chronic organ failure. In addition, we aimed to explore whether and to what extent the quality of EOLCC changes toward the end of life and whether EOLCC is related to patient-perceived quality of medical care.

\section{METHODS}

\section{Study design}

The present study is a secondary analysis of data from a multicenter, longitudinal study concerning palliative care needs among outpatients with advanced COPD, CHF, or CRF. ${ }^{11,14,16-20}$ Home visits took place at baseline, and four, eight, and 12 months after baseline. Two years after baseline, all patients, or their participating relatives, were contacted by telephone to assess survival status. The Medical Ethical Committee of the Maastricht University Medical Centre+, Maastricht, The Netherlands, approved this study (MEC 07-3-054). The study was registered at the Dutch Trial Register (NTR 1552). 


\section{Patients}

Patients with advanced chronic organ failure and their closest relatives were recruited by their physician specialist at the outpatient clinic of one academic and six general hospitals in The Netherlands between January 2008 and June 2009. Patients were included if they had severe to very severe COPD (Global initiative for chronic Obstructive Lung Disease Stage III or IV), ${ }^{21}$ end-stage CHF (New York Heart Association Class III or IV), or end-stage CRF (requiring dialysis). All participating patients provided written informed consent.

\section{Instruments}

The following outcomes were assessed at baseline: demographics; smoking history; hospital admissions in the previous year; previous admissions to intensive care unit; previous mechanical ventilation and cardiopulmonary resuscitation; weight and height; current self-reported comorbidities (Charlson comorbidity index ${ }^{22}$ ); anxiety and depression (Hospital Anxiety and Depression Scale ${ }^{23}$ ); satisfaction with medical treatment patients received for their chronic organ disease, using a Visual Analogue Scale ranging from 0 (not satisfied) to $100 \mathrm{~mm}$ (very satisfied); general health status (Medical Outcomes Study 36-Item Short-Form Health Survey ${ }^{24}$ ).

Quality of EOLCC was assessed using the EOL subscale of the Quality of Communication (QOC) questionnaire. ${ }^{25}$ In this questionnaire, patients are asked to rate how good the physician specialist primarily responsible for the management of their chronic disease is at each of the communication skills. The subscale EOL communication (QOC-EOL) comprises seven items, and each item is rated on a scale of 0 ("the very worst") to 10 ("the very best"). In addition, patients were offered two additional response options: "My doctor didn't do this" and "Don't know". The domain score was calculated from the average from all endorsed items and was calculated for patients who had at least four valid items. This score ranges from 0 ("worst") to 10 ("best"). The answer "My doctor didn't do this" was replaced by a score of 0 , and "Don't know" was replaced by the median domain score of the valid items for the individual, as suggested by the QOC questionnaire developers. ${ }^{25,26}$ The QOC questionnaire is a validated instrument and meets the standards of scale measurement including good construct validity and internal consistency (Cronbach's $\alpha \geq 0.79){ }^{26}$

Details of the study design and baseline data on EOLCC have been previously published. ${ }^{11,12,14,17,27}$ 
Statistical analysis

Statistics were done using SPSS 21.0 (SPSS Inc., Chicago, IL). Categorical variables are described as frequencies, and continuous variables were tested for normality and are presented as mean and SD or median and interquartile range. Categorical variables were compared between patients who completed the study, patients who died during the study, and patients who withdrew from the study because of other reasons, using a one-way analysis of variances with independent sample t-tests as post hoc tests or Kruskall-Wallis followed by Mann-Whitney U-tests, as appropriate.

Quality of EOLCC at baseline and four, eight, and 12 months was compared using the Friedman test. Only patients who completed the study were included in this analysis. A Mann-Whitney U-test was used to compare the quality of EOLCC at baseline and four, eight, and 12 months between patients who completed a two year follow-up and patients who died between one and two year follow-up over one year. A Kruskal-Wallis test was used to compare the quality of EOLCC at baseline among patients with COPD, CHF, and CRF. Finally, a Spearman correlation test was used to study the correlation between quality of EOLCC and satisfaction with medical treatment at baseline and four, eight, and 12 months. A priori, a two-sided level of significance has been set at $P \leq 0.05$. 


\section{RESULTS}

\section{Patient characteristics}

The present study included 265 patients at baseline (COPD, $n=105 ; C H F, n=80 ; C R F$, $\mathrm{n}=80$ ). The proportion of eligible patients who participated in the study was $58.9 \%$. All home visits were completed by 206 patients (77.7\%). In total, 24 patients (9.1\%) died during the 1 st year of the study, and 35 patients (13.2\%) withdrew from the study. Another 42 patients (15.8\%) died between Years 1 and 2 after enrollment. A detailed flowchart of the study has been previously published. ${ }^{27}$ There were no significant differences found in baseline patient characteristics between the three groups (Table 1).

Table 1. Baseline patient characteristics

\begin{tabular}{|c|c|c|c|}
\hline & Completed study $(n=206)$ & Died $(n=24)$ & Withdrawn $(n=35)$ \\
\hline Age (years) & $67.2(13.1)^{\mathrm{a}}$ & $74.0(7.8)$ & $69.0(11.2)$ \\
\hline Male & $132(64.1 \%)$ & $14(58.3 \%)$ & $21(60.0 \%)$ \\
\hline Married/living with partner & $135(65.5 \%)$ & $17(70.8 \%)$ & $23(65.7 \%)$ \\
\hline Current smokers & 41 (19.9\%) & $4(16.7 \%)$ & $4(11.4 \%)$ \\
\hline $\begin{array}{l}\geq 1 \text { hospital admissions year } \\
\text { previous study }{ }^{b, c}\end{array}$ & 115 (55.8\%) & $11(45.8 \%)$ & $14(40 \%)$ \\
\hline Previous ICU admission ${ }^{c, d}$ & $113(55.9 \%)$ & $11(57.9 \%)$ & $13(41.9 \%)$ \\
\hline Previous $\mathrm{MV}^{\mathrm{d}}$ & $46(22.8 \%)$ & $4(21.1 \%)$ & $6(19.4 \%)$ \\
\hline Previous CPR $^{d}$ & $21(10.4 \%)$ & $2(10.5 \%)$ & $1(3.2 \%)$ \\
\hline BMI $\left(\mathrm{kg} / \mathrm{m}^{2}\right)^{\mathrm{c}}$ & $26.7(6.2)$ & $27.5(8.1)$ & $26.6(4.8)$ \\
\hline Charlson index (points) & $3.4(2.0)$ & $3.9(2.4)$ & $3.7(1.7)$ \\
\hline QOC general (points) ${ }^{c}$ & $8.0(7.4-9.0)^{\mathrm{e}}$ & $7.3(6.6-8.5)$ & $7.7(6.3-8.0)$ \\
\hline QOC-EOL (points) ${ }^{c}$ & $0.0(0.0-2.4)$ & $0.4(0.0-3.9)$ & $0.0(0.0-1.3)$ \\
\hline HADS-A score (points) & $5.1(4.0)$ & $6.0(5.6)$ & $5.5(4.5)$ \\
\hline HADS-D score (points) & $5.6(4.0)$ & $6.8(3.8)$ & $6.8(3.5)$ \\
\hline $\begin{array}{l}\text { Satisfaction with treatment } \\
(\text { VAS-score, } \mathrm{mm})^{\mathrm{d}}\end{array}$ & $80.3(16.4)$ & $78.9(13.8)$ & $82.9(13.0)$ \\
\hline \multicolumn{4}{|l|}{ SF-36 } \\
\hline Physical component score & $25.7(11.7)$ & $22.8(10.3)$ & 25.5 (12.9) \\
\hline Mental component score & $48.4(13.1)$ & $45.3(15.7)$ & $48.2(12.7)$ \\
\hline
\end{tabular}

Data reported as mean (SD), number (\%), or median (interquartile range)

. ${ }^{a}<0.05$ versus died; ${ }^{b}$ completed: $n=201$, died: $n=18$, withdrew: $n=3$; ${ }^{C}$ Nonparametric statistical tests have been used because of skewed data. ${ }^{d}$ completed: $n=202$, died: $n=19$, withdrew: $n=31 ;{ }^{e} n=205$.

Abbreviations: $I C U=$ intensive care unit; $M V=$ mechanical ventilation; $C P R=$ cardiopulmonary resuscitation; $\mathrm{BMI}=$ body mass index; $\mathrm{QOC}$ general= Quality of Communication Questionnaire, general communication subscale; QOC-EOL= Quality of Communication Questionnaire, end-of-life communication subscale; HADS-A= Hospital Anxiety and Depression Scale, anxiety subscale; HADS-D= Hospital Anxiety and Depression Scale, depression subscale; VAS= Visual Analogue Scale; SF-36= 36-Item Short-Form Health Survey. 
QOC-EOL scores were low at baseline and did not change at four, eight, and 12 months (Figure 1).

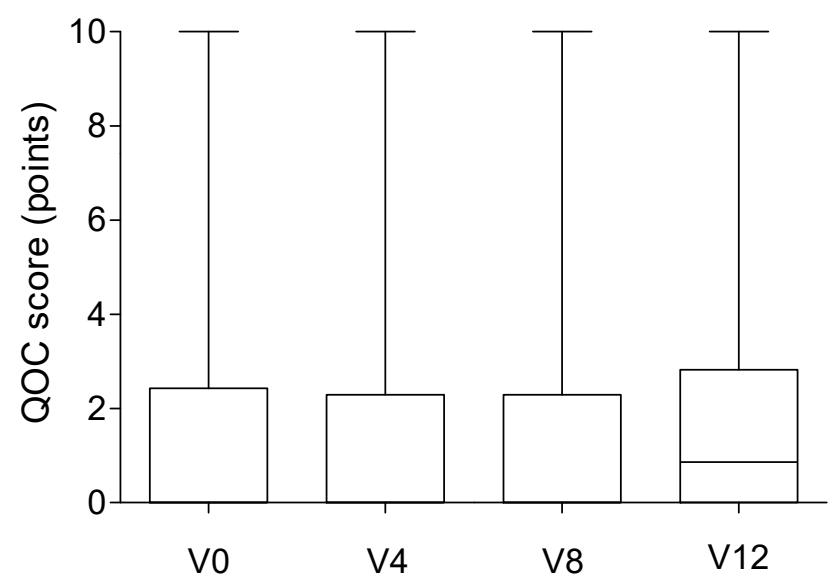

Figure 1. Quality of Communication (QOC) end-of-life care communication (EOLCC) scores over one year. Median (interquartile range, minimum, and maximum) QOC questionnaire scores for the domain "EOLCC" at baseline and four, eight, and 12 months. p>0.05 for all comparisons.

In general, patients reported that they had not discussed EOL items with their physician. Items that were rarely discussed during one year follow-up were "asking about spiritual or religious beliefs", "talking about what dying might be like", and/or "talking about how long you have to live". However, when items were discussed, the quality was moderate to good, with medians ranging from 6.0 to 8.0 points (Table 2). 
Table 2. Changes in quality of end-of-life care communication items during one-year follow-up ( $n=206)$

\begin{tabular}{|c|c|c|c|c|c|c|c|c|}
\hline & \multicolumn{2}{|l|}{ Baseline } & \multicolumn{2}{|l|}{4 months } & \multicolumn{2}{|l|}{8 months } & \multicolumn{2}{|c|}{12 months } \\
\hline & $\begin{array}{l}\text { Item } \\
\text { discussed } \\
\mathrm{n}(\%)\end{array}$ & $\begin{array}{l}\text { QOC-score, } \\
\text { when item } \\
\text { discussed } \\
\text { Median (IQR) }\end{array}$ & $\begin{array}{l}\text { Item } \\
\text { discussed } \\
\mathrm{n}(\%)\end{array}$ & $\begin{array}{l}\text { QOC-score, } \\
\text { when item } \\
\text { discussed } \\
\text { Median (IQR) }\end{array}$ & $\begin{array}{l}\text { Item } \\
\text { discussed } \\
\mathrm{n}(\%)\end{array}$ & $\begin{array}{l}\text { QOC-score, } \\
\text { when item } \\
\text { discussed } \\
\text { Median (IQR) }\end{array}$ & $\begin{array}{l}\text { Item } \\
\text { discussed } \\
\mathrm{n}(\%)\end{array}$ & $\begin{array}{l}\text { QOC-score, } \\
\text { when item } \\
\text { discussed } \\
\text { Median (IQR) }\end{array}$ \\
\hline $\begin{array}{l}\text { Talking about your } \\
\text { feelings about } \\
\text { getting sicker }\end{array}$ & $58(28.2)$ & $8.0(7.0-9.0)$ & $60(29.1)$ & $8.0(7.0-9.0)$ & $59(28.6)$ & $8.0(7.0-8.0)$ & $68(33.0)$ & $8.0(7.0-8.0)$ \\
\hline $\begin{array}{l}\text { Talking about details } \\
\text { if you got sicker }\end{array}$ & $56(27.2)$ & $8.0(7.0-9.0)$ & $57(27.7)$ & $8.0(7.0-9.0)$ & $53(25.7)$ & $8.0(7.0-8.0)$ & $61(29.6)$ & $8.0(7.0-8.5)$ \\
\hline $\begin{array}{l}\text { Talking about how } \\
\text { long you have to live }\end{array}$ & $23(11.2)$ & $8.0(6.0-9.0)$ & $28(13.6)$ & 7.5 (6.0-9.0) & $17(8.3)$ & $7.0(4.5-8.0)$ & $26(12.6)$ & $6.5(4.0-8.0)$ \\
\hline $\begin{array}{l}\text { Talking about what } \\
\text { dying might be like }\end{array}$ & $19(9.2)$ & $7.0(3.0-9.0)$ & $22(10.7)$ & $7.5(4.0-9.0)$ & $18(8.7)$ & $7.0(2.0-8.0)$ & $22(10.7)$ & $6.0(3.8-7.3)$ \\
\hline $\begin{array}{l}\text { Involving you in } \\
\text { treatment } \\
\text { discussions about } \\
\text { your care }\end{array}$ & $44(21.3)$ & $8.0(8.0-9.0)$ & $48(23.3)$ & $8.0(7.0-9.0)$ & $49(23.8)$ & $8.0(7.0-8.5)$ & 64 (31.1) & $8.0(7.0-8.0)$ \\
\hline $\begin{array}{l}\text { Asking you about } \\
\text { important things in } \\
\text { life }\end{array}$ & $46(22.3)$ & $8.0(7.0-9.0)$ & $46(22.3)$ & $8.0(7.0-9.0)$ & $54(26.2)$ & $8.0(7.0-9.0)$ & $62(30.1)$ & $8.0(7.0-8.0)$ \\
\hline $\begin{array}{l}\text { Asking about } \\
\text { spiritual, religious } \\
\text { beliefs }\end{array}$ & $16(7.8)$ & $8.0(5.3-9.8)$ & $21(10.2)$ & $8.0(5.0-9.0)$ & $23(11.2)$ & $8.0(3.0-9.0)$ & $27(13.1)$ & $7.0(3.0-8.0)$ \\
\hline
\end{tabular}

Abbreviations: $\mathrm{QOC}=$ Quality of Communication; $\mathrm{IQR}=$ Interquartile Range.

Table 3. Quality of end-of-life communication of patients who completed the two-year follow-up and those who died between one and two year follow-up.

\begin{tabular}{llll}
\hline & Completed two year follow-up $(\mathrm{n}=177)$ & $\begin{array}{l}\text { Died between one and two year } \\
\text { follow-up }(\mathrm{n}=29)\end{array}$ & P-value $^{\mathrm{a}}$ \\
\hline Baseline & $0.0(0.0-2.8)$ & $0.0(0.0-1.1)$ & .17 \\
4 months & $0.0(0.0-2.5)^{\mathrm{b}}$ & $0.0(0.0-1.8)$ & .26 \\
8 months & $0.0(0.0-2.3)^{\mathrm{c}}$ & $0.0(0.0-3.7)$ & .17 \\
12 months & $0.9(0.0-2.6)^{\mathrm{d}}$ & $0.0(0.0-3.9)$ & .51 \\
\hline
\end{tabular}

Data are presented as median (interquartile range).

${ }^{a}$ P-values based on Mann-Whitney U-test.

${ }^{b} \mathrm{n}=176$.

${ }^{c} n=174$.

${ }^{d} n=175$.

There was a significant difference in quality of EOLCC at baseline among patients with COPD, CHF, and CRF ( $p=0.001)$. Mann-Whitney U-tests demonstrated a significant difference in quality of EOLCC between patients with CRF and patients with COPD ( $p=0.007)$ and CHF ( $p=0.001)$, respectively. However, the quality of EOLCC was low in all three groups, and the differences may be too small to be of clinical relevance. In all three groups, the quality of EOLCC did not change over one year. 
In general, patients were satisfied with the medical treatment they received for their chronic organ disease (Table 1). At four and eight months, a significant but low correlation was found between quality of EOLCC and satisfaction with medical treatment (Spearman's rho $=0.16(p=0.03)$ and $0.17(p=0.02)$, respectively). At baseline and 12 months the correlation was weak and non-significant (Spearman's rho $=0.05(p=0.50)$ and $-0.01(p=0.85)$, respectively).

\section{DISCUSSION}

\section{Key findings}

Quality of EOLCC was rated low by patients with advanced chronic organ failure, mainly because EOL care topics were not discussed at all. When items were discussed, the quality was moderate to good. Quality of EOLCC did not change during one year and did not differ between patients who died within one year and patients with a life expectancy of more than one year. The correlation between quality of EOLCC and satisfaction with treatment was weak.

\section{Quality of EOLCC}

The present study is the first to explore whether the quality of EOLCC will change during the course of the disease or toward the end of life among patients with advanced chronic organ failure. The quality of EOLCC was very low at baseline and did not change over one year. The quality of EOLCC was rated low mainly because most patients reported that items concerning EOL care were not discussed at all. This is in line with previous studies in patients with COPD, which showed that clinicians discussed some topics, such as prognosis, dying, and religion, with less than $25 \%$ of their patients. ${ }^{15,25}$ In accordance with the present study, when physicians talked with their patients about EOL care topics, the quality was rated high. ${ }^{15,25}$ This suggests that the problem is not so much the quality of EOLCC, but the initiation of EOLCC.

Both patients and physicians find it hard to initiate EOLCC. ${ }^{29}$ However, clinicians acknowledged that they often fail to discuss EOL care with their patients with advanced COPD. ${ }^{30,31}$ In fact, these discussions are often postponed until patients are too ill to make decisions about care. ${ }^{31}$ A frequently physician-endorsed barrier is "the patient is not ready to talk about the care she/he wants if she/he gets sick". ${ }^{28}$ This implies that physicians will talk about EOL care topics toward the end of life. Nevertheless, we did not find a difference in quality of EOLCC between patients 
who survived and patients who died within one year. This could probably be partly explained by the fact that patients in the present study were patients with advanced chronic organ failure in which life expectancy is difficult to predict. Indeed, the disease trajectories of patients with COPD, CHF, and CRF are characterized by progressive decline punctuated by episodes of acute deterioration, which are associated with an increased risk of dying. ${ }^{32,33}$ However, not all patients with organ failure conform to this theoretical trajectory of dying, and other dying trajectories are possible. ${ }^{34}$ Therefore, it is hard for physicians and patients to decide the appropriate timing of EOLCC. There are, however, some clinical events, such as acute illness or hospitalization, which could be used as a moment to initiate EOLCC. ${ }^{35}$

Although improving the quality of EOLCC was not the purpose of the study, it is remarkable how little impact the study had on the quality of EOLCC. A priori, we expected that participation in the study could influence the behavior of patients and physicians, because it might stimulate patients and physicians to talk about EOL care. However, this Hawthorne effect ${ }^{36}$ was not observed. Possibly, this could be explained by the fact that patients and physicians endorse too many barriers to EOLCC. Indeed, physician barriers include time constraints and fear of taking away the patient's hope. Patients may not know what kind of care they want if they get very sick or would rather concentrate on staying alive than talking about death. ${ }^{12,14,}$ ${ }^{28}$ In fact, a previous study also showed that questionnaires such as the QOC do not have a significant effect on EOLCC. ${ }^{5}$ In addition, physicians were not asked to complete questionnaires every four months during one year.

The present study shows that quality of EOLCC was not associated with satisfaction with the general medical treatment patients received for their chronic organ disease. Another cross-sectional study demonstrated an association between general patient-clinician communication and best-imagined quality of care. This study did not focus on EOLCC. ${ }^{37}$ The present study did not include a long-term follow-up allowing us to explore the impact of quality of EOLCC on satisfaction with EOL care.

A recently published controlled trial in patients with advanced illness showed that a palliative care-specific communication intervention for general practitioners, which focused on availability of the general practitioner to the patient, issues the general practitioner should discuss with the patient and anticipation of various scenarios by the general practitioner, did not alter patient satisfaction. ${ }^{38}$ Another randomized trial failed to show an improvement in quality of EOL care as assessed by patients, families, or clinicians after a communication skills training for residents and nurse practitioners. ${ }^{39}$ Nevertheless, a recent systematic review showed that advance care 
planning interventions could improve the satisfaction with EOL care in family members of deceased patients and increase the prevalence and quality of EOLCC. ${ }^{40}$

\section{Methodological considerations}

There were several potential limitations to our study. First, participating patients were volunteers, and we do not know whether their views are different from patients who were unwilling to participate. This may limit the generalizability of the results. Nevertheless, patients were recruited during outpatient consultations at seven hospitals, and, in turn, are representative for this setting.

Second, quality of EOLCC was measured by a self-report questionnaire and does not include an objective quality of communication measure. However, the QOC questionnaire is a validated research instrument ${ }^{26}$ and has been previously used in other studies with patients with life-limiting illness. $5,14,15,39$

Third, the study did not assess the views of physicians concerning changes in EOLCC over time. However, previous cross-sectional data from this study showed major disagreement between patients and physicians about whether or not EOL care had been discussed. ${ }^{11}$ There may be many reasons discordance would occur, for example, physicians may have tried to discuss EOL care but felt the patient was not ready or the patient did not want to talk about EOL care. Indeed, previous studies $^{41,42}$ showed that patients' preferences for EOL care conversations vary greatly in patients with CHF and COPD.

Finally, patients were recruited by their physician and, therefore, it could be that they felt coerced to participate or were more positive in their responses. However, considering the fact that quality of EOLCC was rated low at baseline and did not change over one year, this seems to be of little influence.

\section{Conclusions}

The current findings show that there was generally an absence of discussions about EOL care among patients with advanced chronic organ failure; this did not change during one year and did not improve toward the end of life. However, when items were discussed the quality was moderate to good. Therefore, future studies are needed to develop an intervention aimed at initiating high-quality EOLCC between patients with advanced chronic organ failure and their clinicians at the appropriate time during their disease trajectory. 


\section{REFERENCES}

1. Coventry PA, Grande GE, Richards DA, Todd CJ. Prediction of appropriate timing of palliative care for older adults with non-malignant life-threatening disease: a systematic review. Age and ageing 2005;34:218-27.

2. Fox E, Landrum-McNiff K, Zhong Z, Dawson NV, Wu AW, Lynn J. Evaluation of prognostic criteria for determining hospice eligibility in patients with advanced lung, heart, or liver disease. SUPPORT Investigators. Study to Understand Prognoses and Preferences for Outcomes and Risks of Treatments. JAMA 1999;282:1638-45.

3. United States Renal Data System (USRDS). 2013 Annual Data Report: Atlas of Chronic Kidney Disease and End-Stage Renal Disease in the United States. Bethesda, MD: National Institutes of Health, National Institute of Diabetes and Digestive and Kidney Diseases; 2013:263-70.

4. Claessens MT, Lynn J, Zhong Z, et al. Dying with lung cancer or chronic obstructive pulmonary disease: insights from SUPPORT. Study to Understand Prognoses and Preferences for Outcomes and Risks of Treatments. J Am Geriatr Soc 2000;48:S146-53.

5. Au DH, Udris EM, Engelberg RA, et al. A randomized trial to improve communication about end-of-life care among patients with COPD. Chest 2012;141:726-35.

6. Murray MA, Stacey D, Wilson KG, O'Connor AM. Skills training to support patients considering place of end-of-life care: a randomized controlled trial. J Palliat Care 2010;26:112-21.

7. Detering KM, Hancock AD, Reade MC, Silvester W. The impact of advance care planning on end of life care in elderly patients: randomised controlled trial. BMJ 2010;340:c1345.

8. Kirchhoff KT, Hammes BJ, Kehl KA, Briggs LA, Brown RL. Effect of a disease-specific planning intervention on surrogate understanding of patient goals for future medical treatment. I Am Geriatr Soc 2010;58:1233-40.

9. Morrison RS, Chichin E, Carter J, Burack O, Lantz M, Meier DE. The effect of a social work intervention to enhance advance care planning documentation in the nursing home. J Am Geriatr Soc 2005;53:290-94.

10. Curtis JR, Wenrich MD, Carline JD, Shannon SE, Ambrozy DM, Ramsey PG. Understanding physicians' skills at providing end-of-life care perspectives of patients, families, and health care workers. J Gen Intern Med 2001;16:41-9.

11. Janssen DJ, Spruit MA, Schols JM, Wouters EF. A call for high-quality advance care planning in outpatients with severe COPD or chronic heart failure. Chest 2011;139:1081-8.

12. Janssen DJ, Spruit MA, Schols JM, van der Sande FM, Frenken LA, Wouters EF. Insight into advance care planning for patients on dialysis. J Pain Symptom mMnage 2013;45:104-13.

13. Patel K, Janssen DJ, Curtis JR. Advance care planning in COPD. Respirology 2012;17:72-8.

14. Janssen DJ, Curtis JR, Au DH, et al. Patient-clinican communication about end-of-life care for Dutch and US patients with COPD. Eur Respir J 2011;38:268-76.

15. Reinke LF, Slatore CG, Uman J, et al. Patient-clinician communication about end-of-life care topics: is anyone talking to patients with chronic obstructive pulmonary disease? J Palliat Med 2011;14:923-8.

16. Janssen DJ, Spruit MA, Schols JM, et al. Predicting changes in preferences for life-sustaining treatment among patients with advanced chronic organ failure. Chest 2012;141:1251-9.

17. Janssen DJ, Wouters EF, Schols JM, Spruit MA. Self-perceived symptoms and care needs of patients with severe to very severe chronic obstructive pulmonary disease, congestive heart failure or chronic renal failure and its consequences for their closest relatives: the research protocol. BMC Palliat Care 2008;7:5.

18. Janssen DJ, Spruit MA, Uszko-Lencer NH, Schols JM, Wouters EF. Symptoms, comorbidities, and health care in advanced chronic obstructive pulmonary disease or chronic heart failure. J Palliat Med 2011;14:735-43.

19. Janssen DJ, Franssen FM, Wouters EF, Schols JM, Spruit MA. Impaired health status and care dependency in patients with advanced COPD or chronic heart failure. Qual Life Res 2011;20:1679-88.

20. Janssen DJ, Spruit MA, Wouters EF, Schols JM. Family caregiving in advanced chronic organ failure. JAMDA 2012;13:394-9. 
21. Rabe KF, Hurd S, Anzueto A, et al. Global strategy for the diagnosis, management, and prevention of chronic obstructive pulmonary disease: GOLD executive summary. Am J Respir Crit Care Med 2007;176:532-55.

22. Charlson ME, Pompei P, Ales KL, Mackenzie CR. A new method of classifying prognostic comorbidity in longitudinal studies: development and validation. J Chronic Dis 1987;40:373-83.

23. Zigmond AS, Snaith RP. The hospital anxiety and depression scale. Acta Psychiatr Scand 1983;67:361-70.

24. Ware JE, Jr., Sherbourne CD. The MOS 36-item short-form health survey (SF-36). I. Conceptual framework and item selection. Medical care 1992;30:473-83.

25. Curtis JR, Engelberg RA, Nielsen EL, Au DH, Patrick DL. Patient-physician communication about end-of-life care for patients with severe COPD. Eur Respir J 2004;24:200-5.

26. Engelberg R, Downey L, Curtis JR. Psychometric characteristics of a quality of communication questionnaire assessing communication about end-of-life care. Journal Palliat Med 2006;9:1086-98.

27. Janssen DJ, Spruit MA, Schols JM, Wouters EF. Dynamic preferences for site of death among patients with advanced chronic obstructive pulmonary disease, chronic heart failure, or chronic renal failure. J Pain Symptom Manage 2013;46:826-36.

28. Knauft E, Nielsen EL, Engelberg RA, Patrick DL, Curtis JR. Barriers and facilitators to end-of-life care communication for patients with COPD. Chest 2005;127:2188-96.

29. Heffner JE, Fahy B, Hilling L, Barbieri C. Attitudes regarding advance directives among patients in pulmonary rehabilitation. Am J Respir Crit Care Med 1996;154:1735-40.

30. Janssen DJ, Engelberg RA, Wouters EF, Curtis JR. Advance care planning for patients with COPD: past, present and future. Patient Educ Couns 2012;86:19-24.

31. Gott M, Gardiner C, Small N, et al. Barriers to advance care planning in chronic obstructive pulmonary disease. Palliat Med 2009;23:642-8.

32. Lorenz KA, Shugarman LR, Lynn J. Health care policy issues in end-of-life care. J Palliat Med 2006;9:73148.

33. Holley JL. Palliative care in end-stage renal disease: illness trajectories, communication, and hospice use. Adv Chronic Kidney Dis 2007;14:402-8.

34. Gott M, Barnes S, Parker C, et al. Dying trajectories in heart failure. Palliat Med 2007;21:95-99.

35. Reinke LF, Engelberg RA, Shannon SE, et al. Transitions regarding palliative and end-of-life care in severe chronic obstructive pulmonary disease or advanced cancer: themes identified by patients, families, and clinicians. J PalliatMed 2008;11:601-9.

36. McCambridge J, Witton J, Elbourne DR. Systematic review of the Hawthorne effect: new concepts are needed to study research participation effects. J Clinic Epidemiol 2014;67:267-77.

37. Slatore CG, Cecere LM, Reinke LF, et al. Patient-clinician communication: associations with important health outcomes among veterans with COPD. Chest 2010;138:628-34.

38. Slort W, Blankenstein AH, Schweitzer BP, et al. Effectiveness of the palliative care 'Availability, Current issues and Anticipation' (ACA) communication training programme for general practitioners on patient outcomes: A controlled trial. Palliat Med 2014.

39. Curtis JR, Back AL, Ford DW, et al. Effect of communication skills training for residents and nurse practitioners on quality of communication with patients with serious illness: a randomized trial. JAMA 2013;310:2271-81.

40. Houben CH, Spruit MA, Groenen MT, Wouters EF, Janssen DJ. Efficacy of advance care planning: a systematic review and meta-analysis. J Am Med Dir Assoc 2014;15: 477-489.

41. Barclay S, Momen N, Case-Upton S, Kuhn I, Smith E. End-of-life care conversations with heart failure patients: a systematic literature review and narrative synthesis. Br J Gen Pract 2011;61:e49-62.

42. Momen N, Hadfield P, Kuhn I, Smith E, Barclay S. Discussing an uncertain future: end-of-life care conversations in chronic obstructive pulmonary disease. A systematic literature review and narrative synthesis. Thorax 2012;67: 777-780. 



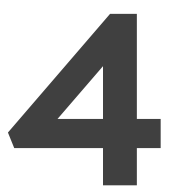

\section{Instability of willingness to accept life-sustaining treatments of patients with advanced chronic organ failure during one year}
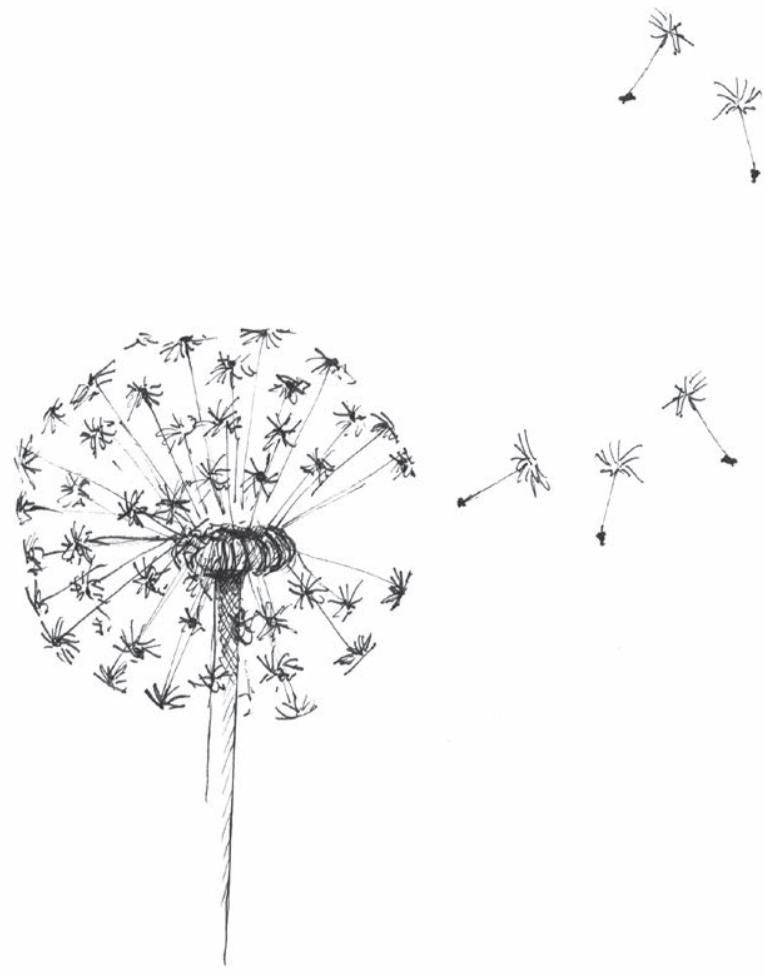

Carmen H.M. Houben, Martijn A. Spruit, Jos M.G.A. Schols, Emiel F.M. Wouters, and Daisy J.A. Janssen. CHEST, 2017. 151(5):1081-1087.

Reproduced with permission from CHEST. 


\section{ABSTRACT}

Background: For optimal end-of-life decision-making, it is important to understand the stability of patients' treatment preferences. The aim of this article is to examine the stability of willingness to accept life-sustaining treatments during 1-year followup in Dutch patients with advanced chronic organ failure. In addition, we want to explore the association between willingness to accept high-burden treatment and preferences for CPR and mechanical ventilation (MV).

Methods: In this multicenter longitudinal study, 265 clinically stable outpatients with advanced COPD (Global Initiative for Chronic Obstructive Lung Disease stage III/IV ( $n=105)$ ), chronic heart failure (New York Heart Association class III/IV ( $n=80)$ ), or chronic renal failure (requiring dialysis $(n=80)$ ) were visited at baseline and at 4 , 8 , and 12 months to assess the stability of life-sustaining treatment preferences using the Willingness to Accept Life-sustaining Treatment instrument.

Results: Two hundred six patients completed 1-year follow-up (mean age, 67.2 years (SD, 13.1 years); 64.1\% men). Overall, proportions of patients who were willing to accept life-sustaining treatment during 1 year did not change over time. However, individual trajectories showed that about two-thirds of patients changed their preferences at least once during a year. Moreover, there was no association found between the stability of willingness to undergo high-burden therapy and the stability of preferences for CPR and MV.

Conclusion: The current findings show the complexity of preferences for end-of-life care and indicate once again that advance care planning is a continuous process between patients and physicians, in which preferences for specific situations are discussed and that needs to be regularly reevaluated in order to deliver high-quality end-of-life care. 


\section{INTRODUCTION}

Advance Care Planning (ACP) is the process of timely communication between patients, healthcare professionals, and the patient's loved ones about preferences for end-of-life care and is important to deliver high-quality end-of-life care. ${ }^{1}$ This certainly applies to patients with COPD, chronic heart failure (CHF), and chronic renal failure (CRF)in which unexpected deaths occur frequently. ${ }^{2}$ However, preferences for CPR and mechanical ventilation (MV) change in more than one-third of outpatients with advanced COPD, CHF, or CRF at least once during 1 year. ${ }^{3}$ These patients may have unstable life-sustaining treatment preferences because of lack of information about the burden and outcome of the treatment. In fact, research has demonstrated that most patients prefer CPR or MV, or both, whereas most patients do not want high-burden interventions with a low likelihood of success. Indeed, the burden of MV or CPR and the likelihood of a negative outcome may be considerable in patients with chronic organ failure. ${ }^{4-6}$ In 2012, Fried et al. ${ }^{7}$ developed the Willingness to Accept Life-Sustaining Treatment (WALT) instrument, which was designed to assess patients' treatment preferences using their attitudes toward treatment burden weighed against a variety of treatment outcomes and the likelihood of their occurrence. The instrument has previously been used in patients with chronic organ failure, and indeed patients' treatment preferences were influenced by burden of treatment, outcome of treatment, and likelihood of outcome. ${ }^{8}$ Previous research in older US patients with COPD, CHF, or cancer suggested that preferences for lifesustaining treatment, as assessed with the WALT, are inconsistent over time. ${ }^{9}$ Until now, European data regarding the stability of the WALT that focused exclusively on patients with advanced chronic organ failure were lacking. Differences might be present between European and US patients. Indeed, US patients with COPD more frequently reported that their preferences for medical care changed at different times than did Dutch patients with COPD. ${ }^{10}$ Therefore, the aim of this paper is to examine the stability of a willingness to accept life-sustaining treatments during a 1year follow-up in Dutch patients with COPD, CHF, CRF. In addition, we compared the stability of a willingness to undergo high-burden therapy, as assessed with scenario 3 of the WALT instrument, between patients with a stable, increased, or decreased willingness regarding CPR and MV during 1 year. We hypothesized a priori that the willingness to accept life-sustaining treatments would be stable over time if patients received information about the burden of treatment, expected outcome of treatment, and the likelihood of an adverse outcome. 


\section{METHODS}

\section{Study design}

The current manuscript is based on a secondary analysis of longitudinal data from a multicenter prospective study concerning palliative care needs among outpatients with advanced COPD, CHF, or CRF. Home visits took place at baseline and subsequently every 4 months for a period of 1 year. This study was conducted in accordance with the amended Declaration of Helsinki. ${ }^{11}$ The Medical Ethical Committee of the Maastricht University Medical Centre, Maastricht, The Netherlands, approved this study (MEC 07-3-054). The study was registered with the Netherlands National Trial Register (NTR 1552). Written informed consent was obtained from all patients.

\section{Patients}

The study population consisted of a convenience sample of clinically stable patients with advanced chronic organ failure, defined as a primary diagnosis of severe to very severe COPD (Global initiative for Chronic Obstructive Lung Disease, stage III or IV), end-stage CHF (New York Heart Association class III or IV), or end-stage CRF (requiring dialysis). Patients were recruited by their physician specialist between January 2008 and June 2009 at the outpatient clinic of one academic and six general hospitals in The Netherlands. All participating patients provided written informed consent. Data on $\mathrm{ACP}^{8}$, patient-clinician communication ${ }^{10,12}$, preferences for life-sustaining treatment ${ }^{3}$ and site of death ${ }^{13}$ have been published previously.

\section{Instruments}

The following outcomes were assessed at baseline: demographics; weight and height; current self-reported comorbidities (Charlson Comorbidity Index) ${ }^{14}$, smoking history, hospital admissions in the previous year, previous admissions to the ICU, and previous MV and CPR. Patients' preferences in their current health status for CPR and invasive MV were assessed using two validated questions (e-Table 1 ), in which patients did not receive detailed information regarding burden of treatment, expected outcome of treatment and the likelihood of an adverse outcome. ${ }^{15}$

Patients' willingness to accept life-sustaining treatments was assessed using the WALT, which consists of six scenarios in which information regarding burden of treatment, expected outcome of treatment, and likelihood of an adverse outcome is provided (e-Appendix 1). ${ }^{7}$ For the current manuscript, we focused on the results 
of scenarios 3, 5, and 6 of the WALT. In scenario 3, patients were asked their willingness to undergo high-burden therapy that would get them back to their current state of health, and without the treatment they would not survive. In scenario 5, patients were asked about their willingness to risk physical disability as a result of low-burden therapy, and without the treatment they would not survive. In scenario 6 , patients were asked about their willingness to risk cognitive disability as a result of low-burden therapy, and without the treatment they would not survive. For each scenario, the highest likelihood of death or physical or cognitive disability at which the participant would want to receive therapy was determined. The results of the other three scenarios are presented in the e-Appendix 1.

\section{Statistical analysis}

Statistics were obtained using IBM SPSS Statistics, version 21.0 (SPSS Inc., Chicago, IL). Categorical variables are described as frequencies, and continuous variables are presented as mean and SD.

We used frequencies to describe the 1-year stability of the WALT in patients who completed all visits. For each WALT scenario, a log-rank test was used to determine whether ratings changed significantly over time. Next, likelihoods for an adverse outcome were combined into the following categories: low WALT (1\% and 10\%), $50 \%$ WALT, and high WALT (90\% and 99\%). Thereafter, the following trajectories were defined for WALT scores over time: stable willingness (patient provided responses in the same category during 1 year), decreased willingness (preference changed to a category with a lower willingness during 1 year), increased willingness (preference changed to a category with a higher willingness during 1 year), and variable willingness (inconsistent pattern of preferences). For each scenario, Kruskal-Wallis tests and $X^{2}$ tests were used to compare demographic characteristics of patients with stable, increased, decreased, and variable trajectories of WALT. Finally, the relationship between stability of willingness to undergo high-burden therapy and the stability of preferences for CPR and MV was explored using $X^{2}$ tests.

Patients who responded "don't know" or who refused to give a response to a scenario were excluded from the analysis of that scenario. A priori, a two-sided level of significance was set at $\mathrm{p} \leq .01$. 


\section{RESULTS}

\section{Patient characteristics}

The present study included 265 patients with severe to very severe COPD ( $n=105)$, $\mathrm{CHF}(\mathrm{n}=80)$, or CRF $(\mathrm{n}=80)$ at baseline. All home visits were completed by 206 patients (77.7\%) (Table 1). In total, 24 patients (9.1\%) died during the first year of the study, and 35 patients (13.2\%) withdrew from the study. A detailed flowchart of the study has been published previously. ${ }^{13}$ There were no significant differences found in baseline patient characteristics between the three groups, as published previously. ${ }^{3}$

Table 1. Baseline patient characteristics

\begin{tabular}{ll}
\hline Characteristic & Completed Study (N=206) \\
\hline Age, years & $67.2(13.1)$ \\
Male & $132(64.1)$ \\
Married/living with partner & $135(65.5)$ \\
BMI, kg/m² & $26.7(6.2)$ \\
Disease & \\
- COPD & $86(41.7)$ \\
- CHF & $61(29.6)$ \\
- CRF & $59(28.6)$ \\
Charlson Comorbidity Index, points & $3.4(2.0)$ \\
Current smokers & $41(19.9)$ \\
$\geq 1$ hospital admissions year previous study & $115(55.8)$ \\
Previous ICU admission & \\
Previous CPR & $113(55.9)$ \\
Previous MV & $21(10.4)$ \\
Prefers CPR at baseline & $46(22.8)$ \\
Prefers MV at baseline & $152(73.8)$ \\
\hline
\end{tabular}

Data reported as mean (SD) or number (\%).

${ }^{a} \mathrm{n}=201 ;{ }^{b} \mathrm{n}=202$.

Abbreviations: $\mathrm{BMI}=$ Body Mass Index; $\mathrm{COPD}=$ chronic obstructive pulmonary disease; $\mathrm{CHF}=$ chronic heart failure; $C R F=$ chronic renal failure; $C P R=$ cardiopulmonary resuscitation; $M V=$ mechanical ventilation.

\section{STABILITY OF WALT}

At all different time points, the proportion of patients choosing treatment decreased as the likelihood of death or functional or cognitive impairment as the outcome of treatment increased. In addition, the proportion of patients choosing treatment increased when life extension following treatment increased. The overall proportions of patients who would undergo therapy at a given likelihood of death 
or disability or a given amount of life extension during 1 year did not change over time ( $p>01$ for each scenario) (Figure 1 (scenarios 3, 5, and 6), e-Figure 1 (scenarios 1,2 , and 4)).
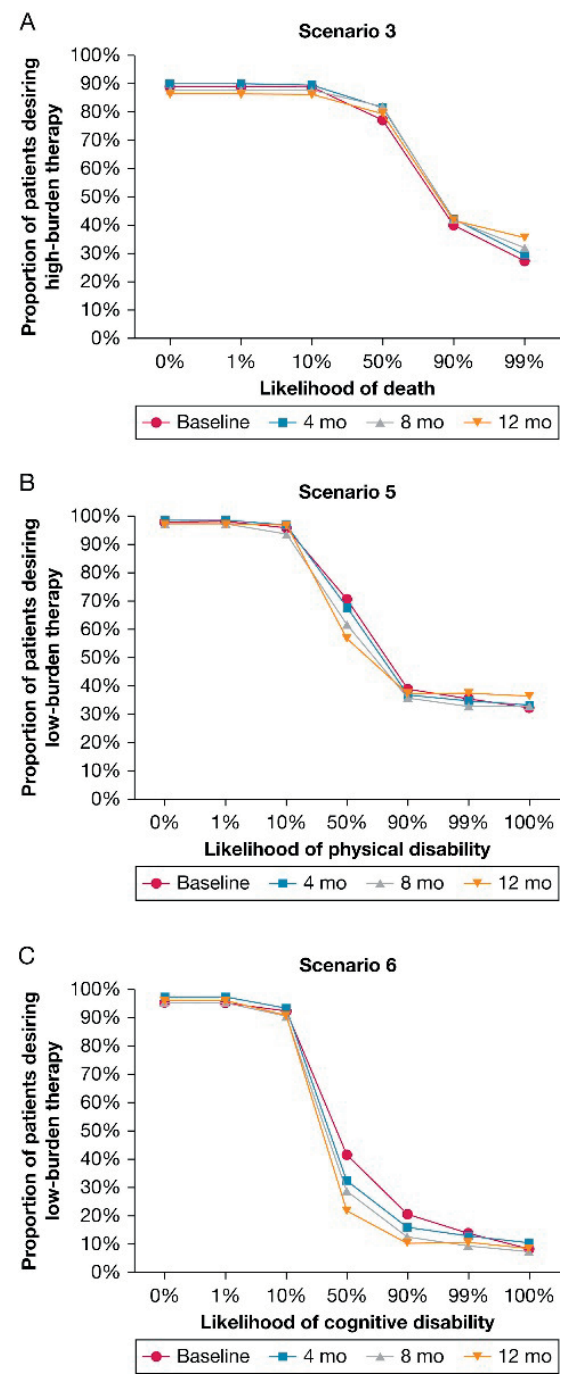

Figure 1. Treatment preferences according to burden of treatment and likelihood of different health states following treatment.

A, Proportion of patients who accepted high-burden treatment according to a given likelihood of death $(p=.190 ; n=188)$.

B, Proportion of patients who accepted low-burden treatment according to a given likelihood of functional impairment following treatment $(p=.932 ; n=201)$.

C, Proportion of patients who accepted low-burden treatment according to a given likelihood of cognitive impairment following treatment $(p=.056 ; n=195)$. 
Further analysis of the individual trajectories showed that depending on the burden of treatment, outcome of treatment and likelihood of outcome, $60.7 \%$ to $75.6 \%$ of the patients changed their willingness to accept life-sustaining treatment at least once during a year. The proportion of patients with an unstable trajectory was highest for a willingness to risk physical disability (Figure 2 (scenarios 3, 5, and 6), eFigure 2 (scenarios 1, 2, and 4)). In addition, current smokers had a less stable trajectory in scenario 5 . We did not find a relationship between all other demographics from Table 1 and a stability of willingness to undergo life-sustaining treatment $(p>01)$.

$X^{2}$ tests revealed no significant associations between the stability of a willingness to undergo high-burden therapy (scenario 3 ) and the stability of preferences for CPR and MV (p>.01) (Figure 3). The analyses showed, for example, that about half of the patients changed their minds about a willingness to undergo high-burden therapy, irrespective of the 1-year stability of preferences regarding CPR and MV.
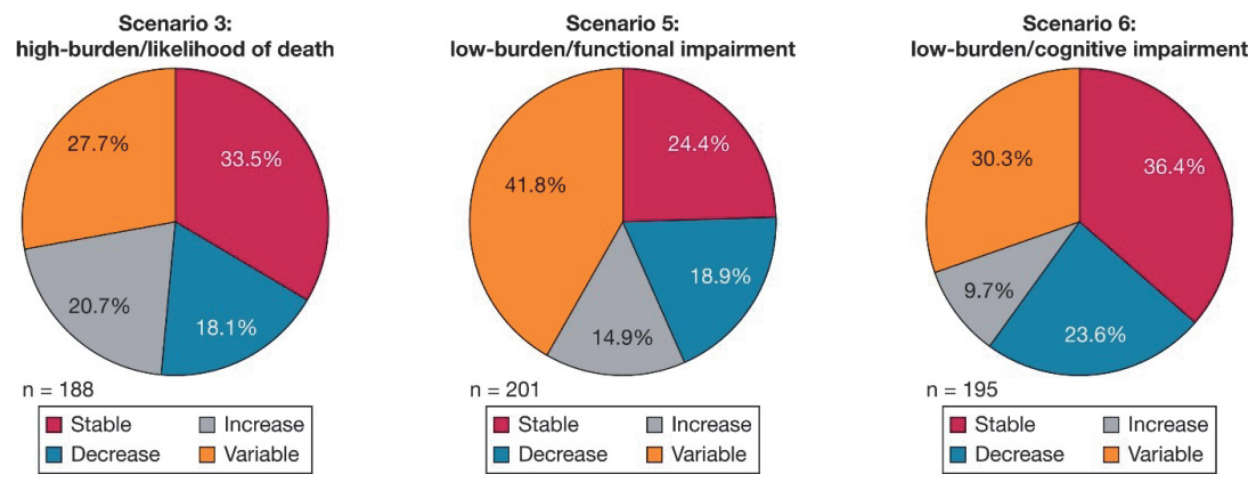

Figure 2. Stability of Willingness to Accept Life-Sustaining Treatments (WALT) during 1 year for scenarios 3, 5, and 6 . 
Stable willingness regarding CPR during 1 year ( $n=143$ )

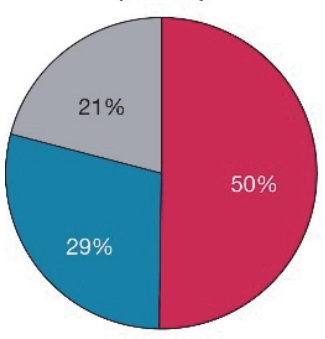

Stable willingness regarding MV during 1 year ( $n=144$ )

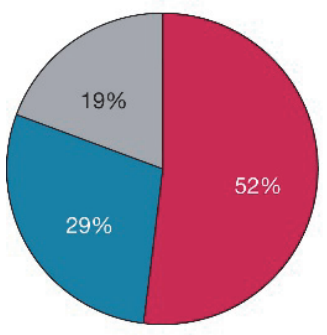

Increased willingness regarding CPR during 1 year ( $n=22)$

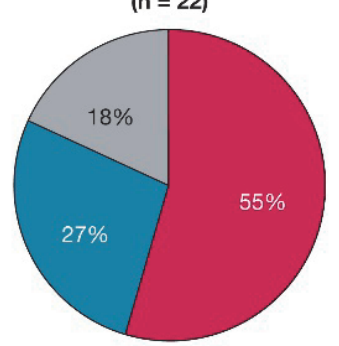

Increased willingness regarding MV during 1 year ( $n=21$ )

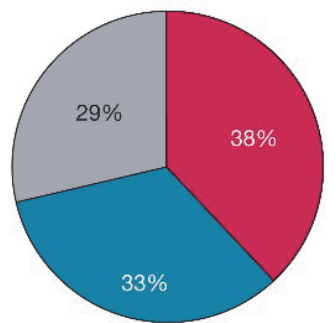

Decreased willingness regarding CPR during 1 year ( $n=30)$

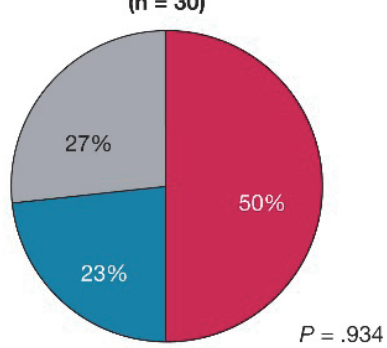
$=.934$

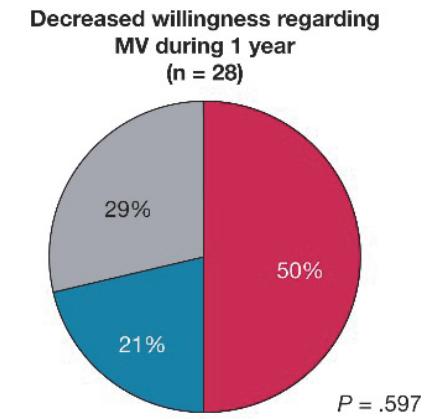

Stable willingness to undergo high-burden therapy

Increased willingness to undergo high-burden therapy

Decreased willingness to undergo high-burden therapy

Figure 3. Relationship between stability of Willingness to Accept Life-Sustaining Treatment (WALT) scenario 3 and stability of preferences for CPR and mechanical ventilation (MV).

\section{DISCUSSION}

\section{Key findings}

Despite the fact that the overall proportions of patients who were willing to accept life-sustaining treatments did not change during 1 year, individual trajectories showed that about two-thirds of the patients changed their preferences at least once during a year. Moreover, there was no relationship between the stability of a willingness to undergo high-burden therapy and the stability of preferences for CPR and MV. 
Previous studies showed that preferences for life-sustaining treatments are influenced by the burden of treatment, the expected outcome of treatment, and the likelihood of an adverse outcome, including death or physical or cognitive impairment. ${ }^{7,8,16,17}$ Previous studies also showed the instability of preferences regarding life-sustaining treatments such as $\mathrm{CPR}^{3,18,19}$, but that life-sustaining treatments were rarely discussed by physicians. We hypothesized in advance that preferences for life-sustaining treatments would be stable over time if patients received information about burden of treatment, the expected outcome of treatment, and the likelihood of an adverse outcome. However, the present study shows that even when patients do have this information their willingness to accept life-sustaining treatment changes during 1 year. Interestingly, the proportion of patients with an inconsistent pattern of preferences based on the WALT questionnaire is even higher than the proportion of patients who changed their preferences for CPR and MV. These findings reflect the complexity of end-of-life decision-making in clinical practice and suggest that the amount of information and details provided to patients contributed to the instability of preferences for end-of-life care.

Furthermore, the WALT is based on hypothetical scenarios in which patients are asked about their future preferences for life-sustaining treatment. It can be questioned if patients are able to indicate their future preferences accurately. In fact, patients with advanced illness seem to adapt to their deteriorating state of health, which may affect their WALT. ${ }^{20,21}$ Social circumstances for which it is often difficult to predict stability in advance, such as a change in marital status, may also be related to a change in life-sustaining treatment preferences. $^{3}$

The consistency of WALT in the present study was higher than in previous research with the WALT questionnaire performed in the United States. Indeed, the consistency was $72 \%$ in this Dutch study vs $65 \%$ in the US sample of Fried et al. ${ }^{9,22}$ for scenario $3,58 \%$ vs $52 \%$ for scenario 5 , and $70 \%$ vs $51 \%$ for scenario 6 . Fried et al. ${ }^{9,22}$ included both patients with COPD and CHF and also patients with cancer and showed that in general, patients with cancer had a more stable pattern than patients with COPD or CHF. It is, therefore even more obvious that the stability of the WALT is higher in the current study, in which no patients with cancer were included. However, we also included patients with CRF and in this patient population, discussions about end-of-life care preferences are more common than in patients with COPD and $\mathrm{CHF}^{8,17}$, which is associated with a greater stability of preferences. ${ }^{23}$ Nevertheless, the most important explanation for the different results in Europe 
and the United States has to be sought in international differences. Previous research in patients with COPD has shown that a higher proportion of US than Dutch patients reported that their ideas about the kind of medical care they want change at different times. ${ }^{10}$ In fact, the majority of ACP studies are performed in the United States, and important differences exist in the communication about and the provision of end-of-life care between Europe and the United States. ${ }^{10,24}$ Indeed, communication about end-of-life care is less common in Dutch patients in comparison with US patients, and Dutch patients are more often involved in decision-making than are US patients. ${ }^{10,25}$

\section{Methodological considerations}

There were several potential limitations to our study. First, as mentioned before the WALT questionnaire is a subjective questionnaire in which hypothetical scenarios are used. Therefore, the preferences for end-of-life care as assessed with the WALT questionnaire probably differ from preferences that patients indicate when the scenario in question becomes reality. However, the WALT questionnaire has good psychometric properties in older seriously ill persons and has been found to be useful as an instrument for systematic assessment of preferences for end-of-life care. ${ }^{7}$ Second, participants were volunteers and probably have different views about preferences for end-of-life care than do patients who were unwilling to participate. Indeed, patient refusal is a common challenge in palliative care research and can result in selection bias. However, in that respect, research reflects clinical practice in which there are also patients who refuse discussions about end-of-life care preferences. ${ }^{26}$ Third, at the time of inclusion, participating patients with CRF were already undergoing a life-sustaining treatment, namely, dialysis, which may bias the current results. However, baseline data show that both patients with COPD, CHF, and CRF were unwilling to undergo a treatment with a low likelihood of success. ${ }^{8,17}$ Therefore, we did not assume that the inclusion of patients with CRF biased the results of the current analysis. Fourth, almost all participants were white, which may limit the generalizability of the current results. Fifth, although cognitive impairment was not formally assessed in the current study, it may be possible that patients were cognitively overwhelmed by the complexity of the choices as presented in the WALT. Indeed, previous research has shown an association between the prevalence of chronic organ failure and education level ${ }^{27-29}$ and there is evidence that cognitive impairment is common in these patients. ${ }^{30,31}$ Sixth, preferences for life-sustaining treatment could have been influenced by religion, which was not measured in the current study. However, previous research has shown a 


\section{Chapter 4}

limited relationship between religion and preferences regarding CPR and MV in patients with $\mathrm{CHF}^{32}$

\section{Conclusion}

The current findings show the complexity of preferences for life-sustaining treatments. Even when patients do have information about the burden of treatment, the expected outcome and the likelihood of an adverse outcome, their preferences are instable. These results indicated once again that ACP is a continuous process between patients and physicians, in which preferences for specific situations have to be discussed and need to be regularly reevaluated in order to deliver high-quality end-of-life care. This is in line with the aim of ACP, for which Sudore and Fried ${ }^{21}$ argue for, namely, that ACP should prepare patients and their loved ones to participate with physicians in making the best possible in-the-moment medical decisions. 


\section{REFERENCES}

1. Institute of Medicine. Dying in America: Improving quality and honoring individual preferences near the end of life. Washington, DC: The National Academies Press, 2015.

2. Claessens MT, Lynn J, Zhong Z, et al. Dying with lung cancer or chronic obstructive pulmonary disease: insights from SUPPORT. Study to Understand Prognoses and Preferences for Outcomes and Risks of Treatments. J Am Geriatr Soc 2000;48:S146-53.

3. Janssen DJ, Spruit MA, Schols JM, et al. Predicting changes in preferences for life-sustaining treatment among patients with advanced chronic organ failure. Chest 2012;141:1251-9.

4. Stapleton RD, Ehlenbach WJ, Deyo RA, Curtis JR. Long-term outcomes after in-hospital CPR in older adults with chronic illness. Chest 2014;146:1214-25.

5. Saeed F, Adil MM, Malik AA, Schold JD, Holley JL. Outcomes of In-Hospital Cardiopulmonary Resuscitation in Maintenance Dialysis Patients. Journal of the American Society of Nephrology : JASN 2015;26:3093-101.

6. Funk GC, Bauer P, Burghuber OC, et al. Prevalence and prognosis of COPD in critically ill patients between 1998 and 2008. Eur Respir J 2013;41:792-9.

7. Fried TR, Bradley EH, Towle VR. Assessment of patient preferences: integrating treatments and outcomes. J Gerontol B Psychol Sci Soc Sci 2002;57:S348-54.

8. Janssen DJ, Spruit MA, Schols JM, Wouters EF. A call for high-quality advance care planning in outpatients with severe COPD or chronic heart failure. Chest 2011;139:1081-8.

9. Fried TR, O'Leary J, Van Ness P, Fraenkel L. Inconsistency over time in the preferences of older persons with advanced illness for life-sustaining treatment. J Am Geriatr Soc 2007;55:1007-14.

10. Janssen DJ, Curtis JR, Au DH, et al. Patient-clinician communication about end-of-life care for Dutch and US patients with COPD. Eur Respir J 2011;38:268-76.

11. World Medical Association (WMA). WMA Declaration of Helsinki - Ethical Principles for Medical Research Involving Human Subjects. 2013. http://www.wma.net/en/30publications/10policies/b3/. Accessed July, 29, 2016.

12. Houben CH, Spruit MA, Schols JM, Wouters EF, Janssen DJ. Patient-Clinician Communication About Endof-Life Care in Patients With Advanced Chronic Organ Failure During One Year. J Pain Symptom Manage 2015;49:1109-15.

13. Janssen DJ, Spruit MA, Schols JM, Wouters EF. Dynamic preferences for site of death among patients with advanced chronic obstructive pulmonary disease, chronic heart failure, or chronic renal failure. J Pain Symptom Manage 2013;46:826-36.

14. Charlson ME, Pompei P, Ales KL, MacKenzie CR. A new method of classifying prognostic comorbidity in longitudinal studies: development and validation. J Chronic Dis 1987;40:373-83.

15. Stapleton RD, Nielsen EL, Engelberg RA, Patrick DL, Curtis JR. Association of depression and lifesustaining treatment preferences in patients with COPD. Chest 2005;127:328-34.

16. Fried TR, Bradley EH, Towle VR, Allore H. Understanding the treatment preferences of seriously ill patients. N Engl J Med 2002;346:1061-6.

17. Janssen DJ, Spruit MA, Schols JM, van der Sande FM, Frenken LA, Wouters EF. Insight into advance care planning for patients on dialysis. J Pain Symptom Manage2013;45:104-13.

18. Ditto PH, Smucker WD, Danks JH, et al. Stability of older adults' preferences for life-sustaining medical treatment. Health Psychol 2003;22:605-15.

19. Kim YS, Escobar GJ, Halpern SD, Greene JD, Kipnis P, Liu V. The Natural History of Changes in Preferences for Life-Sustaining Treatments and Implications for Inpatient Mortality in Younger and Older Hospitalized Adults. J Am Geriatr Soc 2016;64:981-9.

20. Ubel PA, Loewenstein G, Schwarz N, Smith D. Misimagining the unimaginable: the disability paradox and health care decision making. Health Psychol 2005;24:S57-62.

21. Sudore RL, Fried TR. Redefining the "planning" in advance care planning: preparing for end-of-life decision making. Ann Intern Med 2010;153:256-61. 


\section{Chapter 4}

22. Fried TR, Van Ness PH, Byers AL, Towle VR, O'Leary JR, Dubin JA. Changes in preferences for lifesustaining treatment among older persons with advanced illness. J Gen Intern Med 2007;22:495-501.

23. Auriemma CL, Nguyen CA, Bronheim R, et al. Stability of end-of-life preferences: a systematic review of the evidence. JAMA Intern Med 2014;174:1085-92.

24. Curtis JR, Engelberg RA, Nielsen EL, Au DH, Patrick DL. Patient-physician communication about end-of-life care for patients with severe COPD. European Respir J 2004;24:200-5.

25. Schoen C, Osborn R, How SK, Doty MM, Peugh J. In chronic condition: experiences of patients with complex health care needs, in eight countries, 2008. Health Aff (Millwood) 2009;28:w1-16.

26. Kars MC, van Thiel GJ, van der Graaf R, Moors M, de Graeff A, van Delden JJ. A systematic review of reasons for gatekeeping in palliative care research. Palliat Med 2016;30:533-48.

27. Vart P, Gansevoort RT, Coresh J, Reijneveld SA, Bultmann U. Socioeconomic measures and CKD in the United States and The Netherlands. Clin J Am Soc Nephrol 2013;8:1685-93.

28. Christensen S, Mogelvang R, Heitmann M, Prescott E. Level of education and risk of heart failure: a prospective cohort study with echocardiography evaluation. Eur Heart J 2011;32:450-8.

29. Hetlevik O, Melbye H, Gjesdal S. GP utilisation by education level among adults with COPD or asthma: a cross-sectional register-based study. NPJ Prim Care Respir Med 2016;26:16027.

30. Cleutjens FA, Janssen DJ, Ponds RW, Dijkstra JB, Wouters EF. COgnitive-pulmonary disease. BioMed Res Int 2014;2014:697825.

31. Alagiakrishnan K, Mah D, Ahmed A, Ezekowitz J. Cognitive decline in heart failure. Heart Fail Rev 2016.

32. Janssen DJ, Boyne J.J., Jorg, L., Pfisterer, M.E., Rickly, H., Brunner-La Rocca, H.P. Religious beliefs towards the end of life among elderly patients with chronic heart failure and the relationship with end-of-life preferences. J Palliat Care Med 2016;6:244 


\section{SUPPLEMENTARY MATERIAL}

\section{E-APPENDIX 1}

\section{Scenario 1}

Think about if you were suddenly to get sick with an illness that would require you to be in the hospital for a few days to a week. It would either be that your (CHF, COPD, CRF) worsened or you got sick with a different illness. In the hospital you would need to have minor tests, such as x-rays and blood draws, and therapies such as intravenous antibiotics and oxygen. Without the treatment, you would not survive. If this treatment would get you back to your current state of health, would you want to have it?

If NO: Question complete.

If YES: Now, what if the doctor told you that there was a 50/50 chance that it would work and get you back to your current state of health. If it did not work, you would not survive. Without the treatment, then you would not survive for certain. Would you want the treatment?

If NO: Now what if the doctor told you there was a 90\% (99\%) chance that it would work and get you back to your current state of health and a $10 \%(1 \%)$ chance that it would not. Without the treatment, then you would not survive for certain. Would you want the treatment?

If YES: Now, what if the doctor told you there was a $10 \%(1 \%)$ chance that it would work and get you back to your current state of health and a 90\% (99\%) chance that it would not work. Without the treatment, then you would not survive for certain. Would you want the treatment?

\section{Scenario 2}

Think again about if you were suddenly to get sick with an illness that would require you to be in the hospital for a few days to a week. It would either be that your (CHF, COPD, CRF) worsened or you got sick with a different illness. In the hospital you would need to have minor tests, such as x-rays and blood draws, and therapies such as intravenous antibiotics and oxygen. Without the treatment, you would not sur- 
vive. If this treatment would lengthen your life with one week in your current state of health, would you want to have it?

\section{Scenario 3}

Think about if you were suddenly to get sick with an illness that would require you to be in the hospital for at least a month. It would either be that your (CHF, COPD, CRF) worsened or you got sick with a different illness. In the hospital, you would need to have many minor tests, such as x-rays and blood draws, and you would require more tests, such as $\mathrm{CT}$ scans. You would need major therapies such as being in the intensive care unit, receiving surgery, or having a breathing machine. Without the treatment, you would not survive. If this treatment would get you back to your current state of health, would you want to have it?

If NO: Question complete.

If YES: Now, what if the doctor told you that there was a 50/50 chance that it would work and get you back to your current state of health. If it did not work, you would not survive. Without the treatment, then you would not survive for certain. Would you want the treatment?

If NO: Now what if the doctor told you there was a 90\% (99\%) chance that it would work and get you back to your current state of health and a 10\% (1\%) chance that it would not. Without the treatment, then you would not survive for certain. Would you want the treatment?

If YES: Now, what if the doctor told you there was a $10 \%(1 \%)$ chance that it would work and get you back to your current state of health and a 90\% (99\%) chance that it would not work. Without the treatment, then you would not survive for certain. Would you want the treatment?

\section{Scenario 4}

Think about if you were suddenly to get sick with an illness that would require you to be in the hospital for at least a month. It would either be that your (CHF, COPD, CRF) worsened or you got sick with a different illness. In the hospital, you would need to have many minor tests, such as x-rays and blood draws, and you would require more tests, such as $\mathrm{CT}$ scans. You would need major therapies such as being in the intensive care unit, receiving surgery, or having a breathing machine. Without 
the treatment, you would not survive. If this treatment would lengthen your life with one week in your current state of health, would you want to have it?

If YES: Question complete.

If NO: Now, what if the doctor told you that the treatment would lengthen your life with one month. Would you want the treatment?

If NO: Now, what if the doctor told you that the treatment would lengthen your life with a half year. Would you want the treatment?

If NO: Now, what if the doctor told you that the treatment would lengthen your life with one year. Would you want the treatment?

\section{Scenario 5}

Think again about if you were suddenly to get sick with an illness that would require you to be in the hospital for a few days to a week. It would either be that your (CHF, COPD, CRF) worsened or you got sick with a different illness. In the hospital you would need to have minor tests, such as x-rays and blood draws, and therapies such as intravenous antibiotics and oxygen. However, this time, imagine that, at the end of the treatment, you would be in a state where you would be bedbound.

You would not be able to get up out of bed to the bathroom by yourself, and you would need help with all of your daily activities. Without the treatment, you would not survive. Would you want the treatment?

If YES: Question complete.

If NO: Now, what if the doctor told you that there was a 50/50 chance that it would get you back to your current state or would leave you bedbound. Without the treatment, then you would not survive for certain. Would you want the treatment?

If NO: Now what if the doctor told you there was a 90\% (99\%) chance that it would work and get you back to your current state of health and a $10 \%(1 \%)$ chance that it would leave you bedbound. Without the treatment, then you would not survive for certain. Would you want the treatment?

If YES: Now, what if the doctor told you there was a $10 \%(1 \%)$ chance that it would work and get you back to your current state of health and a 90\% (99\%) chance that 


\section{Chapter 4}

it would leave you bedbound. Without the treatment, then you would not survive for certain. Would you want the treatment?

\section{Scenario 6}

Think again about if you were suddenly to get sick with an illness that would require you to be in the hospital for a few days to a week. It would either be that your (CHF, COPD, CRF) worsened or you got sick with a different illness. In the hospital you would need to have minor tests, such as x-rays and blood draws, and therapies such as intravenous antibiotics and oxygen. Now imagine that the treatment would leave you in a state where your mind would not be working, such that you would not be aware of what was going on around you or be able to recognize your loved ones. Without the treatment, you would not survive. Would you want the treatment?

If YES: Question complete.

If NO: Now, what if the doctor told you that there was a 50/50 chance that it would get you back to your current state or would leave you unaware. Without the treatment, then you would not survive for certain. Would you want the treatment?

If NO: Now what if the doctor told you there was a 90\% (99\%) chance that it would work and get you back to your current state of health and a $10 \%(1 \%)$ chance that it would leave you unaware. Without the treatment, then you would not survive for certain. Would you want the treatment?

If YES: Now, what if the doctor told you there was a $10 \%(1 \%)$ chance that it would work and get you back to your current state of health and a 90\% (99\%) chance that it would leave you unaware. Without the treatment, then you would not survive for certain. Would you want the treatment? 
e-Table 1. Questions asked to patients about their treatment preferences

\begin{tabular}{ll}
\hline Treatment & Question \\
\hline $\begin{array}{l}\text { Mechanical } \\
\text { ventilation }\end{array}$ & 'The first treatment is short-term mechanical ventilation. You would be in an ICU, and a \\
& tube would be placed through your mouth or nose into your lungs. This tube would be \\
& attached to a breathing machine for a few days. During that time, you would have to be \\
& continuously on the breathing machine and would be unable to talk. If you were in your \\
& current health and were unable to breathe on your own, would you want to be on a \\
& breathing machine for a few days? There would be no guarantee that you would be able \\
& to come off the breathing machine and be able to breathe on your own.' \\
Cardiopulmonary & 'The second treatment is CPR, which consists of electric shocks to the heart, pumping on \\
Resuscitation & the chest, help with breathing and heart medications given through the veins. Possible \\
& side effects of CPR include broken ribs and memory loss. Because you would be \\
& unconscious, other people would need to make the decision for you regarding your \\
& treatment. In your current health, would you want resuscitation (CPR) if your heart were \\
& to stop beating?'
\end{tabular}


e-Figure 1. Treatment preferences according to burden of treatment and length of life following treatment
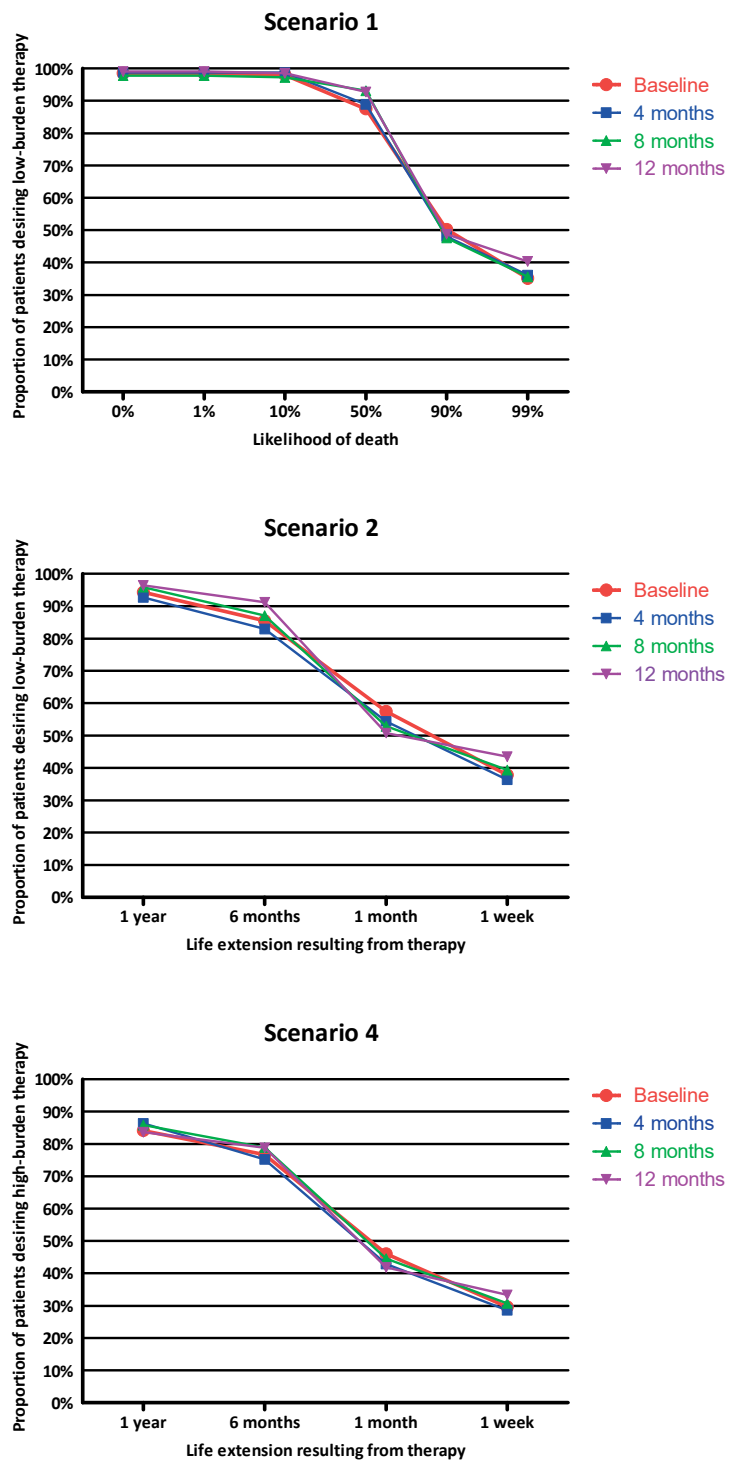

e-Figure 1a: Proportion of patients who accepts low-burden treatment according to a given likelihood of death. $p=.717 ; n=191$.

e-Figure 1b: Proportion of patients who accepts low-burden treatment according to a given length of life following treatment. $p=.718 ; n=193$.

e-Figure 1c: Proportion of patients who accepts high-burden treatment according to a given length of life following treatment. $p=.978 ; n=189$. 
e-Figure 2. Stability of willingness to accept life-sustaining treatments during one year for scenario 1,2 , and 4

Scenario 1:

low-burden/likehood of death

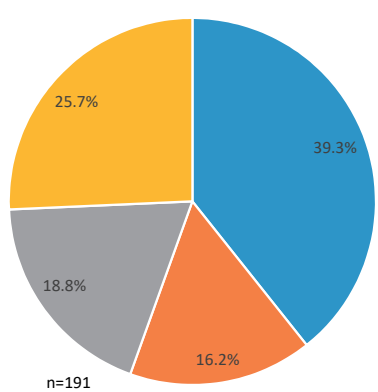

Scenario 2:

low- burden/life-extension

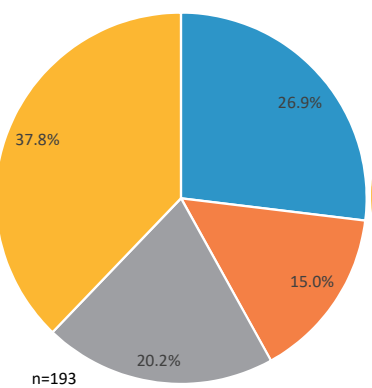

Scenario 4:

high-burden/life-extension

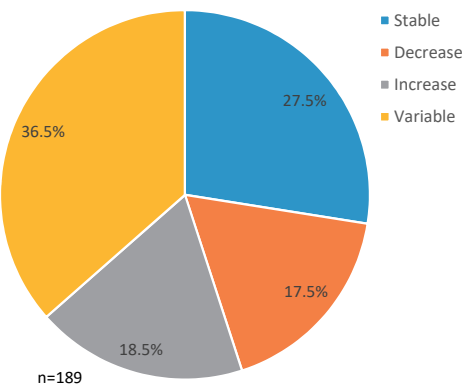





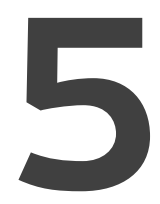

\section{“Am I dying Doctor?”: How end-of-life care is portrayed in television medical dramas}
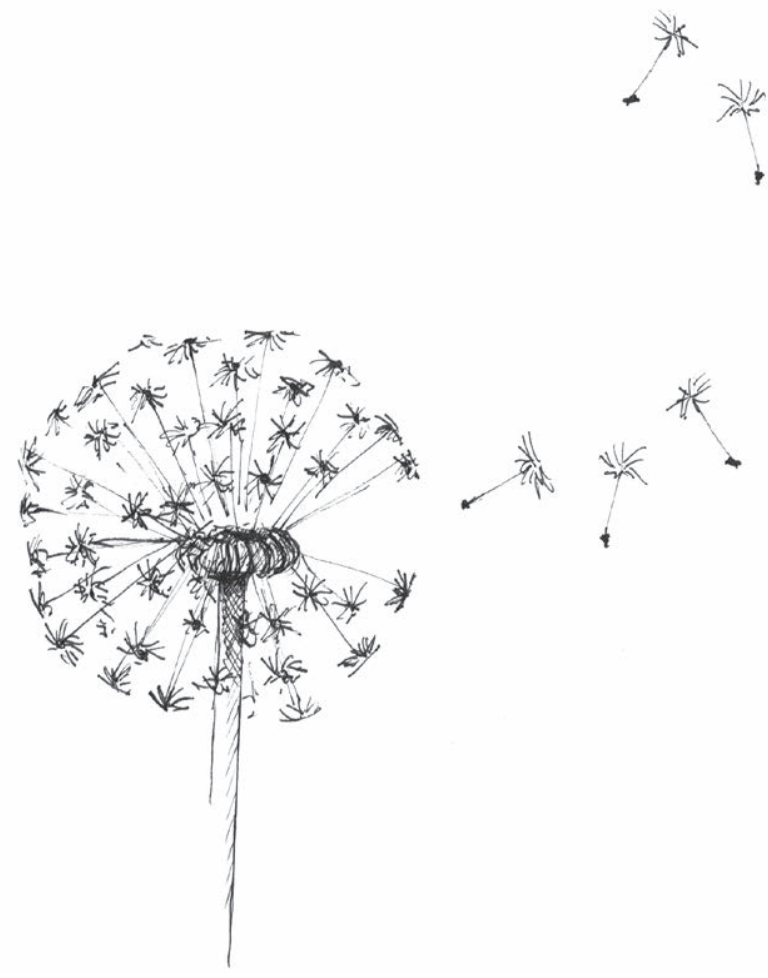

Carmen H.M. Houben, Martijn A. Spruit, Emiel F.M. Wouters, and Daisy J.A. Janssen. Journal of Palliative Care and Medicine, 2016. 6:247.

Reproduced with permission from Journal of Palliative Care and Medicine. 


\section{ABSTRACT}

Background: Patient-clinician communication about end-of-life care is important for patients with chronic life-limiting diseases and their loved ones but requires engagement from patients and loved ones. Television is a powerful medium in influencing people's behavior. However, it is unknown which image is sketched on television about end-of-life care communication.

Objective: To explore communication about end-of-life care between healthcare professionals and patients or loved ones in popular medical dramas on television.

Methods: 68 episodes of television medical drama were reviewed (22 episodes of House, 22 episodes of ER, and 24 episodes of Grey's Anatomy). Three types of events were identified: communication between healthcare professionals and patients or loved ones about end-of-life care, cardiopulmonary resuscitation (CPR), and death.

Results: In total, 99 events of end-of-life care communication, 47 events of CPR, and 27 events of death were observed. Discussions about end-of-life care were mostly initiated by physicians in the presence of patients and loved ones. The most frequently addressed topics were: talking about the possibility of dying, treatment options, and life-sustaining treatments. The immediate success rate of CPR was $51.1 \%$. Of the patients who deceased, the majority died unexpected, usually a lifeprolonging treatment was performed before death, and advance directives were uncommon.

Conclusion: Healthcare professionals in television medical dramas talked with patients or loved ones about end-of-life. However, topics important for patients in real life were often not discussed. 


\section{INTRODUCTION}

Advance Care Planning (ACP) is defined as an ongoing process whereby patients, in consultation with healthcare professionals and loved ones, make individual decisions about their future healthcare, to prepare for future medical treatment decisions, which often take place at the end-of-life. ${ }^{1}$ A systematic review and metaanalysis showed that ACP interventions increase the completion of advance directives, occurrence of discussions about ACP, and the concordance between preferences for care and delivered care. ${ }^{2}$ However, despite these benefits, discussions between physicians, patients and loved ones about end-of-life care are still uncommon. ${ }^{3,4}$

Most patients will not initiate these discussions and will wait for their physician to initiate end-of-life discussions, especially when patients were unaware about the life-threatening nature of their disease ${ }^{5}$ or had little knowledge of ACP. ${ }^{6}$ Indeed, lack of patient knowledge and understanding of medical information are physicianreported barriers for $\mathrm{ACP} .^{7}$ In addition, patients reported that they had "never thought about it" ${ }^{8}$ and often did not know that they can be involved in discussions about end-of-life care. ${ }^{7,8}$

Previous research showed that the behavior change theory is important in motivating individuals to engage in ACP. ${ }^{9}$ According to this theory, willingness to engage in ACP behavior is determined by knowledge and beliefs about ACP and expectations about treatment outcomes. ${ }^{9-11}$ Increased public awareness of the importance of timely end-of-life discussions may facilitate patients' and loved ones' willingness to be engaged in end-of-life care discussions and may improve patient empowerment. ${ }^{12,13}$ Patient empowerment is defined as an educational process to help patients develop the knowledge to effectively make their own health-related decisions. ${ }^{14}$ Traditionally, doctors were the primary source of information for patients. However, patients can also empower themselves through self-education facilitated by for example internet or television. ${ }^{15}$ In fact, previous studies showed that television is a powerful medium in influencing people's behavior ${ }^{16-18}$ and that the majority of elderly patients obtain information about cardiopulmonary resuscitation (CPR) from television. ${ }^{19}$ However, a previous study showed that in movies dealing with life-threatening illness and death the level of reality is limited. ${ }^{20}$ Furthermore, a recent study demonstrated that discussions about ACP rarely occur in television medical dramas. ${ }^{21}$ 
To the present authors' knowledge, detailed data concerning communication about end-of-life care on television are currently lacking. It seems reasonable that television can play an important role in patient perceptions about end-of-life care. The aim of this study is to explore communication about end-of-life care between healthcare professionals and patients or loved ones in popular medical dramas on television.

\section{METHODS}

We viewed all episodes of the last season available on DVD of the television medical dramas ER (season 15), House (season 8), and Grey's Anatomy (season 9). All three programs are American medical drama series in the hospital setting. A predesigned data sheet was used to identify and score three types of events: 1) communication between healthcare professionals and patients or loved ones (defined as persons who are close to the patient, regardless of whether they are spouse, significant others, relatives, grown-up children, or friends ${ }^{22}$ ) about end-of-life care; 2) CPR; and 3 ) death of a patient. For all events the patient's sex and life stage (unborn, baby, child, adolescent, or adult) were recorded.

For every occurrence of end-of-life care communication between a healthcare professional and patient or loved one the following information was recorded: who initiated communication about end-of-life care (patient, physician, nurse, loved one, or other); who were present during the conversation (patient, physician, nurse, loved one, or other); which words were used when talking about the end of life (death, dying, or other), and which topics were discussed. Discussed topics recorded were based on expert suggestions and partly derived from the end-of-life subscale of the Quality of Communication (QOC) questionnaire ${ }^{23}$, a validated instrument to measure quality of communication between patients and healthcare professionals.

In addition, for every occurrence of CPR the following information was recorded: the location where CPR was performed (Intensive Care Unit (ICU), Operating Room (OR), Emergency Room (ER), hospital department, other location in hospital, or outof-hospital), and whether patients survived CPR. CPR was defined as each observed situation in which chest compressions and/or defibrillation was performed on a patient. 
Finally, for all deaths the following information was recorded: whether death of the patient was (un)expected; who were present at time of death (physician, nurse, loved one, or not shown); location of death (ICU, OR, ER, hospital department, other, or not shown); whether the patient had an advance directive; whether lifesustaining treatments were performed and if so, whether these were discontinued before death, and whether there was distress during the dying phase.

All episodes were independently watched and events were scored by two authors (C.H. and D.J.), blinded to each other findings. In case of disagreement, the event was watched again by both authors and disagreements were solved by consensus.

Frequencies and percentages were used to present the results. The frequencies of the use of the words "death" and "dying" were compared between patients, loved ones and healthcare professionals using a Chi square test.

\section{RESULTS}

A total of 68 episodes (in total 48 hours) of television medical dramas were reviewed. We viewed 22 episodes of ER (15 hours), 22 episodes of House (16 hours), and 24 episodes of Grey's Anatomy (17 hours).

\section{End-of-life communication}

We observed 99 events of end-of-life communication between a healthcare professional and patient or loved one $(27.3 \%$ in ER, $41.4 \%$ in Grey's Anatomy and $31.3 \%$ in House) shown in Table 1. 


\section{Chapter 5}

Table 1. End-of-life communication in television medical dramas

\begin{tabular}{|c|c|}
\hline Total events of end-of-life communication & 99 \\
\hline$E R$ & $27(27.3)$ \\
\hline Grey's Anatomy & $41(41.4)$ \\
\hline House & $31(31.3)$ \\
\hline \multicolumn{2}{|l|}{ Gender of the patient* } \\
\hline Male & $63(63.6)$ \\
\hline Female & $34(34.3)$ \\
\hline Unborn & $3(3.1)$ \\
\hline \multicolumn{2}{|l|}{ Life stage of the patient } \\
\hline Unborn & $4(4.1)$ \\
\hline Baby & $3(3.0)$ \\
\hline Child & $8(8.1)$ \\
\hline Adolescent & $11(11.1)$ \\
\hline Adult & $73(73.7)$ \\
\hline \multicolumn{2}{|l|}{ Initiator of end-of-life communication } \\
\hline Patient & $23(23.2)$ \\
\hline Physician & $45(45.5)$ \\
\hline Nurse & $2(2.0)$ \\
\hline Loved one & $27(27.3)$ \\
\hline Not shown & $2(2.0)$ \\
\hline \multicolumn{2}{|l|}{ Present during end-of-life communication } \\
\hline Patient $^{\#}$ & $62(62.6)$ \\
\hline Physician & $90(90.9)$ \\
\hline Nurse & $12(12.1)$ \\
\hline Loved one & $69(69.7)$ \\
\hline \multicolumn{2}{|l|}{ Words used during end-of-life communication } \\
\hline Death & $16(16.2)$ \\
\hline by patient & $6(37.5)$ \\
\hline by physician & $3(18.8)$ \\
\hline by loved one & $7(43.7)$ \\
\hline Dying & $47(47.5)$ \\
\hline by patient & $18(38.3)$ \\
\hline by physician & $13(27.7)$ \\
\hline by nurse & $1(2.1)$ \\
\hline by loved one & 15 (31.9) \\
\hline \multicolumn{2}{|l|}{ Content } \\
\hline Talking about patients' feelings about getting sicker ${ }^{\dagger}$ & $0(0.0)$ \\
\hline Talking about possibility of getting sicker ${ }^{+}$ & $10(10.1)$ \\
\hline Talking about life expectancy $^{+}$ & $3(3.0)$ \\
\hline Talking about what dying might be like ${ }^{+}$ & $4(4.0)$ \\
\hline Talking about the possibility of dying ${ }^{+}$ & $56(56.6)$ \\
\hline Talking about life-sustaining treatments or withdrawing life-sustaining treatments ${ }^{\dagger}$ & $12(12.1)$ \\
\hline
\end{tabular}




\begin{tabular}{lc}
\hline Asking about important things in life $^{\dagger}$ & $7(7.1)$ \\
Asking about spiritual, religious beliefs & \\
Talking about treatment options & $1(1.0)$ \\
Talking about advance directives & $32(32.3)$ \\
Talking about surrogate decision making & $6(6.1)$ \\
Talking about palliative care & $3(3.0)$ \\
Talking about closure & $6(6.1)$ \\
Talking about organ donation & $5(5.1)$ \\
Brain death & $8(8.1)$ \\
Other & $5(5.1)$ \\
\hline
\end{tabular}

Data are presented as number of patients or events (\%). ${ }^{*}$ In one event the patients were a couple, which is scored as one event, but under the heading "gender" separated into male and female. " 8 patients were unconscious and 2 patients were unborn. ${ }^{\dagger}$ Items derived from Quality of Communication (QOC) questionnaire.

Most patients were male adults. In $45.5 \%$ of the events a physician initiated a discussion about end-of-life care. The words "death" and "dying" were used in 16.2\% and $47.5 \%$ of the events, respectively. Chi square tests revealed no significant differences in the use of the words "death" and "dying" between patients, loved ones and healthcare professionals ( $p>0.05)$. Other words used when talking about endof-life care were for example "fatal", "the heart will stop", and "nothing we can do". The most frequently addressed topics were: talking about the possibility of dying, treatment options, and life-sustaining treatments. Patients' feelings about getting sicker were not discussed at all. In $12.1 \%$ other topics were discussed such as talking about sedation, talking about the fact that the patient has already died, talking about the death of a loved one, talking about a death wish or preferred place of death. 
CPR

A total of 47 CPR attempts were shown (63.8\% in ER, 25.5\% in Grey's Anatomy and $10.7 \%$ in House) (Table 2). The immediate success rate of CPR was $51.1 \%$.

Table 2. Cardiopulmonary resuscitation (CPR) in television medical dramas

\begin{tabular}{|c|c|}
\hline Total CPR events & 47 \\
\hline ER & $30(63.8)$ \\
\hline Grey's Anatomy & $12(25.5)$ \\
\hline House & $5(10.7)$ \\
\hline \multicolumn{2}{|l|}{ Gender } \\
\hline Male & $32(68.1)$ \\
\hline Female & $14(29.8)$ \\
\hline Unknown & $1(2.1)$ \\
\hline \multicolumn{2}{|l|}{ Life stage } \\
\hline Unborn & $0(0.0)$ \\
\hline Baby & $2(4.3)$ \\
\hline Child & $5(10.6)$ \\
\hline Adolescent & $5(10.6)$ \\
\hline Adult & $34(72.4)$ \\
\hline Unknown & $1(2.1)$ \\
\hline \multicolumn{2}{|l|}{ Location of CPR } \\
\hline $\mathrm{ICU}$ & $9(19.1)$ \\
\hline OR & $4(8.5)$ \\
\hline ER & $25(53.2)$ \\
\hline Hospital department & $2(4.3)$ \\
\hline Out-of-hospital & $3(6.4)$ \\
\hline Other location in hospital ${ }^{*}$ & $4(8.5)$ \\
\hline \multicolumn{2}{|l|}{ CPR successful } \\
\hline Yes & $24(51.1)$ \\
\hline No & $18(38.3)$ \\
\hline Not shown & $5(10.6)$ \\
\hline
\end{tabular}

Death

During the 68 episodes, 27 patients died (59.3\% in ER, 33.3\% in Grey's Anatomy and $7.4 \%$ in House) (Table 3). In general, death was unexpected and patients were surrounded by a physician, loved one and/or nurse. Life-sustaining treatments were shown for $81.5 \%$ of the patients who eventually died and mechanical ventilation 
was discontinued in a minority before death. In only $11.1 \%$ of the situations in which patients died there was a reference to an advance directive.

Table 3. Dying in television medical dramas

\begin{tabular}{|c|c|}
\hline Total events of dying & 27 \\
\hline ER & $16(59.3)$ \\
\hline Grey's Anatomy & $9(33.3)$ \\
\hline House & $2(7.4)$ \\
\hline \multicolumn{2}{|l|}{ Gender } \\
\hline Male & $15(55.6)$ \\
\hline Female & $12(44.4)$ \\
\hline \multicolumn{2}{|l|}{ Life stage } \\
\hline Unborn & $0(0.0)$ \\
\hline Baby & $0(0.0)$ \\
\hline Child & $3(11.1)$ \\
\hline Adolescent & $2(7.4)$ \\
\hline Adult & $22(81.5)$ \\
\hline \multicolumn{2}{|l|}{ Unexpected death } \\
\hline Unexpected & $20(74.1)$ \\
\hline Expected & $5(18.5)$ \\
\hline Unknown & $2(7.4)$ \\
\hline \multicolumn{2}{|l|}{ Present at the time of death } \\
\hline Physician & $19(70.4)$ \\
\hline Nurse & $8(29.6)$ \\
\hline Loved one & $10(37.0)$ \\
\hline Not shown & $6(22.2)$ \\
\hline \multicolumn{2}{|l|}{ Location of death } \\
\hline $\mathrm{ICU}$ & $6(22.2)$ \\
\hline Hospital department & $1(3.7)$ \\
\hline OR & 4 (14.9) \\
\hline ER & $12(44.4)$ \\
\hline Other $^{*}$ & $2(7.4)$ \\
\hline Not shown & $2(7.4)$ \\
\hline \multicolumn{2}{|l|}{ Advance directive known } \\
\hline Yes & $3(11.1)$ \\
\hline Not shown & 24 (88.9) \\
\hline \multicolumn{2}{|c|}{ Life-sustaining treatment(s) performed before death } \\
\hline CPR & $18(66.7)$ \\
\hline NIV & $0(0.0)$ \\
\hline Mechanical ventilation & $16(59.3)$ \\
\hline Cardiopulmonary bypass & $1(3.7)$ \\
\hline No life-sustaining treatments performed & $2(7.4)$ \\
\hline Not shown & $3(11.1)$ \\
\hline
\end{tabular}




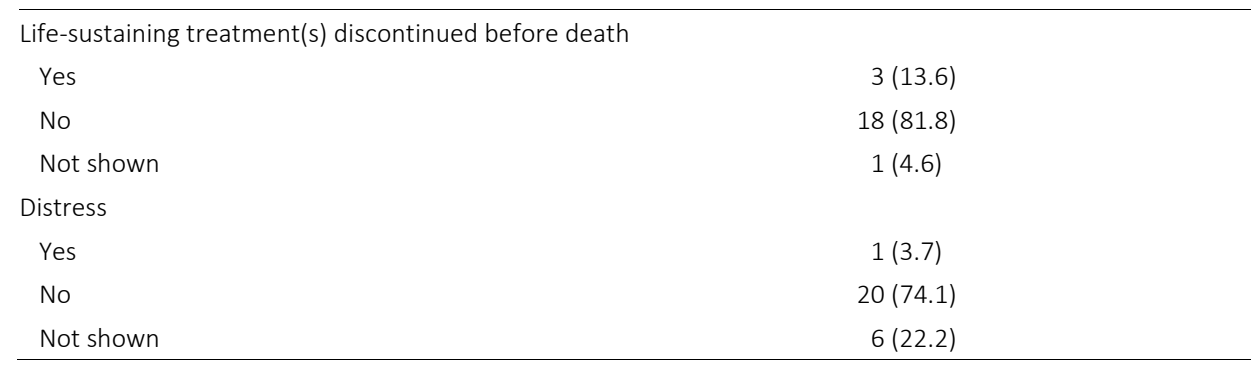

Data are presented as number of patients or events (\%). Abbreviations: ICU= Intensive Care Unit; OR= Operation Room; $E R=$ Emergency Room; $C P R=$ Cardiopulmonary Resuscitation; NIV= Non-Invasive Ventilation. *Other $=$ in front of the hospital $(n=1)$ or in the elevator of the hospital $(n=1)$.

\section{DISCUSSION}

\section{Key findings}

The present study shows that in television medical dramas healthcare professionals and patients or loved ones talked regularly about end-of-life care. Also CPR and death were frequently portrayed. Discussions about end-of-life care in television medical dramas were mostly initiated by physicians in the presence of patients and loved ones. The most frequently addressed topics were: talking about the possibility of dying, treatment options, and life-sustaining treatments. The immediate success rate of CPR was 51.1\%. Death was often unexpected. Usually, a life-prolonging treatment was performed before death. Finally, advance directives were uncommon.

\section{Communication}

The physician was mostly the initiator of the discussion about end-of-life care and the discussion was rarely initiated by a patient. Therefore, watching television medical dramas will not activate people to engage in ACP and initiate a discussion about end-of-life care by themselves. Indeed, studies performed in real life showed that patients believe it is the healthcare professional's responsibility to initiate discussions and that patients will rarely initiate these discussions. ${ }^{8,24}$ However, physicians perceive initiation of a discussion about end-of-life care by a patient as a facilitator for communication about end-of-life care. ${ }^{24}$ In addition, preferences for end-of-life care in the observed television medical dramas were mostly discussed because of an acute life-threatening trauma or injury, while in real life healthcare professionals need to have these conversations with chronically ill patients or elderly living in long term care settings. ${ }^{2}$ Therefore, television medical dramas do not contribute to the 
public awareness of the fact that ACP is of major importance for patients with a chronic disease.

The possibility of dying was discussed in more than half of the events, but topics as life expectancy, what dying might be like, feelings about getting sicker and things that are important in life were rarely discussed. However, research performed in real life showed that a majority of the patients want more information regarding prognosis than is provided in current care. ${ }^{25}$ Patients and caregivers also desired more detailed information about what dying might be like ${ }^{26}$, whereby in general caregivers require more detailed information about the dying process, allowing them to prepare for what to expect. ${ }^{27}$ Moreover, patients emphasized the importance of talking about things that are important for them during the end-of-life, such as maintaining dignity, getting support from healthcare professionals and family, and pain management. ${ }^{27}$ Finally, it is important for patients to talk about their feelings about getting sicker and probably dying, because they are often afraid of the dying process and also want to talk about the meaning of death in order to prepare for a "good death". ${ }^{28}$

Although treatment options were frequently discussed, there was little attention for documenting preferences for life-sustaining treatments in the form of an advance directive or appointing a surrogate decision maker. Therefore television medical dramas did not contribute to the public awareness about the possibility to document preferences for end-of-life and will not stimulate viewers to change behavior regarding completion of an advance directive.

Further, in the television medical dramas palliative care was rarely discussed. A previous study aimed to analyze how issues of illness and death were presented in movies also showed that the term "palliative care" was not mentioned once in any films. ${ }^{20}$ This could be explained by the fact that palliative care is still not known well enough by the general public ${ }^{20}$ and includes too little action and sensation to be shown on television. ${ }^{29}$ When physicians in television medical dramas do discuss palliative care this may raise public awareness by providing education about for example preferences regarding end-of-life care and the possibility of shareddecision making. Video-based tools are found to be effective in improving patient knowledge about ACP and palliative care ${ }^{30}$ and were even used in large-scale national campaigns, such as Dying Matters ${ }^{31}$ to increase public awareness about endof-life care. ${ }^{32}$ In the television medical dramas words as "death" and "dying" were regularly used and in this respect the television medical dramas contribute to normalizing the use of these words. Previous studies have shown that using clear 
words as "death" and "dying" instead of vague euphemisms is important for good end-of-life communication. ${ }^{33}$ After all, there are many things that could be done in the end-of-life concerning pain and symptom management or hospice referral for example. ${ }^{34}$ The use of clear words when talking about end-of-life may contribute to enhanced acceptance of the reality of impending death and it possibly can help patients prepare for death. ${ }^{35}$

$C P R$

The immediate success rate of CPR in the reviewed television medical dramas was 51.1\%. Comparing success rates of CPR in television medical dramas with those in the medical literature is difficult. First, television medical dramas only show the results immediately after CPR and did not portray longterm outcomes, while success rates in the medical literature are mainly focused on survival rates to discharge. In fact, in real life the survival rate of in-hospital CPR to hospital discharge in patients without a chronic disease is only $17.3 \% .{ }^{36}$ Second, in the television medical dramas CPR was mainly performed in the ER or operation room (OR), while studies usually exclude patients whose cardiac arrest happened when they were in the ER or OR, because of the distinct circumstances of cardiac arrest in these settings. ${ }^{37}$ Third, cardiac arrests in the television medical dramas were often caused by acute injury, while in real life most of arrests results from underlying cardiac disease. ${ }^{37}$ Since previous research assumed that television medical dramas have an effect on the perceptions and attitudes regarding the outcome of $\mathrm{CPR}^{38}$, the current authors recommend physicians to discuss differences between CPR in television medical dramas and real life in daily clinical practice.

Death

Nearly half of all deaths portrayed in the studied television medical dramas occurred in the ER and were associated with trauma, resulting in mainly unexpected deaths. Although trauma was a common cause of death in the 1900s, nowadays people often die from chronic diseases and cancer. ${ }^{39}$ Therefore, the image portrayed in television medical dramas does not reflect reality regarding causes of death. This can be largely explained by the fact that series were mostly set in the ER and add drama and action to make the series attractive for the general public. ${ }^{29}$

In almost all events a physician or nurse was present at the time of death and in addition often a loved one. This is in line with what seriously ill patients and their 
family caregivers rated as important at the end-of-life in real life, namely "presence of family" and "not die alone". 40

In only three of the deceased patients in the television medical dramas an explicit reference was made to an advance directive. In the meantime, life-sustaining treatment preferences were performed before death in almost all patients and were discontinued in only three patients. Research performed in real life showed that many people in the general public are unwilling to undergo life-sustaining treatments in the case of cancer, cardiac failure, dementia, or persistent vegetative state following a road traffic accident. In fact, regardless of the presented scenario, about $70 \%$ do not want CPR or mechanical ventilation in these situations. ${ }^{41}$ However, the documentation rate of preferences for end-of-life care in the general population is still low. ${ }^{6}$ Perhaps videos which have been developed for more educational purposes will affect the completion of advance directives rather than television medical dramas. Indeed, recent research has shown that video education enhance the completion of advance directives and are therefore useful tools in helping patients and clinicians to discuss and document preferences for end-of-life care. ${ }^{42}$

\section{Limitations}

The present study has some limitations. First, we reviewed only one season of three television medical dramas. However, since the structure of the television medical dramas seems to remain the same during the seasons it is not to be expected that reviewing more seasons would have led to different results. Second, discussions about end-of-life care were not completely shown and consequently we could only analyze the broadcasted part of the discussion. Despite this limitation, we were able to review almost hundred events of communication about end-of-life care. Third, the reviewed medical dramas were all from American origin and therefore maybe not comparable with the depiction of end-of-life care in television series from other countries. Indeed, previous studies regarding depiction of CPR in medical series showed that CPR survival rates in British and Flemish medical series seem to be more realistic than in American television medical dramas. ${ }^{43,44}$ Whether this is also true for end-of-life care communication remains currently unknown.

\section{Conclusions}

The present study shows that healthcare professionals in television medical dramas talked with patients or loved ones about end-of-life. However, these discussions are often limited to discussions about the possibility of dying and treatment options. 


\section{Chapter 5}

Topics such as preferences for life-sustaining treatments, advance directives, and palliative care were rarely discussed. Therefore television medical dramas don't seem to contribute in empowerment of patients and loved ones in the process of ACP and don't facilitate behavior change resulting in increased willingness to be engaged in end-of-life communication. However they could influence patients' and loved ones' attitudes regarding ACP, CPR, and dying. Therefore, healthcare professionals need to take into account this influence when having discussions about endof-life. 


\section{REFERENCES}

1. International Society of Advance Care Planning and End of Life Care (ACPEL) (2011) Definition of Advance Care Planning.

2. Houben $\mathrm{CH}$, Spruit MA, Groenen MT, Wouters EF, Janssen DJ. Efficacy of advance care planning: a systematic review and meta-analysis. J Am Med Dir Assoc 2014;15:477-89.

3. Janssen DJ, Curtis JR, Au DH, Spruit MA, Downey L. Patient-clinician communication about end-of-life care for Dutch and US patients with COPD. Eur Respir J 2011;38:268-76

4. Janssen DJ, Spruit MA, Schols JM, Wouters EF. A call for high-quality advance care planning in outpatients with severe COPD or chronic heart failure. Chest 2011;139:1081-8.

5. De Vleminck A, Pardon K, Beernaert K, et al. Barriers to advance care planning in cancer, heart failure and dementia patients: a focus group study on general practitioners' views and experiences. PloS one 2014;9:e84905.

6. Teixeira AA, Hanvey L, Tayler C, Barwich D, Baxter S, Heyland DK. What do Canadians think of advanced care planning? Findings from an online opinion poll. BMJ Support Palliat Care 2015;5:40-7.

7. Hajizadeh N, Uhler LM, Perez Figueroa RE. Understanding patients' and doctors' attitudes about shared decision making for advance care planning. Health Expect 2015;18(6):2054-65.

8. Simon J, Porterfield P, Bouchal SR, Heyland D. 'Not yet' and 'Just ask': barriers and facilitators to advance care planning--a qualitative descriptive study of the perspectives of seriously ill, older patients and their families. BMJ Support Palliat Care 2015;5:54-62.

9. Sudore RL, Stewart AL, Knight SJ, et al. Development and validation of a questionnaire to detect behavior change in multiple advance care planning behaviors. PloS one 2013;8:e72465.

10. Sudore RL, Knight SJ, McMahan RD, et al. A novel website to prepare diverse older adults for decision making and advance care planning: a pilot study. J Pain Symptom Manage 2014;47:674-86.

11. Schickedanz AD, Schillinger D, Landefeld CS, Knight SJ, Williams BA, Sudore RL. A clinical framework for improving the advance care planning process: start with patients' self-identified barriers. J Am Geriatr Soc 2009;57:31-9.

12. Nelson JM, Nelson TC. Advance directives: empowering patients at the end of life. Nurse Pract 2014;39:34-40.

13. Browning AM. Empowering family members in end-of-life care decision making in the intensive care unit. Dimens Crit Care Nurs 2009;28(1):18-23.

14. Feste C, Anderson RM. Empowerment: from philosophy to practice. Patient Educ Couns 1995;26:139-44.

15. McAllister M, Dunn G, Payne K, Davies L, Todd C. Patient empowerment: the need to consider it as a measurable patient-reported outcome for chronic conditions. BMC Health Serv Res 2012;12:157.

16. Morgenstern M, Sargent JD, Engels RC, et al. Smoking in movies and adolescent smoking initiation: longitudinal study in six European countries. Am J Prev Med2013;44:339-44.

17. Hanewinkel R, Sargent JD, Hunt K, et al. Portrayal of alcohol consumption in movies and drinking initiation in low-risk adolescents. Pediatrics 2014;133:973-82.

18. Hanewinkel R, Sargent JD, Poelen EA, et al. Alcohol consumption in movies and adolescent binge drinking in 6 European countries. Pediatrics 2012;129:709-20.

19. Schonwetter RS, Walker RM, Kramer DR, Robinson BE. Resuscitation decision making in the elderly: the value of outcome data. J Gen Intern Med 1993;8:295-300.

20. Drukarczyk L, Klein C, Ostgathe C, Stiel S. Life threatening illness in popular movies-a first descriptive analysis. SpringerPlus 2014;3:411.

21. Portanova J, Irvine K, Yi JY, Enguidanos S. It isn't like this on TV: Revisiting CPR survival rates depicted on popular TV shows. Resuscitation 2015;96:148-50.

22. Benkel I, Wijk H, Molander U. How to estimate understanding: professionals' assessment of loved ones' insight into a patient's fatal disease. J Palliat Med 2014;17:448-52.

23. Curtis JR, Engelberg RA, Nielsen EL, Au DH, Patrick DL. Patient-physician communication about end-of-life care for patients with severe COPD. Eur Respir J 2004;24:200-5. 
24. De Vleminck A, Houttekier D, Pardon $K$, et al. Barriers and facilitators for general practitioners to engage in advance care planning: a systematic review. Scand J Prim Health Care 2013;31:215-26.

25. Kirk P, Kirk I, Kristjanson $L$. What do patients receiving palliative care for cancer and their families want to be told? A Canadian and Australian qualitative study. BMJ 2004;328:1343.

26. Curtis JR, Wenrich MD, Carline JD, Shannon SE, Ambrozy DM, Ramsey PG. Patients' perspectives on physician skill in end-of-life care: differences between patients with COPD, cancer, and AIDS. Chest 2002;122:356-62.

27. Clayton JM, Butow PN, Arnold RM, Tattersall MH. Discussing end-of-life issues with terminally ill cancer patients and their carers: a qualitative study. Support Care Cancer 2005;13:589-99.

28. Steinhauser KE, Christakis NA, Clipp EC, et al. Preparing for the end of life: preferences of patients, families, physicians, and other care providers. management Pain Symptom Manage 2001;22:727-37.

29. Harris D, Willoughby $H$. Resuscitation on television: realistic or ridiculous? A quantitative observational analysis of the portrayal of cardiopulmonary resuscitation in television medical drama. Resuscitation 2009;80:1275-9.

30. Austin CA, Mohottige D, Sudore RL, Smith AK, Hanson LC. Tools to Promote Shared Decision Making in Serious IIIness: A Systematic Review. JAMA Intern Med 2015;175:1213-21.

31. http://www.dyingmatters.org.

32. Mcllfatrick S, Hasson F, McLaughlin D, et al. Public awareness and attitudes toward palliative care in Northern Ireland. BMC Palliat Care 2013;12:34.

33. Wenrich MD, Curtis JR, Shannon SE, Carline JD, Ambrozy DM, Ramsey PG. Communicating with dying patients within the spectrum of medical care from terminal diagnosis to death. Arch Intern Med 2001;161:868-74.

34. Norton SA, Talerico KA. Facilitating end-of-life decision-making: strategies for communicating and assessing. J Gerontol Nurs 2000;26:6-13

35. Workman SR. Never say die?--as treatments fail doctors' words must not. Int J Clin Pract 2011;65:117-9.

36. Stapleton RD, Ehlenbach WJ, Deyo RA, Curtis JR. Long-term outcomes after in-hospital CPR in older adults with chronic illness. Chest 2014;146:1214-25.

37. Goldberger ZD, Chan PS, Berg RA, et al. Duration of resuscitation efforts and survival after in-hospital cardiac arrest: an observational study. Lancet 2012;380:1473-81.

38. Diem SJ, Lantos JD, Tulsky JA. Cardiopulmonary resuscitation on television. Miracles and misinformation. N Engl J Med 1996;334:1578-82.

39. Seale C. Changing patterns of death and dying. Soc Sci Med 2000;51:917-30.

40. Steinhauser KE, Christakis NA, Clipp EC, McNeilly M, Mclntyre L, Tulsky JA. Factors considered important at the end of life by patients, family, physicians, and other care providers. JAMA 2000;284:2476-82.

41. Kissane LA, Ikeda B, Akizuki R, Nozaki S, Yoshimura K, Ikegami N. End-of-life preferences of the general public: Results from a Japanese national survey. Health Policy 2015.

42. Hickman RL, Jr., Lipson AR, Pinto MD, Pignatiello G. Multimedia decision support intervention: a promising approach to enhance the intention to complete an advance directive among hospitalized adults. J Am Assoc Nurse Pract 2014;26:187-93.

43. Van den Bulck J, Damiaans K. Cardiopulmonary resuscitation on Flemish television: challenges to the television effects hypothesis. Emerg Med J 2004;21:565-7.

44. Gordon PN, Williamson S, Lawler PG. As seen on TV: observational study of cardiopulmonary resuscitation in British television medical dramas. BMJ 1998;317:780-3. 


\section{6}

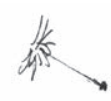

\section{A randomized controlled trial on the efficacy of advance care planning on the quality of end-of-life care and communication in patients with COPD: The research protocol}
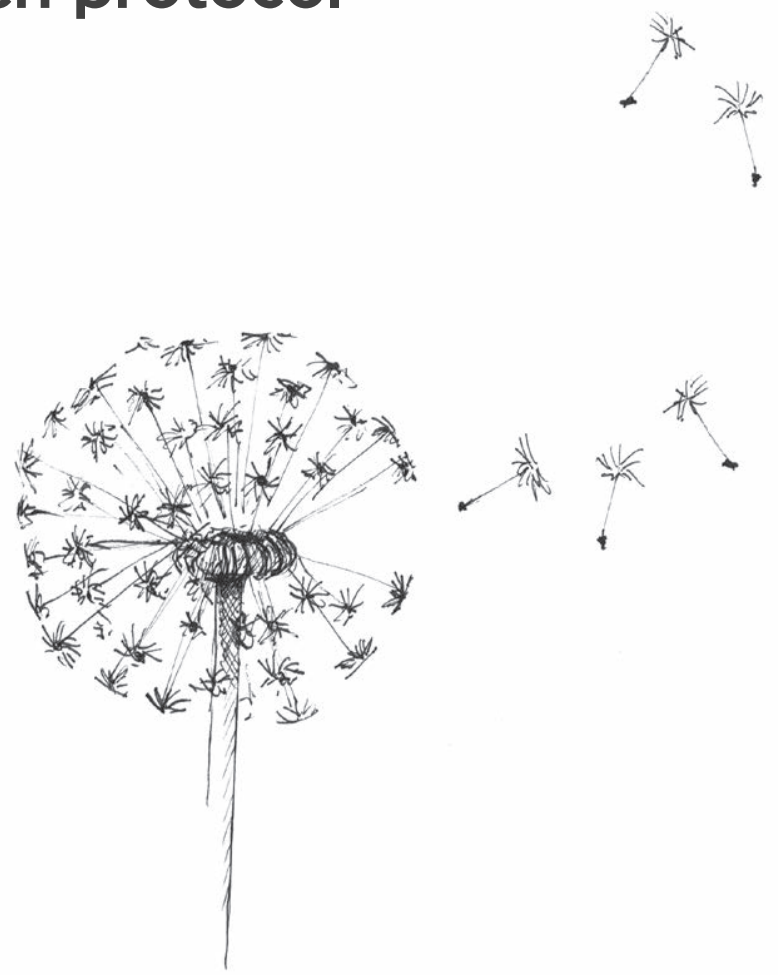

Carmen H.M. Houben, Martijn A. Spruit, Emiel F.M. Wouters, and Daisy J.A. Janssen. BMJ Open, 2014. 4(1):e004465.

Reproduced from [A randomized controlled trial on the efficacy of advance care planning on the quality of end-of-life care and communication in patients with COPD: The research protocol. Houben CHM, Spruit MA, Wouters EFM, Janssen DJA. 2014. 4(1):e004465] with permission from BMJ Publishing Group Ltd. 


\section{ABSTRACT}

Introduction: Recent research shows that advance care planning (ACP) for patients with Chronic Obstructive Pulmonary Disease (COPD) is uncommon and poorly carried out. The aim of the present study was to explore whether and to what extent structured ACP by a trained nurse, in collaboration with the chest physician, can improve outcomes in Dutch patients with COPD and their family.

Methods and analysis: A multicentre cluster randomised controlled trial in patients with COPD who are recently discharged after an exacerbation has been designed. Patients will be recruited from three Dutch hospitals and will be assigned to an intervention or control group, depending on the randomisation of their chest physician. Patients will be assessed at baseline and after six and 12 months. The intervention group will receive a structured ACP session by a trained nurse. The primary outcomes are quality of communication about end-of-life care, symptoms of anxiety and depression, quality of end-of-life care, and quality of dying. Secondary outcomes include concordance between patient's preferences for end-of-life care and received end-of-life care, and psychological distress in bereaved family members of deceased patients. Intervention and control groups will be compared using univariate analyses and clustered regression analysis.

Ethics and dissemination: Ethical approval was received from the Medical Ethical Committee of the Catharina Hospital Eindhoven, The Netherlands (NL42437.060.12). The current project provides recommendations for guidelines on palliative care in COPD and supports implementation of ACP in regular clinical care. 


\section{INTRODUCTION}

Advance care planning (ACP) provides patients with an opportunity to plan their future care, should they become incapable of participating in medical treatment decisions. These discussions can result into documentation of end-of-life care preferences in an advance directive. ${ }^{1}$ However, ACP is not limited to the completion of advance directives. ACP is an ongoing process in which patients, together with health care professionals and loved ones, discuss topics such as goals of care, resuscitation and life support, palliative care options, and surrogate decision making. ${ }^{2}$

Previous studies have shown that ACP increases the occurrence of discussions about $A C P^{3,4}$, improves concordance between patient's preferences and end-of-life care received $^{5-7}$, and improves quality of care at the end-of-life ${ }^{8}$ in different adult populations. Despite the fact that chronic obstructive pulmonary disease (COPD) is a leading cause of mortality worldwide ${ }^{9}$ and unexpected deaths occur frequently ${ }^{10}$, ACP studies are rarely focused on patients with COPD. A prospective cross-sectional study showed that outpatients with COPD Global Initiative for Chronic Obstructive Lung Disease (GOLD) stage III or IV are able to discuss preferences about lifesustaining treatments and are willing to discuss end-of-life care preferences. However, discussions about end-of-life care are rare and patients rated the quality of patient-physician communication about end-of-life care as poor. ${ }^{11}$ The most common endorsed barriers for end-of-life care communication reported by physicians are lack of time, anxiety to take away patient's hope, and the assumption that the patient is not ready to talk about end-of-life care. ${ }^{12}$

Although patients often prefer doctors to discuss ACP, they also accept other healthcare professionals as sources of ACP information. Nurses, for example, have specific skills that may facilitate communication about end-of-life care. They can provide prognostic information and support patients' hopes by understanding individual aspects of hope, focusing on patient's quality of life, and building trust with patients. $^{13}$

However, to date it remains unknown whether and to what extent structured $A C P$, by a trained nurse in collaboration with the chest physician, can improve outcomes in Dutch patients with COPD and their family. Therefore, we have designed a cluster-randomised controlled trial on the efficacy of structured ACP on quality of endof-life care communication and quality of end-of-life care in Dutch patients with COPD. The current manuscript describes the research protocol and provides an outline of possible strengths, weaknesses and clinical consequences. 
Hypothesis to be examined in the study

We hypothesise that structured ACP by a trained nurse, in collaboration with the patient's physician, can improve quality of end-of-life care communication, as well as quality of end-of-life care and quality of dying for patients with COPD. In addition, we hypothesise that structured ACP will not result in increased symptoms of anxiety or depression.

\section{METHODS AND ANALYSIS}

\section{Study design}

A multicentre, cluster randomised controlled trial has been designed. Patients with COPD who were recently discharged after an exacerbation will be recruited in an academic hospital and two general hospitals in the Netherlands. Patients in the intervention group will receive an ACP intervention within four weeks after discharge. The control group will receive usual care. The intervention and control group will be assessed at baseline and six and 12 months after enrolment (Figure 1).

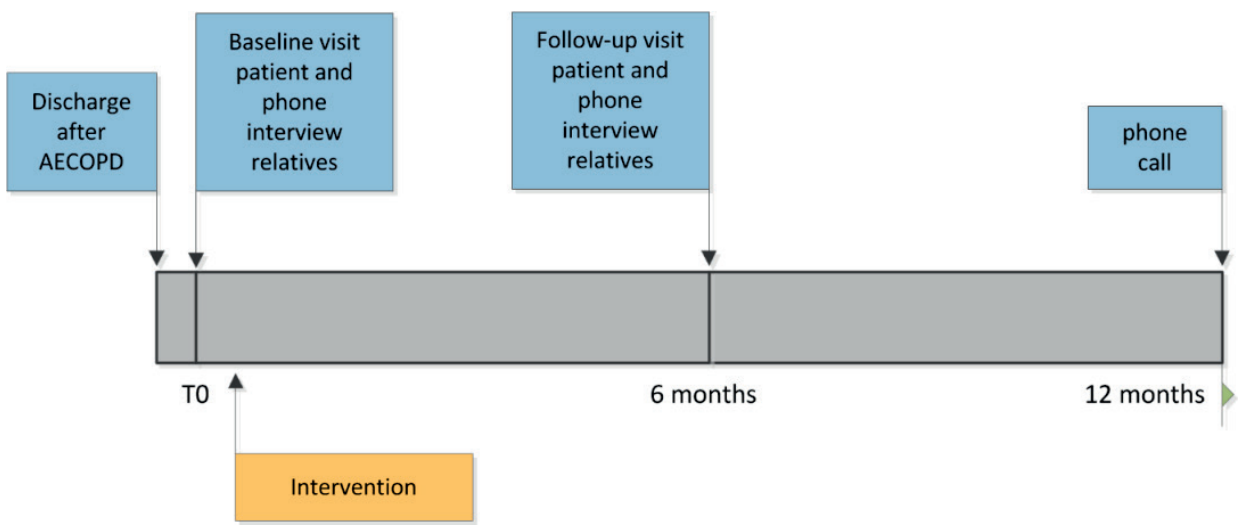

Figure 1. Timing of the interviews and intervention: all patients receive data collection in the blue boxes, only patients of clinicians randomised to the intervention group receive the intervention.

\section{Eligibility criteria}

Eligible patients are those who satisfy all of the following criteria:

1. A diagnosis of severe to very severe COPD (GOLD grade III or IV). ${ }^{14}$

2. Discharged after hospital admission for a COPD exacerbation.

3. At least one loved one, who will participate in the study. 
Patients will be excluded if they are unable to complete the questionnaires because of cognitive impairment or if they are unable to speak or understand Dutch.

\section{Intervention}

Respiratory nurse specialists will receive a two-day training to be able to perform the intervention. The training will consist of theory about the importance and benefits of ACP for patients with COPD and their loved ones. End-of-life care communication skills and the structured ACP session during the study will be taught and practiced. The participants will be asked to perform ACP with a standardized patient. Investigators will use a checklist to confirm adherence to the standardized protocol for ACP and provide certification if participants have achieved competency.

Certified respiratory nurse specialists will provide the structured ACP session in the patient's home environment in the presence of the patient and his or her loved one(s) within 4 weeks after discharge. The session will be prepared with the chest physician in advance. The structured ACP session will pay attention to several elements (Table 1). The content will be adapted to the patient's needs. The duration will be about 1.5 hours. Respiratory nurse specialists will be supervised by the research project team regularly to guarantee the quality of the structured ACP session.

As part of the structured ACP session, the respiratory nurse specialists will complete, together with the patient, a feedback form showing patient's: general goals of care; preferences for life-sustaining treatments (cardiopulmonary resuscitation (CPR), non-invasive positive pressure ventilation, and mechanical ventilation); and questions and concerns regarding end-of-life care. This feedback form will be provided to the patient, the chest physician and the general practitioner. Finally, the patients will receive a brochure about palliative care for patients with COPD. This brochure is based on the Dutch guideline 'palliative care for patients with COPD' and was developed for patients and their loved ones by the Lung Foundation Netherlands.

Table 1. Elements of structured ACP intervention

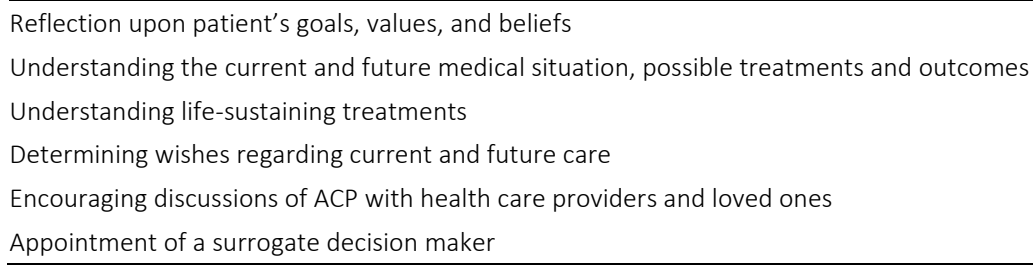




\section{Outcomes}

The following variables will be recorded during home visits at baseline and after six months in patients in the intervention and usual care group: demographics (including age, sex, educational level, religion); smoking history; medical history; current medication; post-bronchodilator forced expiratory volume in the $1 \mathrm{~s}$; use of longterm oxygen therapy; and use of non-invasive positive pressure ventilation.

\section{Primary outcomes}

The primary outcomes for all patients are:

- Quality of communication about end-of-life care (Quality of Communication $(\mathrm{QOC}))^{15}$;

- Symptoms of anxiety and depression (Hospital Anxiety and Depression Scale $(\mathrm{HADS}))^{16}$;

For patients who died during the study period, primary outcomes are:

- Quality of end-of-life care (Toolkit After-Death Bereaved Family Member Interview) ${ }^{17}$;

- Quality of death and dying (Quality of Death and Dying (QODD)) $)^{18}$.

\section{Secondary outcomes}

The secondary outcomes are:

- Concordance between patient's preferences for end-of-life care (patient's preferences for CPR and mechanical ventilation; End-of-life Preferences Interview $(E L P I)^{19}$ and received end-of-life care (life-sustaining treatment before dying; Toolkit After-Death Bereaved Family Member Interview) ${ }^{17}$;

- Psychological distress in bereaved family members of deceased patients with COPD (HADS ${ }^{16}$; Inventory of Complicated Grief $\left.(I C G)^{20}\right)$.

Patients in the intervention and usual care group will receive a phone call 12 months after enrolment to assess survival state. If the patient cannot be reached, the participating family members will be contacted. If the patient has deceased during the study period, a bereavement interview will be conducted with the participating family members. The following outcomes will be assessed: QODD ${ }^{18}$; Toolkit After-Death Bereaved Family Member Interview ${ }^{17} ; \mathrm{ICG}^{20}$; and HADS ${ }^{16}$. 
Questionnaires that were not available in Dutch (QOC, ELPI, and Toolkit After-Death Bereaved Family Member Interview) have been translated into Dutch using a forward-backward translation procedure.

\section{Sample size}

A sample size calculation with a level of significance of $5 \%$ and a power of $90 \%$ has shown that 53 patients per group are needed in order to detect a difference of 1 point change in QOC end-of-life care domain score (SD estimated as 2.53 points) ${ }^{15}$ between the intervention and control group. A sample size calculation with a level of significance of $5 \%$ and power of $90 \%$ has shown that 32 deceased patients per group are needed in order to detect a difference of 10 points change in QODD scores between the intervention and control group. Since we expect a mortality rate within one year of about $23 \%$ and a dropout rate of about $10 \%$ because of other reasons, we will include 150 patients per group.

\section{Recruitment and randomization}

Patients will be informed about the study during their hospital admission for a COPD exacerbation. After discharge, the potential participant will receive a phone call. If the patient wants to participate, an appointment for a first home visit will be made. Informed consent will be obtained at the start of this visit. Each subject will be assigned a study identification number. A list with identification codes linking the participant's names to participant's identification numbers will be stored in a limited access space.

Chest physicians of participating hospitals will be randomized into an intervention or usual care group using sealed opaque envelopes. We will cluster for chest physician to prevent cross-contamination between the intervention and usual care group. Participating patients and their family members will receive the intervention or usual care, depending on the randomization of their chest physician. The researcher who will visit and phone the participants will not offer ACP.

\section{Data management and statistical analysis}

The data will be screened for outliers and missing values. These values will be excluded by list wise deletion. Missing data will be minimised because patients will be visited at home for completing the questionnaires and the researcher will check if all the questions have been answered. The study variables will be tested for normal- 
ity. Demographic variables (such as age, sex, educational level, religion, and smoking history) will be compared between patients in the intervention group and control group, using independent-samples t tests or Mann-Whitney $U$ tests, as appropriate, for continuous variables and $\mathrm{X}^{2}$ tests for categorical variables.

The differences in the primary outcome measures between the intervention and the usual care group will be compared using independent-sample t tests or MannWhitney $U$ tests, as appropriate. The Wilcoxon signed rank test will be used to compare changes in the primary outcome measures within the intervention and usual care group. Multivariate regression models will be developed to compare changes in the primary and secondary outcome measures between the intervention and control group while clustering by physician and controlling for possible confounders. Finally, concordance between the patient's preferences for end-of-life care and the end-of-life care received will be calculated using Intraclass Correlation Coefficients (ICC) for continuous variables and Cohen's k for categorical variables.

All statistical analyses will be performed using statistics software (SPSS V.21.0 for Windows, Chicago, Illinois, USA) and STATA V.11.1 (StataCorp LP, College Station, Texas, USA) for clustered regression analysis. A priori, a two-tailed p-value of $<0.05$ was considered as significant.

\section{Dissemination}

The study will be monitored according to the guidelines of the Dutch Federation of University Medical Centres (NFU) and will be conducted in accordance with the Medical Research Involving Human Subjects Act (WMO). The results will be submitted for publication in peer-reviewed journals and will be presented at (inter)national conferences. Participants will be informed about the results of the study. The results of this project provide direction for further development of palliative care for patients with COPD.

\section{DISCUSSION}

The present study has been designed to examine whether and to what extent structured ACP by a trained nurse, in collaboration with the chest physician, can improve outcomes for patients with advanced COPD and their family. The study has several strengths and limitations which will be described below. 
Strengths

The current project is designed to improve ACP by overcoming the previously reported physician-endorsed barriers towards ACP. The most common barrier to communication about end-of-life care, endorsed by physicians, is lack of time. ${ }^{12}$ The present study will overcome this barrier, because the intervention will be delivered by trained respiratory nurses. Nurses have specific communication skills important for end-of-life care communication, such as listening to patients, being responsive to emotional needs, treating the whole person and respecting patients' cultural and religious beliefs. ${ }^{21}$ Another barrier frequently endorsed by physicians is their assumption that patients are not ready to talk about end-of-life care. ${ }^{12}$ However, research has shown that patients with severe-to-very severe COPD have clear preferences concerning life-sustaining treatments and are willing to discuss end-of-life care. ${ }^{11,22}$ These discussions about end-of-life care are particularly important for patients with COPD, because they follow a disease trajectory characterised by a gradual decline in health status and punctuated by exacerbations. ${ }^{23}$ Although survival in patients with COPD is hard to predict ${ }^{24}$, research has shown that exacerbations are associated with an increased risk of dying. ${ }^{25}$ Patients who survived a hospitalization for an exacerbation often experience an increase in the intensity of dyspnoea and had a poor quality of life. ${ }^{26,27}$ Therefore, clinicians see exacerbations as a clinical event that defines an important transition in the course of the disease and is therefore a moment to initiate ACP. ${ }^{28}$ In addition, patients who were hospitalized for an exacerbation describe the hospital admission itself as chaotic, but are willing to discuss their preferences for end-of-life care after discharge. ${ }^{29}$ Consequently, an approach may be to discuss ACP after discharge.

The present study also has some methodological strengths. First, the present study is a randomised controlled trial. This study design in general has good validity and causal conclusions can be drawn. ${ }^{30}$ Second, patients will be recruited in one academic and two general hospitals in the Netherlands to guarantee internal and external validity. Finally, we will perform cluster-analysis to prevent crosscontamination between the intervention and usual care group and allocation is concealed using sealed opaque envelops in order to prevent systematic biases.

\section{Limitations}

The present study has the following limitations: First, it may be possible that eligible patients and family members who refuse participation in this study are less willing to discuss issues concerning end-of-life care than participating patients and family 
members. Demographics will be collected from eligible patients and family members who refuse participation in the study for comparison with participating patients and family members. However, since these patients may also refuse an ACP intervention in clinical practice, this may mitigate the importance of this limitation. Second, drop-out is to be expected and is unavoidable in a longitudinal study including patients with severe disease. We expect about $23 \%$ of the patients to die during the study period. ${ }^{31}$ In addition, we expect about $10 \%$ to withdraw because of other reasons. ${ }^{22}$ Third, in the present study the perception of the patient of communication about end-of-life care will be assessed. The present project does not provide objective measures for QOC. In addition, the present project assesses the family members' perception of quality of end-of-life care and quality of dying and does not provide objective measures for quality of end-of-life care and quality of dying. However, we believe that the perception from the patient and his or her family members is the most important construct with respect to end-of-life care. Moreover, validated instruments will be used to assess the patient perception from QOC about end-of-life care ${ }^{15}$ and the family members' perception of quality of endof-life care and quality of death and dying. ${ }^{17,18}$ Fourth, quality of end-of-life care and quality of dying will be assessed retrospectively. We do not assess prospectively quality of end-of-life care in terminally ill patients. Prospectively identifying terminally ill patients with COPD is extremely difficult. ${ }^{10}$ Moreover, we want to avoid extra burden for dying patients. However, retrospective assessments may be altered by grief or recall difficulties. ${ }^{32}$ This should be taken into account in interpreting the results. Fifth, it may be possible that QOC about end-of-life care at baseline is different between the physicians in the intervention group and physicians in the usual care group. Therefore, data-analysis will correct for baseline QOC scores. Sixth, it may be possible that participants in the usual care group will be stimulated to discuss their life-sustaining treatment preferences or end-of-life care due to the assessment of their preferences during the study period. However, a prior study suggested that these questionnaires do not have a significant effect on discussions about end-of-life care. ${ }^{33}$ Finally, the current intervention consists of a single session with a trained respiratory nurse specialist and providing a feedback form. We acknowledge that ACP should not be a single intervention, but should be an ongoing process between patients, their loved ones and professional caregivers during the course of the disease. However, the aim of the intervention in the present study is to facilitate the on-going process of ACP between patients, families and physicians. 


\section{Clinical consequences}

The present study will examine the effects of structured ACP by a trained respiratory nurse. When this relatively simple intervention is able to improve outcomes for patients regarding end-of-life care and their loved ones, the project can be followed by implementation of ACP in regular clinical care. In addition, the current project provides recommendations for guidelines on palliative care in COPD. Moreover, if the current intervention is able to improve outcomes for patients with COPD and their families, this programme can possibly be implemented for other patients with advanced chronic life-limiting diseases, like congestive heart failure or idiopathic pulmonary fibrosis. Indeed, mortality rates are also high in these patient populations. $^{34,35}$

\section{Conclusion}

To date, ACP for patients with severe-to-very severe COPD is uncommon and poorly carried out. The present study aims to improve quality of end-of-life care communication, as well as quality of end-of-life care and quality of dying for patients with COPD using structured ACP by a trained nurse, in collaboration with the patient's chest physician. This study is necessary to develop an evidence based ACP programme in the Netherlands. Here, the study protocol is described and a preliminary analysis of the possible strengths and weaknesses is outlined. 


\section{REFERENCES}

1. Barnes KA, Barlow CA, Harrington J, et al. Advance care planning discussions in advanced cancer: analysis of dialogues between patients and care planning mediators. Palliat Support Care 2011;9:73-9.

2. Patel K, Janssen DJ, Curtis JR. Advance care planning in COPD. Respirology 2012;17:72-8.

3. Clayton JM, Butow PN, Tattersall MH, et al. Randomized controlled trial of a prompt list to help advanced cancer patients and their caregivers to ask questions about prognosis and end-of-life care. J Clin Oncol 2007;25:715-23.

4. Dexter PR, Wolinsky FD, Gramelspacher GP, et al. Effectiveness of computer-generated reminders for increasing discussions about advance directives and completion of advance directive forms. A randomized, controlled trial. Ann Intern Med 1998;128:102-10.

5. Detering KM, Hancock AD, Reade MC, Silvester W. The impact of advance care planning on end of life care in elderly patients: randomised controlled trial. BMJ 2010;340:c1345.

6. Kirchhoff KT, Hammes BJ, Kehl KA, Briggs LA, Brown RL. Effect of a disease-specific advance care planning intervention on end-of-life care. J Am Geriatr Soc 2012;60:946-50.

7. Morrison RS, Chichin E, Carter J, Burack O, Lantz M, Meier DE. The effect of a social work intervention to enhance advance care planning documentation in the nursing home. J Am Geriatr Soc 2005;53:290-4.

8. Bischoff KE, Sudore R, Miao Y, Boscardin WJ, Smith AK. Advance care planning and the quality of end-oflife care in older adults. J Am Geriatr Soc 2013;61:209-14.

9. Lopez AD, Shibuya K, Rao C, et al. Chronic obstructive pulmonary disease: current burden and future projections. Eur Respir J 2006;27:397-412.

10. Claessens MT, Lynn J, Zhong Z, et al. Dying with lung cancer or chronic obstructive pulmonary disease: insights from SUPPORT. Study to Understand Prognoses and Preferences for Outcomes and Risks of Treatments. J Am Geriatr Soc 2000;48:S146-53.

11. Janssen DJ, Spruit MA, Schols JM, Wouters EF. A call for high-quality advance care planning in outpatients with severe COPD or chronic heart failure. Chest 2011;139:1081-8.

12. Knauft E, Nielsen EL, Engelberg RA, Patrick DL, Curtis JR. Barriers and facilitators to end-of-life care communication for patients with COPD. Chest 2005;127:2188-96.

13. Reinke LF, Shannon SE, Engelberg RA, Young JP, Curtis JR. Supporting hope and prognostic information: nurses' perspectives on their role when patients have life-limiting prognoses. J Pain Symptom Manage 2010;39:982-92.

14. Vestbo J, Hurd SS, Rodriguez-Roisin R. The 2011 revision of the global strategy for the diagnosis, management and prevention of COPD (GOLD)--why and what? Clin Respir J 2012;6:208-14.

15. Engelberg R, Downey L, Curtis JR. Psychometric characteristics of a quality of communication questionnaire assessing communication about end-of-life care. J Palliat Med 2006;9:1086-98.

16. Zigmond AS, Snaith RP. The hospital anxiety and depression scale. Acta Psychiatr Scand 1983;67:361-70.

17. Teno JM, Clarridge B, Casey V, Edgman-Levitan S, Fowler J. Validation of Toolkit After-Death Bereaved Family Member Interview. J Pain Symptom Manage 2001;22:752-8.

18. Downey L, Curtis JR, Lafferty WE, Herting JR, Engelberg RA. The Quality of Dying and Death Questionnaire (QODD): empirical domains and theoretical perspectives. J Pain Symptom Manage 2010;39:9-22.

19. Borreani C, Brunelli C, Miccinesi G, et al. Eliciting individual preferences about death: development of the End-of-Life Preferences Interview. J Pain Symptom Manage 2008;36:335-50.

20. Prigerson HG, Maciejewski PK, Reynolds CF, 3rd, et al. Inventory of Complicated Grief: a scale to measure maladaptive symptoms of loss. Psychiatry Res 1995;59:65-79.

21. Reinke LF, Shannon SE, Engelberg R, Dotolo D, Silvestri GA, Curtis JR. Nurses' identification of important yet under-utilized end-of-life care skills for patients with life-limiting or terminal illnesses. J Palliat Med 2010;13:753-9.

22. Janssen DJ, Spruit MA, Schols JM, et al. Predicting changes in preferences for life-sustaining treatment among patients with advanced chronic organ failure. Chest 2012;141:1251-9.

23. Lorenz KA, Shugarman LR, Lynn J. Health care policy issues in end-of-life care. J Palliat Med 2006;9:73148. 
24. Fox E, Landrum-McNiff K, Zhong Z, Dawson NV, Wu AW, Lynn J. Evaluation of prognostic criteria for determining hospice eligibility in patients with advanced lung, heart, or liver disease. SUPPORT Investigators. Study to Understand Prognoses and Preferences for Outcomes and Risks of Treatments. JAMA 1999;282:1638-45.

25. Murray SA, Kendall M, Boyd K, Sheikh A. Illness trajectories and palliative care. BMJ 2005;330:1007-11.

26. Rocker GM, Dodek PM, Heyland DK. Toward optimal end-of-life care for patients with advanced chronic obstructive pulmonary disease: insights from a multicentre study. Can Respir J 2008;15:249-54.

27. Lynn J, Ely EW, Zhong Z, et al. Living and dying with chronic obstructive pulmonary disease. J Am Geriatr Soc 2000;48:S91-100.

28. Reinke LF, Engelberg RA, Shannon SE, et al. Transitions regarding palliative and end-of-life care in severe chronic obstructive pulmonary disease or advanced cancer: themes identified by patients, families, and clinicians. J Palliat Med 2008;11:601-9.

29. Seamark D, Blake S, Seamark C, et al. Is hospitalisation for COPD an opportunity for advance care planning? A qualitative study. Prim Care Respir J 2012;21:261-6.

30. Richter B, Berger M. Randomized controlled trials remain fundamental to clinical decision making in Type II diabetes mellitus: a comment to the debate on randomized controlled trials (For debate) [corrected]. Diabetologia 2000;43:254-8.

31. Groenewegen $\mathrm{KH}$, Schols AM, Wouters EF. Mortality and mortality-related factors after hospitalization for acute exacerbation of COPD. Chest 2003;124:459-67.

32. Higginson I, Priest P, McCarthy M. Are bereaved family members a valid proxy for a patient's assessment of dying? Soc Sci Med 1994;38:553-7.

33. Au DH, Udris EM, Engelberg RA, et al. A randomized trial to improve communication about end-of-life care among patients with COPD. Chest 2012;141:726-35.

34. McMurray JJ, Adamopoulos S, Anker SD, et al. ESC guidelines for the diagnosis and treatment of acute and chronic heart failure 2012: The Task Force for the Diagnosis and Treatment of Acute and Chronic Heart Failure 2012 of the European Society of Cardiology. Developed in collaboration with the Heart Failure Association (HFA) of the ESC. Eur J Heart Fail 2012;14:803-69.

35. Barlo NP, van Moorsel CH, van den Bosch JM, Grutters JC. Predicting prognosis in idiopathic pulmonary fibrosis. Sarcoidosis Vasc Diffuse Lung Dis 2010;27:85-95. 



\section{A cluster-randomized trial of a nurse-led advance care planning session in patients with COPD and their loved ones}
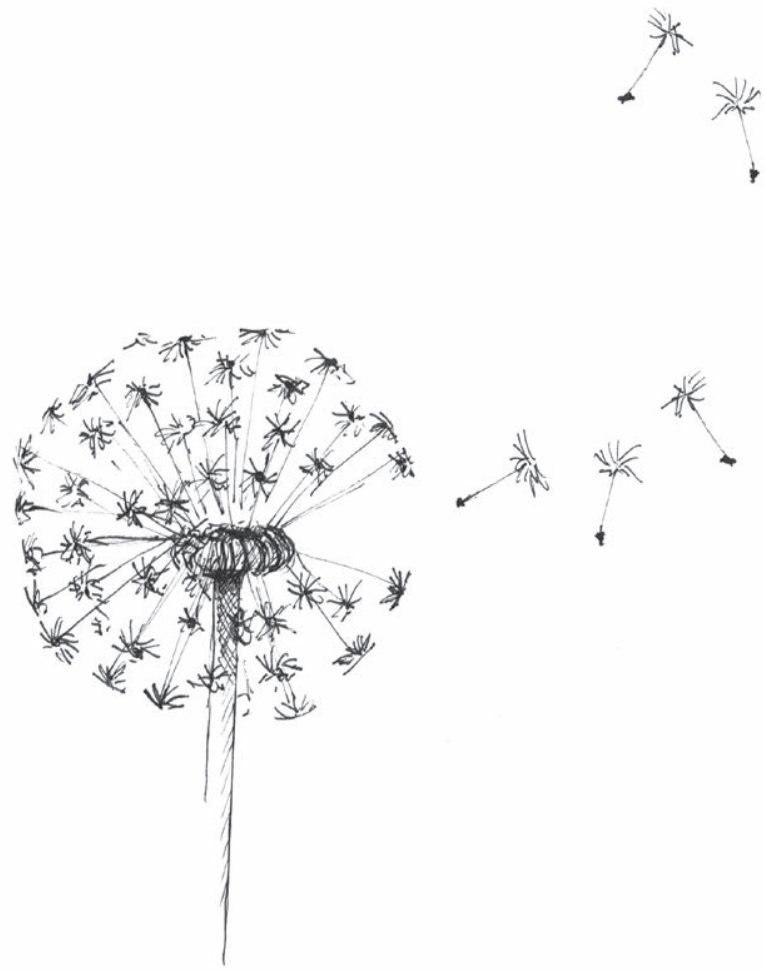

Carmen H.M. Houben, Martijn A. Spruit, Hans Luyten, Herman-Jan Pennings, Vivian E.M. van den Boogaart, Jacques P.H.M. Creemers, Geertjan Wesseling, Emiel F.M. Wouters, and Daisy J.A. Janssen.

Submitted 


\section{ABSTRACT}

Rationale: Advance Care Planning (ACP) is uncommon in patients with COPD.

Objectives: To assess whether a nurse-led ACP-intervention can improve quality of patient-physician end-of-life care communication in patients with COPD. Furthermore, the influence of an ACP-intervention on symptoms of anxiety and depression in patients and loved ones was studied.

Methods: A multicenter cluster randomized controlled trial (RCT) in patients with advanced COPD was performed. Patients were assigned to an intervention or control group, depending on the randomization of their chest physician. The intervention group received an 1.5-hours structured nurse-led ACP-session. Outcomes were: quality of patient-physician end-of-life care communication (end-of-life subscale of the Quality of Communication (QOC) Questionnaire), symptoms of anxiety and depression (Hospital Anxiety and Depression Scale (HADS)) in patients and loved ones and prevalence of ACP-discussions six months after baseline.

Measurements and main results: 171 patients were enrolled (92 intervention; 79 control).

The improvement of quality of patient-physician end-of-life care communication was significantly higher in the intervention group compared to the control group $(B=1.81$ points; $95 \% \mathrm{Cl}[0.88-2.83] ; p=.001)$. At follow-up symptoms of anxiety were significantly lower in loved ones in the intervention group compared to the control group ( $\mathrm{B}=-1.13 ; 95 \% \mathrm{Cl}[-2.18--0.08]$; $\mathrm{p}=.04)$. Symptoms of anxiety in patients, and symptoms of depression in both patients and loved ones were comparable at follow-up ( $p>0.05$ ). The ACP-intervention was significantly associated with the occurrence of an ACP-discussion with physicians within 6 months (intervention group: 52.6\%; control group: $28.4 \%$; $=.003$ ).

Conclusion: A nurse-led ACP-intervention improves patient-physician end-of-life care communication without causing psychosocial distress in both patients and loved ones. 


\section{INTRODUCTION}

Advance care planning (ACP), the continuous process of timely communication between patients, healthcare professionals, and loved ones, about patients' personal values, life goals, and preferences for future medical care ${ }^{1}$, is uncommon in patients with chronic obstructive pulmonary disease (COPD). ${ }^{2}$ Previous research has shown that only $5.9 \%$ of patients with advanced COPD reported a discussion with their chest physician about preferences for life-sustaining treatments. ${ }^{2}$ Important physician-reported barriers for ACP in COPD are lack of time ${ }^{3,4}$, the unpredictable disease trajectory of COPD which makes it difficult for physicians to choose the appropriate timing for ACP, and healthcare professionals' fear of causing psychosocial distress.

We designed this trial to assess whether a structured, 1.5-hours, nurse-led ACPsession can improve quality of end-of-life care communication between physicians and patients with COPD. Secondary objectives were to study changes in symptoms of anxiety and depression of patients and loved ones and the prevalence of ACPdiscussions with physicians six months after ACP.

\section{METHODS}

\section{Design and setting}

This cluster-randomized controlled trial recruited patients from one academic and three general hospitals in the Netherlands between June 2013 and October 2015. Patients in the intervention group received a 1.5-hours nurse-led ACP-session and patients in the control group received usual care. The methodology of this study was described in detail previously. ${ }^{5}$ The Medical Ethical Committee of the Catharina Hospital Eindhoven (NL42437.060.12) approved this trial and the study was registered at the Dutch Trial Register (NTR3940).

\section{Participants}

The study population consisted of a consecutive sample of patients with advanced COPD (Global initiative for chronic Obstructive Lung Disease (GOLD) stage III, IV or quadrant $D$ with $m M R C$-score $\geq 2)^{6}$ discharged after hospital admission for an acute COPD exacerbation. During the study patients who recently started on long-term oxygen therapy were also included in order to enhance the recruitment rate. Pa- 
tients were asked to identify one to four loved ones for participation in the study. Exclusion criteria were: unable to complete questionnaires because of cognitive impairment or unable to speak and/or understand Dutch. All participants provided written informed consent.

\section{Randomization}

Cluster random sampling was used to assign chest physicians to either the intervention or control group using sealed opaque envelopes. Participating patients received the intervention or usual care, depending on the randomization of their chest physician.

\section{Intervention}

Eight respiratory nurse specialists received a two-day training, starting with theoretical background of the importance and benefits of ACP for patients with COPD and their loved ones. End-of-life care communication skills and the structured ACPsession during the study were taught and practiced. Finally, the nurses were asked to perform an ACP-session in which a specific case was simulated. Investigators used a 21-item checklist to confirm adherence to the standardized protocol for ACP. Only nurses with 17 or more adequately performed items on the checklist were certified. The training was pilot-tested with a group of eight nurses from a center not recruiting patients for the study and optimized. The training was delivered by an elderly care physician and medical psychologist. After preparation with the chest physician, nurses provided an ACP-session in the patient's home environment in the presence of the patient and loved one(s) within four weeks after discharge or soon after the start of long-term oxygen therapy at home. The 1.5hour intervention included several elements, including reflection on patient's goals, values, and beliefs; understanding the current and future medical situation, possible treatment and outcomes; understanding life-sustaining treatments; determining wishes regarding current and future care; encouraging discussions concerning ACP with healthcare providers and loved ones; and appointment of a surrogate decision maker. The intervention was adapted to the patient's needs, by titrating information to the patient's needs and paying attention to questions and concerns of both patients and loved ones. After the ACP-session, nurses completed a feedback form with the patient, which summarized patient's preferences for end-of-life care and end-of-life care communication, and remaining questions (e-Figure 1). The feedback form was provided to the patient, chest physician and general practitioner 
(GP). Finally, patients received a brochure about palliative care in COPD developed by the Netherlands Lung Foundation.

\section{Procedures}

Patients were informed about the study during their hospital admission for a COPD exacerbation or during a regular clinical visit after a recent start of oxygen therapy. After review of eligibility and consent, all patients and their loved ones were visited at home by a researcher $(\mathrm{CH})$ to collect baseline date. Afterwards, patients in the intervention group received the intervention and patients in the control group received care as usual.

\section{Outcome measures}

The primary outcome measure was quality of quality of end-of-life care communication six months after baseline, which was assessed using the end-of-life subscale of the Quality of Communication (QOC) questionnaire. ${ }^{7}$ The QOC questionnaire consists of 13 items that form two domains: general communication and end-of-life care communication. Patients were asked to rate the communications skills of their chest physician. The subscale end-of-life care communication comprises seven items and the subscale general communication comprises six items. Each item is rated on a scale of 0 ("the very worst") to 10 ("the very best"). In addition, patients were offered two additional response options: "My doctor didn't do this" and "Don't know". The domain scores were calculated from the average from all endorsed items. This score ranges from 0 ("worst") to 10 ("best"). The answer "My doctor didn't do this" was replaced by a score of 0 and "Don't know" (26 items (2.2\%) from the domain end-of-life care communication) was replaced by the median domain score of the valid items for the individual, as suggested by the QOC questionnaire developers. ${ }^{7,8}$ For 26 items (2.2\%) from the domain end-of-life care communication on both baseline and follow-up the value of "don't know" was replaced by the median domain score of the valid items for the individual. The QOC questionnaire is a validated instrument and meets the standards of scale measurement, including good construct validity and internal consistency (Cronbach's $\alpha$ $\geq 0.79){ }^{7}$ A priori, we defined a 1 point change in QOC end-of-life care domain score as clinically relevant.

Symptoms of anxiety and depression were measured at baseline and six months in patients and loved ones using the Hospital Anxiety and Depression Scale (HADS) ${ }^{9}$. The HADS is divided into an anxiety (HADS-A) and depression (HADS-D) subscale, 
respectively. Total scores for each subscale can range from 0 (=optimal) to 21 (=worst) points. A score equal to or greater than 10 for anxiety and/or depression has been defined as indicative for the presence of clinically relevant symptoms of anxiety and/or depression. ${ }^{9}$ A priori, we defined a 1.5 point change in HADS-A or HADS-D score as clinically relevant. ${ }^{10}$

To measure prevalence of ACP-discussions, patients were asked at baseline and after six months whether they had a discussion about end-of-life care preferences with a healthcare professional and if so, with which healthcare professional they discussed their preferences.

Furthermore, the following other data were collected during home visits at baseline and six months after enrolment in patients in the intervention and control group: demographics (including age, sex, marital status, educational level, and religion); Body Mass Index (BMI); smoking history; self-reported comorbidities (Charlson Comorbidity Index $)^{11}$; number of hospital admissions during the 6-month follow-up period; post bronchodilator forced expiratory volume in the 1s (FEV1); use of longterm oxygen therapy and/or non-invasive positive pressure ventilation; previous ACP-discussions with healthcare professionals; disease-specific health status (COPD Assessment Test $(\mathrm{CAT}))^{12}$; generic health status (36-Item Short Form Health Survey $(S F-36))^{13}$; care dependency (Care Dependency Scale $\left.(C D S)\right)^{14}$; preferences for cardiopulmonary resuscitation (CPR) and mechanical ventilation (MV) ${ }^{15}$.

\section{Statistical analyses}

Categorical variables are described as frequencies, and continuous variables were tested for normality and presented as mean (SD) or median (interquartile range $(\mathrm{IQR})$ ). Baseline characteristics were compared using unpaired t-tests or MannWhitney U-tests for continuous variables and Chi-squared tests for categorical variables. Multilevel linear regression analysis was used to compare the mean difference score of the QOC end-of-life care communication domain score in the intervention and control group (random intercepts models were fitted). The mean difference score is defined as the difference between baseline and 6-month follow-up. By means of multilevel analysis the nesting of patients within chest physicians was taken into account and variation among physicians with regard to the outcome measures could readily be assessed. Age was included as possible confounder into the regression models for quality of end-of-life care communication and general communication. To assess differences between the four hospitals involved, three dummy variables were included as covariates as well. A priori, we defined a 1 point 
change in QOC end-of-life care communication domain score as clinically relevant. In addition, for each item of the QOC end-of-life care communication domain the proportion of patients that discussed this item was compared at baseline and 6month follow-up between intervention and control group using log-binomial models. To compare symptoms of anxiety and depression at 6-month follow-up between the intervention and usual care group linear regression analyses were used in both patients and loved ones. The nesting of patients within chest physicians was taken into account by means of multilevel analysis. Symptoms of anxiety or depression at baseline were included as covariate in both patients and loved ones. In addition, age was included as covariate in patients and gender as covariate in loved ones, because these differed between the intervention and control group. When the variance on physician-level was found to be not significant the analysis was repeated as a linear regression analysis.

The frequency of self-reported ACP-discussions between the intervention and control group at 6-month follow-up was compared using a log-binomial model. Statistics were compiled using SPSS, version 23.0 (SPSS, Inc; Chicago, Illinois) and MLWin, version 3.00. A priori, a two-sided level of significance was set at $p<0.05$. All analyses were done by intention to treat, using all available data from randomly assigned patients according to group assignment. 


\section{RESULTS}

\section{Baseline characteristics}

616 of the 732 screened patients (84.2\%) were eligible, of which 545 patients were informed about the study and 171 patients participated (31.4\%). 92 patients were randomized to the ACP-intervention group and 79 to the control group (Figure 1). 170 patients (99.4\%) identified participating loved one(s). 143 patients (84.1\%) identified one loved one, 24 patients (14.1\%) identified two loved ones, two patients $(1.2 \%)$ identified three loved ones and one patient $(0.6 \%)$ identified four loved ones. 111 loved ones of patients randomized to the intervention group and 90 loved ones of patients randomized to the control group were included. At baseline, patients in the ACP-intervention group were younger than controls and had discussed ACP less frequently. Loved ones in the ACP-intervention group were more often male than loved ones in the control group. All other baseline characteristics were comparable between both groups (Table 1-3).

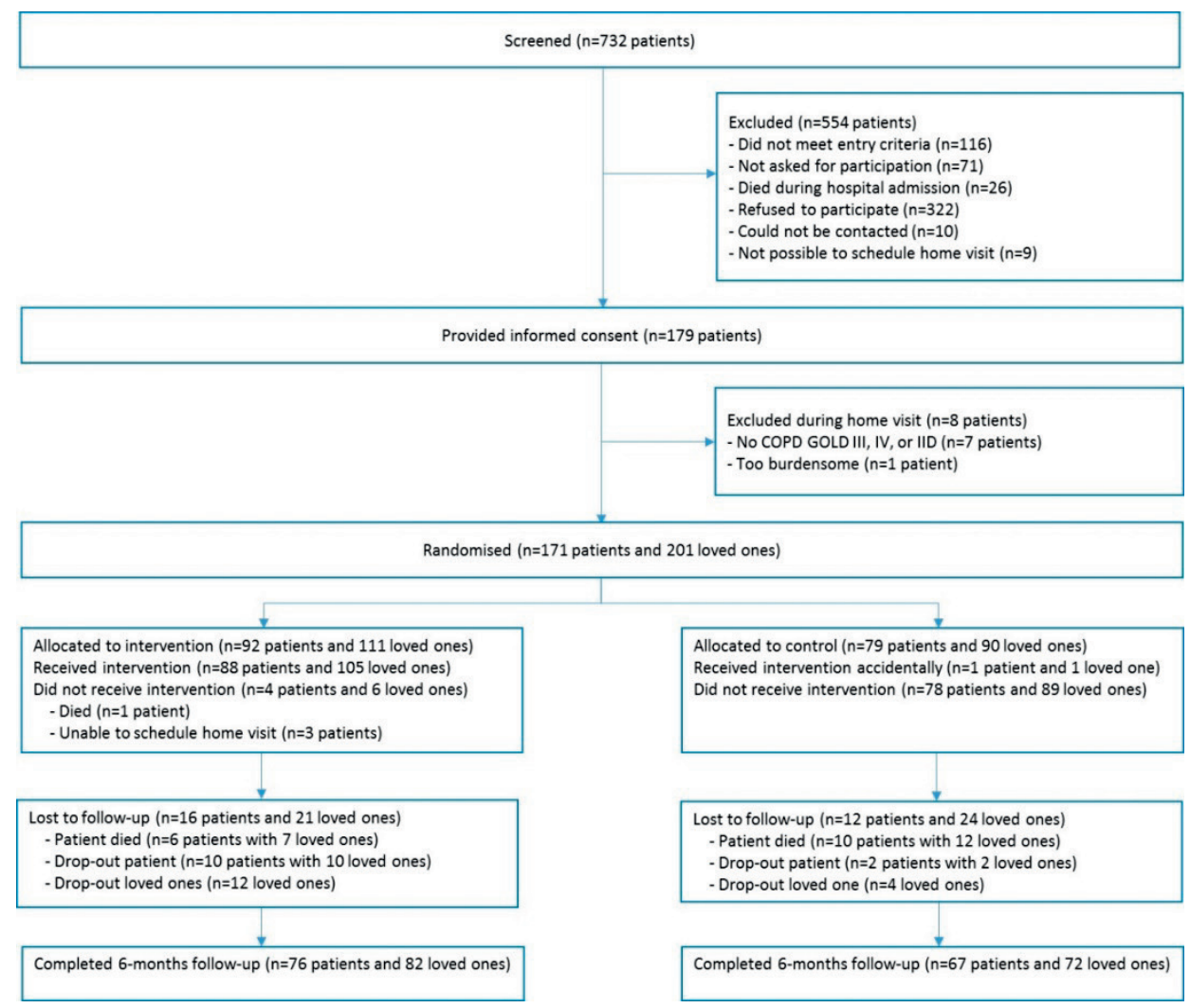

Figure 1. Flowchart 
Table 1. Baseline patient characteristics

\begin{tabular}{|c|c|c|}
\hline & Intervention group ( $\mathrm{n=92}$ ) & Control group $(n=79)$ \\
\hline Gender (male), n (\%) & $46(50.0)$ & $45(57.0)$ \\
\hline Age (years), mean (SD) $)^{\S \S}$ & $65.9(9.1)^{*}$ & $69.7(9.0)$ \\
\hline $\mathrm{BMI}\left(\mathrm{kg} / \mathrm{m}^{2}\right)$, mean (SD) & $25.3(6.1)$ & $26.9(6.1)$ \\
\hline Marital status (married/living with partner), n (\%) & $59(64.1)$ & $54(68.4)$ \\
\hline Education (high school or more), n (\%) & $66(71.7)$ & $61(77.2)$ \\
\hline Current smokers, n (\%) & $17(18.5)$ & $12(15.2)$ \\
\hline $\mathrm{FEV}_{1}(\%$ predicted), mean (SD) & $43.7(17.1)^{\dagger}$ & $43.3(14.4)^{\ddagger}$ \\
\hline Charlson index (points), mean (SD) & $2.24(1.23)$ & $2.46(1.54)$ \\
\hline Long-term oxygen therapy, n (\%) & $38(41.3)$ & $34(43.0)$ \\
\hline Non-invasive positive pressure ventilation, $\mathrm{n}(\%)$ & $10(10.9)$ & $6(7.6)$ \\
\hline Religious affiliation ${ }^{\S}, \mathrm{n}(\%)$ & $55(59.8)$ & $51(64.6)$ \\
\hline Previous ACP, $\mathrm{n}(\%)^{\S \S}$ & $13(14.1)^{*}$ & $27(34.2)$ \\
\hline COPD Assessment Test (points), mean (SD) & $23.0(6.7)^{\|}$ & $22.8(6.7)$ \\
\hline Care Dependency Scale (points), mean (SD) & $65.1(8.5)^{\|}$ & $64.6(10.0)^{* *}$ \\
\hline HADS-A score (points), mean (SD) & $6.9(4.7)^{+\dagger}$ & $6.0(4.5)$ \\
\hline HADS-D score (points), mean (SD) & $6.6(4.2)^{++}$ & $6.7(4.1)$ \\
\hline SF-36 physical component score (points), mean (SD) & $20.1(9.9)$ & $20.0(9.8)$ \\
\hline SF-36 mental component score (points), mean (SD) & $40.8(14.9)$ & $41.1(14.9)$ \\
\hline Prefers CPR at baseline, $\mathrm{n}(\%)$ & $50(54.3)$ & $35(44.3)$ \\
\hline Prefers MV at baseline, $\mathrm{n}(\%)$ & $29(31.5)$ & $18(22.8)$ \\
\hline \multicolumn{3}{|l|}{ Moment of recruitment } \\
\hline - Hospitalization exacerbation COPD, n (\%) & $90(97.8)$ & $76(96.2)$ \\
\hline - Initiation oxygen therapy, n (\%) & $2(2.2)$ & $3(3.8)$ \\
\hline Loved ones & Intervention group $(n=111)$ & Control group $(n=90)$ \\
\hline Gender (male), n (\%) ${ }^{|| \| \mid}$ & $45(40.5)$ & $23(25.6)$ \\
\hline Age (years), mean (SD) & $54.1(15.3)$ & $57.1(14.5)$ \\
\hline $\begin{array}{l}\text { Relationship to patient } \\
\text { - } \text { Spouse, n (\%) } \\
\text { - } \text { Child, n (\%) } \\
\text { - } \text { Other }^{\neq \ddagger}, \mathrm{n}(\%)\end{array}$ & $\begin{array}{l}56(50.5) \\
37(33.3) \\
18(16.2)\end{array}$ & $\begin{array}{l}50(55.6) \\
30(33.3) \\
10(11.1)\end{array}$ \\
\hline Education (high school or more), n (\%) & $100(90.1)$ & $77(85.6)$ \\
\hline Current smokers, n (\%) & $29(26.1)$ & $32(35.6)$ \\
\hline Religious affiliation ${ }^{\S}, \mathrm{n}(\%)$ & $63(56.8)$ & $48(53.3)$ \\
\hline
\end{tabular}

Data presented as mean (SD) or number of patients (\%).

Abbreviations: $\mathrm{BMI}=$ Body Mass Index; $\mathrm{FEV}_{1}=$ Forced Expiratory Volume in the first second; $\mathrm{ACP}=\mathrm{Advance}$ Care Planning; HADS-A= Hospital Anxiety and Depression Scale, Anxiety subscale; HADS-D= Hospital Anxiety and Depression Scale, Depression subscale; SF-36= Short Form 36; CPR= Cardiopulmonary Resuscitation; MV= Mechanical Ventilation. ${ }^{*} p<0.05$ versus control group; ${ }^{\dagger} n=88 ;{ }^{\ddagger} n=73$; ${ }^{\S}$ Religious affiliation indicates having religious affiliation versus none; $n=91 ;{ }^{* *} n=78 ;{ }^{+\dagger} n=90 ;{ }^{\neq \ddagger}$ other= brother, sister, daughter-in-law, sister-in-law, brother-in-law, parent, cousin, foster-son, friend, ex-partner; ${ }^{\S \S} p<0.01 ;{ }^{\text {IIII }} p<0.05$. 


\section{Chapter 7}

Quality of communication

QOC end-of-life care communication score significantly improved in the ACPintervention group (2.32 points; $95 \% \mathrm{Cl}$ [1.72-2.92]; $\mathrm{p}=<.001$ ), but did not change in the control group (0.21 points; $95 \% \mathrm{Cl}[-0.28-0.69] ; \mathrm{p}=.40)$. Multilevel linear regression analysis showed that the difference in QOC end-of-life care communication score was significantly higher in the ACP-intervention group compared to the control group, when clustering for physician (28 clusters) and adjusting for age (Table 2 and Figure 2). The difference in QOC general domain scores was comparable between intervention and control group (Table 2 and Figure 2). The QOC item analysis showed that five QOC end-of-life care communication items were more frequently discussed at six months in the intervention group than in the control group. When items were discussed the quality was fair well to well ${ }^{16}$ in both groups (Figure 3). The quality of the items "talking about your feelings about getting sicker" and "talking about what dying might be like" was significantly higher in the intervention group compared to the control group (both $p=.03$ ). 

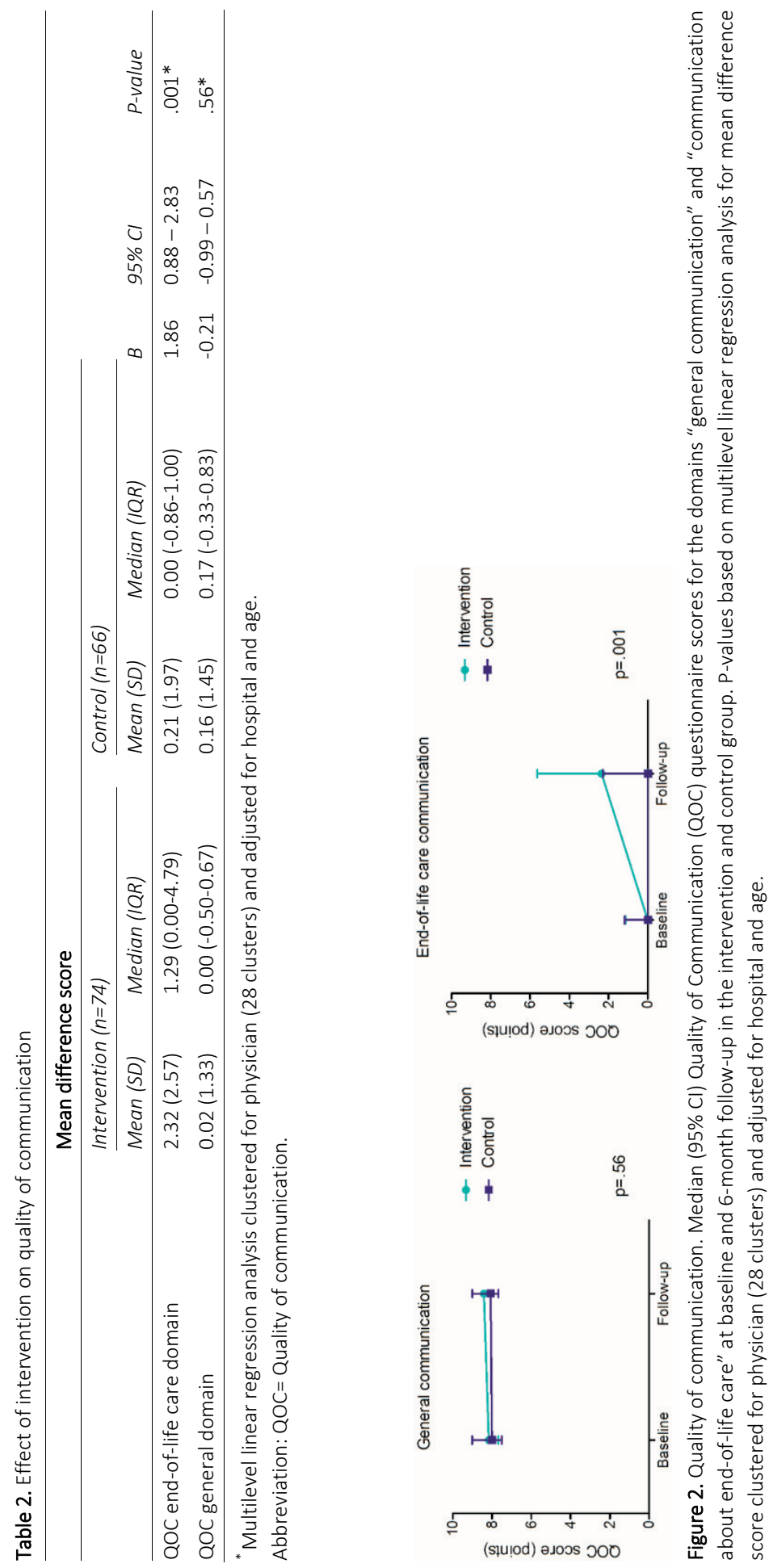

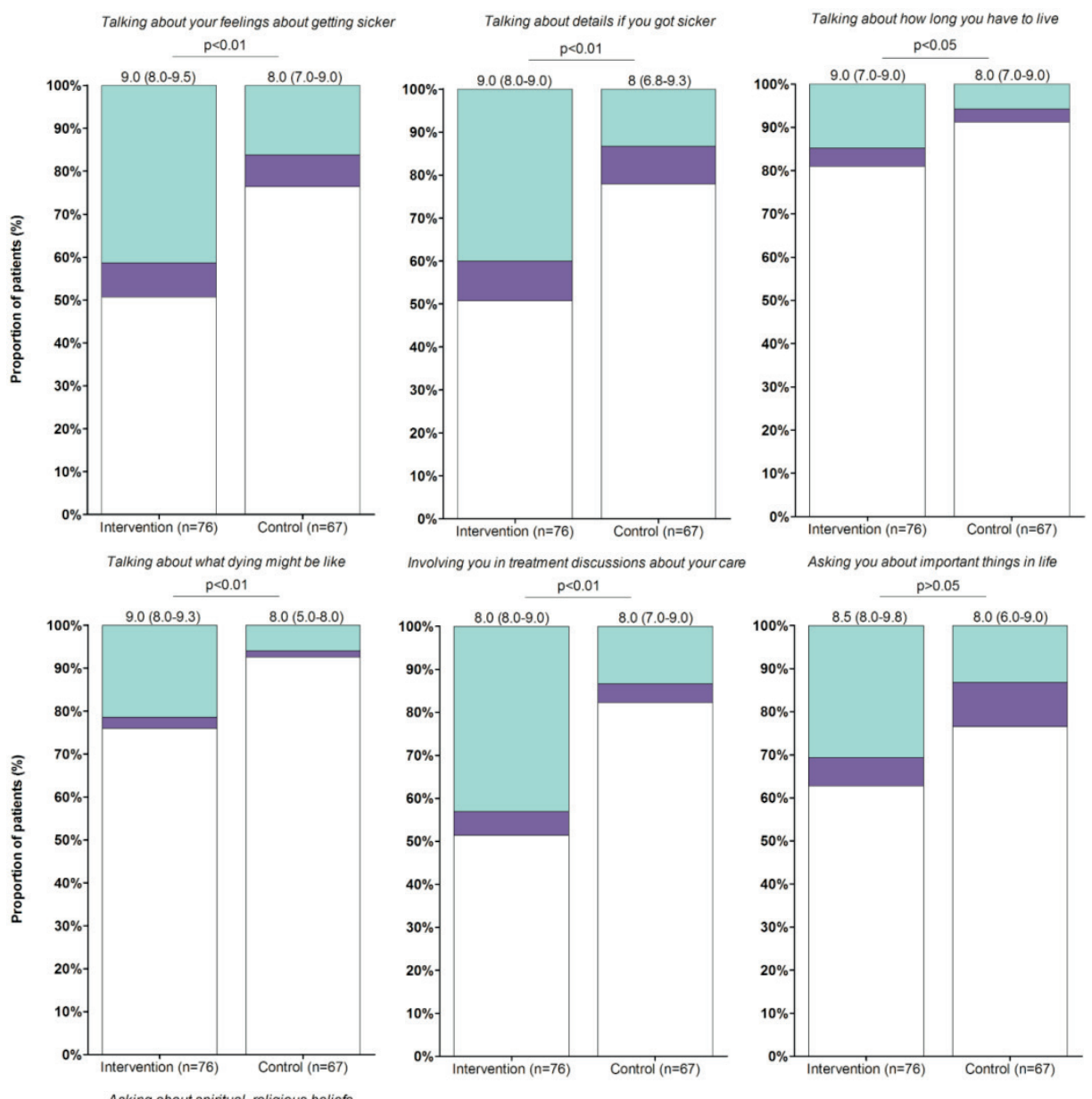

Involving you in treatment discussions about your care
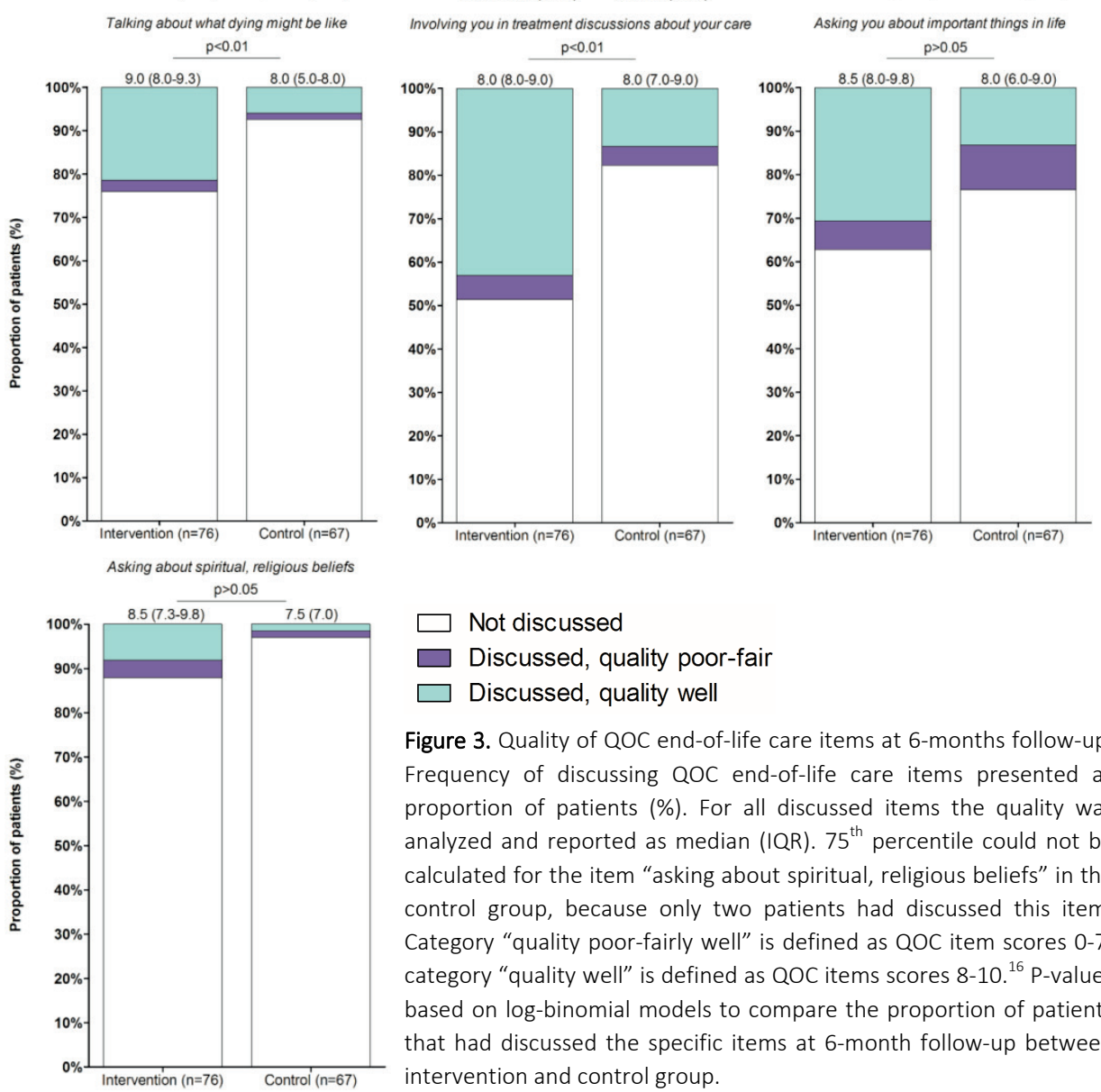

Figure 3. Quality of QOC end-of-life care items at 6-months follow-up. Frequency of discussing QOC end-of-life care items presented as proportion of patients (\%). For all discussed items the quality was analyzed and reported as median (IQR). $75^{\text {th }}$ percentile could not be calculated for the item "asking about spiritual, religious beliefs" in the control group, because only two patients had discussed this item. Category "quality poor-fairly well" is defined as QOC item scores 0-7; category "quality well" is defined as QOC items scores 8-10. ${ }^{16} \mathrm{P}$-values based on log-binomial models to compare the proportion of patients that had discussed the specific items at 6-month follow-up between intervention and control group. 


\section{Symptoms of anxiety and depression}

Symptoms of anxiety improved significantly within the ACP-intervention group $(-1.3$ points; $95 \% \mathrm{Cl}[-2.17--0.41]$; $p=.006)$, but did not significantly improve in the control group (-0.5 points; $95 \% \mathrm{Cl}[-1.48-0.49]$; $p=.32$ ). Symptoms of depression did not change within both groups $(p=.53$ and $p=.17$ for intervention and control group, respectively). Linear regression analysis showed no significant difference in symptoms of anxiety and depression between patients in both groups at 6-month followup, when adjusting for age and symptoms of anxiety or depression at baseline, respectively (Table 3). Symptoms of anxiety improved significantly within the loved ones in the ACP-intervention group (intervention group: -0.9 points; $95 \% \mathrm{Cl}[-1.63-$ -0.15]; $p=.02)$, but did not change in the control group (-0.1 points; $95 \% \mathrm{Cl}[-0.99$ $0.80] ; p=.83)$. Furthermore, symptoms of depression did not change within both groups ( $p=.54$ and $p=.81$ for intervention and control group, respectively).

Linear regression analysis showed that loved ones in the intervention group had significantly less symptoms of anxiety in comparison with loved ones in the control group at 6-month follow-up, when adjusting for symptoms of anxiety at baseline and gender. Symptoms of depression at 6-month follow-up were comparable between loved ones in the intervention and control group, when adjusting for symptoms of depression at baseline and gender (Table 3).

\section{ACP-discussions}

Six months after randomization, 40 patients in the ACP-intervention group (52.6\%) reported an ACP-discussion with another healthcare professional than the intervention nurse against 19 patients in the control group (28.4\%) ( $p=.003)$. From the patients in the ACP-intervention group who self-reported an ACP discussion with a healthcare professional at follow-up, 28 patients (70\%) described that this discussion was in the last six months. Of these patients, 16 patients $(57.1 \%)$ reported an ACP-discussion with the chest physician, four patients with the GP (14.3\%), five patients (17.9\%) with both the chest physician and the GP, two patients (7.1\%) with the respiratory nurse specialist and one patient (3.6\%) with the chest physician and the respiratory nurse specialist (e-Figure 2). 


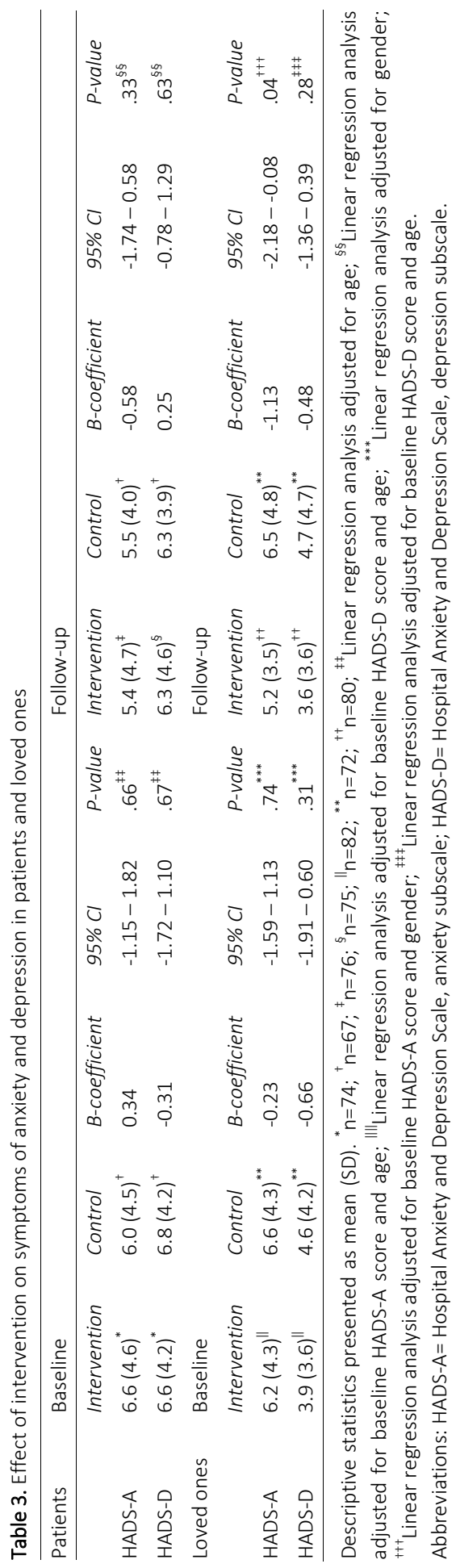




\section{DISCUSSION}

\section{Key findings}

One structured nurse-led ACP-session improved quality of end-of-life care communication between patients with COPD and their chest physicians. The intervention was positively associated with the occurrence of patient-reported ACP-discussions with healthcare professionals after six months. Moreover, symptoms of anxiety and depression did not increase following the intervention in both patients and loved ones. Actually, at 6-month follow-up symptoms of anxiety were significantly lower in loved ones in the intervention group compared to the control group.

\section{ACP-intervention: strengths and opportunities for improvement}

The ACP-intervention was designed to improve ACP for patients with COPD by overcoming important barriers. First, the ACP-intervention was facilitated by nurses to overcome the physician-reported barrier of lack of time. Second, patients were recruited at important milestones in the course of the disease and therefore appropriate moments to initiate ACP. ${ }^{17}$ Furthermore, ACP discussions are often avoided by healthcare professionals, because of fear to cause psychosocial distress. ${ }^{18}$ This study did not find evidence for this assumption and even suggests that ACP can reduce anxiety in loved ones. This is supported by several other ACP studies in other populations. $^{19-22}$

The current intervention showed an increase in both prevalence and quality of patient-physician end-of-life care communication. However, based on the current study no conclusions can be drawn about which components of the intervention were responsible for this effect. One possible explanation could be that in the ACPstudy chest physicians were provided a starting point to initiate an ACP-discussion during an outpatient visit, because patients already had a ACP-discussion with the nurse specialist and were aware of the fact that all feedback forms were send to the chest physician. Indeed, previous research has shown that when physicians discussed with their patients topics with regard to ACP, the quality was rated high. ${ }^{23}$ This suggests that the problem is not so much the quality of end-of-life care communication, but the initiation of end-of-life care communication. In fact, ACP is such a complex process that probably more components are needed to improve ACP. A previously published US trial ${ }^{24}$, in which the intervention was limited to the use of a one-page feedback form showed for example an initial positive effect on the occurrence of ACP-discussions and quality of end-of-life care communication, but also 
showed that the intervention did not increase the documentation of subsequent ACP-discussions, nor did it improve the documentation of advance directives in those patients who had died during the follow-up period. ${ }^{25}$ Future research is needed to reveal if the multicomponent intervention which is used in the ACP-study and combines a nurse-led ACP-session, a feedback form for chest physician and a palliative care brochure for patients can also improve ACP on the long term.

Despite these positive results a considerable proportion of patients still did not report an ACP-discussion and patients reported that some topics had not been discussed. There are several explanations. First, the ACP-intervention focused mainly on behavior change in healthcare professionals. However, ACP is a process between patients, loved ones and healthcare professionals. ${ }^{26}$ Therefore, optimal ACP interventions probably need to address all participants in this triangle. In fact, most patients will wait for caregivers to initiate discussion about the end-of-life, despite the fact that they have worries about their future or end-of-life care. ${ }^{27}$ Therefore, future ACP-interventions should also pay attention to patient empowerment, by for example providing information about the importance of ACP and how to initiate discussions with loved ones and healthcare professionals. Finally, the ACPintervention was a nurse-led intervention and therefore only nurses received an ACP-training. Although nurses prepared the ACP-session with physicians in advance and physicians did receive the feedback forms, they did not receive an ACP-training. The intervention would probably be more effective when also physicians had received training in order to develop effective ACP communication skills. Indeed, previous research found that workshops for physicians focusing on end-of-life communication skills are feasible in clinical practice and are effective for improving discussions about palliative care. ${ }^{28}$ Furthermore, the current literature recommends a multidisciplinary approach for ACP that includes multidisciplinary training to ensure high-quality palliative care for patients with COPD. ${ }^{29,30}$

\section{Methodological considerations}

The present study has several strengths. First, an RCT is considered to be the gold standard for a clinical trial, because causal conclusions can be drawn. ${ }^{31}$ Second, patients were recruited from one academic and three general hospitals in the Netherlands to guarantee external validity. Third, we performed cluster analysis to prevent cross contamination between the intervention and usual care group and allocation was concealed to prevent systematic biases. 
Several limitations should also be considered. First, the participation rate was $31.4 \%$. It may be possible that eligible patients who refused participation in this study were less willing to participate in ACP-discussions than patients who agreed participation, which may have influenced the current results. However, these patients may also refuse an ACP-discussion in clinical care, which may mitigate the importance of this limitation. Furthermore, the response rate conforms the previously reported difficulty of recruitment in palliative care studies. ${ }^{32}$ Second, we assessed quality of end-of-life care communication and prevalence of ACP-discussions improved only six months after the single ACP- intervention. We did not continue to assess whether the intervention stimulated future ACP-discussions after 6 months and also the influence of multiple ACP-sessions is unknown. We acknowledge that ACP should be an ongoing process between patients, loved ones and professional caregivers during the course of the disease. In addition, the single intervention in the current study has shown to be an adequate facilitator for the initiation of ACP between patients, families and physicians. Third, the current study was based on a home-based intervention for which the nurses travelled to the patient's home to deliver the ACP-session. This could be a potential barrier in dissemination and implementation, because in clinical practice it may not always be feasible to deliver the ACP-session in the home environment. Fourth, the study did only assess communication about end-of-life care and the prevalence of ACP-discussions from the patient's perspective, which may raise the risk of recall bias. Previous research has for example shown major disagreement between patients and physicians about whether or not preferences for end-of-life care were discussed. ${ }^{2}$ Finally, in the current study GPs were not actively involved in the ACP-process. Their role was limited to the receipt of the feedback form from patients in the intervention group. Nevertheless, almost one third of the patients in the intervention group who reported an ACP-discussion with a healthcare professional in the last 6 months had discussed these preferences with the GP.

\section{Conclusion and clinical implications}

One structured, nurse-led ACP session can facilitate patient-physician communication about end-of-life care without causing psychological distress in both patients and their loved ones. The results of this study provide direction for further development of ACP in patients with COPD. The project can be followed by implementation of structured, nurse-led ACP in regular clinical care and the intervention can possibly be implemented for other patients with advanced chronic life-limiting diseases, such as congestive heart failure or idiopathic pulmonary fibrosis. In addition, the two-day training developed to train the respiratory nurse specialists in ACP 


\section{Chapter 7}

could also be used to train other healthcare professionals, such as medical specialists, GPS, physician assistants etcetera. The training could then be shortened to one day to be more feasible, because the second day was mainly focused on how to deliver the ACP-intervention during the study. Further follow-up is needed to explore whether the intervention can improve quality of end-of-life care and quality of dying. Furthermore, the influence of ACP on bereavement in family members of deceased patients with COPD has to be studied. 


\section{REFERENCES}

1. Institute of Medicine. Dying in America: Improving quality and honoring individual preferences near the end of life. Washington DC: The National Academies Press, 2015.

2. Janssen DJ, Spruit MA, Schols JM, Wouters EF. A call for high-quality advance care planning in outpatients with severe COPD or chronic heart failure. Chest 2011;139:1081-8.

3. Patel K, Janssen DJ, Curtis JR. Advance care planning in COPD. Respirology 2012;17:72-8.

4. Knauft E, Nielsen EL, Engelberg RA, Patrick DL, Curtis JR. Barriers and facilitators to end-of-life care communication for patients with COPD. Chest 2005;127:2188-96.

5. Houben $\mathrm{CH}$, Spruit MA, Wouters EF, Janssen DJ. A randomised controlled trial on the efficacy of advance care planning on the quality of end-of-life care and communication in patients with COPD: the research protocol. BMJ Open 2014;4:e004465.

6. Global Strategy for the Diagnosis, Management and Prevention of COPD, Global Initiative for Chronic Obstructive Lung Disease (GOLD) 2017. Available from: http://goldcopd.org.

7. Engelberg R, Downey L, Curtis JR. Psychometric characteristics of a quality of communication questionnaire assessing communication about end-of-life care. J Palliat Med 2006;9:1086-98.

8. Curtis JR, Engelberg RA, Nielsen EL, Au DH, Patrick DL. Patient-physician communication about end-of-life care for patients with severe COPD. Eur Respir J 2004;24:200-5.

9. Zigmond AS, Snaith RP. The hospital anxiety and depression scale. Acta Psychiatr Scand 1983;67:361-70.

10. Smid DE, Franssen FM, Houben-Wilke S, et al. Responsiveness and MCID Estimates for CAT, CCQ, and HADS in Patients With COPD Undergoing Pulmonary Rehabilitation: A Prospective Analysis. J Am Med Dir Assoc 2016

11. Charlson ME, Pompei P, Ales KL, MacKenzie CR. A new method of classifying prognostic comorbidity in longitudinal studies: development and validation. J Chronic Dis 1987;40:373-83.

12. Jones PW, Harding G, Berry P, Wiklund I, Chen WH, Kline Leidy N. Development and first validation of the COPD Assessment Test. Eur Respir J 2009;34:648-54.

13. Ware JE, Jr., Sherbourne CD. The MOS 36-item short-form health survey (SF-36). I. Conceptual framework and item selection. Med Care 1992;30:473-83.

14. Dijkstra A, Tiesinga LJ, Goossen WT, Dassen TW. Further psychometric testing of the Dutch Care Dependency Scale on two different patient groups. Int J Nurs Pract 2002;8:305-14.

15. Janssen DJ, Spruit MA, Schols JM, et al. Predicting changes in preferences for life-sustaining treatment among patients with advanced chronic organ failure. Chest 2012;141:1251-9.

16. Reinke LF, Slatore CG, Uman J, et al. Patient-clinician communication about end-of-life care topics: is anyone talking to patients with chronic obstructive pulmonary disease? J Palliat Med 2011;14:923-8.

17. Reinke LF, Engelberg RA, Shannon SE, et al. Transitions regarding palliative and end-of-life care in severe chronic obstructive pulmonary disease or advanced cancer: themes identified by patients, families, and clinicians. J Palliat Med 2008;11:601-9.

18. Brighton LJ, Bristowe K. Communication in palliative care: talking about the end of life, before the end of life. Postgrad Med J 2016;92:466-70.

19. Houben $\mathrm{CH}$, Spruit MA, Groenen MT, Wouters EF, Janssen DJ. Efficacy of advance care planning: a systematic review and meta-analysis. J Am Med Dir Assoc 2014;15:477-89.

20. Brinkman-Stoppelenburg A, Rietjens JA, van der Heide A. The effects of advance care planning on end-oflife care: a systematic review. Palliat Med 2014;28:1000-25.

21. Green MJ, Schubart JR, Whitehead MM, Farace E, Lehman E, Levi BH. Advance Care Planning Does Not Adversely Affect Hope or Anxiety Among Patients With Advanced Cancer. J Pain Symptom Manage 2015;49:1088-96.

22. Vandervoort A, Houttekier D, Vander Stichele R, van der Steen JT, Van den Block L. Quality of dying in nursing home residents dying with dementia: does advanced care planning matter? A nationwide postmortem study. PLoS One 2014;9:e91130. 


\section{Chapter 7}

23. Houben $\mathrm{CH}$, Spruit MA, Schols JM, Wouters EF, Janssen DJ. Patient-clinician communication about endof-life care in patients with advanced chronic organ failure during one year. J Pain Symptom Manage 2015;49(6):1109-1115.

24. Au DH, Udris EM, Engelberg RA, Diehr PH, Bryson CL, Reinke LF, Curtis JR. A randomized trial to improve communication about end-of-life care among patients with COPD. Chest 2012;141(3):726-35.

25. Reinke LF, Feemster LC, McDowell J, Gunnink E, Tartaglione EV, Udris E, Curtis JR, Au DH. The long term impact of an end-of-life communication intervention among veterans with COPD. Heart Lung 2017;46:30-34

26. Janssen DJ, Engelberg RA, Wouters EF, Curtis JR. Advance care planning for patients with COPD: past, present and future. Patient Educ Couns 2012;86:19-24.

27. Heffner JE, Fahy B, Hilling L, Barbieri C. Attitudes regarding advance directives among patients in pulmonary rehabilitation. Am J Respir Crit Care Med 1996;154:1735-40.

28. Back AL, Arnold RM, Baile WF, et al. Efficacy of communication skills training for giving bad news and discussing transitions to palliative care. Arch Intern Med 2007;167:453-60.

29. Duenk RG, Verhagen C, Dekhuijzen P, Vissers K, Engels Y, Heijdra Y. The view of pulmonologists on palliative care for patients with COPD: a survey study. Int J Chron Obstruct Pulmon Dis 2017;12:299-311.

30. Spathis A, Booth S. End of life care in chronic obstructive pulmonary disease: in search of a good death. Int J Chron Obstruct Pulmon Dis 2008;3:11-29.

31. Richter B, Berger M. Randomized controlled trials remain fundamental to clinical decision making in Type II diabetes mellitus: a comment to the debate on randomized controlled trials (For debate) [corrected]. Diabetologia 2000;43:254-8.

32. Kars MC, van Thiel GJ, van der Graaf R, Moors M, de Graeff A, van Delden JJ. A systematic review of reasons for gatekeeping in palliative care research. Palliat Med 2016;30:533-48. 


\section{SUPPLEMENTARY MATERIAL}

e-Figure 1. Feedback form for the physician

\section{Name \\ Date of birth}

Preferences for communication about the end-of-life

$\square$ The patient wants to talk with you about his/her preferences for end-of-life care

$\square$ The patient thinks that you probably don't know his/her preferences for end-of-life care.

\section{General goals of care}

$\square$ The best possible quality of life. (tick the box if this is the most important)

$\square$ To live as long as possible. (tick the box if this is the most important)

$\square$

$\square$

\section{Life-sustaining treatments}

The patient doesn't have a preference, and do / didn't want to talk about it.

$\square$ The patient wants / doesn't want CPR during cardiac arrest.

$\square$ The patient wants / doesn't want invasive ventilation when spontaneous breathing is not possible.

$\square$ The patient wants / doesn't want non-invasive ventilation.

\section{Other preferences for end-of-life care}

$\square$ None

$\square$ Advance directive, i.e.

$\square$ Surrogate decision maker, i.e.

$\square$

\section{Questions about end-of-life care}

$\square$ None

$\square$ Fear of choking

$\square$

$\square$

$\begin{array}{ll}\text { Signature } & \text { Date }\end{array}$


e-Figure 2. Healthcare professionals who engaged in ACP-discussions

Healthcare professionals who engaged in ACP-discussions

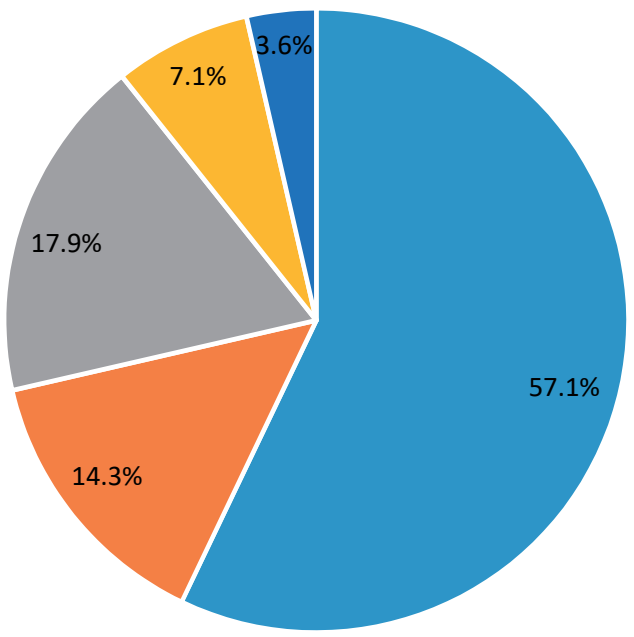

- Chest physician

$n=28$

- General practitioner

- Chest physician and general practitioner

- Respiratory nurse specialist

- Chest physician and respiratory nurse specialist 


\section{8}

\section{General discussion}
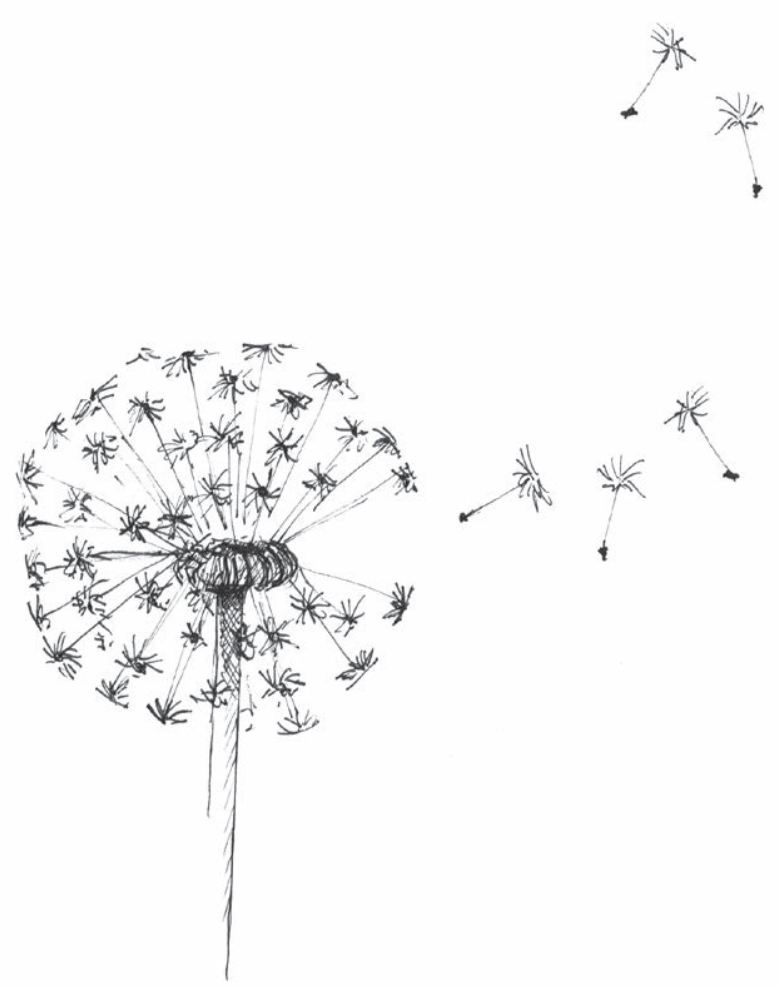

Part of the general discussion has been submitted as:

Carmen H.M. Houben, Martijn A. Spruit, Randall Curtis, Emiel F.M. Wouters, and Daisy J.A. Janssen.

Recruitment challenges in conducting a randomized controlled trial on the efficacy of advance care planning

Submitted 



\section{GENERAL DISCUSSION}

The World Health Organization (WHO) defines palliative care as an approach which addresses physical, psychological, social and existential problems, with the ultimate goal to improve the quality of life of patients and their loved ones. ${ }^{1}$ Historically, palliative care was focused on patients with malignant diseases. However, in recent years there has been growing awareness for palliative care in patients with nonmalignant diseases. ${ }^{2}$ Patient-physician communication is an important prerequisite to deliver high-quality palliative care. Therefore, advance care planning (ACP), defined as the continuous process of timely communication between patients, healthcare professionals, and loved ones, about patients' personal values, life goals, and preferences for future medical care $^{3}$, is an essential component of palliative care for patients with a life-limiting illness, such as for example chronic heart failure $(\mathrm{CHF})$, chronic renal failure (CRF), and COPD. ${ }^{4,5}$ Although there is increasing attention for ACP in patients with life-limiting illnesses, it is still uncommon in clinical practice. $^{6-8}$ Therefore, the main aim of this thesis was to gain more insight into the quality of end-of-life care communication in patients with life-limiting illnesses. In addition, we explored how and whether a nurse-led ACP intervention could improve outcomes for patients with COPD and their loved ones. First, definitions of ACP in the recent years will be discussed. Then elements important for ACP in patients with COPD will be described, followed by the results of the ACP-study and methodological considerations. Finally, implications for clinical practice and recommendations for future research with the aim to further improve ACP for patients with life-limiting illnesses will be described.

\section{ACP: A CONTINUOUS PROCESS OF COMMUNICATION}

A systematic review and meta-analysis were performed to systematically evaluate the efficacy of ACP in different adult patient populations at the start of this study (chapter 2). This review showed that ACP interventions can be effective in changing completion of advance directives and occurrence of discussions about end-of-life care and are likely to improve quality of communication. In addition, patients in intervention groups more often received end-of-life care in concordance with their preferences than patients in control groups. Furthermore, ACP did not have detrimental effects on psychosocial well-being. The systematic review also identified a significant association between the type of intervention and the period in which the study was conducted. Indeed, across time more studies have been conducted in which people were offered an ACP-discussion in addition to the opportunity to 
complete an advance directive. This shift in focus from interventions limited to the completion of advance directives to interventions focused on communication about $A C P$, in addition to advance directives, seems to run parallel to the development in definitions of ACP as described in the literature. Indeed, in the '90s, ACP was often seen as synonymous with the completion of advance directives. ${ }^{9}$ However, early studies showed that advance directives did not change outcomes for patients ${ }^{10}$ and although the majority of physicians identified patient preferences as most important guideline for decision making, the presence of an advance directive did not predict the physicians' reliance on those documented patient preferences. ${ }^{11}$ This could probably be partly explained by the fact that preferences documented in the advance directive may not applicable to the specific clinical decision that has to be made ${ }^{12}$ or may have been written prior to important changes in the patient's health status that could influence patient preferences. ${ }^{11}$ These findings suggest that ongoing communication about end-of-life care is needed to improve outcomes for patients and loved ones. ${ }^{13}$ Therefore, more recent definitions describe ACP as the continuous process of communication between patients, healthcare professionals and loved ones. However, a formal unifying definition of ACP to guide clinical, research, and policy initiatives was lacking. ${ }^{3}$ Therefore, in 2017 a multidisciplinary Delphi panel developed the following consensus definition for ACP: 'Advance care planning is a process that supports adults at any age or stage of health in understanding and sharing their personal values, life goals, and preferences regarding future medical care. The goal of advance care planning is to help ensure that people receive medical care that is consistent with their values, goals and preferences during serious and chronic illness'.3 Furthermore, the authors stated that the aim of this definition of ACP was also to prepare patients for current and future medical decision making. This is in line with the current literature which stated that ACP promotes patient autonomy and shared decision making, by informing patients about their own health and let them participate in decision making regarding their care. ${ }^{14,15}$ However, this definition has also some limitations, including the fact that the panel members were only from four countries (predominant US) ${ }^{3}$, which may limit the generalizibility of this definition. Therefore, recently an international taskforce developed the first unifying, transcultural, international consensus defintion of ACP and defined ACP as: 'Advance care planning enables individuals to define goals and preferences for future medical treatment and care, to discuss these goals and preferences with family an healthcare providers, and to record and review these preferences if appropriate'.16

A common element across the definitions and also central in the new definition is the fact that ACP is a process that occurs on a continuum and which needs to be 
regularly reevaluated in order to deliver care in concordance with patient's preferences. Indeed, previous research in patients with chronic organ failure has shown that more than a third of patients change their preferences regarding life-sustaining treatments, such as CPR and mechanical ventilation, at least once during one year. These changing preferences were associated with changes over time in generic health status, mobility, symptoms of anxiety and depression, and marital status. ${ }^{17}$ In order to deliver end-of-care in concordance with preferred end-of-life care regular reevaluation of preferences is needed. However, to participate adequately in decision making it is important for patients to have sufficient information about possible treatments and outcomes.

A priori to chapter 4, we hypothesized that the willingness to accept life-sustaining treatments would be stable over time if patients received information about burden of treatment, expected outcome of treatment, and the likelihood of an adverse outcome. However, chapter 4 shows that even when patients do have this information their preferences are unstable, which shows the complexity of preferences for life-sustaining treatments and underlines the fact that ACP must be seen as a process which needs regular reevaluation. ${ }^{18}$

Beside the fact that studies underline the efficacy of ACP, it is still uncommon in clinical practice for patients with COPD. ${ }^{19}$ This despite the fact that COPD is a chronic, life-limiting illness with an increasing prevalence and mortality. ${ }^{20,21}$ Patients with advanced COPD often experience a significant burden of symptoms and other concerns for which no curative treatment exists and which requires symptom-based palliative treatments. ${ }^{22}$ Barriers for ACP from both the clinician and patient perspective as described in Chapter 1 could be possible explanations for the low ACP uptake in patients with COPD and will be discussed in more detail.

\section{ACP: INTERDISCIPLINARY TEAMWORK}

In Chapter 1 we described lack of time as one of the most important physicianendorsed barriers for $\mathrm{ACP}^{23}$, which could possibly be overcome by facilitating ACP by other healthcare professionals. The majority of healthcare professionals in fact believe that non-physicians could have ACP-discussions after appropriate training. ${ }^{24}$ However, in clinical practice the locus of responsibility is often unclear and active collaboration and communication between healthcare professionals about ACP is uncommon. ${ }^{25}$ An interdisciplinary approach in which all healthcare professionals with their own unique expertise and understanding play important roles, is recom- 
mended and preferred by clinicians. ${ }^{26,27}$ For example, physicians can provide important medical information to patients, whereas nurses support patients' hopes by understanding individual aspects of these hopes, focusing on patients' quality of life, and building trust with patients. ${ }^{28}$ Given that patients with COPD often suffer from comorbidities ${ }^{29}$ and are cared for by multiple providers, collaboration and communication between those healthcare professionals is crucial. ${ }^{30}$

Furthermore, loved ones can be involved in the process of ACP and in that respect ACP can be seen as an interdisciplinary triangle in which the corners are made up of the patient, the loved ones and the healthcare professionals. When loved ones are aware of patients' preferences of end-of-life care this could decrease the stress of surrogate decision-making. ${ }^{9,31}$ However, a systematic review has shown that loved ones are often unaware of these preferences. ${ }^{32}$ A recent study showed that ACP is most successful if both patients' and loved ones' needs were taken into account during ACP-discussions ${ }^{33}$, whereby attention is needed for the tendency of both patients and loved ones to protect each other for possible harm of talking about end-of-life. ${ }^{26,33}$ In addition, loved ones do have the tendency to overestimate the patient's desire for treatment. ${ }^{34}$

\section{ACP: WHEN TO START?}

Choosing the appropriate timing for ACP in patients with COPD is challenging for physicians, which is caused by the unpredictability of the disease trajectory, the lack of prognostic estimates ${ }^{35}$ and the survival of seemingly similar episodes in the past. ${ }^{36}$ A recent Dutch study showed that almost all chest physicians (92\%) indicate that they are able to distinguish a palliative phase in the COPD trajectory, which suggests that physicians are able to timely discuss preferences for end-of-life care. ${ }^{27}$ However, we showed in chapter 3 that in general there was an absence of discussions about end-of-life care among patients with advanced COPD, CHF and CRF and that this did not improve towards the end of life. In the literature several instruments are described to identify patients at high risk of dying and therefore serve as a prompt for referral to palliative care. For example, in the last years, the surprise question -"Would I be surprised if this patient died in the next 12 months?"- has been widely promoted as a simple test for physicians to assist in prognostication and to identify patients who could benefit from palliative care. ${ }^{37}$ Although the surprise question has been used in several patient populations, the predictive value was poor to modest, especially in non-cancer illness. ${ }^{38}$ In 2011, the Gold Standards Framework developed a prognostic indicator guidance in which general and dis- 
ease-specific indicators of decline were used, in addition to the surprise-question, in order to help physicians in recognizing patients near the end of life and as a consequence trigger early ACP. ${ }^{39}$ The added value of the surprise question and the clinical indicators lies in enhancing physicians' awareness of the fact that they are taking care of a dying patient. However, it does not reflect patients' palliative care needs. Indeed, patients with a chronic illness could have palliative care needs before the last phase of their illness. In the current literature no evidence was found for a relation between the surprise question and palliative care needs. ${ }^{40}$ However, research has shown that patients with COPD experience some clinical events, such as the start of oxygen therapy and hospitalizations, as milestones in the evolution of their illness. ${ }^{41,42}$ Therefore these events provide physicians the opportunity to start ACP-discussions. In addition to being aware of these trigger moments, it is important to listen to patient's cues for initiation of ACP and take patients' readiness to talk about their end-of-life into account. ${ }^{43}$ Indeed, choosing the appropriate timing for ACP-discussions is further complicated by the poor prognostic awareness of patients with COPD. ${ }^{44}$ Moreover, patients are often unaware that palliative care can contribute to manage their disease ${ }^{44}$ or see themselves as too well for ACP. ${ }^{26}$ In fact, patients are not always aware of the possibility to be involved in discussions about end-of-life care or differ in their preferences for involvement in the process of decision making. ${ }^{45}$ Nonetheless, it has been shown that when patients and clinicians make healthcare choices together, a process also known as shared decision making ${ }^{46}$, patients experience less uncertainty and conflict about their decisions. However, a qualitative study in patients with chronic lung disease showed that although patients prefer participation in decision making, many deferred the final decision to their physician, whereby the physician take their preferences into account. $^{35}$ The authors therefore suggest a more collaborative form of decision making in which patients co-operate with their healthcare professionals and loved ones and the final decision is made by the physician, instead of shared decision making which implies that decisions were made together. ${ }^{35,47}$ In order to engage all patients in ACP-discussions, healthcare professionals should tailor ACP information to the patients' needs, for example by adapting the decision making process to the extent in which the patient wants to get involved in decision making and reframing the ACP-discussion to focus on worries and fears instead of talking about death and dying. ${ }^{35,48}$ Furthermore, patients' readiness had to be taken into account when engaging individuals in ACP. ${ }^{49}$ The readiness for ACP can be conceptualized using the stage of change model ${ }^{50}$, in which ACP is seen as a set of interrelated health behaviors. ${ }^{51}$ According to this model behavior change is a process involving progress through five stages. These five stages include pre-contemplation, contemplation, preparation, action, and maintenance. ${ }^{50}$ When we adapt this model to the 
process of $\mathrm{ACP}$, patients in the pre-contemplation stage have never considered $A C P .{ }^{52}$ Those patients are for example unfamiliar with the term $A C P^{53}$ or are more concerned with their everyday troubles than planning for the future and therefore perceived ACP as not being relevant yet. ${ }^{54}$ In this stage it is important to explain to patients what ACP is and what could be the benefits of ACP for their individual situation. Patients in the contemplation stage start to think about their preferences for end-of-life care, but are not ready to discuss their preferences for end-of-life care. ${ }^{52}$ In this stage it can be helpful to start a discussion with a patient in an approachable manner, during which "what is important for you to live well?" is the central question. ${ }^{55}$ Patients in the preparation stage are aware of the relevance of ACP and are willing to discuss their preferences for end-of-life care. In this stage it is important for patients to have sufficient information in order to prepare themselves for effective discussions with healthcare professionals and loved ones. ${ }^{52}$ Traditionally, physicians were the primary source of information for patients. However, patients can also empower themselves by self-education facilitated by for example internet or television. ${ }^{56}$ Indeed, video-tools are found to be effective in improving patient knowledge about ACP and palliative care $^{57}$ and most patients obtain information about life-sustaining treatments, such as CPR, from television. ${ }^{58}$ It must be emphasized, however, that information portrayed on television does not always reflect reality. $^{59}$ In Chapter 5 we have reviewed television medical dramas and showed for example that the immediate success rate of CPR was $51.1 \%$, which is significantly higher than the survival rate of CPR in real life. Indeed, in real life the survival rate of in-hospital CPR to hospital discharge in patients without a chronic disease is only $17.3 \%{ }^{60}$ In addition, we showed in this chapter that healthcare professionals and patients or loved ones talked regularly about the end-of-life in television medical dramas. However, discussions about topics important in real life, such as preferences for end-of-life care or advance directives are uncommon. We conclude that television medical dramas don't facilitate behavior change, but they could have influence on patients' and loved ones' attitudes regarding ACP. Therefore, healthcare professionals need to take into account this influence when having ACPdiscussions. In addition, videos depicting the nature of different treatment options can be used as educational resource when having ACP-discussions. ${ }^{61}$ Patients in the action stage are having active discussions and document their preferences in advance directives. Patients can only achieve the action stage if loved ones and healthcare professionals are accessible and willing to engage in ACP. Patients in the maintenance stage update these documents when their preferences change. ${ }^{52}$ We already showed (Chapter 4 ) that even when patients do have information about the burden and possible outcome of treatments, their preferences are unstable. There- 
fore it is important for patients to know that documents, such as advance directives can be adapted when preferences change.

\section{ACP INTERVENTIONS FOR PATIENTS WITH COPD}

The ACP-study, of which the research protocol is described in Chapter 6, is a RCT designed to improve ACP for patients with COPD by overcoming the previously reported barriers towards ACP.

First, this RCT was based on a nurse-led intervention, by which we tried to overcome the physician-reported barrier of lack of time. ${ }^{23}$ Previous studies have proven the beneficial effects of nurse-led ACP. For example, Detering et al. ${ }^{62}$ showed that nurse-led ACP led to a higher concordance between preferred end-of-life care and delivered end-of-life care in elderly hospitalized patients. A recent study ${ }^{63}$ in patients with severe lung disease even suggests that the nurse-led character of the intervention may be responsible for the high quality of the ACP-discussions, because nurses already had an ongoing relationship with the patient. Indeed, nurses are often the first point of contact for patients and nurses can build on that relationship when having ACP-discussions with patients and their loved ones. ${ }^{28}$ In addition, nurses have specific communication skills important for end-of-life communication, such as listening to patients, being responsive to emotional needs, treating the whole person and respecting patients' cultural and religious beliefs. ${ }^{64}$ In the $A C P$-study, respiratory nurse specialists received a 2-day training to be able to perform the intervention. During this training, among other things, above mentioned end-of-life care communication skills were practiced. Second, in the ACP-study the structured ACP-session was delivered by trained respiratory nurses, by which we tried to overcome the physician-reported barrier lack of time. ${ }^{23}$ In addition, we took into account the recommendation of an interdisciplinary approach for ACP by involving several healthcare professionals, including trained respiratory nurse specialists, chest physicians, and general practitioners (GP). ${ }^{26,27}$ However, the role of the GP in the current study was limited. Indeed, GPs received the feedback forms and were not actively stimulated to start ACP-discussions during the study. Nevertheless, almost one third of the patients in the intervention group who reported an ACP-discussion with a healthcare professional in the last 6 months had discussed these preferences with the GP. Finally, patients were recruited at important milestones in the disease trajectory, namely during a hospital admission for an acute COPD exacerbation or soon after the start of long-term oxygen therapy. By this we make use of clinical events which are defined by patients as milestones in the evo- 
lution of their illness and therefore are important trigger points for physicians to start an ACP-discussion. ${ }^{42}$

Chapter 7 shows that the nurse-led intervention improves patient-physician communication about end-of-life care without causing psychosocial distress in both patients and loved ones. In addition, patients randomized to the intervention group reported significantly more often a ACP-discussion with a healthcare professional after six months. A previously published US trial ${ }^{65}$, showed that a relatively simple intervention using a patient-specific feedback form increased the occurrence of patient-reported ACP-discussions and modestly improved the quality of end-of-life care communication in patients with COPD. In both the US trial and the ACP-study, a feedback form was used to show patient's preferences for end-of-life care. In the US trial, the feedback form was sent to patients to review and share with loved ones, but the authors did not explicitly checked if patients indeed discussed the feedback form with their loved one. Furthermore, loved ones in this trial were not involved in the actual ACP-conversation. ${ }^{65}$ In the ACP-study, the nurse-led interventions were delivered in the presence of at least one loved one and therefore the loved one was aware of patient's preferences. In addition, this provides the nurse who delivered the intervention the opportunity to take into account both patient's and loved ones' needs.

Recently, a patient-preference trial about ACP in patients with severe lung disease, including COPD was conducted. ${ }^{63}$ This study shows that a nurse-led facilitated ACPintervention was effective in increasing ACP-discussions and completion of advance directives. In this study, performed by Sinclair et al. ${ }^{63}$, a preference design was used, which potentially improves generalizability by enabling recruitment of patients who were unwilling to be randomized. ${ }^{63}$ However, a preference arm also introduces a self-selection bias which should be taken into account when interpreting the study results. ${ }^{66}$ In fact, $40 \%$ of included patients strongly preferred to receive the intervention and among those randomly allocated to the intervention group no significant increases were found in ACP-uptake in comparison with patients randomized to the control group. In line with the findings of the ACP-study, Sinclair et al. ${ }^{63}$ also found that discussions about prognosis, cultural, spiritual and religious beliefs occurred less often in the intervention group. Healthcare professionals may be more focused on discussing medical issues instead of psychosocial and spiritual issues. ${ }^{67}$ Indeed, previous research has shown that many physicians prefer referral to psychosocial care professionals or a chaplain to discuss these issues. ${ }^{68,69}$ 
In the ACP-study, we assessed the prevalence of ACP-discussions and the quality of end-of-life care communication only after six months after a single intervention. Therefore it is unknown whether preferences regarding end-of-life care are stable over time or whether the intervention stimulated future ACP-discussions after six months. In addition, the influence of multiple ACP-sessions is not assessed. Indeed, the previously described US trail showed an initial positive effect on the occurrence of ACP-discussions and quality of end-of-life care communication of providing a patient feedback form. ${ }^{65}$ However, a follow-up study based on this RCT showed that despite these initial improvements, the intervention did not increase the documentation of subsequent ACP-discussions, nor did it improve the documentation of advance directives in those patients who had died during the follow-up period. ${ }^{70}$

Finally, the nurse-led ACP intervention studied in the ACP-study is different from other ACP-interventions in patients with COPD because of the involvement of disease-specific topics in addition to more general topics of ACP. For example, during the ACP-intervention not only preferences for life-sustaining treatments and the opportunity to document these preferences in advance directives were discussed, but also disease-specific topics like fear of breathlessness and suffocation, which are highly prevalent in patients with COPD. ${ }^{71}$ As already described at the beginning of this chapter patients with COPD experience many symptoms, for which palliative care is required. ${ }^{22}$ In that respect, it would be important to broaden ACP in patients with COPD to preparation for medical decision during the disease trajectory and not just at the end of life. Indeed, in patients with advanced COPD decisions regarding major treatments often have to be made. For example, in patients with COPD with acute respiratory failure or severe chronic hypercapnia it is important to discuss the use of non-invasive ventilation. ${ }^{22}$ Furthermore, the possibility of surgical treatments, like lung volume reduction surgery and lung transplantation, has to be discussed in eligible patients with advanced COPD. Indeed, the goal of ACP is to help ensure that patients receive medical care in concordance with their values, goals and preferences during their disease trajectory. ${ }^{3}$ Therefore, ACP in patients with COPD should focus on overall goals of medical care and on preparing patients to make informed decisions regarding their future medical care based on what is most important to them. ${ }^{3}$ In fact, the involvement of patients in the decision making process has the potential to increase patient autonomy. ${ }^{14,15}$ 


\section{RECRUITMENT CHALLENGES IN CONDUCTING A RANDOMIZED CONTROLLED TRIAL ON THE EFFICACY OF ACP}

The recruitment of patients for the ACP-study was challenging, with only $31 \%$ of the patients who were eligible for and informed about the study participating. ACP is an important aspect of palliative care. From the literature it is known that palliative care studies are challenging, as there are difficulties with recruitment, attrition and compliance. ${ }^{72,73}$ ACP-studies are a special type of palliative care research, because it is not necessarily focused on patients near the end-of-life, but on early communication about end-of-life preferences. ${ }^{74}$ Therefore it is unknown whether and to what extent previously reported difficulties in palliative care research are also applicable to ACP-studies. In addition, research participation in ACP studies has rarely been studies from the patient's perspective ${ }^{75}$ and an adequate analysis of the recruitment process in RCTs focused on ACP is lacking. Therefore, we explored three methodological challenges in RCTs focusing on ACP in more detail.

\section{Methodological challenge 1: clinician gatekeeping}

Clinician gatekeeping, defined as the process whereby clinicians involved in the recruitment or research process prevent participation of eligible patients in clinical research, is a frequently reported reason for recruitment problems in palliative care research. ${ }^{76}$ In fact, for patients who were eligible according to a research protocol and who were not asked for participation, recruiters often made the assumption that these patients would prefer not to participate. This assumption is unjustified, because by not asking potentially eligible patients, gatekeepers prevent these patients from making their own decisions regarding research participation. ${ }^{77}$ Gatekeepers thereby override patients' autonomy and patients miss the opportunity to be empowered by participating in an ACP intervention. ${ }^{76}$ Indeed, previous studies have shown that patients view participation as positive and it can confer a sense of being valued and of contributing to future care. ${ }^{78,79}$

A systematic review ${ }^{76}$ showed a comprehensive overview of the reasons for gatekeeping in palliative care research, which were also applicable to the field of ACPresearch. These reasons were divided into the following categories: fear of burdening the patient; difficulty with disclosure in health status; fear of burdening the patient's relatives; doubts about the importance or quality of the proposed study; negative attitude towards research; and logistics. The fear of burdening vulnerable patients was the most reported reason for gatekeeping, which is in line with our own experience. Indeed, in the ACP-study fear of burdening the patient due to psy- 
chiatric comorbidities or psychosocial factors was the most important reason reported by nurses for not asking the patient.

ACP-studies that suffer from gatekeeping may result in selection bias by the fact that some subgroups, for example patients with psychiatric comorbidities or cognitive deficits, are excluded or are even not informed about the possibility to participate. As a consequence of excluding these patients from ACP-studies the effect of ACP in these subgroups is unknown and the study population becomes a smaller subset of the reference population which may limit the generalizability of results from ACP-studies. ${ }^{80,81}$

\section{Methodological challenge 2: patient refusal}

Another methodological challenge in ACP-studies is the number of patients refusing participation, which may reduce the statistical power of ACP-studies and may increase the probability to make a Type II error. ${ }^{82,83}$

A possible reason why patients refuse to participate in ACP-studies could be that they perceive themselves as too ill, in which the timing of recruitment may be important. In the ACP-study patients were informed about the study during a hospitalization. It could be hypothesized that less patients would perceive themselves as too ill when they were informed about this study for example at discharge, instead of during their hospital admission. At that time, patients are not acutely ill, but the admission is still fresh in their mind. However, studies ${ }^{62,84-88}$ comparable with the ACP-study also recruited patients in the hospital setting and provided data regarding the enrollment rate, which suggested that the enrollment rate was higher when patients were recruited during hospital admission (range 49.2\%-98.1\%; median $65.3 \%)^{62,84,86,87}$, in comparison with recruitment during outpatient visits or after hospital discharge (range 30.4\%-49.9\%; median 40.2\%). ${ }^{85,88}$ Interestingly, Detering et al. ${ }^{62}$ recruited patients during hospital admission and reported an impressive enrollment rate of $98.1 \%$. Nevertheless, the abovementioned studies were not perfectly comparable, because studies were performed in different patient populations and used different interventions and questionnaires. Therefore it is not possible to make clear statements regarding the appropriateness of recruiting patients for an ACP-study during or after hospital admissions, respectively.

Another important reason to refuse participation could be that patients do not want to talk about the end-of-life. This is in line with previous research which shows that patients' unwillingness to talk about their prognosis and patients' preference 
to rather concentrate on staying alive than talk about death are frequently endorsed barriers for discussing end-of-life care. ${ }^{23,89}$ In addition, it could be that some patient populations are less willing to talk about end-of-life care, because they are not aware of their diagnosis, prognosis, and life-limiting character of their disease and therefore underestimate the relevance of ACP. ${ }^{90}$ Indeed, patients' lack of awareness of prognosis is expressed as a barrier to the initiation of ACP in patients with chronic organ failure compared with cancer patients, in which the disease trajectory is relatively more predictable. ${ }^{91}$ These barriers are not only relevant to clinical practice but also to scientific research. Consequently, results may not be generalizable to patients unwilling to participate in ACP-studies. ${ }^{23}$ Indeed, selection bias which occurs by the fact that enrolled patients are more willing to discuss endof-life care preferences in comparison with patients who refuse participation may influence intervention effects ${ }^{80}$ and may limit the generalizability of results from ACP-studies. However, also in clinical practice there will be patients who refuse ACP-discussions when a healthcare professional wants to talk about preferences for end-of-life care and in that respect ACP-studies more accurately reflect recruitment into ACP interventions in clinical practice.

\section{Methodological challenge 3: the need for sustained participation}

Finally, researchers of ACP-studies have to deal with the fact that some patients will die during the study period. For these patients, it is no longer possible to assess the intervention effects of ACP on patient outcomes. However, patient's death does provide researchers the possibility to explore the effect of ACP on the quality of delivered end-of-life care and the psychological distress experiences by bereaved family members (Chapter 6). Moreover, as in any research, patients withdrew from ACP-studies for other reasons. Overall, this mortality and drop-out rate might reduce the effective sample size and can lead to an over- or underestimate of treatment effects, especially when the drop-out rate differs between study arms. ${ }^{92}$

\section{Recommendations}

To conclude, RCTs can be challenging to perform when evaluating complex interventions like ACP. Yet, robust data are needed to inform policy makers and guide funding bodies regarding the effectiveness and cost effectiveness of ACP. ${ }^{93}$ Therefore we provide some recommendations for future research (Figure 1). First, based on our findings of clinician gatekeeping and low participation rates, we would recommend that researchers take the possible low enrollment rates into account by designing multicenter studies with a longer recruitment period. Indeed, this may 
increase the time required for recruitment and as a consequence research costs will be higher. Importantly, some studies suggest that the burden for patients and family members associated with research on palliative and end-of-life care is often quite low and this is important information for clinicians involved in recruitment. ${ }^{94}$ Second, for ACP-studies to succeed, a dedicated research team which has regular interdisciplinary meetings, is trained in recruitment strategies and the importance of $A C P$, and takes sufficient time to inform patients about the possibility to participate in an ACP-study is needed. ${ }^{75,95}$ Regular interdisciplinary meetings between all professionals involved in the study to discuss eligibility of patients might enhance recruitment and minimize gatekeeping. Approaching patients in a manner respectful to their needs, during which patients were able to ask questions, can possibly increase the enrollment rate. ${ }^{72,75}$ Although it would be optimal for patients to be approached by the physician who is primarily responsible for the management of

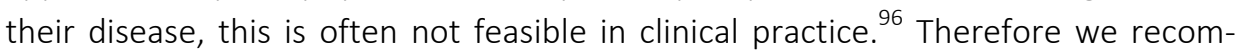
mend that ideally patients could be approached by another healthcare professional, with whom they already have a patient-professional relationship, for example a nurse. Indeed, previous research has shown that this is an important prerequisite for discussing delicate issues, such as preferences for end-of-life care. ${ }^{97,98}$ Finally, clear and detailed reporting of the recruitment process is important in order to assess the generalizability, relevance and comparability of trials. ${ }^{99,100}$ Additionally, exploring patients' reasons for refusal is important to clarify potential misconceptions regarding ACP and can possibly enhance the enrollment rate.

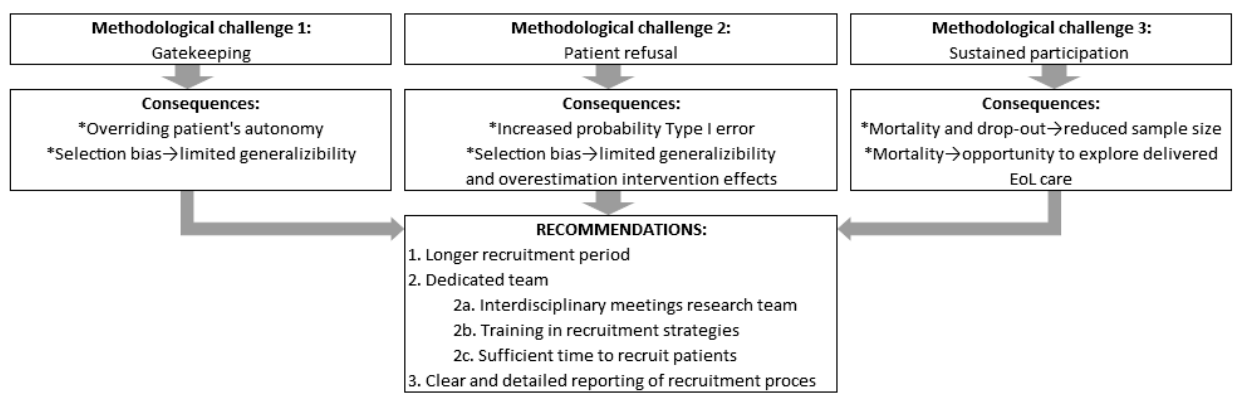

Figure 1. Recruitment challenges in advance care planning studies

\section{CLINICAL IMPLICATIONS AND RECOMMENDATIONS FOR FUTURE RESEARCH}

This thesis has shown the importance of ACP in patients with life-limiting illnesses and indicates that an intervention was needed aimed at the initiation of ACPdiscussions between healthcare professionals, patients, and loved ones at the ap- 
propriate time during the disease trajectory. The structured, nurse-led intervention developed for the ACP-study has proved to be an adequate facilitator for patientphysician communication about end-of-life care without causing psychological distress in both patients and their loved ones. The current project should be followed by implementation of structured nurse-led ACP in regular clinical care. However, changes found in the ACP-study were small and six months after randomization $47.4 \%$ of the patients in the intervention group still did not report an ACPdiscussion with another healthcare professional than the intervention nurse. These findings implicated that to further improve ACP in patients with COPD more is needed than only an intervention focused on behaviour change in one healthcare professional. First, since ACP is a process between patients, healthcare professionals, and loved ones ${ }^{13,16}$, future ACP-interventions should take into account the needs of all participants in this triangle. In fact, most patients will wait for their physician to initiate a discussion about the end-of-life, despite the fact that they have worries about their future or end-of-life care. ${ }^{101}$ Therefore, future studies should also focus on increasing patient empowerment to discuss ACP. An effective strategy could be the use of patient education about ACP. Indeed, previous research has shown that education about ACP can empower patients with chronic lung diseases to engage in ACP discussions. ${ }^{102}$ Moreover, a recent randomized controlled trial (RCT) performed in the US showed that a patient-centered ACP website (PREPARE) can induce increase ACP behavior. Indeed, the use of PREPARE resulted in higher self-reported ACP engagement at follow-up. ${ }^{103}$ Second, we recommend to use the two-day training developed to train respiratory nurse specialists in ACP also to train other healthcare professionals, such as medical specialists, general practitioners, physician assistants etcetera. Indeed, training healthcare professionals is an important resource to systematically incorporate ACP into clinical practice. ${ }^{24}$ Third, given the high refusal of patients to participate in the ACP-study we suggest to take patients' readiness into account and to individualize and titrate ACP-interventions to the patients' needs and preferences. Indeed, patients differ in their need for prognostic information. ${ }^{104}$ Some patients with COPD want to know all available information, while other patients are reluctant to receive information about worsening of their condition. ${ }^{105}$ Therefore, an "ask-tell-ask" approach, in which is explored whether patients prefer certain information before delivering information seems the most appropriate. ${ }^{106}$ Fourth, the intervention can possibly be implemented for other patients with advanced chronic life-limiting illness, such as CHF or idiopathic pulmonary fibrosis (IPF). Indeed, the disease trajectories of CHF and IPF are also characterized by unpredictability and uncertainty. ${ }^{107,108}$ In fact, CHF is the leading cause of death worldwide ${ }^{109,110}$ and the prognosis of IPF is poor, with a median survival of about three years. ${ }^{111}$ This underlines the important of timely ACP 
in those patients. Previous research has already shown that ACP in patients with $\mathrm{CHF}$ and IPF is uncommon, while both patient populations experience palliative care needs and are willing to discuss their future medical care. ${ }^{6,7}$ Fifth, future research is needed to explore whether the ACP-intervention can influence the most important outcome of ACP, namely concordance between preferred and delivered end-of-life care. Furthermore, the influence of ACP on bereavement in family members of deceased patients with COPD has to be studied.

\section{GENERAL CONCLUSION}

In conclusion, this thesis demonstrated that ACP-interventions increase the completion of advance directives, occurrence of discussions about ACP, and the concordance between preferences for end-of-life care and delivered end-of-life care. However, in patients with advanced chronic organ failure end-of-life care communication is poor and does not change toward the end-of-life. In addition, we showed that preferences for life-sustaining treatments are complex in patients with advanced chronic organ failure. Even when patients do have information about the burden of treatment, the expected outcome and the likelihood of an adverse outcome their preferences are instable. Further, healthcare professionals in television medical dramas talked with patients or loved ones about end-of-life. However, topics important for patients in real life were often not discussed. In order to improve ACP for patients with COPD a RCT was developed. The inclusion of patients for this trial was challenging, due to gatekeeping, and patient refusal. Although this is common in palliative care research, little attention is paid to these methodological challenges in current research articles. Finally, this thesis showed that the nurseled ACP-intervention improves patient-physician communication about end-of-life care without causing psychosocial distress in both patients and loved ones. 


\section{REFERENCES}

1. World Health Organisation. WHO definition of palliative care. http://www.who.int/cancer/palliative/ definition/en/ Accessed 30-03-2017.

2. Traue DC, Ross JR. Palliative care in non-malignant diseases. J R Soc Med 2005;98:503-6.

3. Sudore RL, Lum HD, You JJ, et al. Defining Advance Care Planning for Adults: A Consensus Definition From a Multidisciplinary Delphi Panel. J Pain Symptom Manage 2017;53:821-32 e1.

4. Institute of Medicine. Dying in America: Improving quality and honoring individual preferences near the end of life. Washington DC: The National Academies Press, 2015.

5. Bausewein C, Currow DC, Johnson MJ (Eds). ERS Monograph: Palliative Care in Respiratory Disease. European Respiratory Society Publications: 2016.

6. Janssen DJ, Spruit MA, Schols JM, Wouters EF. A call for high-quality advance care planning in outpatients with severe COPD or chronic heart failure. Chest 2011;139:1081-8.

7. Rajala K, Lehto JT, Saarinen M, Sutinen E, Saarto T, Myllarniemi M. End-of-life care of patients with idiopathic pulmonary fibrosis. BMC Palliat Care 2016;15:85.

8. Siouta N, van Beek K, Preston N, et al. Towards integration of palliative care in patients with chronic heart failure and chronic obstructive pulmonary disease: a systematic literature review of European guidelines and pathways. BMC Palliat Care 2016;15:18

9. Fried TR, O'Leary JR. Using the experiences of bereaved caregivers to inform patient- and caregivercentered advance care planning. J Gen Intern Med 2008;23:1602-7.

10. Schneiderman LJ, Kronick R, Kaplan RM, Anderson JP, Langer RD. Effects of offering advance directives on medical treatments and costs. Ann Intern Med 1992;117:599-606.

11. Torke AM, Moloney R, Siegler M, Abalos A, Alexander GC. Physicians' views on the importance of patient preferences in surrogate decision-making. J Am Geriatr Soc 2010;58:533-8.

12. Teno JM, Licks S, Lynn J, et al. Do advance directives provide instructions that direct care? SUPPORT Investigators. Study to Understand Prognoses and Preferences for Outcomes and Risks of Treatment. J Am Geriatr Soc 1997; 45:508-12.

13. Janssen DJ, Engelberg RA, Wouters EF, Curtis JR. Advance care planning for patients with COPD: past, present and future. Patient Educ Couns 2012;86:19-24.

14. Boyd K, Mason B, Kendall M, et al. Advance care planning for cancer patients in primary care: a feasibility study. Br J Gen Pract 2010;60:e449-58.

15. Hamilton IJ. Advance care planning in general practice: promoting patient autonomy and shared decision making. Br J Gen Pract 2017;67:104-5.

16. Rietjens JA, Sudore RL, Connolly M, et al. Definition and recommendations for advance care planning: an international consensus supported by the European Association for Palliative Care. Lancet Oncol 2017;18:e543-51.

17. Janssen DJ, Spruit MA, Schols JM, et al. Predicting changes in preferences for life-sustaining treatment among patients with advanced chronic organ failure. Chest 2012;141:1251-9.

18. Sudore RL, Fried TR. Redefining the "planning" in advance care planning: preparing for end-of-life decision making. Ann Intern Med 2010;153:256-61.

19. Janssen DJ, Curtis JR, Au DH, et al. Patient-clinician communication about end-of-life care for Dutch and US patients with COPD. Eur Respir J 2011;38:268-76.

20. Mathers CD, Loncar D. Projections of global mortality and burden of disease from 2002 to 2030. PLoS Med 2006;3:e442.

21. Adeloye D, Chua S, Lee C, et al. Global and regional estimates of COPD prevalence: Systematic review and meta-analysis. J Glob Health 2015;5:020415.

22. Global Strategy for the Diagnosis, Management and Prevention of COPD, Global Initiative for Chronic Obstructive Lung Disease (GOLD) 2017. Available from: http://goldcopd.org.

23. Knauft E, Nielsen EL, Engelberg RA, Patrick DL, Curtis JR. Barriers and facilitators to end-of-life care communication for patients with COPD. Chest 2005;127:2188-96. 
24. Arnett K, Sudore RL, Nowels D, Feng CX, Levy CR, Lum HD. Advance Care Planning. Am J Hosp Palliat Care 2016:1049909116666358.

25. O'Hare AM, Szarka J, McFarland LV, et al. Provider Perspectives on Advance Care Planning for Patients with Kidney Disease: Whose Job Is It Anyway? Clin J Am Soc Nephrol 2016;11:855-66.

26. Hutchison LA, Raffin-Bouchal DS, Syme CA, Biondo PD, Simon JE. Readiness to participate in advance care planning: A qualitative study of renal failure patients, families and healthcare providers. Chronic IIIn 2017:1742395316675023.

27. Duenk RG, Verhagen C, Dekhuijzen P, Vissers K, Engels $Y$, Heijdra Y. The view of pulmonologists on palliative care for patients with COPD: a survey study. Int J Chron Obstruct Pulmon Dis 2017;12:299-311.

28. Reinke LF, Shannon SE, Engelberg RA, Young JP, Curtis JR. Supporting hope and prognostic information: nurses' perspectives on their role when patients have life-limiting prognoses. J Pain Symptom Manage 2010;39:982-92.

29. Vanfleteren LE, Spruit MA, Groenen M, et al. Clusters of comorbidities based on validated objective measurements and systemic inflammation in patients with chronic obstructive pulmonary disease. Am J Respir Crit Care Med 2013;187:728-35.

30. Wong JS, Gottwald M. Advance Care Planning Discussions in Chronic Obstructive Pulmonary Disease: A critical review. J Palliat Care 2015;31:258-64.

31. Vig EK, Starks H, Taylor JS, Hopley EK, Fryer-Edwards K. Surviving surrogate decision-making: what helps and hampers the experience of making medical decisions for others. J Gen Intern Med 2007;22:1274-9.

32. Shalowitz DI, Garrett-Mayer E, Wendler D. The accuracy of surrogate decision makers: a systematic review. Arch Intern Med 2006;166:493-7.

33. Fried T, Zenoni M, lannone L. A Dyadic Perspective on Engagement in Advance Care Planning. J Am Geriatr Soc 2017;65:172-8.

34. Bravo G, Trottier L, Arcand M, et al. Promoting advance care planning among community-based older adults: A randomized controlled trial. Patient Educ Couns 2016;99:1785-95.

35. Hajizadeh N, Uhler LM, Perez Figueroa RE. Understanding patients' and doctors' attitudes about shared decision making for advance care planning. Health Expect 2015;18:2054-65.

36. Vermylen JH, Szmuilowicz E, Kalhan R. Palliative care in COPD: an unmet area for quality improvement. Int J Chron Obstruct Pulmon Dis 2015;10:1543-51.

37. Moss AH, Ganjoo J, Sharma S, et al. Utility of the "surprise" question to identify dialysis patients with high mortality. Clin J Am Soc Nephrol 2008;3:1379-84.

38. Downar J, Goldman R, Pinto R, Englesakis M, Adhikari NK. The "surprise question" for predicting death in seriously ill patients: a systematic review and meta-analysis. CMAJ 2017;189:E484-E93.

39. The GSF Prognostic Indicator Guidance: The Gold Standards Framework Centre in End of Life Care CIC; 2011. Available from: http://www.goldstandardsframework.org.uk/cd-content/uploads/files/General \%20Files/Prognostic\%20Indicator\%20Guidance\%200ctober\%202011.pdf

40. Janssen DJ, Van den Beuken, M.H.J. Verrast door de 'surprise question'. Nederlands Tijdschrift voor Geneeskunde 2015;159.

41. Seamark D, Blake S, Seamark C, et al. Is hospitalisation for COPD an opportunity for advance care planning? A qualitative study. Prim Care Respir J 2012;21:261-6.

42. Reinke LF, Engelberg RA, Shannon SE, et al. Transitions regarding palliative and end-of-life care in severe chronic obstructive pulmonary disease or advanced cancer: themes identified by patients, families, and clinicians. J Palliat Med 2008;11:601-9.

43. De Vleminck A, Pardon K, Beernaert K, Houttekier D, Vander Stichele R, Deliens L. How Do General Practitioners Conceptualise Advance Care Planning in Their Practice? A Qualitative Study. PLoS One 2016;11:e0153747.

44. Lilly EJ, Senderovich H. Palliative care in chronic obstructive pulmonary disease. J Crit Care 2016;35:1504.

45. Chewning B, Bylund CL, Shah B, Arora NK, Gueguen JA, Makoul G. Patient preferences for shared decisions: a systematic review. Patient Educ Couns 2012;86:9-18. 


\section{Chapter 8}

46. Hoffmann TC, Montori VM, Del Mar C. The connection between evidence-based medicine and shared decision making. JAMA 2014;312:1295-6.

47. Politi MC, Street RL, Jr. The importance of communication in collaborative decision making: facilitating shared mind and the management of uncertainty. J Eval Clin Pract 2011;17:579-84.

48. Dingfield LE, Kayser JB. Topics in Practice Management: Integrating Advance Care Planning into Practice. Chest 2017.

49. Lum HD, Sudore RL. Advance Care Planning and Goals of Care Communication in Older Adults with Cardiovascular Disease and Multi-Morbidity. Clin Geriatr Med 2016;32:247-60.

50. Prochaska JO, Redding, C.A., Evers, K.E. The Transtheoretical Model and Stages of Change. In: Glanz K, Rimer B.K., Viswanath, K.V. and editors, ed. Health Behavior and Health EducationL Theory Research, and Practice. 4th ed. San Francisco: Jossey-Bass; 2008:170-222.

51. Fried TR, Redding CA, Robbins ML, Paiva A, O'Leary JR, lannone L. Stages of change for the component behaviors of advance care planning. J Am Geriatr Soc 2010;58:2329-36.

52. Ernecoff NC, Keane CR, Albert SM. Health behavior change in advance care planning: an agent-based model. BMC Public Health 2016;16:193.

53. Shaw M, Hewson J, Hogan DB, Raffin Bouchal S, Simon J. Characterizing Readiness for Advance Care Planning From the Perspective of Residents, Families, and Clinicians: An Interpretive Descriptive Study in Supportive Living. Gerontologist 2017.

54. Andreassen $P$, Neergaard MA, Brogaard T, Skorstengaard MH, Jensen AB. The diverse impact of advance care planning: a long-term follow-up study on patients' and relatives' experiences. BMJ Support Palliat Care 2015.

55. Milnes S, Corke C, Orford NR, Bailey M, Savulescu J, Wilkinson D. Patient values informing medical treatment: a pilot community and advance care planning survey. BMJ Support Palliat Care 2017.

56. McAllister M, Dunn G, Payne K, Davies L, Todd C. Patient empowerment: the need to consider it as a measurable patient-reported outcome for chronic conditions. BMC Health Serv Res 2012;12:157.

57. Austin CA, Mohottige D, Sudore RL, Smith AK, Hanson LC. Tools to Promote Shared Decision Making in Serious IIIness: A Systematic Review. JAMA Intern Med 2015;175:1213-21.

58. Schonwetter RS, Walker RM, Kramer DR, Robinson BE. Resuscitation decision making in the elderly: the value of outcome data. J Gen Intern Med 1993;8:295-300.

59. Drukarczyk L, Klein C, Ostgathe C, Stiel S. Life threatening illness in popular movies-a first descriptive analysis. Springerplus 2014;3:411.

60. Stapleton RD, Ehlenbach WJ, Deyo RA, Curtis JR. Long-term outcomes after in-hospital CPR in older adults with chronic illness. Chest 2014;146:1214-25.

61. Van Scoy LJ, Green MJ, Dimmock AE, et al. High satisfaction and low decisional conflict with advance care planning among chronically ill patients with advanced chronic obstructive pulmonary disease or heart failure using an online decision aid: A pilot study. Chronic Illn 2016;12:227-35.

62. Detering KM, Hancock AD, Reade MC, Silvester $W$. The impact of advance care planning on end of life care in elderly patients: randomised controlled trial. BMJ 2010;340:c1345.

63. Sinclair C, Auret KA, Evans SF, et al. Advance care planning uptake among patients with severe lung disease: a randomised patient preference trial of a nurse-led, facilitated advance care planning intervention. BMJ Open 2017; 7:e013415.

64. Reinke LF, Shannon SE, Engelberg R, Dotolo D, Silvestri GA, Curtis JR. Nurses' identification of important yet under-utilized end-of-life care skills for patients with life-limiting or terminal illnesses. J Palliat Med 2010;13:753-9.

65. Au DH, Udris EM, Engelberg RA, et al. A randomized trial to improve communication about end-of-life care among patients with COPD. Chest 2012;141:726-35.

66. Torgerson DJ, Sibbald B. Understanding controlled trials. What is a patient preference trial? BMJ 1998;316:360.

67. Schulman-Green DJ. Psychosocial issues in palliative care: physicians' self-perceived role and collaboration with hospital staff. Am J Hosp Palliat Care 2003;20:34-40. 
68. Best $\mathrm{M}$, Butow $\mathrm{P}$, Olver I. Doctors discussing religion and spirituality: A systematic literature review. Palliat Med 2016;30:327-37.

69. Fan SY, Lin IM, Hsieh JG, Chang CJ. Psychosocial Care Provided by Physicians and Nurses in Palliative Care: A Mixed Methods Study. J Pain Symptom Manage 2017;53:216-23.

70. Reinke LF, Feemster LC, McDowell J, et al. The long term impact of an end-of-life communication intervention among veterans with COPD. Heart Lung 2017;46:30-4.

71. Tselebis A, Pachi A, Ilias I, et al. Strategies to improve anxiety and depression in patients with COPD: a mental health perspective. Neuropsychiatr Dis Treat 2016;12:297-328.

72. Barnes S, Gott M, Payne S, et al. Recruiting older people into a large, community-based study of heart failure. Chronic IIIn 2005;1:321-9.

73. Mitchell GK, Abernethy AP, Investigators of the Queensland Case Conferences T, Palliative Care T. A comparison of methodologies from two longitudinal community-based randomized controlled trials of similar interventions in palliative care: what worked and what did not? J Palliat Med 2005;8:1226-37.

74. Brinkman-Stoppelenburg A, Rietjens JA, van der Heide A. The effects of advance care planning on end-oflife care: a systematic review. Palliat Med 2014;28:1000-25.

75. Hanson LC, Bull J, Wessell K, et al. Strategies to support recruitment of patients with life-limiting illness for research: the Palliative Care Research Cooperative Group. J Pain Symptom Manage 2014;48:1021-30.

76. Kars MC, van Thiel GJ, van der Graaf R, Moors M, de Graeff A, van Delden JJ. A systematic review of reasons for gatekeeping in palliative care research. Palliat Med 2016;30:533-48.

77. Sharkey K, Savulescu J, Aranda S, Schofield P. Clinician gate-keeping in clinical research is not ethically defensible: an analysis. J Med Ethics 2010;36:363-6.

78. Barnett M. Interviewing terminally ill people: is it fair to take their time? Palliat Med 2001;15:157-8.

79. Bradburn J, Maher J. User and carer participation in research in palliative care. Palliat Med 2005;19:91-2.

80. McKee M, Britton A, Black N, McPherson K, Sanderson C, Bain C. Methods in health services research. Interpreting the evidence: choosing between randomised and non-randomised studies. BMJ 1999;319:312-5.

81. Minder CE, Muller T, Gillmann G, Beck JC, Stuck AE. Subgroups of refusers in a disability prevention trial in older adults: baseline and follow-up analysis. Am J Public Health 2002;92:445-50.

82. Shelby-James TM, Hardy J, Agar M, et al. Designing and conducting randomized controlled trials in palliative care: A summary of discussions from the 2010 clinical research forum of the Australian Palliative Care Clinical Studies Collaborative. Palliat Med 2012;26:1042-7.

83. Altman DG. Statistics and ethics in medical research: III How large a sample? Br Med J 1980;281:1336-8.

84. Grimaldo DA, Wiener-Kronish JP, Jurson T, Shaughnessy TE, Curtis JR, Liu LL. A randomized, controlled trial of advanced care planning discussions during preoperative evaluations. Anesthesiology 2001;95:4350; discussion 5A.

85. Sampson EL, Jones $L$, Thune-Boyle IC, et al. Palliative assessment and advance care planning in severe dementia: an exploratory randomized controlled trial of a complex intervention. Palliat Med 2011;25:197-209.

86. Gade G, Venohr I, Conner D, et al. Impact of an inpatient palliative care team: a randomized control trial. J Palliat Med 2008;11:180-90.

87. Song MK, Kirchhoff KT, Douglas J, Ward S, Hammes B. A randomized, controlled trial to improve advance care planning among patients undergoing cardiac surgery. Med Care 2005;43:1049-53.

88. Pearlman RA, Starks H, Cain KC, Cole WG. Improvements in advance care planning in the Veterans Affairs System: results of a multifaceted intervention. Arch Intern Med 2005;165:667-74.

89. Slort W, Schweitzer BP, Blankenstein AH, et al. Perceived barriers and facilitators for general practitioner-patient communication in palliative care: a systematic review. Palliat Med 2011;25:613-29.

90. Curtis JR, Wenrich MD, Carline JD, Shannon SE, Ambrozy DM, Ramsey PG. Patients' perspectives on physician skill in end-of-life care: differences between patients with COPD, cancer, and AIDS. Chest 2002;122:356-62. 


\section{Chapter 8}

91. De Vleminck A, Pardon K, Beernaert K, et al. Barriers to advance care planning in cancer, heart failure and dementia patients: a focus group study on general practitioners' views and experiences. PLoS One 2014;9:e84905.

92. AkI EA, Briel M, You JJ, et al. Potential impact on estimated treatment effects of information lost to follow-up in randomised controlled trials (LOST-IT): systematic review. BMJ 2012;344:e2809.

93. Clayton JM, Houben $\mathrm{CH}$, Gilissen J, et al.. The challenge of conducting randomised controlled trials (RCTs) to study ACP effectiveness: Practical insights from four current RCTs. Abstract ACPEL congress 2015, Munich (Germany).

94. Kross EK, Nielsen EL, Curtis JR, Engelberg RA. Survey burden for family members surveyed about end-oflife care in the intensive care unit. J Pain Symptom Manage 2012;44:671-80.

95. Abernethy AP, Currow DC, Wurzelmann J, et al. Enhancing enrollment in palliative care trials: key insights from a randomized, placebo-controlled study. J Support Oncol 2010;8:139-44.

96. Nicolasora N, Pannala R, Mountantonakis S, et al. If asked, hospitalized patients will choose whether to receive life-sustaining therapies. J Hosp Med 2006;1:161-7.

97. Simon J, Porterfield P, Bouchal SR, Heyland D. 'Not yet' and 'Just ask': barriers and facilitators to advance care planning--a qualitative descriptive study of the perspectives of seriously ill, older patients and their families. BMJ Support Palliat Care 2015;5:54-62.

98. Michiels E, Deschepper R, Van Der Kelen G, et al. The role of general practitioners in continuity of care at the end of life: a qualitative study of terminally ill patients and their next of kin. Palliat Med 2007;21:40915.

99. Toerien M, Brookes ST, Metcalfe $\mathrm{C}$, et al. A review of reporting of participant recruitment and retention in RCTs in six major journals. Trials 2009;10:52.

100. Wright JR, Bouma S, Dayes I, et al. The importance of reporting patient recruitment details in phase III trials. J Clin Oncol 2006;24:843-5.

101. Heffner JE, Fahy B, Hilling L, Barbieri C. Attitudes regarding advance directives among patients in pulmonary rehabilitation. Am J Respir Crit Care Med 1996;154:1735-40.

102. Heffner JE, Fahy B, Hilling L, Barbieri C. Outcomes of advance directive education of pulmonary rehabilitation patients. Am J Respir Crit Care Med 1997;155:1055-9.

103. Sudore RL, Boscardin J, Feuz MA, McMahan RD, Katen MT, Barnes DE. Effect of the PREPARE Website vs an Easy-to-Read Advance Directive on Advance Care Planning Documentation and Engagement Among Veterans: A Randomized Clinical Trial. JAMA Intern Med 2017.

104. Curtis JR, Engelberg R, Young JP, et al. An approach to understanding the interaction of hope and desire for explicit prognostic information among individuals with severe chronic obstructive pulmonary disease or advanced cancer. J Palliat Med 2008;11:610-20.

105. Gardiner C, Gott M, Small N, et al. Living with advanced chronic obstructive pulmonary disease: patients concerns regarding death and dying. Palliat Med 2009;23:691-7.

106. Heffner JE. Advance care planning in chronic obstructive pulmonary disease: barriers and opportunities. Curr Opin Pulm Med 2011;17:103-9.

107. Raghu G, Collard HR, Egan JJ, et al. An official ATS/ERS/JRS/ALAT statement: idiopathic pulmonary fibrosis: evidence-based guidelines for diagnosis and management. Am J Respir Crit Care Med 2011;183:788824.

108. Lorenz KA, Shugarman LR, Lynn J. Health care policy issues in end-of-life care. J Palliat Med 2006;9:73148.

109. Rich MW. Heart failure in the 21st century: a cardiogeriatric syndrome. J Gerontol A Biol Sci Med Sci 2001;56:M88-96.

110. Murray CJ, Lopez AD. Alternative projections of mortality and disability by cause 1990-2020: Global Burden of Disease Study. Lancet 1997;349:1498-504.

111. Borie R, Justet A, Beltramo G, et al. Pharmacological management of IPF. Respirology 2016;21:615-25. 


\section{Summary}
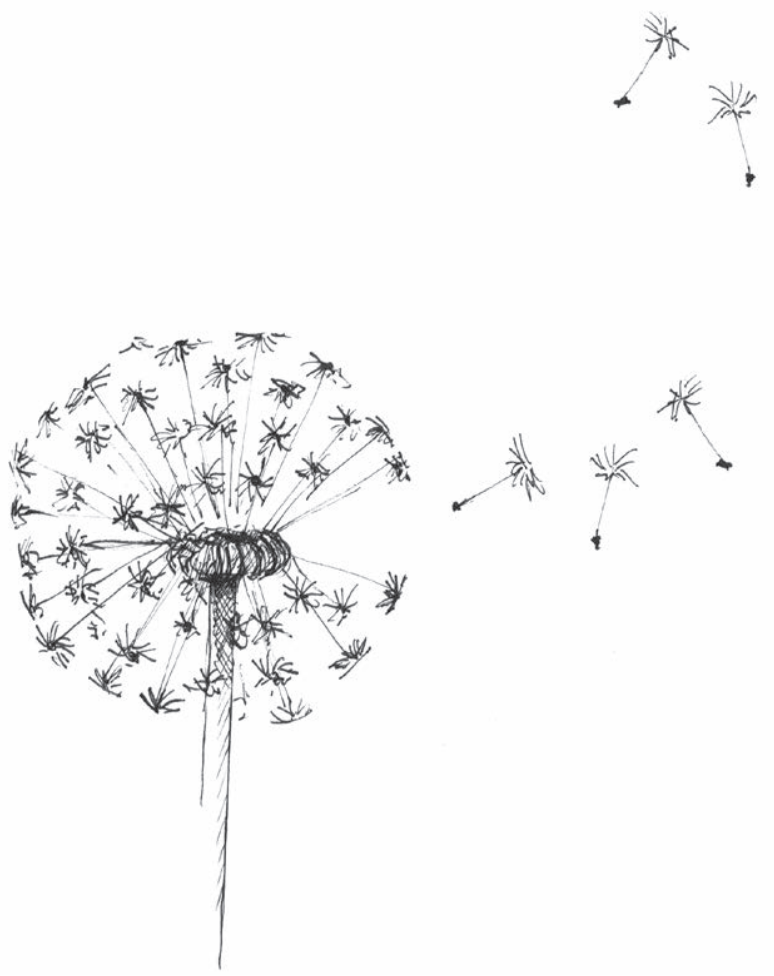



\section{SUMMARY}

Advance care planning ( $A C P$ ) enables individuals to define goals and preferences for future medical treatment and care, to discuss these goals and preferences with family and health-care providers, and to record and review these preferences if appropriate. ACP is an important prerequisite to deliver high-quality palliative care, and therefore an essential component of palliative care for patients with lifelimiting illnesses, such as for example chronic heart failure (CHF), chronic renal failure (CRF), and chronic obstructive pulmonary disease (COPD). Although there has been growing attention for ACP in the last decade, it is still uncommon in clinical practice. Therefore, the main aim of this thesis was to gain more insight into the process of ACP in patients with life-limiting illnesses. In addition, we explored how and whether a nurse-led ACP intervention could improve outcome for patients with COPD and their loved ones (Chapter 1 ).

In Chapter 2 a systematic review was performed to study the efficacy of ACP interventions in different adult patient populations. Randomized controlled trials (RCTs) that described original data on the efficacy of ACP interventions in adult populations and were written in English were included. Fifty-five studies were identified and we found that interventions focusing on advance directives as well as interventions that also included communication about end-of-life care increased the completion of advance directives and the occurrence of end-of-life care discussions between patients and healthcare professionals. In addition, interventions that also included communication about ACP, improved concordance between preferences for care and delivered care and may improve other outcomes, such as quality of communication. Based on this systematic review it can be concluded that ACP interventions increase the completion of advance directives, occurrence of discussions about ACP, concordance between preferences for care and delivered care, and are likely to improve other outcomes for patients and their loved ones in different adult populations.

Although the systematic review showed that ACP is able to improve outcomes for patients and loved ones in diverse adult patient populations, discussions about endof-life care are uncommon in patients with advanced chronic organ failure. However, it was unknown if these discussions about end-of-life care would change during the course of the disease or toward the end of life. Therefore, in Chapter 3 longitudinal data were analyzed in order to examine the quality of end-of-life care communication during one year follow-up of patients with advanced chronic organ failure. In addition, we aimed to explore whether and to what extent quality of 
communication about end-of-life care changes towards the end of life and whether end-of-life care communication is related to patient perceived quality of medical care. Quality of end-of-life care communication was rated low at baseline and did not change over one year. Quality of end-of-life care communication was comparable for patients who completed two-year follow-up and patients who died during the study. The correlation between quality of end-of-life care communication and satisfaction with medical treatment was weak. This manuscript highlighted that end-of-life care communication is poor in patients with chronic organ failure and does not change towards the end of life.

In addition, we examined stability of willingness to accept life-sustaining treatments during one-year follow-up in Dutch patients with advanced chronic organ failure (Chapter 4). We found that overall, proportions of patients who were willing to accept life-sustaining treatment during one year did not change over time. However, individual trajectories showed that about two third of patients changed their preferences at least once during a year. These findings show the complexity of preferences for end-of-life care and indicated once again that ACP is a continuous process between patients and physicians, in which preferences for specific situations need to be regularly reevaluated in order to deliver high-quality end-of-life care.

Although doctors are the primary source of information for most patients, media such as television are also powerful mediums in influencing people's behavior. However, it was unknown which image is sketched on television about end-of-life care communication. Therefore, we explored in Chapter 5 how healthcare professionals, patients, and loved ones communicate about end-of-life care in popular television medical dramas. We concluded that healthcare professionals in television medical dramas talked with patients or loved ones about end-of-life. However, topics important for patients in real life were often not discussed.

Finally, a RCT (ACP-study) was designed to explore whether and to what extent structured ACP by a trained nurse, in collaboration with the chest physician, can improve the quality of end-of-life care and communication about end-of-life care in patients with COPD and their loved ones. Patients with COPD who are recently discharged after an exacerbation or who recently started oxygen therapy at home were eligible to participate. Patients were recruited from four Dutch hospitals and were assigned to an intervention or control group, depending on the randomization of their chest physician. Patients were assessed at baseline and after 6, 12 and 24 months. The intervention group received a structured ACP-session by a trained 
nurse (Chapter 6). The ACP-study showed that a structured ACP-session by a trained nurse can facilitate patient-physician communication about end-of-life care. Indeed, quality of communication improved statistically significant in the intervention group in comparison with the control group. However, changes were small and there is still considerable room for improvement as about half of the patients in the intervention group still hadn't discussed ACP with their clinician. Moreover, we showed that symptoms of anxiety and depression did not increase following the intervention in both patients and loved. Actually, at 6-months follow-up symptoms of anxiety were significantly lower in loved ones in the intervention group compared to the control group (Chapter 7).

The recruitment of patients for the ACP-study was more difficult than expected $a$ priori. However, to our knowledge a detailed analysis of the recruitment process in RCTs focusing on ACP was lacking. Therefore, we wrote a review which provides an overview of the recruitment processes of the ACP-study and other RCTs focusing on ACP. The difficulties and consequences of gatekeeping, patient's refusal and sustained participation were discussed and recommendations on how to deal with these challenges in the future were described (Chapter 8).

In Chapter 8, the main findings of this thesis were discussed in depth by combining our results with the findings of (recently) published literature. We concluded that ACP is a continuous process of communication between the patient, loved ones and healthcare professionals, that should start at the appropriate time during the disease trajectory, and is tailored to the individual needs of the patient and his/her loved one(s). In addition, the developed nurse-led ACP-intervention has proved to be an adequate facilitator for patient-physician communication about end-of-life care and should be implemented in regular clinical care. However, in order to further improve ACP in patients with COPD and other life-limiting illnesses, more is needed than only an intervention focused on behavior change in one healthcare professional. 



\section{Samenvatting}

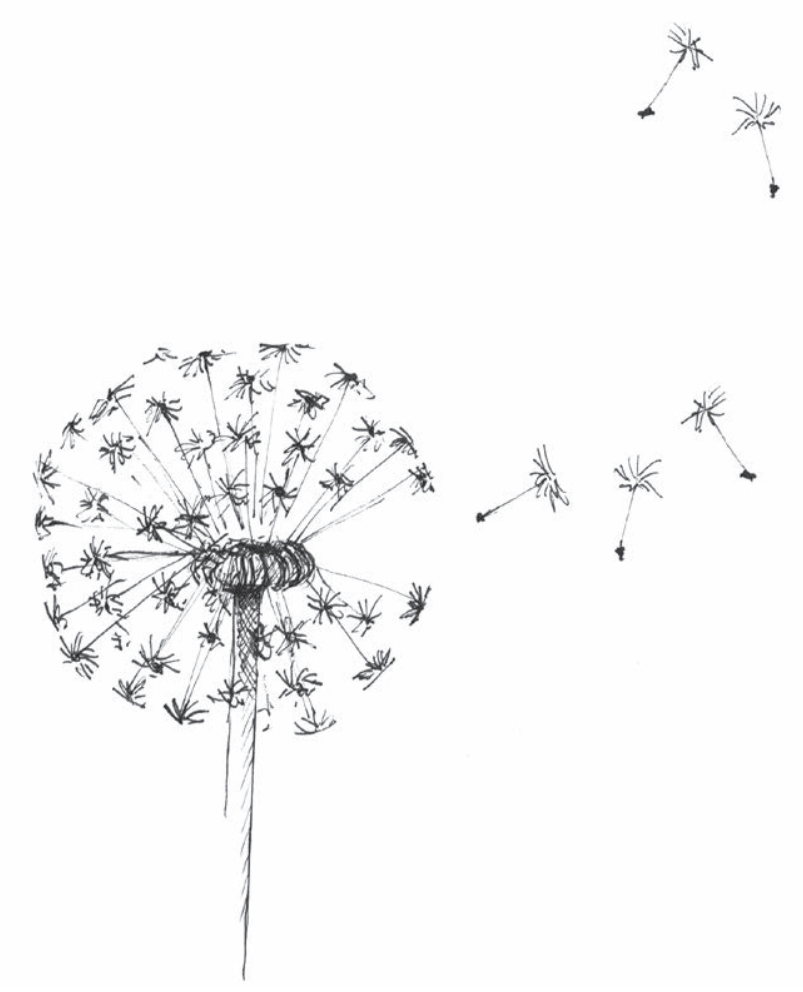





\section{SAMENVATTING}

Proactieve zorgplanning stelt individuen in staat om doelen en voorkeuren voor toekomstige medische zorg en behandeling te bepalen, deze doelen en voorkeuren te bespreken met naasten en zorgverleners, en vast te leggen en indien nodig tussentijds te herzien. Proactieve zorgplanning is een belangrijke voorwaarde voor het leveren van kwalitatief hoogwaardige palliatieve zorg en is daarom een essentieel onderdeel van palliatieve zorg voor patiënten met levensbeperkende ziekten, zoals bijvoorbeeld chronisch hartfalen, chronisch nierfalen en chronisch obstructieve longziekten (COPD). Hoewel de aandacht voor proactieve zorgplanning in het laatste decennium is toegenomen, wordt het nog maar weinig toegepast in de klinische praktijk. Daarom heeft dit proefschrift tot doel om meer inzicht te verkrijgen in het proces van proactieve zorgplanning bij patiënten met levensbeperkende ziekten. Daarnaast hebben we onderzocht of en hoe een proactieve zorgplanning interventie, geleid door een verpleegkundige, uitkomsten voor patiënten met COPD en hun naasten kan verbeteren.

In Hoofdstuk 2 is een systematische review uitgevoerd om de effectiviteit van proactieve zorgplanning interventies in diverse volwassen patiëntenpopulaties te bestuderen. Gerandomiseerde interventiestudies, die geschreven waren in het Engels, en waarin originele data werden beschreven met betrekking tot de effectiviteit van proactieve zorgplanning interventies in volwassen patiëntenpopulaties zijn geïncludeerd. Vijfenvijftig studies zijn geïdentificeerd op basis waarvan we hebben kunnen constateren dat zowel interventies gericht op wilsverklaringen als interventies die zich daarnaast ook richtten op communicatie over zorg rondom het levenseinde, het aantal voltooide wilsverklaringen en het aantal discussies tussen patiënten en gezondheidsprofessionals over zorg rondom het levenseinde deden toenemen. Daarnaast is gebleken dat interventies die zich tevens richtten op communicatie over proactieve zorgplanning, de mate van overeenstemming tussen voorkeuren voor zorg en daadwerkelijk geleverde zorg vergrootten. Tenslotte verbeterden deze interventies een aantal andere uitkomsten, zoals bijvoorbeeld de kwaliteit van communicatie. Gebaseerd op deze systematische review kan geconcludeerd worden dat proactieve zorgplanning interventies een positief effect hebben op het aantal voltooide wilsverklaringen, het plaatsvinden van discussies over proactieve zorgplanning en de mate van overeenstemming tussen gewenste en geleverde zorg in diverse volwassen patiëntenpopulaties.

Hoewel de systematische review aantoonde dat proactieve zorgplanning meerdere uitkomsten voor patiënten en naasten verbetert in diverse volwassen patiëntenpo- 
pulaties, blijken patiënten met gevorderd chronisch orgaanfalen zelden met gezondheidszorgprofessionals te praten over zorg rondom het levenseinde. Echter, het was onbekend of het plaatsvinden van gesprekken over zorg rondom het levenseinde veranderde gedurende het ziektetraject of richting het levenseinde. Daarom zijn in Hoofdstuk 3 longitudinale data geanalyseerd om de kwaliteit van communicatie over zorg rondom het levenseinde gedurende 1 jaar te onderzoeken bij patiënten met gevorderd chronisch orgaanfalen. Daarnaast is onderzocht of en in welke mate de kwaliteit van communicatie over zorg rondom het levenseinde veranderde richting het levenseinde en of communicatie over zorg rondom het levenseinde samenhangt met de door de patiënt ervaren kwaliteit van medische zorg. Kwaliteit van communicatie over zorg rondom het levenseinde was laag bij de beginmeting en veranderde niet gedurende een jaar. De kwaliteit van communicatie over zorg rondom het levenseinde was vergelijkbaar voor patiënten die de tweejarige follow-up voltooiden en patiënten die overleden gedurende de studie. De correlatie tussen kwaliteit van communicatie over zorg rondom het levenseinde en tevredenheid met de medische behandeling was laag. Dit hoofdstuk benadrukt dat de communicatie over zorg rondom het levenseinde slecht is bij patiënten met chronisch orgaanfalen en dat dit ook niet verandert richting het levenseinde.

Vervolgens hebben we in Hoofdstuk 4 onderzoek gedaan naar de vraag hoe stabiel de bereidheid om levensverlengende behandelingen te ondergaan is gedurende een jaar bij patiënten met gevorderd chronisch orgaanfalen. We hebben vastgesteld dat, in het algemeen, de proportie patiënten die bereid waren levensverlengende behandelingen te accepteren niet veranderde gedurende een jaar. Echter, individuele trajecten lieten zien dat ongeveer twee derde van de patiënten zijn/haar voorkeuren minimaal één keer veranderde gedurende één jaar. Deze bevindingen tonen de complexiteit van voorkeuren voor zorg rondom het levenseinde aan en vormen opnieuw een indicatie voor het feit dat proactieve zorgplanning een continu proces tussen patiënten en artsen is, waarbij voorkeuren voor specifieke situaties regelmatig opnieuw dienen te worden geëvalueerd om kwalitatief hoogwaardige zorg rondom het levenseinde te leveren.

Hoewel artsen voor de meeste patiënten de primaire informatiebron zijn, zijn media, zoals televisie ook krachtige communicatiekanalen om het menselijk gedrag te beïnvloeden. Echter, het was onbekend welk beeld op televisie geschetst wordt over communicatie over zorg rondom het levenseinde. Daarom is in Hoofdstuk 5 onderzocht hoe gezondheidszorgprofessionals, patiënten en naasten over zorg rondom het levenseinde communiceren in populaire medische televisiedrama's. We concludeerden dat gezondheidszorgprofessionals in medische televisiedrama's 
met patiënten of naasten praten over het levenseinde. Echter, onderwerpen die belangrijk zijn voor patiënten in het echte leven werden vaak niet besproken.

Tenslotte is een gerandomiseerde interventiestudie (ACP-studie) opgezet om te onderzoeken of en in welke mate gestructureerde proactieve zorgplanning door een getrainde verpleegkundige, in samenwerking met de longarts, de kwaliteit van zorg rondom het levenseinde en communicatie over zorg rondom het levenseinde bij patiënten met COPD en hun naasten kan verbeteren. Patiënten met COPD die recent met ontslag waren uit het ziekenhuis na een exacerbatie of die recentelijk gestart waren met zuurstoftherapie, waren geschikt voor deelname. Deze patiënten zijn geworven in vier Nederlandse ziekenhuizen en zijn toegewezen aan een interventie- of een controlegroep, afhankelijk van de randomisatie van hun longarts. Metingen bij de patiënten hebben plaatsgevonden op baseline en na 6, 12 en 24 maanden. De interventiegroep heeft een gestructureerde sessie proactieve zorgplanning door een getrainde verpleegkundige ontvangen (Hoofdstuk 6). De ACPstudie toonde aan dat een gestructureerde sessie proactieve zorgplanning, door een getrainde verpleegkundige, patiënt-arts communicatie over zorg rondom het levenseinde kan faciliteren. Inderdaad, de kwaliteit van communicatie verbeterde statistisch significant in de interventiegroep in vergelijking met de controlegroep. Echter, de verbetering is summieren er is aanzienlijke ruimte voor verbetering gezien ongeveer de helft van de patiënten in de interventiegroep nog steeds niet met de arts gesproken had over proactieve zorgplanning. Daarnaast hebben we laten zien dat symptomen van angst en depressie niet toe zijn genomen na de interventie bij zowel patiënten als naasten. Symptomen van angst zijn bij de naasten na 6 maanden zelfs significant lager in de interventiegroep in vergelijking met de controlegroep (Hoofdstuk 7).

De rekrutering van patiënten voor de ACP-studie was moeilijker dan vooraf gedacht. Echter, voor zover wij weten ontbrak een gedetailleerde analyse van het rekruteringsproces van gerandomiseerde interventiestudies gericht op proactieve zorgplanning. Daarom hebben we een review geschreven waarin we een overzicht geven van het rekruteringsproces van de ACP-studie en andere gerandomiseerde interventiestudies gericht op proactieve zorgplanning. De moeilijkheden en consequenties van poortwachten, het weigeren van deelname door patiënten en het verliezen van patiënten tijdens de studie is in deze review uitgebreid aan de orde gesteld. Tevens werden aanbevelingen gedaan over hoe met deze uitdagingen om te gaan in de toekomst (Hoofdstuk 8). 
In Hoofdstuk 8 zijn de belangrijkste bevindingen van dit proefschrift grondig besproken door onze resultaten te combineren met de bevindingen van (recent) gepubliceerde literatuur. We concluderen dat proactieve zorgplanning een continu proces van communicatie tussen de patiënt, naasten en gezondheidszorgprofessionals is. Dit proces dient te starten op het juiste moment tijdens het ziektetraject en moet worden aangepast aan de individuele behoeften van de patiënt en zijn/haar naaste(n). Daarnaast heeft de ontwikkelde proactieve zorgplanning interventie, geleid door een verpleegkundige, aangetoond een adequate facilitator te zijn voor patiënt-arts communicatie over zorg rondom het levenseinde en wordt aanbevolen deze interventie te implementeren in de reguliere klinische zorg. Echter, om proactieve zorgplanning voor patiënten met COPD en andere levensbeperkende ziekten te verbeteren is meer nodig dan enkel een interventie gericht op gedragsverandering bij de gezondheidszorgprofessional. 


\section{Valorization}
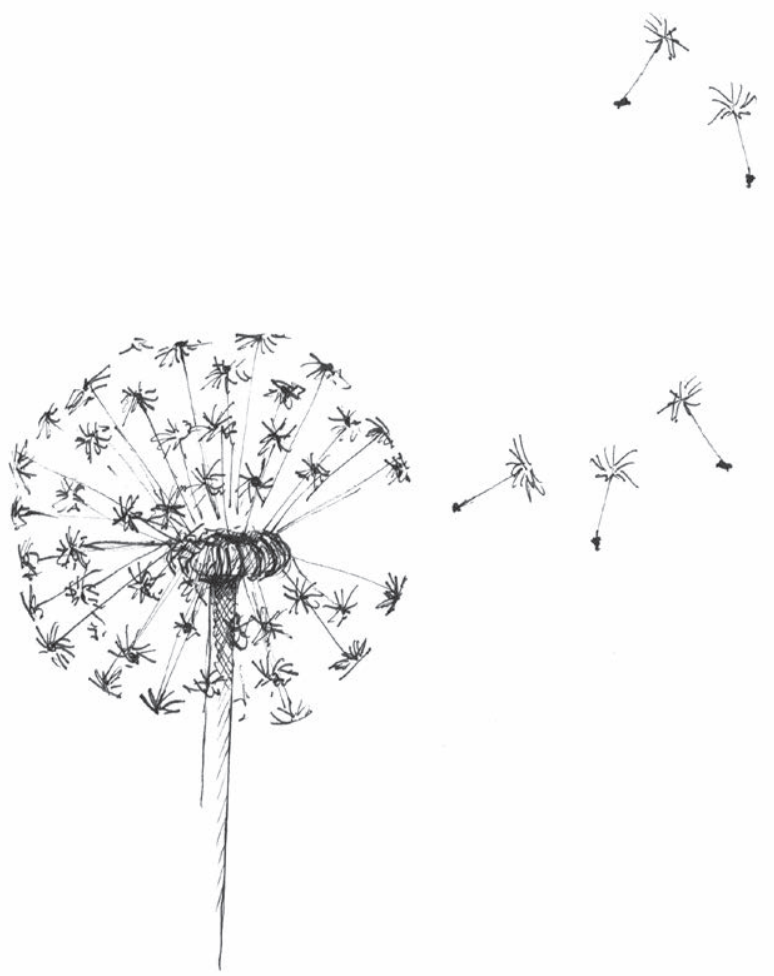



\section{VALORIZATION}

Knowledge valorization refers to 'the process of creating value from knowledge, by making knowledge suitable and/or available for social (and/or economic) use and by making knowledge suitable for translation into competitive products, services, processes and new commercial activities' (adapted definition based on the National Valorization Committee 2011:8). Given this definition, the societal value will be reflected on from five different perspectives: 1 . Relevance - What is the social and/or economic relevance of the research results? 2. Target groups - To whom, in addition to the academic community, are your research results of interest and why? 3. Activities and products - Into which concrete products, services, processes, activities or commercial activities will the results be translated and shaped? 4. Innovation - To what degree can the results be called innovative in respect to the existing range of products, services, processes, activities and commercial activities?

\section{RELEVANCE AND INNOVATION}

The prevalence and mortality rate of life-limiting illnesses, such as chronic heart failure (CHF), chronic renal failure (CRF), and COPD are increasing worldwide. The disease trajectories of life-limiting illnesses are often characterized by uncertainty and are heterogeneous. The uncertainty of the disease trajectory makes it difficult for both physicians, patients and loved ones to timely start to talk about preferences for end-of-life care. However, patient-physician communication is an important prerequisite to deliver high-quality palliative care. Therefore, advance care planning (ACP), which enables individuals to define goals and preferences for future medical treatment and care, to discuss these goals and preferences with family and healthcare providers, and to record and review these preferences if appropriate, is essential for patients with life-limiting illnesses. Indeed, active involvement in the process of ACP is important to maintain patient autonomy and improve quality of care near the end-of-life for both patients and their loved ones. Furthermore, ACP can contribute to the delivery of end-of-life care in concordance with patients' preferences, which may reduce healthcare costs at the end-of-life. Indeed, previous research has shown that ACP-interventions have the potential to reduce highintensity care and associated healthcare costs at the end-of-life. Despite the fact that patients with life-limiting illnesses are able to indicate their preferences for end-of-life care and ACP has proven to be effective in diverse adult patient populations, ACP is uncommon in patients with life-limiting illnesses. Therefore the main aim of the current thesis was to gain more insight into the quality of end-of-life care 
communication in patients with life-limiting illnesses. In addition, we developed, executed and analyzed a structured, nurse-led ACP-intervention in order to improve ACP for patients with COPD and their loved ones.

\section{TARGET GROUPS}

Beside patients with life-limiting illnesses, especially patients with COPD, and their loved ones, also healthcare providers, the government and health insurance companies are important target groups of this thesis, because all of these target groups are involved in delivering optimal high-quality end-of-life care in concordance with patients' preferences.

\section{Patients with life-limiting illnesses}

ACP is an interdisciplinary process between patients, loved ones and healthcare professionals. The patient is the most important component in this triangle, as ACP is a process tailored to elicit patient's preferences for end-of-life care in order to ensure that clinical care is shaped by and in concordance with patient's preferences. ACP is an important element to achieving patient autonomy because it provides patients the opportunity to timely discuss their preferences for end-of-life care instead of waiting for a medical crisis. Therefore, ACP is especially important for patients with life-limiting illnesses, such as chronic organ failure, as those disease trajectories are often characterized by unpredictability and uncertainty. In addition, ACP can contribute to enhance the sense of control, as patients with lifelimiting illnesses often perceive a low sense of control about their disease as a consequence of physical impairments. In this thesis we have shown that by having timely discussions about end-of-life care ACP can improve patient-physician end-oflife care communication without causing psychosocial distress in patients with COPD. Although the ACP-study was focused on patients with advanced COPD, the intervention could also be applied to other life-limiting illnesses, such as CHF or idiopathic pulmonary fibrosis (IPF). In fact, CHF is the leading cause of mortality worldwide and the prognosis of IPF is poor, which underlines the importance of timely ACP in those patients. Unfortunately, also in patients with CHF or IPF, ACP is uncommon, while both patient populations experience palliative care needs and are willing to discuss their future medical care.

In current healthcare there has been growing attention for personalized medicine. This patient-centered approach is focused on disease management tailored to indi- 
vidual care needs of patients in order to improve quality of life. In fact, ACP can be seen as part of personalized medicine. Indeed, ACP-discussions have to be adapted to the patients' needs in order to deliver end-of-life care in concordance with patients' preferences. To achieve this goal the question 'what is important for this individual patient?' is essential.

Loved ones of patients with life-limiting illnesses

The designation of a surrogate decision maker is part of the process of ACP. Loved ones often act as surrogate decision maker and as a consequence have a pivotal role in ACP. Indeed, when patients are no longer able to make decisions about personal healthcare, the surrogate decision maker must provide direction in decision making. Surrogate decision-making can be emotional burdensome, especially when the loved one is not sure about the patient's preferences for end-of-life care. Therefore, it is important for loved ones to know the end-of-life care preferences of the patient and to be actively involved in ACP-discussions. In this sense, ACP may help loved ones in deciding about patient's end-of-life care and decrease the burden of surrogate decision-making. For this reason, we actively involved loved ones in the ACP-study by providing the ACP-session in the presence of the patient and his or her loved one(s).

\section{Healthcare providers}

ACP is not only important for patients with life-limiting illnesses and their loved ones, but also for healthcare providers, since they are involved in the process of decision-making and delivering the actual end-of-life care. Indeed, some patients prefer to leave final decisions regarding end-of-life care to the physician. Furthermore, healthcare providers have to collaborate with loved ones to make surrogate decisions when the patient lacks decisional capacity. In fact, healthcare professionals can only adequately fulfill this task when they are aware of patient's preferences. Therefore, timely communication about preferences for end-of-life care in terms of ACP is important for healthcare professionals in order to deliver end-of-life care in concordance with patient's wishes. Here too, ACP should not be limited to the discussion and documentation of preferences for life-sustaining treatments, but should also include comprehensive discussions about different scenarios which could occur in patients with life-limiting illnesses during the disease trajectory. Indeed, when ACP is limited to the documentation of life-sustaining treatment preferences those preferences are often not applicable to the clinical situation at hand. 
The economic burden of life-limiting illnesses, as for example COPD, is substantial by a high burden of healthcare consumptions. The prevalence of COPD is expected to increase in the next years and as a consequence the health care costs will rise further. Although the cost-effectiveness of ACP was not assessed in this thesis, it is possible that early ACP can improve those healthcare costs by preventing unwanted life-sustaining treatments, ICU admissions or hospitalizations at the end-of-life. Indeed, as a consequence of continuous improvements in healthcare technology people with life-limiting illnesses live longer. However, it can be questioned how treatments aimed at life extension will affect a patient's quality of life. ACP is of particular importance in a constantly developing world of medicine to answer the question: "Would you want everything possible to be done?".

\section{ACTIVITIES AND PRODUCTS}

As part of the ACP-study we have developed a two-day training for respiratory nurse specialists, during which end-of-life care communication skills and the structured ACP session during the study were taught and practiced. This training can be used to teach ACP to other healthcare professionals, such as chest physicians, general practitioners or medical students. In addition, the training can be adapted to be used to teach ACP to nurses working in outpatient settings, such as homecare organizations, or other departments, such as cardiology or oncology.

The findings presented in this thesis have led to several activities in the field of expertise. Besides the fact that the results of this thesis were published in professional scientific journals, they were also presented during symposia and congresses. The results published in Chapter 2 were presented during the 'Junior Research Symposium Centres of Expertise for Palliative Care' in 2014. The results of Chapter 3 were presented as a poster during the $4^{\text {th }}$ International Seminar of the PRC/EAPC in 2014 and in Dutch during the 'Vlaams-Nederlands Onderzoeksforum Palliatieve Zorg' in 2015. The results of Chapter 4 were presented during the International Society of Advance Care Planning and End-of-Life Care (ACPEL) conference in 2015. In addition, for the presentation about the results published in Chapter 2 the award for 'best oral presentation' was received in 2014. Moreover, the 'NRS Travel Grant' was received in 2015 and provided the opportunity to present the results published in Chapter 4 during the ACPEL conference. Furthermore, data of the ACP-study about preferences for end-of-life care (not included in this thesis), were presented 
during the European Respiratory Society (ERS) Congress in 2016. Finally, presentations about the importance of ACP in patients with COPD were presented during several other events

\section{INNOVATION AND IMPLEMENTATION}

The lack of communication about end-of-life care in patients with COPD is well described in the current literature. However, adequate, structured and individualized ACP-interventions aimed at improving this quality of end-of-life care communication were lacking. The ACP-study has proved that the developed structured nurseled ACP intervention adapted to specific needs for ACP in COPD is an adequate facilitator for patient-physician communication about end-of-life care without causing psychosocial distress in both patients and their loved ones. However, changes found in the ACP-study were small and there is still room for improvement. In our opinion future ACP-studies should therefore not only focus on behavior change in one healthcare professional, but should also include patient empowerment. For example, online personalized ACP education platforms could be developed for patients with life-limiting illnesses in order to induce behavior change regarding initiation of ACP-discussions by increasing awareness in patients and loved ones of the importance of ACP; addressing ACP education needs; and empowering of patients to start an ACP-discussion with a healthcare professional. We believe that those education platforms could be a desirable addition to our developed and in this thesis described ACP-intervention. Indeed, this thesis provided directions for implementation of ACP in regular clinical care. For example, ACP can be implemented in the hospital setting or in other clinical care settings which care for patients with lifelimiting illnesses, such as general practice and rehabilitation centers. Furthermore, this thesis offered clues to include ACP in guidelines on the treatment and management of life-limiting illnesses, in order to make ACP as a routine and standard part of care. In addition, the intervention can possibly be implemented for other patients with advanced chronic life-limiting illness, such as CHF or IPF. 



\section{Dankwoord}

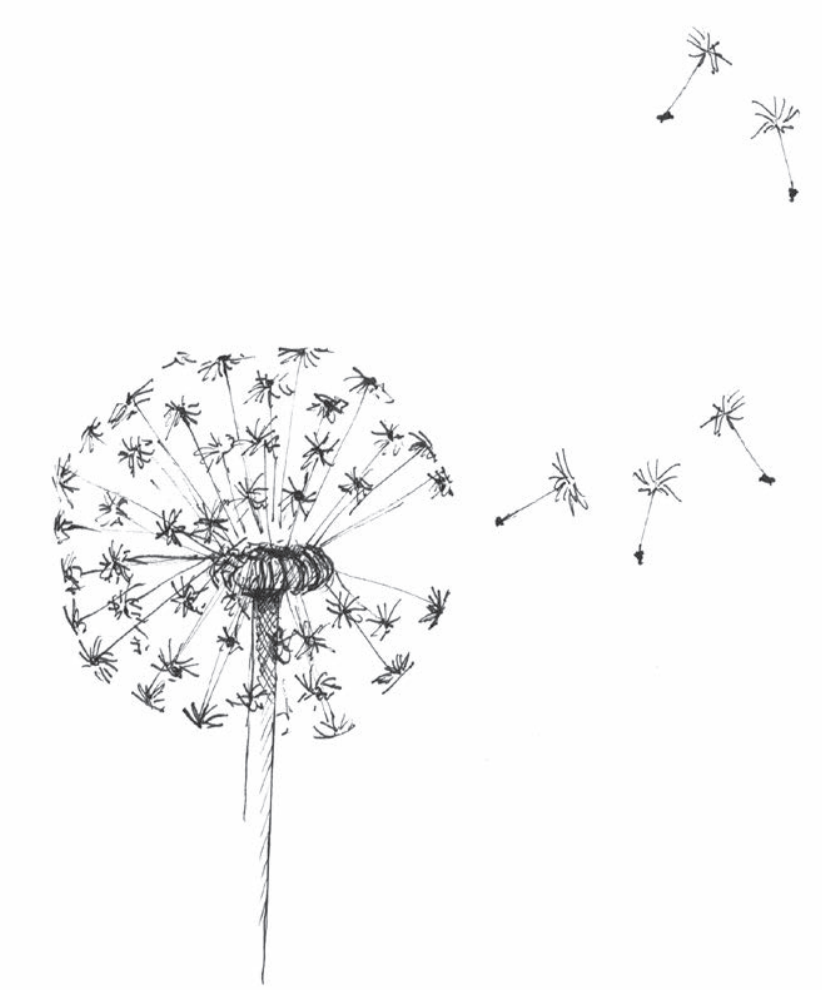





\section{DANKWOORD}

In gedachten heb ik mijn dankwoord al vele malen geschreven, maar nu ik het daadwerkelijk op papier moet gaan zetten, vind ik het toch moeilijker dan gedacht.

De afgelopen jaren waren voor mij als een reis die vandaag zijn eindbestemming gaat bereiken. Deze reis had ik niet kunnen maken zonder de steun van velen en daarom wil ik op deze wijze iedereen die (on)bewust heeft bijgedragen aan de totstandkoming van mijn proefschrift bedanken.

Mijn promotieonderzoek was ook in letterlijke zin een hele reis: meer dan 26.000 kilometer heb ik afgelegd in mijn rode autootje om patiënten en naasten te bezoeken en data te verzamelen voor de ACP-studie. Allereerst wil ik dan ook alle deelnemers van de ACP-studie bedanken. Dank dat ik bij u thuis mocht komen. Dank dat $u$, soms met een lach en een traan, met mij in gesprek wilde gaan over uw wensen in de laatste levensfase. Een bijzonder woord van dank aan de nabestaanden van patiënten die helaas tijdens de studie zijn overleden. Dank dat $u$ op een dergelijk kwetsbaar moment bereid was om samen met mij terug te blikken op de laatste weken van het leven van uw dierbare.

Prof. Wouters, dank voor uw begeleiding in de afgelopen jaren en uw kritische blik op de artikelen die ik de afgelopen jaren heb geschreven. Ik heb bewondering voor de planmatige, proactieve en toekomstgerichte wijze warop u te werk gaat bij het uitdragen van uw visie. Zoals $u$ het zelf ooit zei tijdens een presentatie: "a vision without action remains a dream". Prof. Wouters en Ingrid Augustin, Raad van Bestuur van Ciro, wil ik beiden graag bedanken voor de mogelijkheden die mij binnen Ciro zijn geboden om mij niet alleen als onderzoeker, maar ook als psycholoog te kunnen ontplooien. Ik ben er trots op deel van de Ciro-familie te mogen zijn.

Prof. Spruit, beste Martijn, dank voor het enthousiasme waarmee je mij de afgelopen jaren hebt begeleid. Al is proactieve zorgplanning wellicht niet helemaal jouw onderzoeksgebied, ik kon altijd bij je terecht voor wetenschappelijke adviezen en feedback. Ik heb bewondering voor jouw torenhoge en aanstekelijke ambitie.

Dr. Janssen, beste Daisy, dank voor het delen van al jouw kennis en kunde op het gebied van palliatieve zorg. Ik kan je niet genoeg bedanken voor alle kansen die je me in de afgelopen jaren hebt geboden om in binnen- en buitenland lezingen te geven over proactieve zorgplanning! Dankjewel voor het vertrouwen dat je in me 
hebt gesteld. Ik hoop dat ik ook in de toekomst nog van je mag blijven leren en dat we nog blijven samenwerken.

Het rekruteren van deelnemers voor de ACP-studie was niet altijd gemakkelijk, maar was al helemaal niet gelukt zonder het enthousiasme en de betrokkenheid van de longartsen en longverpleegkundigen van de deelnemende ziekenhuizen. Dank aan de lokale onderzoekers: drs. Creemers (Catharina Ziekenhuis Eindhoven), dr. van Kampen-van den Boogaart (VieCuri Medisch Centrum Venlo), dr. Pennings (Laurentius Ziekenhuis Roermond) en prof. dr. Rohde (Maastricht UMC+).

De ACP-studie heeft tot positieve en mooie onderzoeksresultaten geleid, mede dankzij de professionele en kundige manier waarop de longverpleegkundigen van de deelnemende ziekenhuizen de interventiegesprekken bij de patiënten thuis hebben uitgevoerd. Lieve Annet, Walter, Carien, Nicolle, Marleen, Hilde, Marjo† en Mieke dank voor de fijne samenwerking in de afgelopen jaren en de tijd die jullie met liefde en plezier aan het onderzoek hebben besteed.

Beste co-auteurs, dank voor uw altijd snelle feedback bij het schrijven van artikelen. Zonder andere co-auteurs te kort te doen wil ik twee van hen in het bijzonder bedanken. Beste drs. Groenen, beste Miriam, dank voor je uitgebreide uitleg bij het uitvoeren van de allereerste meta-analyse in mijn leven en de interesse in de voortgang van mijn promotieonderzoek. Beste dr. Luyten, beste Hans, dank voor het geduld en de tijd waarmee je me wegwijs hebt gemaakt in het uitvoeren van multilevel lineaire regressieanalyses. Het waren de kilometers naar Enschede meer dan waard!

Dank aan de leden van de beoordelingscommissie, bestaande uit prof. dr. Smeenk, prof. dr. Muris, prof. dr. van den Beuken, prof. dr. Hertogh en dr. Rietjens, voor het grondig bestuderen van dit proefschrift en het goedkeuren hiervan.

Tevens gaat mijn dank uit naar het Longfonds, voor het financieel mogelijk maken van de ACP-studie en hiermee mijn promotietraject. Dank voor uw interesse in de artikelen voortkomende uit de ACP-studie.

Dank aan mijn allerliefste onderzoekscollega's. Lieve Anouk, Cindy, Coby, Dionne LB, Dionne S, Esther, Fiona, Jeannet, Nienke, Rafael, Sarah, Vasilis, Wai-Yan en Yvonne voor mij zijn jullie veel meer dan collega's. Promoveren werd niet gemakkelijker, maar was wel veel leuker met jullie naast me. De vlaaimomentjes (kruisbessen met schuim blijft favoriet), congresbezoeken, diverse challenges (van de appel contest 
tot de wallsit challenge), lunchwandelingen, dobbelen, etentjes, promoties etc. waren altijd een verademing tussen de huisbezoeken en het schrijven van artikelen door. Dank voor alle steun op alle gebied in de afgelopen jaren!

Dank ook aan mijn lieve (oud-)PST-collega's. Lieve Arlett, Arlette, Candy, Lara, Monique, Nelly, Nicole, Robin en Suzanne, bedankt voor jullie interesse in de vorderingen van mijn promotieonderzoek. Dankzij jullie flexibiliteit was het voor mij mogelijk om de laatste fase van mijn promotietraject te combineren met werken in de kliniek. Lieve Candy, dankjewel voor de mentale ondersteuning bij "de laatste loodjes" en het vinden van balans tussen werk en privé als ik dat zelf even uit het oog dreigde te verliezen.

Ook alle overige collega's van Ciro wil ik graag bedanken voor de interesse in mijn onderzoek. Hoewel we allemaal voor een andere discipline werken, vormen we samen een sterk team waarbij iedereen zich inzet voor één en hetzelfde doel: het verbeteren van de kwaliteit van leven van onze patiënten.

Mevrouw Knot, beste Milou, dank voor het enthousiasme waarmee je mijn vraag beantwoordde om de cover van mijn proefschrift te ontwerpen. Ik vind het ontzettend knap hoe je de ideeën die ik in mijn hoofd had om hebt gezet naar een ontwerp en ben dan ook enorm trots op het eindresultaat!

Meuwissen training en coaching, beste Remco en Miranda, jullie bootcamptrainingen waren in de afgelopen jaren voor mij een welkome afwisseling. Even het hoofd leegmaken en tot het gaatje gaan. Het motto "kan ik niet, bestaat niet" is zeker ook van toepassing op promoveren en heeft me bij tegenslagen geholpen om door te gaan en niet op te geven.

Kapel Gootgemootj, voor deze keer toch in het Nederlands: dank voor de afleiding en gezelligheid tijdens repetities en optredens.

Lieve meiden van med-psy, Merel, Ruth, Sophie en Stefanie, het is alweer heel wat jaartjes geleden dat we samen in de collegebanken zaten in Tilburg. Wat hebben we daar plezier gehad en ook nu nog staan onze gezamenlijke etentjes altijd garant voor gezelligheid.

Lieve meiden van V.V. de Verlepdje Roeëze, lieve Angèle, Floor, Katrien, Kim, Lidy en Miranda (en aanhang en kids), dank voor jullie afleiding in de vorm van humor, lol en flauwekul en de interesse in mijn promotie. 
Lieve meiden van "Wieërt", Kristel, Martine, Sandra en Yvonne, al zijn we na de middelbare school allemaal onze eigen weg gegaan en lagen deze wegen soms letterlijk mijlenver uit elkaar we hebben altijd contact gehouden. Mooi om te zien hoe ieder zijn eigen weg volgt en hoe we elkaar daarin stimuleren. Yf, als jij me in 2012 niet gewezen had op de vacature bij Ciro had ik hier vandaag niet gestaan. Je had toen al gelijk: dit onderzoek past bij mij.

Een speciaal woord van dank voor mijn paranimfen Anique en Nienke. Lieve Anique, hier staat je kleine zusje dan! Wat ben ik trots dat jij vandaag achter me wil staan. Al zijn we nog zo verschillend, we begrijpen elkaar als geen ander en hebben vaak aan een woord genoeg. Eén ding hebben we wel gemeen: ons gevoel voor humor. Al begrijpt niemand ons, samen hebben wij altijd de grootste lol en doen we de beste uitvindingen. Onze "soeur-acitivités" ben ik in mijn promotiejaren enkel maar meer gaan waarderen en vormden altijd een welkome afleiding. Lieve Nienke, in mei 2017 had ik de eer om jouw paranimf te mogen zijn en vandaag heb ik de eer dat jij die rol bij mijn promotie wilt vervullen. Zoals je zelf al schreef in je dankwoord zijn we collega's vanaf het eerste uur en vertonen onze promotietrajecten veel gelijkenissen. Dit leidde tot wederzijds begrip en dat heeft er mede toe geleid dat ik vandaag de finish ga passeren! Ik wil je bedanken voor alle steun de afgelopen jaren, op zowel privé- als werkgebied. Jouw nuchtere denkwijze heeft ervoor gezorgd dat ik me ietsje minder druk maak en ben gaan inzien wat echt belangrijk is in het leven. Ik heb bewondering voor de manier waarop jij jouw carrière combineert met de zorg voor jullie prachtige zoon Rens.

Lieve (schoon)familie, dank voor jullie interesse in "het boekje". Al was het misschien niet altijd duidelijk wat ik precies deed, jullie waren altijd geïnteresseerd in mijn vorderingen.

Lieve Anique en Ries, dank voor jullie luisterend oor in de afgelopen jaren. Ik heb enorme bewondering voor de manier waarop jullie beiden, maar zeker samen, in het leven staan.

Lieve oma, als er iemand heel trots is dat ik ga promoveren bent $\mathrm{u}$ het wel. Ik vind het een enorme eer dat $u$ aanwezig bent bij mijn promotie.

Lieve Jac en Wilmie, Leonie en Felix, wat voel ik me altijd welkom bij jullie. Het is fijn om een tweede thuis te hebben. 
Lieve papa en mama, dat eerste thuis wordt natuurlijk door jullie gevormd en is tevens de basis van alles. Zonder jullie had ik hier vandaag namelijk niet gestaan. Jullie hebben Anique en mij altijd gestimuleerd om onszelf te blijven ontwikkelen en hebben ons hiertoe in alle mogelijke vormen gesteund. Ik kan niet in woorden uitdrukken hoe dankbaar ik jullie hiervoor ben.

Tenslotte wil ik mijn allerliefste Paul bedanken. Paul, al sta je niet graag in de belangstelling en wil je al helemaal niet dat ik nu sentimentele dingen ga schrijven: ik ga het toch doen! De reis van het promoveren en onze reis samen zijn vrijwel tegelijkertijd begonnen. Waar ik blij en opgelucht ben dat mijn promotietraject zijn eindpunt bereikt, hoop ik dat onze reis samen voortduurt tot in de eeuwigheid. De afgelopen jaren waren niet altijd makkelijk voor je, zeker niet wanneer ik weer eens tot laat met werk bezig was of chagrijnig was omdat het tegenzat. Er waren momenten dat ik het geloof in mezelf dreigde kwijt te raken, maar jouw humor, nuchterheid en vertrouwen in mij hebben ervoor gezorgd dat ik het nooit heb opgegeven. Ik weet dat je apetrots op me bent. Lieve Paul, ik hou van jou! 



\section{Curriculum vitae}
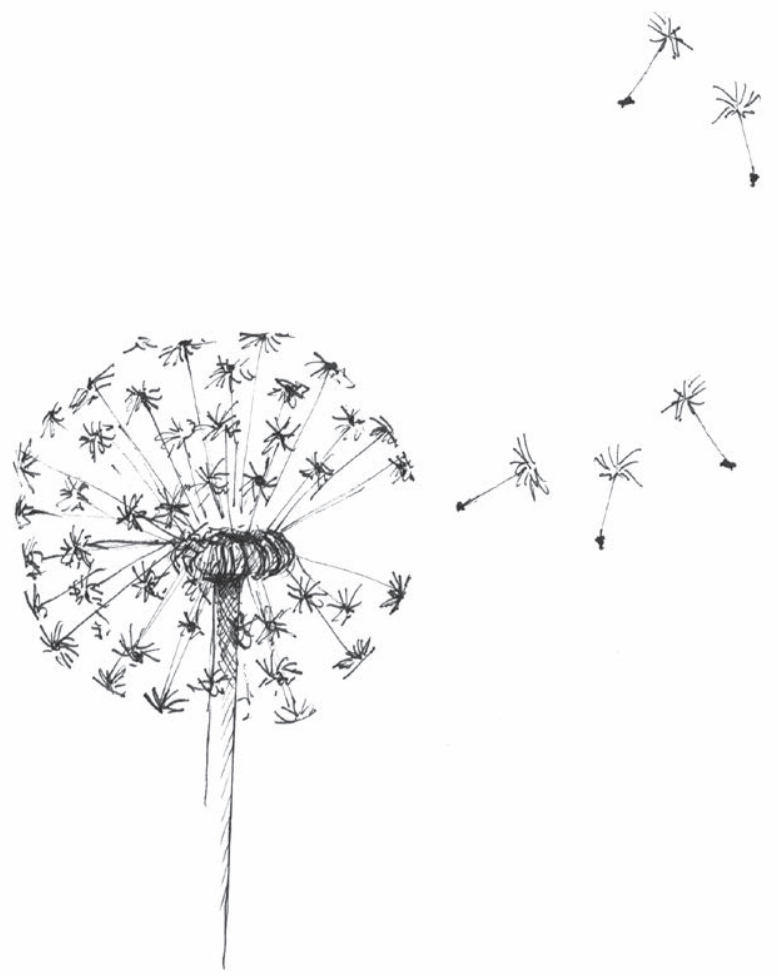



\section{CURRICULUM VITAE}

Carmen H.M. Houben werd geboren op 22 augustus 1988 in Weert. In 2006 behaalde ze haar VWO-diploma aan het Bisschoppelijk College in Weert. Datzelfde jaar startte ze met de bachelor 'klinische gezondheidspsychologie en cognitieve neurowetenschappen' aan Tilburg University. Na het behalen van haar bachelordiploma in 2009 voltooide ze achtereenvolgens de master 'psychologie en geestelijke gezondheid' (2009-2010) en de tweejarige master 'medische psychologie' (20102012), beiden eveneens aan Tilburg University. Gedurende haar masteropleidingen behaalde Carmen haar basisaantekening psychodiagnostiek en deed ze werkervaring op als psycholoog i.o. bij respectievelijk PsyQ Tilburg en de afdeling Medische Psychologie van het VieCuri in Venlo. In oktober 2012 is zij gestart met haar promotieonderzoek naar proactieve zorgplanning voor patiënten met COPD bij Ciro in Horn. Dit promotietraject stond onder leiding van prof. dr. E.F.M. Wouters, prof. dr. M.A. Spruit en dr. D.J.A. Janssen. De bevindingen van het promotieonderzoek werden op verschillende nationale en internationale congressen gepresenteerd en resulteerden in een award voor 'Best Oral Presentation' tijdens het Junior Onderzoekerssymposium Expertisecentra Palliatieve Zorg in 2014 en een NRS Travel Grant in 2015. Sinds 2014 is ze redactielid van E-PAL, een online tijdschrift over palliatieve zorg, en schrijft zij regelmatig referaten over recente publicaties op het gebied van proactieve zorgplanning. Sinds februari 2016 is Carmen, naast haar functie als onderzoeker, werkzaam als psycholoog binnen Ciro. Bovendien is ze sinds september 2017 binnen Ciro projectleider 'Beslist Samen!': een landelijk project gericht op duurzame implementatie en opschaling van gezamenlijke besluitvorming in ziekenhuizen. 



\section{List of publications}

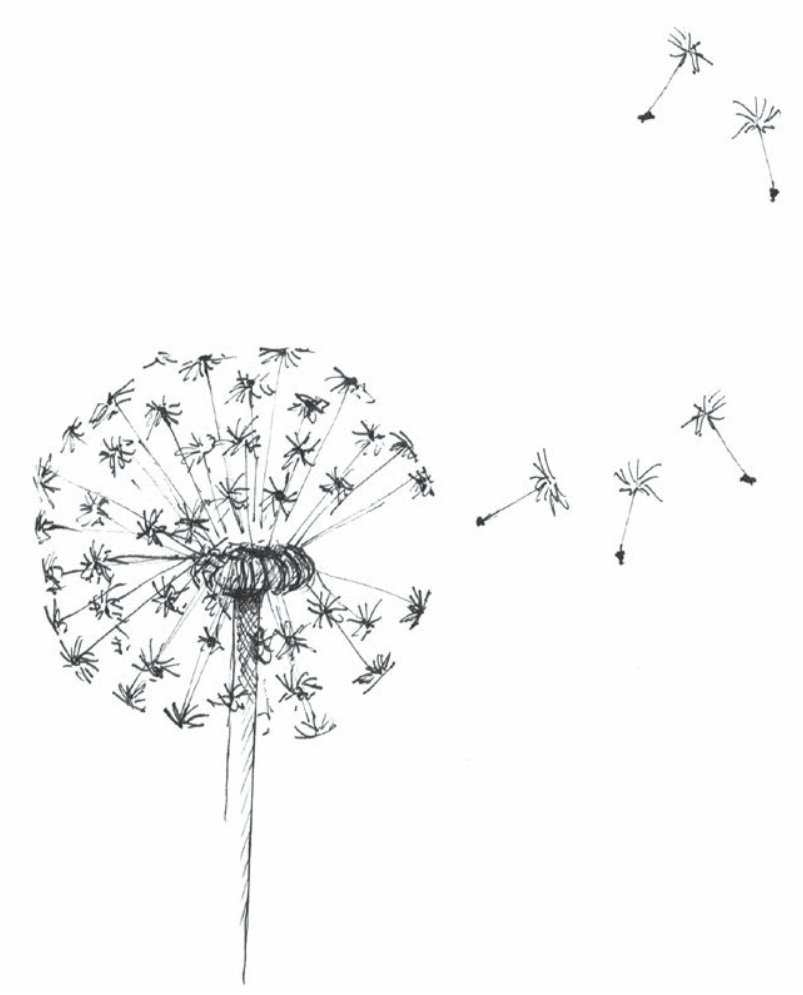





\section{LIST OF PUBLICATIONS}

Houben, C.H.M., Spruit, M.A., Luyten, H., Pennings, H.J., van den Boogaart, V.E.M., Creemers, J.P.H.M., Wesseling, G., Wouters, E.F.M., Janssen, D.J.A. A clusterrandomized trial of a nurse-led advance care planning session in patients with COPD and their loved ones. Submitted.

Houben, C.H.M., Spruit, M.A., Curtis, J.R., Wouters, E.F.M., and Janssen, D.J.A. Recruitment challenges in conducting a randomized controlled trial on the efficacy of advance care planning. Submitted.

Houben, C.H.M., Spruit, M.A., Schols, J.M., Wouters, E.F.M., and Janssen, D.J.A. Instability of willingness to accept life-sustaining treatments of patients with advanced chronic organ failure during one year. CHEST, 2017. 151(5): 1081-1087.

Houben, C.H.M., Spruit, M.A., Wouters, E.F.M., and Janssen, D.J.A. "Am I dying Doctor?": How end-of-life care is portrayed in television medical dramas. J Palliat Care Med, 2016. 6:247.

Houben, C.H.M., Spruit, M.A., Schols, J.M., Wouters, E.F.M., and Janssen, D.J.A. Patient-Clinician Communication About End-of-Life Care in Patients With Advanced Chronic Organ Failure During One Year. J Pain Symptom Manage, 2015. 49(6): 11091115.

Houben, C.H.M., Spruit, M.A., Groenen, M.T.J., Wouters, E.F.M., and Janssen, D.J.A. Efficacy of advance care planning: a systematic review and meta-analysis. JAMDA, 2014. 15(7): 477-489.

Houben, C.H.M., Spruit, M.A., Wouters, E.F.M., and Janssen, D.J.A. A randomized controlled trial on the efficacy of advance care planning on the quality of end-of-life care and communication in patients with COPD: the research protocol. BMJ Open, 2014. 4:e004465. 


\section{-}

○

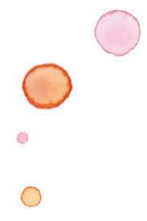

O

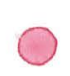

- 0

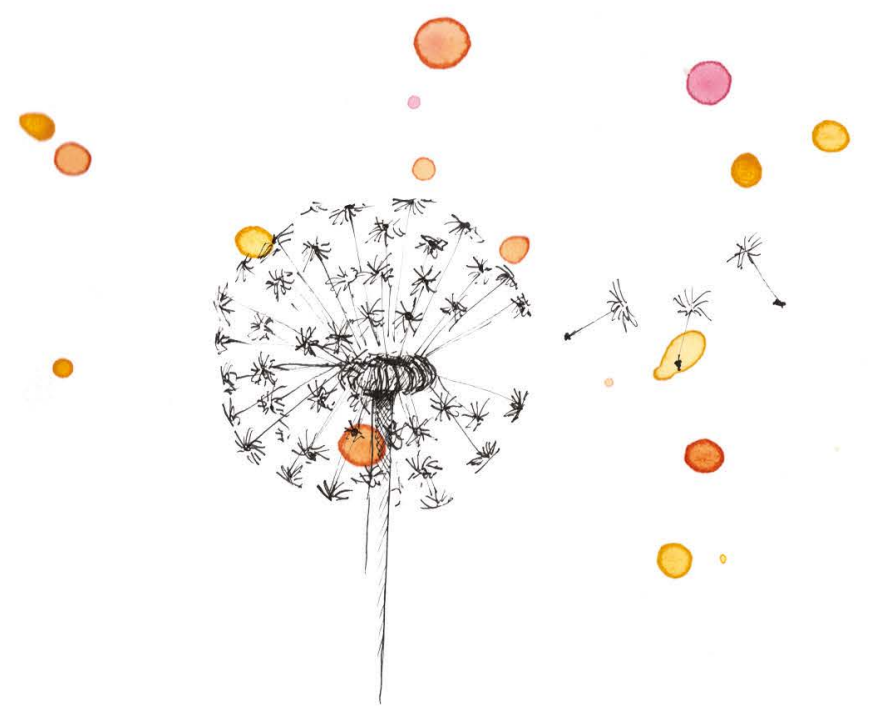

